\title{
Markierungsfreie Proteinanalytik mit oberflächenverstärkter Ramanspektroskopie
}

\author{
Dissertation \\ zur Erlangung des Doktorgrades \\ der Mathematisch-Naturwissenschaftlichen Fakultäten \\ der Georg-August-Universität zu Göttingen
}

vorgelegt von

\section{Konstantin Christou}

aus

Hamburg

Göttingen, 2009 
D7

Referent: Prof. Dr. G. Marowsky

Korreferent: Prof. Dr. W. Lauterborn

Tag der mündlichen Prüfung: 25. August 2009 


\section{Inhaltsverzeichnis}

1 Einleitung 1

1.1 Motivation . . . . . . . . . . . . . . . . . . . . . 1

1.2 Ramanspektroskopische Zugänge in der Proteinanalytik . . . . . . . . . 3

1.3 Forschungsgegenstand . . . . . . . . . . . . . . . . 5

2 Theoretische Grundlagen $\quad 7$

2.1 Der Raman-Effekt . . . . . . . . . . . . . . . . . . . . . . . 7

2.1.1 Klassische und quantenmechanische Betrachtung . . . . . . . 7

2.2 Der oberflächenverstärkte Raman-Effekt . . . . . . . . . . . . . . . . . 12

2.2.1 Elektromagnetischer Verstärkungseffekt . . . . . . . . . . . . . . 12

2.2.2 Ladungstransfer-Effekt . . . . . . . . . . . . . . . . . . 21

2.3 Ramanstreulichtverstärkende Oberflächen . . . . . . . . . . . . . . . . 23

2.4 Grundlagen der Ramanspektren von Proteinen . . . . . . . . . . . . . . 26

2.4.1 Aufbau und Struktur von Proteinen . . . . . . . . . . . . . . . . 26

2.4.2 Charakteristische Ramanbanden von Proteinen . . . . . . . . . 30

3 Experimentelle Grundlagen der Ramanstreulichtmessung 33

3.1 Aufbau und Charakterisierung eines Ramanspektrometers . . . . . . . 34

3.1.1 Diodenlaser . . . . . . . . . . . . . . . . . . . . . . . . . . . . . . . 35

3.1 .2 Sensorkopf . . . . . . . . . . . . . . . . . . . 37

3.1.3 Spektrometer und CCD-Kamera . . . . . . . . . . . . . 39

3.1.4 Beobachtungsoptik . . . . . . . . . . . . . . . . 47

3.2 Wellenlängen- und Leistungsstabilität des eingesetzten Diodenlasers . . 47

4 Herstellung und Charakterisierung ramanstreulichtverstärkender $\begin{array}{ll}\text { Oberflächen } & \mathbf{4 9}\end{array}$

4.1 Herstellungsverfahren . . . . . . . . . . . . . . . . . . . . . 50

4.1.1 Strukturierung eines Silizium-Wafers (Klarite ${ }^{\circledR}{ }_{-}$Substrat) $\quad . \quad .50$

4.1.2 UV-Nanoimprint Lithographie . . . . . . . . . . . . . 52

4.1.3 UV-Laserbestrahlung dünner Goldschichten . . . . . . . . . . . 55

4.2 Charakterisierung der erzeugten Oberflächen . . . . . . . . . . . . . . 59

4.2.1 Experimentelle Grundlagen der Charakterisierung . . . . . . . . 59

4.2.2 Vergleich der ortsabhängigen Ramanstreulichtschwankungen . . 63

4.2.3 Topographische Charakterisierung laserbestrahlter Goldschich-

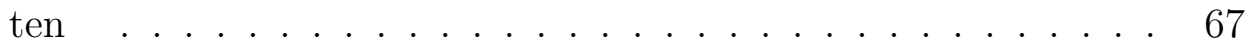

4.2.4 Berechnung der Verstärkungsfaktoren . . . . . . . . . . 72

4.3 Fazit . . . . . . . . . . . . . . . . . . . . . . . 75 
5 Ramanstreulichtmessungen an klinisch relevanten Proteinlösungen $\quad \mathbf{7 9}$

5.1 Experimenteller Aufbau . . . . . . . . . . . . . . . . . . 80

5.2 Datenvorbehandlung . . . . . . . . . . . . . . . . . . . . . . 82

5.3 Konzentrationsmessungen und Nachweisgrenzen . . . . . . . . . . . 83

5.4 Fazit . . . . . . . . . . . . . . . . . . . 87

6 Ramanstreulichtmessungen an Proteinlösungen in Hohlwellenleitern $\quad 89$

6.1 Vorüberlegungen . . . . . . . . . . . . . . . . . . . . . . 90

6.2 Experimenteller Aufbau . . . . . . . . . . . . . . . . . . . . 91

6.3 Voruntersuchungen . . . . . . . . . . . . . . . . . . . . 94

6.3.1 Bestimmung des optimalen Kapillardurchmessers und der Kapillarlänge . . . . . . . . . . . . . . . . . . . . 94

6.3.2 Bestimmung des Reflexionskoeffizienten . . . . . . . . . . . . 96

6.3.3 Erprobung der Absorptionskorrektur . . . . . . . . . . . . . 98

6.4 Konzentrationsmessungen . . . . . . . . . . . . . . . . . 100

6.5 Fazit . . . . . . . . . . . . . . . . . . 103

7 Oberflächenverstärkte Ramanstreulichtmessungen an Proteinen $\quad 105$

7.1 Proteinanlagerung auf Oberflächen . . . . . . . . . . . . . . . 107

7.2 Oberflächenverstärkte Ramanspektren ausgewählter Proteine . . . . . 115

7.3 Zeit- und ortsabhängige Messungen des Blindwertspektrums . . . . . . 121

7.4 Quantifizierung von Proteinen auf dem Klarite ${ }^{\circledR}$-Substrat . . . . . . . . . 124

7.4.1 Analogie zur Langmuir-Isotherme . . . . . . . . . . . . . . . . 125

7.4.2 Konzentrationsmessungen . . . . . . . . . . . . . 126

7.4.3 Abschätzung des Verstärkungsfaktors . . . . . . . . . . . 130

7.5 Identifizierung ausgewählter Proteine auf dem Klarite ${ }^{\circledR}$-Substrat . . . . . 132

7.5.1 Theoretische Grundlagen der Hauptkomponentenanalyse . . . . 133

7.5.2 Experimentelle Vorgehensweise . . . . . . . . . . . . . . . . . . 135

7.5.3 Ergebnisse der Hauptkomponentenanalyse . . . . . . . . . . . . 137

7.6 Fazit . . . . . . . . . . . . . . . . . . . . 143

8 Zusammenfassung und Ausblick $\quad 145$

$\begin{array}{lr}\text { Anhang } & 149\end{array}$

$\begin{array}{ll}\text { Literaturverzeichnis } & 151\end{array}$

$\begin{array}{ll}\text { Danksagung } & 161\end{array}$

$\begin{array}{ll}\text { Lebenslauf } & 163\end{array}$ 


\section{Kapitel 1}

\section{Einleitung}

„Ein Gelehrter in seinem Laboratorium ist nicht nur ein Techniker; er steht auch vor den Naturgesetzen wie ein Kind vor der Märchenwelt."

Marie Curie

\subsection{Motivation}

In den letzten Jahrzehnten hat sich die „Proteomik“, die Aufklärung der biologischen Funktion von Proteinen im Metabolismus, zu einer der aktuell bedeutsamsten Disziplin im Bereich der Lebenswissenschaften entwickelt. Proteine gehören zu den vielfältigsten Makromolekülen der belebten Materie und unterscheiden sich untereinander nicht nur durch ihre Struktur, sondern vor allem durch ihre Dynamik und Strukturvariabilität, worin auch ihre biologische Aktivität begründet ist. Das von den Genen abgelesene und synthetisierte Proteinexpressionsmuster, das „Proteom“ (Gesamtheit aller Proteine im Organismus), reagiert äußerst sensitiv auf krankhafte Veränderungen im Metabolismus, so dass es Rückschlüsse auf die entsprechenden Einflüsse, wie Krankheiten, Medikamente und Umwelteinflüsse, bereits vor dem ersten Auftreten von Symptomen zulässt. Die Proteomik besitzt daher ein großes Potential im Bereich der diagnostischen Früherkennung von Krankheiten, deren Behandlungsmethoden verbessert und die Heilungschancen dadurch drastisch gesteigert werden könnten.

Auf der Suche nach so genannten „Markerproteinen“, die direkt mit einer krankhaften Veränderung im Metabolismus korrelieren, werden unterschiedlichste interdisziplinäre Methoden zum qualitativen und quantitativen Nachweis kombiniert, die eine umfassende Charakterisierung eines Proteins oder Proteingemisches ermöglichen. Dazu werden in der Regel Multi-Parameter-Plattformen, wie z.B. das Protein-Array, eingesetzt, das die gleichzeitige Untersuchung mehrerer Analyte aus einer Körperflüssigkeit heraus erlaubt. Dabei handelt es sich um planare Oberflächen, auf denen gut charakterisierte Biomoleküle äquidistant immobilisiert sind und mit potenziell interagierenden Proteinen aus einer Körperflüssigkeit, wie z.B. Speichel, Urin, Blut oder Plasma, in- 
kubiert werden [31] und eine Bindung eingehen, die so genannte Antigen-AntikörperBindung.

Der anschließende quantitative bzw. qualitative Nachweis der an das Protein-Array gebundenen Proteine erfolgt dabei neben der Chemolumineszenz oder der radioaktiven Markierung bevorzugt durch fluoreszenzbasierte optische Nachweisverfahren. Sie sind kostengünstig und in der Lage, geringste Proteinmengen im femtomolaren Konzentrationsbereich [38, 107] (1 fmol - entspricht ca. 100 Million Moleküle) zu detektieren. Dazu werden den Körperflüssigkeiten aber zunächst Nachweiskonjugate hinzugegeben, die aus einer Vielzahl von Antikörpern bestehen, die mit einem Fluoreszenzfarbstoff markiert sind. Über die bereits erwähnte Antigen-Antikörper-Bindung können die Nachweiskonjugate an die nachzuweisenden Proteine in der Körperflüssigkeit ankoppeln. Die nach diesem Verfahren behandelten Körperflüssigkeiten werden dann auf das Protein-Array gegeben, so dass eine selektive Bindung der nachzuweisenden fluoreszenzmarkierten Proteine an das Protein-Array stattfinden kann. Nach der Reinigung des Protein-Arrays von überflüssigem Probenmaterial und der anschließenden Bestrahlung mit einer ausgewählten Wellenlänge werden die selektiv an das Protein-Array gebundenen Proteine über das emittierte Fluoreszenzlicht der Fluoreszenzfarbstoffe sequentiell nachgewiesen. In einer abgewandelten Form können die nachzuweisenden Proteine aber auch erst biotylisiert und unter Ausnutzung der hohen Affinität zwischen Biotin und Streptavidin bzw. Avidin [28] anschließend mit fluoreszenzmarkiertem Streptavidin bzw. Avidin versehen werden. Beim fluoreszenzbasierten Nachweis handelt es sich somit um eine indirekte Identifizierung und Quantifizierung von Proteinen. Der Einsatz von Nachweiskonjugaten ist aber im Hinblick auf die Anzahl der nachzuweisenden Proteine pro Protein-Array begrenzt, da die Herstellung der dazu benötigten Nachweiskonjugat-Mischungen mit zunehmender Anzahl sehr komplex und aufwendig wird. Darüber hinaus können bei diesen Nachweiskonjugat-Mischungen unspezifische Bindungen der fluoreszenzmarkierten Antikörper an das Protein-Array nicht mehr sicher ausgeschlossen werden, die zu unerwünschten Bindungsereignissen und damit zur falschen Interpretation des Protein-Arrays führen. Aus diesem Grund werden derzeit direkte Nachweisverfahren diskutiert, die in der Lage sein müssen, dem hohen Standard bzgl. Nachweiseffizienz und Automatisierung in der Proteinanalytik Genüge zu tun.

$\mathrm{Zu}$ den bekanntesten direkten Nachweisverfahren zählen die SPR (Surface Plasmon Resonance) [40], die SELDI (Surface-Enhanced Laser Desorption Ionization) [13], die AFM (Atomic Force Microscopy) [18] und die Ramanspektroskopie bzw. die ober- 
flächenverstärkte Ramanspektroskopie (SERS - Surface-Enhanced Raman Spectroscopy). Sie sollen neue Wege in der Proteinanalytik eröffnen, indem sie ohne einen hohen präparativen Aufwand auskommen und dazu schneller, kostengünstiger und effektiver als die bisher angewandten indirekten Nachweisverfahren sind. Bedingt durch die rasanten technologischen Entwicklungen auf dem Gebiet der CCD-Sensoren und Laser rückt besonders die Ramanspektroskopie als direktes Nachweisverfahren immer mehr in den Vordergrund der Proteinanalytik.

\subsection{Ramanspektroskopische Zugänge in der Proteinanalytik}

Die Ramanspektroskopie nutzt den bereits 1923 von Smekal [102] vorhergesagten und nach dem Entdecker C.V. Raman [92] im Jahre 1928 benannten Raman-Effekt. Dieser beschreibt die Wechselwirkung zwischen monochromatischem Licht und den Moleküleigenschwingungen bestrahlter Moleküle, die zu charakteristischen molekülspezifischen Banden im Emissionsspektrum führt. Diese so genannten „fingerprint“-Spektren, die im Vergleich zu fluoreszenzbasierten Nachweisverfahren deutlich schmalere spektrale Banden aufweisen, erlauben einen direkten speziesselektiven Nachweis und bieten einen hohen Informationsgehalt über die jeweilige Molekülstruktur. Die Ramanspektroskopie, die grundsätzlich auf alle optisch zugänglichen Proben angewendet werden kann, ist mit einem sehr geringen Präparationsaufwand verbunden und ermöglicht darüber hinaus die Untersuchung von Molekülen in einer typischerweise stark IR-absorbierenden wässrigen Umgebung. Die breite Ramanbande des Wassermoleküls ist deutlich vom „fingerprint"- Bereich aller anderen Moleküle spektral getrennt. Dadurch eignet sich die Ramanspektroskopie prinzipiell besonders gut für in vivo und in vitro Anwendungen an Organismen. Ein großer Nachteil jeglicher ramanspektroskopischer Anwendung resultiert aber aus dem natürlich kleinen Streuquerschnitt des Ramanstreuprozesses, der bis zu 12 bis 14 Größenordnungen unterhalb des Streuquerschnitts der Fluoreszenz liegen kann [47].

Einen Ausweg hieraus bietet die oberflächenverstärkte Ramanspektroskopie, die seit den siebziger Jahren insbesondere durch die Experimente von Fleischmann et al. [21] zunehmend an Bedeutung gewonnen hat und zu enormen Verstärkungen des Ramanstreulichtes führen kann. Fleischmann entdeckte nach der Adsorption von Pyridinmolekülen auf einer elektrochemisch aufgerauten Silberelektrode unerwartet hohe Ramanstreulichtsignale, die nicht durch eine erhöhte Anzahl von Molekülen auf der Elektrode erklärt werden konnten. Dies war der Startschuss unzähliger ramanspektroskopischer 
Experimente an auf rauen metallischen Oberflächen adsorbierten Molekülen, die seine Ergebnisse untermauerten und Hoffnung gaben, die typischerweise geringen Nachweisempfindlichkeiten in der Ramanspektroskopie zu überwinden.

Seitdem wird der Einfluss nanostrukturierter Oberflächen, meist aus Silber oder Gold bestehend, auf denen ramanaktive Moleküle adsorbiert sind, intensiv untersucht. Daraus sind theoretische Modelle für die Ramanstreulichtverstärkung hervorgegangen und bereits Verstärkungen des Ramanstreulichtes um 14 Größenordnungen [46] gegenüber der herkömmlichen Ramanspektroskopie experimentell bestätigt worden. Die mit der oberflächenverstärkten Ramanspektroskopie erzielten Streuquerschnitte in der Größenordnung von $10^{-16} \mathrm{~cm}^{2} /$ Molekül, die vergleichbar mit denen der Fluoreszenz sind, reichen sogar zum Einzelmolekülnachweis aus. Derart hohe Streuquerschnitte bleiben jedoch die Ausnahme und sind ein Resultat aufwendiger Untersuchungen, die die optimalen Bedingungen für die oberflächenverstärkte Ramanspektroskopie an Modellsubstanzen erfüllen.

Besonders in den Lebenswissenschaften findet die oberflächenverstärkte Ramanspektroskopie ein breites Anwendungsfeld in der ultrasensitiven Detektion und strukturellen Charakterisierung von Biomolekülen in physiologisch relevanten Konzentrationsbereichen. Neben der Detektion und Identifikation diverser Biomoleküle, wie Aminosäuren und Peptiden, sind ebenfalls ramanspektroskopische Untersuchungen an großen Biomolekülen, wie die DNA bzw. RNA, und an Proteinen möglich, bis hin zu Mikroorganismen, wie Bakterien [94, 52]. Dabei werden häufig zwei verschiedene Strategien verfolgt: zum Einen die Nutzung von kolloidalem Silber oder Gold in einer wässrigen Umgebung und zum Anderen planare, raue metallische Oberflächen, ebenfalls aus Gold oder Silber. Was beide Strategien jedoch gemeinsam haben, ist die Notwendigkeit, dass sich die Zielmoleküle möglichst nah an den signalverstärkenden Oberflächen aufhalten, da die ramanstreulichtverstärkenden Effekte oberflächennah sind. Die Adsorption der Zielanalyte an diese Oberflächen setzt jedoch in der Regel eine aufwendige chemische Oberflächenbehandlung voraus.

Während die Detektion von Biomolekülen für bestimmte Konzentrationsbereiche mit Hilfe der oberflächenverstärkten Ramanspektroskopie bereits vielfach gezeigt wurde, bleibt dennoch die Quantifizierung besonders für sehr geringe Konzentrationen eine große Herausforderung. Der Grund dafür ist in der Beschaffenheit der Oberflächen zu finden, denn sie müssen neben hohen Verstärkungsfaktoren zusätzlich eine hohe räumliche Regelmäßigkeit ihrer Strukturen aufweisen, um ausreichende Signalreprodu- 
zierbarkeiten zu gewährleisten. In der Regel werden dazu kostenintensive Oberflächenstrukturierungsverfahren, wie die Elektronenstrahllithographie und die Laserablation, eingesetzt. Desweiteren sind die Oberflächen bei großen biologischen Makromolekülen, wie es bei Proteinen der Fall ist, schon bei sehr kleinen Molekülkonzentrationen bedeckt und die Intensität des oberflächenverstärkten Ramanstreulichtes wegen der nur sehr kurzreichweitigen Verstärkungseffekte gesättigt. Der detektierbare Konzentrationsbereich ist dadurch stark eingeschränkt, so dass Oberflächen mit hoher Signalverstärkung und hoher Signalreproduzierbarkeit benötigt werden.

\subsection{Forschungsgegenstand}

Die Zielsetzung dieser Arbeit knüpft direkt an die Herausforderungen bei der Identifizierung und Quantifizierung von Proteinen mit Hilfe der Ramanspektroskopie an. Dabei sollen die Möglichkeiten und Grenzen dieses Nachweisverfahrens zur Erfassung und Charakterisierung insbesondere von sehr geringen Proteinkonzentrationen mit Schwerpunkt auf die oberflächenverstärkte Ramanspektroskopie aufgezeigt werden.

Dazu werden im zweiten Kapitel zunächst die theoretischen Grundlagen der spontanen und oberflächenverstärkten Ramanspektroskopie sowie ein Einblick in die Zusammensetzung und die Strukturvariabilität von Proteinen gegeben, die sich unmittelbar in den Ramanspektren widerspiegeln.

Im dritten Kapitel wird ein selbstentwickeltes, modulares und hochempfindliches Ramanspektrometer vorgestellt, das speziell auf hohen Lichtdurchsatz und damit hohe Nachweisempfindlichkeit optimiert ist.

Das vierte Kapitel befasst sich mit der Herstellung ramanstreulichtverstärkender Oberflächen, wobei ein besonderer Schwerpunkt auf der Charakterisierung der erzeugten Strukturtopographien und ihrer Signalreproduzierbarkeiten liegt. Darüber hinaus werden zwei neuartige Verfahren zur Herstellung ramanstreulichtverstärkender Oberflächen beschrieben, die sowohl hinsichtlich Verstärkungsfaktor als auch Signalreproduzierbarkeit herausragende Oberflächeneigenschaften erzeugen.

In den beiden darauffolgenden Kapiteln werden systematische quantitative Untersuchungen an wässrigen Proteinlösungen in physiologisch relevanten Konzentrationsbereichen vorgestellt und dabei der Einsatz von Hohlwellenleitern als mögliche Probenkammer zur Erhöhung der Nachweisempfindlichkeit diskutiert. 
Basierend auf diesen Untersuchungen, wird im siebten Kapitel eine Methode zur oberflächenverstärkten ramanspektroskopischen Identifizierung und Quantifizierung von Proteinen im femtomolaren Konzentrationsbereich exemplarisch auf einer in der vorliegenden Arbeit vollständig charakterisierten ramanstreulichtverstärkenden Oberfläche präsentiert. Dabei werden zum Einen die experimentelle Vorgehensweise und zum Anderen der für die Identifizierung eingesetzte chemometrische Auswertealgorithmus hinsichtlich der durchgeführten Datenvorbehandlung und -analyse diskutiert.

Im letzten Kapitel wird schließlich eine Zusammenfassung sowie ein Ausblick dieser Arbeit gegeben. 


\section{Kapitel 2}

\section{Theoretische Grundlagen}

\subsection{Der Raman-Effekt}

Der Raman-Effekt beschreibt den inelastischen nichtresonanten Streuvorgang von elektromagnetischer Strahlung an Kristallen und Molekülen, der im Gegensatz zur Rayleighstreuung zu frequenzverschobenen Anteilen im Streulichtspektrum führt, die auf die Gitter- bzw. Moleküleigenschwingungen sowie Molekülrotationen zurückzuführen sind.

\subsubsection{Klassische und quantenmechanische Betrachtung}

Die klassische Beschreibung des Raman-Effektes basiert im Wesentlichen auf der Wechselwirkung eines oszillierenden elektrischen Feldes mit den mechanischen Eigenschwingungen eines Moleküls bzw. eines Kristalls (Phononen). Der Feldvektor $\vec{E}(t)=\vec{E}_{0} \cos \left(2 \pi \nu_{0} t\right)$ der einfallenden elektromagnetischen Strahlung der Frequenz $\nu_{0}$ und der Amplitude $\vec{E}_{0}$ induziert im Molekül ein Dipolmoment $\vec{p}_{i n d}$, das proportional zum eingestrahlten elektrischen Feld $\vec{E}$ ist und unter Berücksichtigung des permanenten Dipolmoments $\vec{p}_{0}$ des Moleküls mit der Polarisierbarkeit $\alpha$ über folgende Gleichung verknüpft wird:

$$
\vec{p}=\vec{p}_{0}+\vec{p}_{\text {ind }}=\vec{p}_{0}+\alpha \vec{E} .
$$

Die durch das elektrische Feld hervorgerufene Verformung der Elektronenhülle im Molekül ist abhängig von den unterschiedlichen Bindungstypen der Atome, wonach das induzierte Dipolmoment $\vec{p}_{\text {ind }}$ keineswegs in alle Raumrichtungen gleich ist. Mathematisch wird diese molekülspezifische Anisotropie durch die Polarisierbarkeit $\alpha$ ausgedrückt. Aus der Verformung der Elektronenhülle resultieren kleine Verschiebungen der relativen Lagen $q_{i}$ (Normalkoordinaten) der Atomkerne zueinander, wodurch Änderungen der Polarisierbarkeit $\alpha$ auftreten können. Für kleine Änderungen kann sie näherungsweise durch eine Taylorreihe der Form $\alpha_{i}=\alpha_{0}+\sum_{i}\left(\frac{\partial \alpha_{0}}{\partial q_{i}}\right) q_{i}$ unter Vernachlässigung der Terme höherer Ordnung ausgedrückt werden. Eigenschwingungen des Moleküls 
führen ebenfalls zu einer kleinen zeitlichen harmonischen Verschiebung der Normalkoordinaten $q_{i}$, so dass für $q_{i}(t)=q_{i}^{0} \cos \left(2 \pi \nu_{i} t\right)$ angenommen werden kann, wobei $q_{i}^{0}$ die Amplitude und $\nu_{i}$ die Frequenz der schwingenden i-ten Normalkoordinate bezeichnen. Daraus folgt für die Polarisierbarkeit:

$$
\alpha_{i}=\alpha_{0}+\sum_{i}\left(\frac{\partial \alpha_{0}}{\partial q_{i}}\right)_{0} q_{i}^{0} \cos \left(2 \pi \nu_{i} t\right) .
$$

Somit setzt sich die Polarisierbarkeit aus zwei Anteilen zusammen; der permanente Anteil $\alpha_{0}$ und derjenige Anteil, der durch Änderungen der relativen Lagen der Kerne zueinander hervorgerufen wird. Das Einsetzen der Polarisierbarkeit in Gleichung 2.1 liefert mit Hilfe des trigonometrischen Additionstheorems $\cos A \cdot \cos B=\frac{1}{2}(\cos (A+B)+$ $\cos (A-B))$ das zeitabhängige Dipolmoment $\vec{p}(t)$ eines Moleküls unter dem Einfluss eines oszillierenden elektrischen Feldes:

$$
\begin{aligned}
\vec{p}(t)=\vec{p}_{0} & +\alpha_{0} \vec{E}_{0} \cos \left(2 \pi \nu_{0} t\right) \\
& +\frac{1}{2} \vec{E}_{0} \sum_{i}\left(\frac{\partial \alpha_{0}}{\partial q_{i}}\right) q_{i}^{0} \cos \left(2 \pi\left(\nu_{0}-\nu_{i}\right) t\right) \\
& +\frac{1}{2} \vec{E}_{0} \sum_{i}\left(\frac{\partial \alpha_{0}}{\partial q_{i}}\right) q_{i}^{0} \cos \left(2 \pi\left(\nu_{0}+\nu_{i}\right) t\right) .
\end{aligned}
$$

Wie deutlich zu erkennen ist, führt die durch die Eigenschwingungen der Normalkoordinaten verursachte Modulation der erzwungenen Dipolmomente, neben der Rayleighstreuung, zu zwei frequenzverschobenen Anteilen; die so genannte Stokes Ramanstreuung $\nu_{S}=\left(\nu_{0}-\nu_{i}\right)$ und die Anti-Stokes Ramanstreuung $\nu_{A S}=\left(\nu_{0}+\nu_{i}\right)$. In der Regel werden diese Frequenzanteile auch als Ramanverschiebung bezeichnet, die in Wellenzahlen $\left(\mathrm{cm}^{-1}\right)$ angegeben werden. Die Wellenzahl ist definiert als der Kehrwert der Wellenlänge $\lambda$ und wird als Einheit der Energie E betrachtet, was durch den folgenden Zusammenhang deutlich wird:

$$
\frac{1}{\lambda_{S / A S}}=\frac{\mathrm{E}_{S / A S}}{h c}
$$

Somit entspricht die Darstellung von Ramanbanden in Wellenzahlen einer Energieangabe der an der Ramanstreuung beteiligten Eigenschwingungen des Moleküls. Diese Frequenzanteile 1. Ordnung bzw. höherer Ordnung - falls die anharmonischen Terme höherer Ordnung in der Reihenentwicklung von $\alpha$ berücksichtigt werden - treten aber nur dann auf, wenn die Moleküleigenschwingungen die Polarisierbarkeit des Moleküls so stark beeinflussen, dass

$$
\left(\frac{\partial \alpha_{0}}{\partial q_{i}}\right) \neq 0
$$


gilt. Damit ist das Auswahlkriterium für die Ramanstreuung eindeutig definiert. Ändert sich jedoch nicht die Polarisierbarkeit durch die Moleküleigenschwingung sondern das permanente Dipolmoment, so ist die daran beteiligte Schwingung infrarotaktiv, wodurch die Komplementarität der Raman- und Infrarotspektroskopie begründet ist. Das sich im Molekül zeitlich ändernde induzierte Dipolmoment stellt in der klassischen Betrachtung einen Hertzschen Dipol dar, dessen Strahlungsintensität proportional zur vierten Potenz der Frequenz der emittierten Strahlung $\nu$ ist und folgende Abhängigkeit vom Beobachtungswinkel $\theta$ relativ zur Achse des Dipols aufweist:

$$
I(\theta) \propto \nu^{4}|\vec{p}|^{2} \sin ^{2} \theta .
$$

Dieser Zusammenhang ist experimentell bestätigt, doch zeigt sich ein deutlicher Unterschied der Stokes- und Anti-Stokes Ramanstreulichtintensitäten, wie in Abbildung 2.1 am Beispiel des Ramanspektrums von Tetrachlorkohlenstoff verdeutlicht wird. Hier scheitert die klassische Betrachtung, da sie für beide Frequenzanteile gleiche Intensitäten voraussagt.

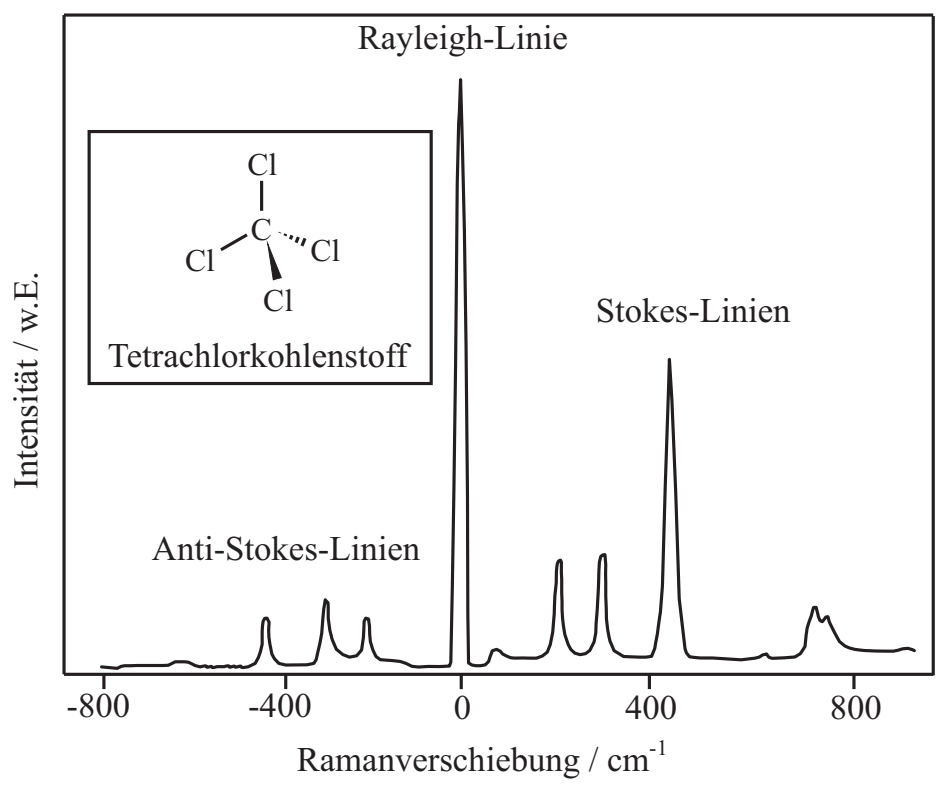

Abbildung 2.1: Stokes und Anti-Stokes Ramanspektrum von Tetrachlorkohlenstoff bei Raumtemperatur [99]; die üblicherweise um Größenordnungen intensivere Rayleighlinie ist in diesem Fall durch einen Notch-Filter um den Faktor $10^{6}$ unterdrückt.

Abhilfe schafft eine quantentheoretische Betrachtung des Raman-Effektes. Dazu wird ein virtueller Zustand $\mathrm{v}^{*}$ mit endlicher Lebensdauer $\left(<10^{-12} \mathrm{~s}\right)$ eingeführt, der sich energetisch unterhalb des ersten elektronisch angeregten Zustandes des Moleküls be- 
findet. Dieser wird deshalb als virtuell bezeichnet, da die Energie $h \nu_{0}$ des polarisierenden und absorbierten einfallenden Photons mit keinem geeigneten Quantenzustand des Moleküls zusammenfällt. Quantentheoretisch ist dieser verbotene energetische Zustand durch die Lorentzprofile der Wellenfunktionen, die sich weit in die verbotenen Energiezustände ausdehnen, zu erklären. Somit wird das einfallende Photon an derjenigen Stelle aller überlagerten Wellenfunktionen absorbiert, wo die Energie gleich $h \nu_{0}$ ist. Damit kann eine Anregung mit Licht jeglicher Wellenlänge vorgenommen werden, da keine Resonanzbedingungen erfüllt sein müssen. Die Zusammensetzung der Ausläufer aller Wellenfunktionen wird dabei durch die Polarisierbarkeit beschrieben. Zum besseren Verständnis der quantentheoretischen Betrachtung der Ramanstreuung ist in Abbildung 2.2 ein Energieniveau-Schema dargestellt. Der Begriff „virtueller Zustand" wird der Einfachheit halber weiterhin verwendet. Das Molekül befindet sich vor der Wechselwirkung mit dem eingestrahlten Photon z.B. im Schwingungsgrundzustand $\mathrm{v}=0$. Bei der Wechselwirkung mit dem eingestrahlten Photon absorbiert das Molekül die gesamte Energie des Photons und wird kurzfristig energetisch in den virtuellen Zustand $\mathrm{v}^{*}$ überführt. Bei der Rayleighstreuung relaxiert das Molekül nahezu instantan
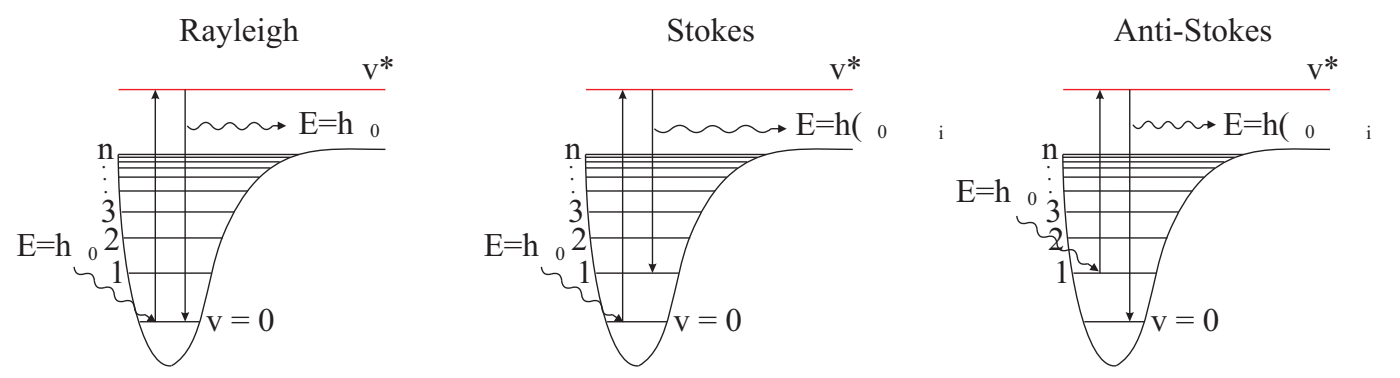

Abbildung 2.2: Energie-Schema der Rayleigh- und Ramanstreuung.

in den Schwingungsgrundzustand $(\mathrm{v}=0)$ und emittiert ein Photon mit der gleichen Energie wie die des eingestrahlten Photons. Im Gegensatz zur Rayleighstreuung tritt bei der Stokes Ramanstreuung ein Energietransfer in Form einer Schwingungsanregung des Moleküls auf. Das in den virtuellen Zustand überführte Molekül relaxiert in einen schwingungsangeregten Zustand, z.B. $v=1$. Die Energie des emittierten Photons ist demnach im Betrag um die zur Schwingungsanregung aufgebrachte Energie geringer. In der Wellendarstellung ist dies gleichbedeutend mit einer Rotverschiebung des emittierten Ramanstreulichtes.

Bei der Anti-Stokes Ramanstreuung findet ein umgekehrter Energietransfer statt. Dabei liegt das Molekül bereits vor Einstrahlung des Photons in einem schwingungsangeregten Zustand, z.B. v = 1, vor. Das in den virtuellen Zustand überführte Molekül relaxiert dabei in einen energetisch tiefer liegenden Schwingungszustand, z.B. $v=0$. 
Die Energie des emittierten Photons ist demnach im Betrag um die zur Schwingungsanregung aufgebrachte Energie höher. In der Wellendarstellung ist dies gleichbedeutend mit einer Blauverschiebung des emittierten Ramanstreulichtes.

Übergänge, bei denen der Betrag von $\Delta v$ größer als 1 ist, werden als Obertöne bezeichnet (Analogie zur klassischen Theorie: anharmonische Terme in der Reihenentwicklung von $\alpha$ ) und in dieser Arbeit auf Grund ihrer vernachlässigbaren Intensitäten nicht berücksichtigt. Da sich im thermischen Gleichgewicht nur wenige Moleküle in Schwingungszuständen v größer 0 befinden, ist die Wahrscheinlichkeit für das Auftreten der Anti-Stokes Ramanstreuung wesentlich geringer als bei der Stokes Ramanstreuung. Aus diesem Grund werden in der vorliegenden Arbeit ausschließlich die Stokes Ramanbanden untersucht. Die Anzahl $n$ der im schwingungsangeregten Zustand vorliegenden Moleküle ist stark temperaturabhängig und wird durch die Boltzmann-Verteilung $n=n_{0} e^{-E / k_{B} T}$ beschrieben. $k_{B}$ ist die Boltzmann-Konstante und $T$ die Temperatur. Eine ausführliche quantenmechanische Betrachtung der Ramanstreuung wird in [63] gegeben. Daraus ist das folgende Ergebnis für die Intensitäten der Stokes- bzw- AntiStokes Ramanbanden entnommen. Grundlage für dieses Ergebnis ist die Lösung der zeitabhängigen Schrödinger-Gleichung mit Hilfe der zeitabhängigen Störungstheorie (s. [63]):

$$
I_{\text {Anti-Stokes } / \text { Stokes }}=C N I_{0} \frac{\left(\nu_{0} \pm \nu_{i}\right)^{4}}{\left|\nu_{i}\right|} \cdot\left(1-e^{-h \nu_{i} / k_{B} T}\right)^{-1}
$$

Darin ist $C$ eine Konstante, die von der Streugeometrie abhängig ist, $N$ die Anzahl der an der Streuung beteiligten Moleküle und $I_{0}$ die eingestrahlte Lichtintensität.

Aus Gleichung 2.7 wird deutlich, dass die spontane Ramanstreuung ein linearer Prozess ist, bei dem die Ramanstreulichtintensität proportional zur Intensität des Anregungslichtes und der Anzahl der an der Streuung beteiligten Moleküle wächst. Desweiteren besteht eine reziproke Abhängigkeit der Ramanstreulichtintensität von der 4. Potenz der Anregungsfrequenz. Deshalb scheinen zunächst besonders hohe Intensitäten und Wellenlängen vom sichtbaren bis in den ultravioletten Spektralbereich zur Erzeugung hoher Ramanstreulichtintensitäten geeignet zu sein. Bei der Untersuchung von Biomolekülen führt Anregungslicht im ultravioletten Spektralbereich aufgrund der hohen Photonenenergien jedoch häufig zur Zerstörung bzw. Photodissoziation der angeregten Moleküle. Außerdem werden mit Anregungswellenlängen im ultravioletten bzw. sichtbaren Spektralbereich häufig Fluoreszenzemissionen induziert, da die Energie der Anregungsstrahlung ausreicht, um einen energetischen Übergang in die elektronisch angeregten Zustände der Moleküle zu ermöglichen. Die spektral breiten und intensiven Banden der Fluoreszenz erlauben jedoch in den meisten Fällen keine Detektion des Ramanstreulichtes, da dieses spektral vollständig vom Fluoreszenzlicht überdeckt werden kann. 
Neben den Vibrationszuständen v existieren außerdem Rotationszustände J. Sie können auf eine zeitliche Variation des Dipolmomentes durch die Rotation des Moleküls zurückgeführt werden. Die Frequenzverschiebungen beim Rotations-Raman-Effekt liegen in der Größenordnung von wenigen Wellenzahlen [32] und können nur mit entsprechend hohem experimentellen Aufwand aufgelöst werden. Im Falle großer Moleküle ist die Rotationsstruktur der Ramanspektren kaum noch auflösbar. Daher wird in der vorliegenden Arbeit nicht näher auf die Rotationsstruktur der Ramanspektren eingegangen.

\subsection{Der oberflächenverstärkte Raman-Effekt}

Der oberflächenverstärkte Raman-Effekt beschreibt die Wechselwirkung zwischen elektromagnetischer Strahlung und Molekülen, die sich in unmittelbarer Nähe zu einer rauen metallischen Oberfläche befinden und eine deutliche Erhöhung ihrer Ramanstreuquerschnitte erfahren. Die ramanstreulichtververstärkenden Eigenschaften dieser rauen metallischen Oberflächen werden in der Theorie im Wesentlichen auf zwei Verstärkungsmechanismen zurückgeführt, die als elektromagnetischer und chemischer Verstärkungseffekt bekannt sind. Während der elektromagnetische Verstärkungseffekt die mit der Erzeugung von Oberflächenplasmonen gekoppelte oberflächennahe Erhöhung des elektrischen Feldes $\vec{E}$ beschreibt, erklärt der chemische Verstärkungseffekt die Änderung der Polarisierbarkeit $\alpha$ der Moleküle aufgrund ihrer Adsorption an die Oberfläche. Die Änderung beider Größen $\vec{E}$ und $\alpha$ führen gemäß Gleichung 2.3 direkt zu einer Ramanstreulichtverstärkung. Im Folgenden sollen die den Verstärkungsmechanismen zugrundeliegenden und allgemein anerkannten Theorien näher erläutert werden.

\subsubsection{Elektromagnetischer Verstärkungseffekt}

Grundlage für den elektromagnetischen Verstärkungseffekt bildet die resonante Anregung kollektiver Oszillationen des quasifreien Elektronengases gegenüber den Ionenrümpfen an metallischen Grenzflächen, die zu elektrischen Felderhöhungen auf der Oberfläche führen können. Dabei ist die Fluktuation der Elektronen auf die ThomasFermi-Länge von 0,1 nm zwischen der Metalloberfläche und dem umgebenden Medium beschränkt und an ein gemischtes transversales und longitudinales elektrisches Feld gekoppelt [91]. In der Festkörperphysik werden diese Oszillationen auch als Plasmonen bezeichnet. Longitudinale Oszillationen parallel zur Oberfläche des Metalls werden dabei unter dem Begriff „Oberflächenplasmonen“ [49] (Oberflächenwellen) zusammengefasst, die sich entlang der Grenzfläche zwischen Metall und Umgebungsmedium ausbreiten. Ihre elektrischen Felder fallen exponentiell senkrecht zur Oberfläche ab. Das elektrische 
Feld von Oberflächenplasmonen wird nach [91] durch

$$
E(\omega)=E_{0}^{ \pm} e^{i\left(k_{x} x \pm k_{z} z-w t\right)}
$$

beschrieben, wobei $x$ die Ausbreitungsrichtung parallel zur Grenzfläche, $z$ die Richtung senkrecht zur Grenzfläche, $k_{i}$ mit $i=x, z$ die jeweilige Wellenvektorkomponente und $\omega$ die Frequenz der longitudinalen Oszillation ist. Für den Fall $z=0$, also in der Grenzfläche, ist die elektromagnetische Feldstärke maximal, was charakteristisch für Oberflächenwellen ist. Desweiteren dissipiert die Energie der Oberflächenplasmonen durch die Erzeugung von Gitterschwingungen (Phononen) in das Metall, wodurch ihre Ausbreitungsrichtungen stark gedämpft und beinahe die gesamte Energie in Wärme umgewandelt wird [96].

Die resonante Anregung von Oberflächenplasmonen mit Photonen im sichtbaren Spektralbereich ist von den optischen Eigenschaften der eingesetzten Metalle und ihrer unmittelbaren Umgebung abhängig. Die optischen Eigenschaften werden für Metalle durch die frequenzabhängige komplexe Dielektrizitätsfunktion $\epsilon_{M}=\epsilon_{M}^{\prime}+i \epsilon_{M}^{\prime \prime}$ und für deren Umgebung durch $\epsilon_{D}$ beschrieben. Darin drückt der Realteil $\epsilon^{\prime}$ die Polarisation durch das einfallende Licht und der Imaginärteil $\epsilon^{\prime \prime}$ die Absorption aus. Eine resonante Anregung von Oberflächenplasmonen ist nur dann möglich, wenn die aus der Literatur [91] bekannten Dispersionsrelationen eines einfallenden Photons $\omega_{P h}\left(\left|\vec{k}_{P h}\right|\right)$ und eines Oberflächenplasmons $\omega_{S P}\left(\left|\vec{k}_{S P}\right|\right)$ die Energie- und Impulserhaltung erfüllen:

$$
\omega_{P h}=\frac{c}{\sqrt{\epsilon_{D}}}\left|\vec{k}_{P h}\right|, \quad \omega_{S P}=c\left|\vec{k}_{S P}\right| \sqrt{\frac{\epsilon_{M}+\epsilon_{D}}{\epsilon_{M} \epsilon_{D}}} .
$$

Der Impuls $\vec{P}$ ist nach Gleichung 2.10 linear mit dem Wellenvektor $\vec{k}$ durch das Plancksche Wirkungsquantum $\hbar$ gekoppelt und die Energie E ebenfalls linear mit der Kreisfrequenz $\omega$ nach Gleichung 2.11:

$$
\begin{aligned}
& \vec{P}=\hbar \vec{k}, \\
& \mathrm{E}=\hbar \omega .
\end{aligned}
$$

Zum besseren Verständnis der resonanten Anregung von Oberflächenplasmonen zeigt Abbildung 2.3 schematisch ein aus dem Dielektrikum $\epsilon_{D}$ einfallendes Photon mit dem Wellenvektor $\vec{k}_{P h}$ und der Frequenz $\omega_{P h}$, das mit einer ebenen Metalloberfläche mit der Dielektrizitätsfunktion $\epsilon_{M}$ wechselwirkt. Dabei wird ein sich nur in $x$-Richtung ausbreitendes Oberflächenplasmon mit der Wellenvektorkomponente $k_{S P, x}$ angenommen. Für den Fall, dass der Betrag der Wellenvektorkomponente des Photons $k_{P h, x}$ gleich dem der Wellenvektorkomponente $k_{S P, x}$ des Oberflächenplasmons entspricht, ist die Impulserhaltung gewahrt. Dabei ist die Wellenvektorkomponente $k_{P h, x}$ vom Ein- 
fallswinkel $\phi$ des Photons abhängig und kann mit Hilfe der Dispersionsrelation des einfallenden Photons durch folgende Gleichung beschrieben werden:

$$
k_{P h, x}=\frac{\omega_{P h}}{c} \sqrt{\epsilon_{D}} \cdot \sin \phi .
$$

Für die Kopplung des Photons an ein Oberflächenplasmon müssen beide Dispersionsrelationen die Energie- und Impulserhaltung erfüllen, so dass mit $\omega=\omega_{P h}=\omega_{S P}$ folgende Gleichung gilt:

$$
k_{P h, x}=\frac{\omega}{c} \sqrt{\epsilon_{D}} \cdot \sin \phi=\frac{\omega}{c} \sqrt{\frac{\epsilon_{M} \epsilon_{D}}{\epsilon_{M}+\epsilon_{D}}}=k_{S P} .
$$
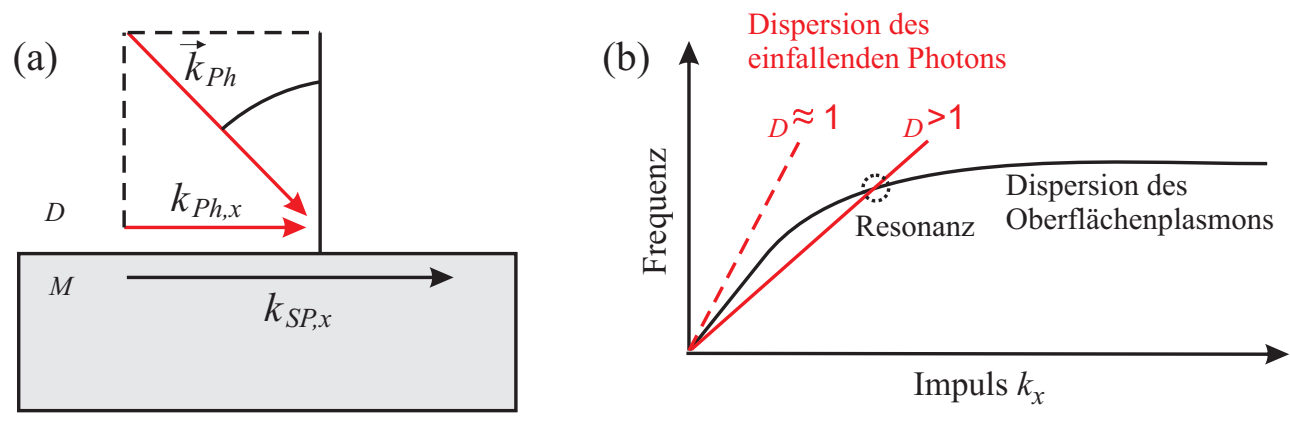

Abbildung 2.3: (a) Verhältnis von Wellenvektorkomponenten eines aus dem Dielektrikum $\epsilon_{D}$ einfallenden Photons und eines Oberflächenplasmons in der Grenzfläche des Metall $\epsilon_{M}$ mit ebener Oberfläche. (b) Dispersionsrelation des einfallenden Photons und des Oberflächenplasmons.

Beim Photoneneinfall aus der Luft $\left(\epsilon_{D} \approx 1\right)$ kann keine Wellenvektorangleichung stattfinden, da für alle Einfallswinkel $\phi>0$ die Relation

$$
k_{P h, x} \neq k_{S P, x}
$$

gilt. Dieser Zusammenhang wird durch die folgenden Überlegungen plausibel: Werden eine reelle Frequenz $\omega$ und Dielektrizitätskonstante $\epsilon_{D}$ angenommen sowie ein Imaginärteil der Dielektrizitätsfunktion des Metalls $\epsilon_{M}^{\prime \prime}$, der kleiner ist als der Betrag des Realteils $\epsilon_{M}^{\prime}$, so lässt sich nach Gleichung 2.9 die Wellenvektorkomponente $k_{S P, x}$ des 
Oberflächenplasmons wie folgt in komplexer Schreibweise darstellen:

$$
\begin{aligned}
& k_{S P, x}=k_{S P, x}^{\prime}+i k_{S P, x}^{\prime \prime}, \\
& k_{S P, x}^{\prime}=\frac{\omega}{c}\left(\frac{\epsilon_{M}^{\prime} \cdot \epsilon_{D}}{\epsilon_{M}^{\prime}+\epsilon_{D}}\right)^{1 / 2}, \\
& k_{S P, x}^{\prime \prime}=\frac{\omega}{c}\left(\frac{\epsilon_{M}^{\prime} \cdot \epsilon_{D}}{\epsilon_{M}^{\prime}+\epsilon_{D}}\right)^{3 / 2} \cdot \frac{\epsilon_{M}^{\prime \prime}}{2\left(\epsilon_{M}^{\prime \prime}\right)^{2}} .
\end{aligned}
$$

Für die Existenz eines reellen Wellenvektors $k_{S P, x}^{\prime}$ müssen die Bedingungen $\epsilon_{M}^{\prime}<0$ und $\left|\epsilon_{M}^{\prime}\right|>\epsilon_{D}$ erfüllt sein. Diese Bedingungen sind besonders gut für Edelmetalle, wie beispielsweise Gold, Silber, Kupfer, Platin, Rubidium und Rhodium bei Anregung mit Photonen im sichtbaren Spektralbereich erfüllt. In Abbildung 2.4 sind exemplarisch die Real- und Imaginärteile der Dielektrizitätsfunktionen von Gold und Silber für Wellenlängen im sichtbaren Spektralbereich aufgetragen. Nach Gleichung 2.16 existiert keine Lösung für eine reale Wellenvektorkomponente $k_{S P, x}^{\prime}$, wenn die Metalloberfläche von Luft $\left(\epsilon_{D}=1\right)$ umgeben ist.

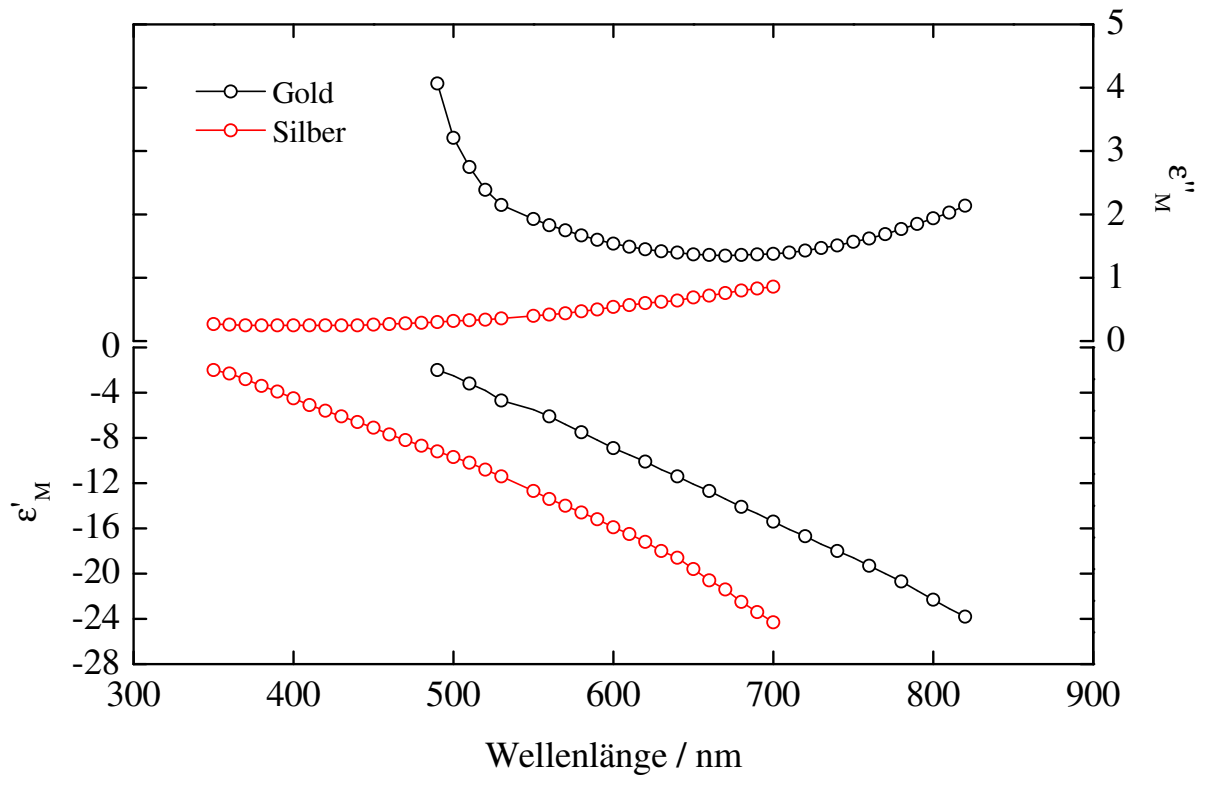

Abbildung 2.4: Realteil $\epsilon_{M}^{\prime}$ und Imaginärteil $\epsilon_{M}^{\prime \prime}$ der Dielektrizitätsfunktion von Gold und Silber nach [91].

Eine Anregung von Oberflächenplasmonen auf ebenen Metalloberflächen mit dem Umgebungsmedium Luft kann nur dann stattfinden, wenn die Metalloberfläche mit einer dünnen Schicht eines dielektrischen Mediums versehen wird, deren Dielektrizitätskonstante größer Eins ist. Damit existiert für jedes Medium, das diese Bedingung erfüllt, genau ein Einfallswinkel $\phi$, unter dem die eingestrahlten Photonen in der Lage sind, 
Oberflächenplasmonen resonant anzuregen. Dieser Effekt wird insbesondere in der resonanten Oberflächenplasmonenspektroskopie zur Identifikation von unterschiedlichen Molekülschichten und -dicken auf metallischen Oberflächen ausgenutzt [33].

Eine weitere Möglichkeit zur resonanten Anregung von Oberflächenplasmonen ist die Strukturierung der metallischen Oberfläche. Dadurch kann beispielsweise bei stochastisch verteilten oder gitterartigen Oberflächenstrukturen ein Kontinuum von Wellenvektorkomponenten $\Delta k_{P h, x}$ des einfallenden Photons in der Oberfläche entstehen, die in einer Linearkombination mit $k_{P h, x}$ übereinstimmen. Für diesen Fall wird die Dispersionsrelation durch

$$
k_{P h, x}=\frac{\omega}{c} \cdot \sin \phi \pm \Delta k_{P h, x}=k_{S P}
$$

erfüllt, wobei $\Delta k_{P h, x}=0$ keine Lösung ist. Zum besseren Verständnis zeigt Abbildung 2.5 eine schematische Darstellung dieser Zusammenhänge.
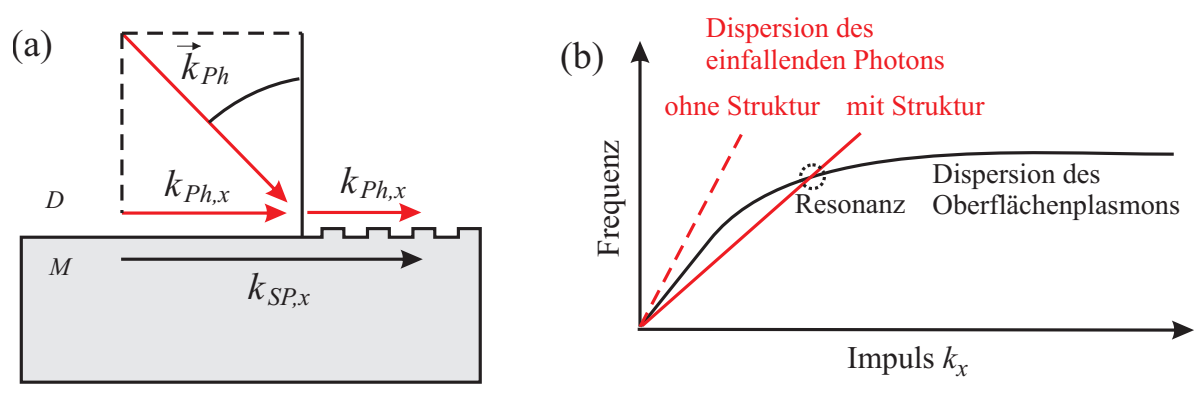

Abbildung 2.5: (a) Verhältnis von Wellenvektorkomponenten eines aus dem Dielektrikum $\epsilon_{D}$ einfallenden Photons und eines Oberflächenplasmons im Metall $\epsilon_{M}$ mit strukturierter Oberfläche. (b) Dispersionsrelation des einfallenden Photons und des Oberflächenplasmons.

Für den Fall, dass die Oberflächenrauigkeit $\delta$, die dem quadratischen Mittel der Höhe $z$ entspricht, größer als $0,5 \mathrm{~nm}$ ist [91], sind die Störeinflüsse der Strukturen so groß, dass sich die Oberflächenplasmonen ungerichtet ausbreiten. Ihre sich in z-Richtung erstreckenden und exponentiell abfallenden elektrischen Feldstärken sind in der Lage, sich akkumulativ zu verstärken.

Das Potential der feldverstärkenden Eigenschaften von Oberflächenplasmonen für die Ramanspektroskopie wurde erstmals 1980 von Gersten und Nitzan [24] und McCall [68] dargestellt und bald darauf von Kerker [42] erweitert. Die elektrischen Feldverstärkungen können demzufolge durch einen Feldverstärkungsfaktor $\Omega$ ausgedrückt werden, der dem Quotienten aus der Intensität des elektrischen Feldes $\left|\vec{E}_{O}\right|^{2}$ auf der 
Oberfläche und der Intensität des eingestrahlten elektrischen Feldes $\left|\vec{E}_{P h}\right|^{2}$ entspricht:

$$
\Omega\left(\omega_{P h}\right)=\frac{\left|\vec{E}_{O}\left(\omega_{P h}\right)\right|^{2}}{\left|\vec{E}_{P h}\left(\omega_{P h}\right)\right|^{2}} .
$$

Der elektromagnetische Verstärkungseffekt berücksichtigt nicht nur die Verstärkung des oberflächennahen elektromagnetischen Feldes, sondern auch die Wechselwirkung mit einem Raman-aktiven Molekül. Abbildung 2.6 zeigt eine vereinfachte Darstellung dieses Zusammenhangs. Die raue Oberfläche ist in diesem Beispiel ein kleiner sphärischer Metallpartikel mit der Dielektrizitätsfunktion $\epsilon_{M}$, der sich in einem Dielektrikum $\epsilon_{D}$ befindet. Die Anregungswellenlänge $\lambda$ soll groß im Vergleich zum Durchmesser $2 r$ des Partikels sein und das Umgebungsmedium nicht absorbierend, so dass $\epsilon_{D}$ reell ist und als konstant angenommen wird. Die Bestrahlung des betrachteten Metallpartikels mit einem elektrischen Feld $\vec{E}_{P h}$ der Frequenz $\nu_{P h}=w_{P h} / 2 \pi$ führt zu einer resonanten Anregung des quasifreien Elektronengases, sofern die Bedingungen für die Anregung von Oberflächenplasmonen erfüllt sind.

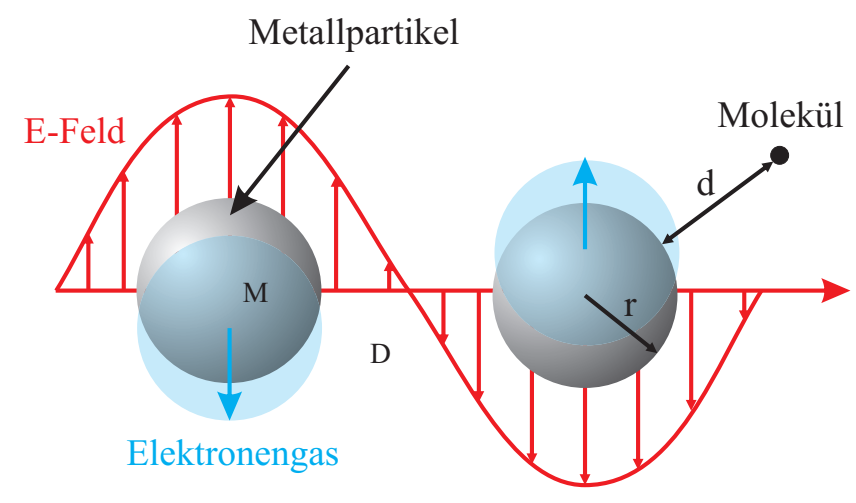

Abbildung 2.6: Schema zur Erklärung des elektromagnetischen Verstärkungseffektes für ein Molekül im Abstand d zu einem Metallpartikel.

Die Oszillation des Elektronengases induziert im Mittelpunkt des Partikels ein Dipolmoment, das ein elektrisches Feld $\vec{E}_{i n d}\left(\nu_{P h}\right)$ erzeugt. Diese Oberflächenplasmonen sind auf das Partikel begrenzt und werden daher auch als lokalisierte Oberflächenplasmonen bezeichnet. Der Betrag des induzierten elektrischen Feldes $E_{\text {ind }}\left(\nu_{P h}\right)$ lässt sich mit Hilfe der Polarisierbarkeit $\alpha_{M}$ einer Metallkugel nach [22] durch

$$
E_{i n d}\left(\nu_{P h}\right)=r^{3} \cdot E_{P h}\left(\nu_{P h}\right) \cdot \frac{\epsilon_{M}\left(\nu_{P h}\right)-\epsilon_{D}}{\epsilon_{M}\left(\nu_{P h}\right)+2 \epsilon_{D}} \cdot(r+d)^{-3}
$$

ausdrücken. Auf ein Molekül, das sich im Abstand $d$ zu dem Metallpartikel befindet, wirkt die Summe aus dem induzierten und dem eingestrahlten elektrischen Feld. In 
Analogie zu Gleichung 2.19 ergibt sich an der Position des Moleküls ein Verstärkungsfaktor von:

$$
\Omega\left(\nu_{P h}\right)=\frac{\left|\vec{E}_{P h}\left(\nu_{P h}\right)+\vec{E}_{i n d}\left(\nu_{P h}\right)\right|^{2}}{\left|\vec{E}_{P h}\left(\nu_{P h}\right)\right|^{2}} .
$$

Das vom Molekül emittierte Ramanstreulicht induziert ebenfalls in dem Metallpartikel ein Dipolmoment und damit ein elektrisches Feld $\vec{E}_{\text {ind }}\left(\nu_{S}\right)$, sofern die Oberflächenplasmonen in Resonanz zu $\nu_{S}$ stehen. Der Betrag des induzierten Feldes folgt analog zu Gleichung 2.20:

$$
E_{\text {ind }}\left(\nu_{S}\right)=r^{3} \cdot E_{S}\left(\nu_{S}\right) \cdot \frac{\epsilon_{M}\left(\nu_{S}\right)-\epsilon_{D}}{\epsilon_{M}\left(\nu_{S}\right)+2 \epsilon_{D}} \cdot(r+d)^{-3}
$$

In realen Systemen, in denen die Ausdehnungen der Metallpartikel bzw. -cluster in derselben Größenordnung liegen wie die Anregungswellenlänge, können Multipole entstehen. Diese führen zu einer spektralen Verbreiterung der Resonanzmaxima, sowie zu einer Verschiebung der Resonanzmaxima zu höheren Wellenlängen. In Abbildung 2.7 wird dieser Sachverhalt anhand der Agglomeration (Clusterbildung) einer monodispersen wässrigen Goldkolloidlösung mit einer Kolloidgröße von $40 \mathrm{~nm}$ deutlich. Zu sehen ist das Extinktionsspektrum der kolloidalen Goldlösung für unterschiedliche Agglomerationszustände.

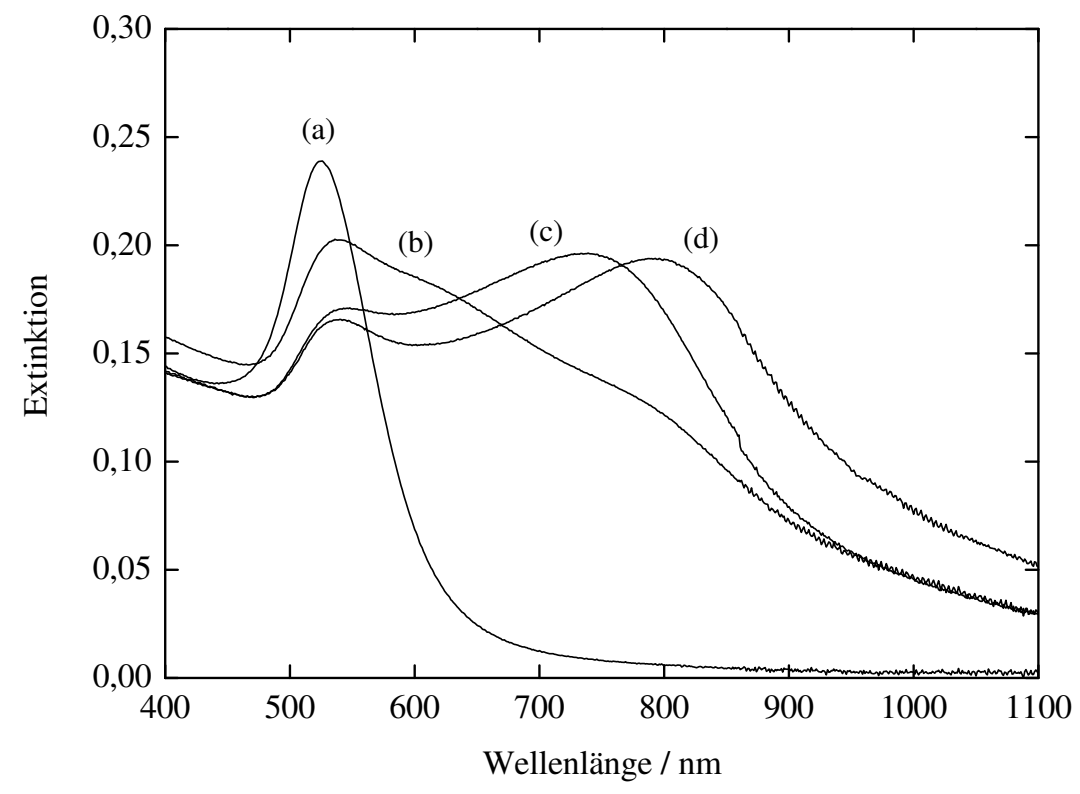

Abbildung 2.7: Extinktionsspektren einer wässrigen Goldkolloidlösung, (a) monodispers $40 \mathrm{~nm}$, (b) - (d) mit zunehmender Aggregation.

Die Maxima der Extinktionsfunktionen geben die spektrale Position der Oberflächenplasmonenresonanzen an. Es ist deutlich zu erkennen, dass durch die Agglomeration 
der Kolloide die anfänglich spektral „scharfe“ Resonanz bei $520 \mathrm{~nm}$ eine stetige Verbreiterung mit zunehmender Agglomeration erfährt. Letztendlich entsteht eine weitere, spektral breite Resonanz bei $810 \mathrm{~nm}$. Somit können Metallpartikelcluster sowohl das Anregungslicht $\left(\nu_{P h}\right)$ als auch das Ramanstreulicht $\left(\nu_{S}\right)$ verstärken, wobei $\nu_{P h} \neq \nu_{S}$ ist. Nach Kerker [42] ergibt sich der absolute elektromagnetische Verstärkungsfaktor $\Omega_{A b s}$ aus dem Produkt der beiden Verstärkungsfaktoren $\Omega\left(\nu_{P h}\right) \cdot \Omega\left(\nu_{S}\right)$. Daraus resultiert

$$
\Omega_{A b s}\left(\nu_{P h}, \nu_{S}\right)=\frac{\left|\epsilon_{M}\left(\nu_{P h}\right)-\epsilon_{D}\right|^{2}}{\left|\epsilon_{M}\left(\nu_{P h}\right)+2 \epsilon_{D}\right|^{2}} \cdot \frac{\left|\epsilon_{M}\left(\nu_{S}\right)-\epsilon_{D}\right|^{2}}{\left|\epsilon_{M}\left(\nu_{S}\right)+2 \epsilon_{D}\right|^{2}} \cdot\left(\frac{r}{r+d}\right)^{12}
$$

mit $E_{\text {ind }}\left(\nu_{P h}\right) \gg E_{P h}\left(\nu_{P h}\right)$ und $E_{\text {ind }}\left(\nu_{S}\right) \gg E_{S}\left(\nu_{S}\right)$. Anhand dieser Gleichung wird deutlich, dass es sich bei dem elektromagnetischen Verstärkungseffekt um einen so genannten „first-layer“-Effekt handelt. Die Ramanstreulichtverstärkung für ein Molekül nimmt mit $(1 / d)^{12} \mathrm{ab}$, so dass nur die der Oberfläche am nächsten gelegene Molekülschicht den maximalen Verstärkungsfaktor erfährt. Desweiteren leitet sich aus der Gleichung 2.23 die notwendige Bedingung für den rechnerisch maximalen Verstärkungsfaktor eines Metallpartikels in Luft ab, nämlich $\epsilon_{M}=-2 \epsilon_{D}$. Für ein Gold- bzw. Silberpartikel ergibt sich unter Berücksichtigung der Daten aus Abbildung 2.4 eine optimale Anregungswellenlänge von $480 \mathrm{~nm}$ und $\epsilon_{M}^{\prime \prime}=4,12$ für Gold und von $350 \mathrm{~nm}$ und $\epsilon_{M}^{\prime \prime}=0,32$ für Silber. Unter der Annahme, dass sich ein Molekül direkt auf der Oberfläche des Partikels befindet $(d=0)$ und die Frequenz des Ramanstreulichtes $\left(\nu_{S}\right)$ gleich der Anregungsfrequenz $\left(\nu_{P h}\right)$ entspricht, lassen sich maximale Verstärkungsfaktoren von $\Omega_{\text {Gold }}=4,5$ und $\Omega_{\text {Silber }}=460$ berechnen. Diese Verstärkungsfaktoren können jedoch mit zunehmender Differenz zwischen Anregungs- $\left(\nu_{P h}\right)$ und Ramanstreulichtfrequenz $\left(\nu_{S}\right)$ abnehmen, da sie dann nicht mehr zwangsläufig die Resonanzbedingungen für die Oberflächenplasmonen erfüllen. Theoretische Berechnungen von Kelly et al. [41] zeigen allerdings auf, dass Verstärkungsfaktoren von bis zu $10^{6}$ für diverse Metallpartikeldurchmesser zwischen 10 bis $100 \mathrm{~nm}$ und für unterschiedliche Partikelkonfigurationen möglich sind.

In der Literatur sind Verstärkungsfaktoren von 10 ${ }^{14}$, mit denen ein Einzelmolekülnachweis [48, 45] stattgefunden hat, am Beispiel kolloidaler Silberlösungen dokumentiert. Derart hohe Verstärkungsfaktoren können nicht durch Gleichung 2.23 für einzelne Metallpartikel erklärt werden. Als Grund für die ungewöhnlich hohen Verstärkungsfaktoren werden zum Einen die so genannten „hot-spots“ und zum Anderen der chemische Verstärkungseffekt aufgeführt. "Hot-spots" entstehen zwischen nah aneinanderliegenden Metallpartikeln, so dass bei geeigneter Polarisation des Anregungslichtes sehr hohe elektrische Feldstärken im interpartikulären Raum erzeugt werden. Abbildung 2.8 zeigt schematisch die Enstehung eines „hot-spot“ zwischen zwei Metallpartikeln. 

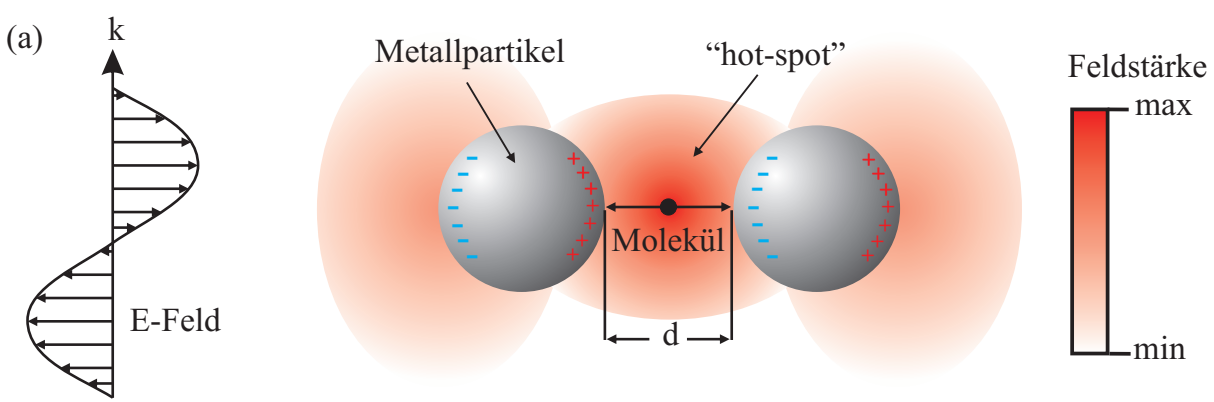

(b)
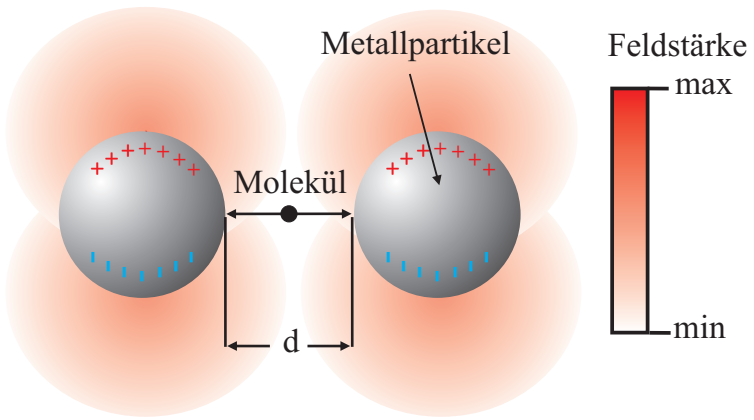

Abbildung 2.8: (a) Entstehung hoher Feldstärken („hot-spot“) durch Anregungslicht mit Polarisationsrichtung parallel zur interpartikulären Achse. (b) Keine Feldverstärkung zwischen den Partikeln aufgrund einer zur interpartikulären Achse senkrechten Polarisationsrichtung des einfallenden Anregungslichtes.

Die rot eingefärbten Bereiche in Abbildung 2.8 markieren Orte unterschiedlicher Feldstärken, die auf Ladungsverschiebungen innerhalb des Metallpartikels zurückzuführen sind. Aus der Interaktion beider Metallpartikel resultiert eine Erhöhung des induzierten Dipolmomentes jedes einzelnen Metallpartikels sowie der Polarisation. Nach Moskovits [71] ist die Feldverstärkung zwischen zwei Partikeln proportional zu $d^{-8}$, die im Falle der Berechnungen von Xu [115] und Käll [116] für zwei sphärische Metallpartikel mit einem Abstand von $d<1 \mathrm{~nm}$ in der Größenordnung von $10^{12}$ liegt. In realen Systemen existieren oft weit mehr als zwei Metallpartikel, so dass wegen der Polarisationsabhängigkeit der Plasmonenresonanzen [8] für Mehrpartikelsysteme sowohl die Verstärkung als auch die Resonanzbedingung simultan stark variieren. Die Komplexität solcher Mehrpartikelsysteme erlaubt derzeit keine numerischen Simulationen für die räumliche Verteilung von Verstärkungsfaktoren.

Die bisher vorgestellten Erklärungsmodelle zur Berechnung der Feldverstärkungen reichen noch nicht aus, um den von Kneipp experimentell nachgewiesenen Verstärkungsfaktor von $10^{14} \mathrm{zu}$ begründen. Dafür wird der so genannte chemische Verstärkungseffekt verantwortlich gemacht, der auch als Ladungstransfer-Effekt bekannt ist. 


\subsubsection{Ladungstransfer-Effekt}

Unter dem Ladungstransfer-Effekt wird im Allgemeinen ein photoneninduzierter Elektronentransfer von einer Metalloberfläche in Molekülorbitale von adsorbierten Molekülen verstanden. Dieser Ladungstransfer wurde erstmals 1981 als Erklärungsmodell für die außergewöhnlich hohen Ramanstreulichtintensitäten von Benzolmolekülen, die auf Platin-Partikeln adsorbiert waren, herangezogen. Trotz stark gedämpfter Plasmonenresonanzen, wie sie typisch für Platin-Partikel im VIS-NIR Spektralbereich sind, beobachtete Adrian [1] eine Verstärkung des Ramanstreulichtes, die nicht mit dem elektromagnetischen Verstärkungseffekt erklärt werden konnte. Auch die von Moskovits und DiLella [72] beobachteten hohen Signalunterschiede von den auf Silberfilmen adsorbierten Gasen Stickstoff und Kohlenmonoxid, die nahezu den gleichen Streuquerschnitt aufweisen, benötigten ein neues theoretisches Modell zur Beschreibung dieses Phänomens. Ein ausführliches und heutzutage favorisiertes Modell zur Beschreibung des Ladungstransfer-Effektes stammt von Lombardi [62] und Otto [82]. Wichtigste Voraussetzung ihres Modells sind Orte atomarer Rauigkeit auf der Metalloberfläche, wie z.B. Stufen, Versetzungen und Cluster von einzelnen Atomen, die so genannten „active-sites“. Sie weisen im Gegensatz zu ebenen Bereichen auf der Oberfläche sehr schmale Verteilungen der elektronischen Zustandsdichten auf und ermöglichen dadurch die Ramanstreulichtverstärkung. Da die Existenz und die Einflüsse der „active-sites“ auf die Ramanstreulichtverstärkung derzeit noch kontrovers diskutiert werden, soll auf sie nicht weiter eingegangen werden.

Trotz dieser Diskussionen spiegelt das Ladungstransfer-Modell viele experimentelle Ergebnisse wider und ist schematisch in Abbildung 2.9 anhand eines vierstufigen Kreisprozesses von Elektronen auf einer mit Molekülen belegten Metalloberfläche dargestellt. Der Kreisprozess beginnt mit der Erzeugung eines Elektronen-Loch-Paares durch ein Anregungsphoton der Frequenz $\nu_{P h}(\mathrm{a})$. Das angeregte Elektron tunnelt vom Metall in das LUMO („Lowest Unoccupied Molecular Orbital“) des adsorbierten im Schwingungsgrundzustand vorliegenden Moleküls und überführt das Molekül in einen schwingungsangeregten Zustand (b). In (c) tunnelt das Elektron in das Metall zurück und überführt dabei das Molekül in das HOMO („Highest Occupied Molecular Orbital“), wobei das Molekül im schwingungsangeregten Zustand verbleibt. Nun rekombiniert das Elektron mit dem Loch unter Aussendung eines Photons der Frequenz $\nu_{S}$, die der Frequenz der Molekülschwingung entspricht (d). Somit bildet sich ein Oberflächen- bzw. Ladungstransfer-Komplex, der Energieniveaus aufweist, die weder im Metall noch im Molekül im Einzelnen vorliegen. Der Ladungstransfer-Komplex erklärt die durch die Adsorption von Molekülen hervorgerufene Verschiebungen von Ramanbanden im Vergleich zum freien Molekül. Mit Hilfe des Ladungstransfer-Modells können ebenfalls die 


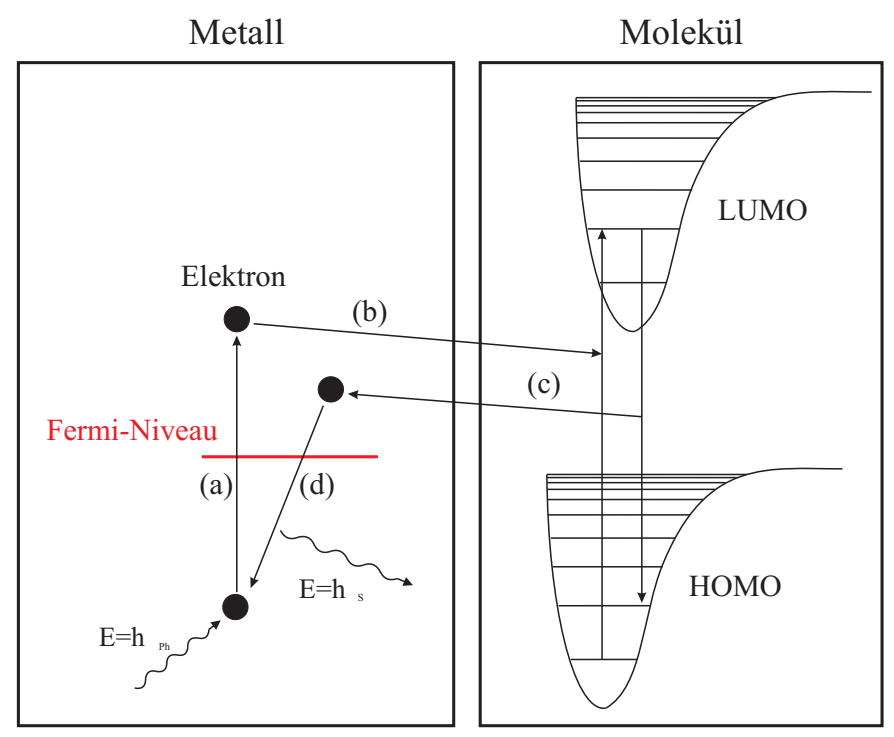

Abbildung 2.9: Schematische Darstellung des vierstufigen Kreisprozesses beim Elektronentransfer im Ladungstransfer-Modell von Lombardi und Otto.

von Fleischmann [21] beobachteten potentialabhängigen Ramanstreulichtverstärkungen von Pyridin auf elektrochemisch angerauten Silberelektroden erklärt werden, da die Veränderung des Potentials an der Elektrode zu einer relativen Verschiebung des FermiNiveaus des Metalls gegenüber der Energieniveaus der adsorbierten Moleküle führt. In Abhängigkeit von der energetischen Lage des Fermi-Niveaus bilden sich unterschiedliche Ladungstransfer-Komplexe aus, so dass maximale Ramanstreulichtverstärkungen jeweils nur mit unterschiedlichen Anregungswellenlängen und Potentialen erreicht werden können. In der Literatur [114] wird von chemischen Verstärkungsfaktoren im Bereich von 10-100 berichtet, was sich mit dem Experiment von Kneipp deckt. Dennoch sei an dieser Stelle gesagt, dass Aussagen über die Größe des chemischen Verstärkungseffektes mit einem relativ großen Fehler behaftet sein können, da beispielsweise durch die Veränderungen des chemischen Potentials ebenfalls die Adsorption begünstigt werden kann, so dass der Verstärkungsfaktor lediglich aus der Erhöhung der Anzahl adsorbierter Moleküle resultiert.

Nachdem die der Ramanstreulichtverstärkung zugrundeliegenden theoretischen Erklärungsmodelle näher beschrieben worden sind, wird im nun folgenden Abschnitt ein kleiner Überblick über die am häufigsten verwendeten ramanstreulichtverstärkenden Substrate gegeben und auf ihre Herstellungsverfahren eingegangen. Dabei kann kein Anspruch auf Vollständigkeit bestehen, da die Variationsmöglichkeiten der Herstellungsverfahren beinahe unbegrenzt sind. 


\subsection{Ramanstreulichtverstärkende Oberflächen}

Seit der Entdeckung der Ramanstreulichtverstärkung auf rauen metallischen Oberflächen sind unzählige Herstellungsverfahren dokumentiert. Diese lassen sich im Wesentlichen in fünf verschiedene Kategorien zusammenfassen: chemisch aufgeraute Elektroden, Metallkolloide, metallische Sol-Gele, Metallinselfilme und nanostrukturierte Metalloberflächen. Sie werden hier kurz vorgestellt und hinsichtlich ihrer Ramanstreulichtverstärkung, räumlichen Signalreproduzierbarkeit und Beständigkeit gegenüber chemischen Einflüssen beschrieben.

\section{Chemisch aufgeraute Elektrode}

Die chemisch aufgeraute Elektrode ist die bekannteste ramanstreulichtverstärkende Oberfläche seit Entdeckung durch Fleischmann et al. [21] im Jahre 1974. Diese zeichnet sich durch ihre einfache Herstellungsprozedur aus, die das elektrochemische Aufrauen metallischer Oberflächen durch Redoxzyklen an speziell angeordneten Elektroden in einer elektrolytischen Umgebung vorsieht. Sie liefert zwar hohe Verstärkungsfaktoren von bis zu $10^{6}$, doch ist sie nicht langzeitstabil, da ihre Oberfläche chemisch reaktiv ist.

\section{Metallkolloide}

Metallkolloide sind feste, weitgehend formstabile Metallpartikel, die in der Regel in einer wässrigen Lösung vorliegen und sich durch ihre charakteristische Lichtstreuung auszeichnen. Ihre Durchmesser können einige Nanometer bis hin zu einem Mikrometer betragen. Die Herstellung von Gold- bzw. Silberkolloiden und ihre Modifizierung hinsichtlich der Erzeugung hoher Verstärkungsfaktoren ist in vielen Veröffentlichungen dokumentiert. Sie basieren im Wesentlichen auf der Reduktion von Tetrachlorgoldsäure-Trihydrat bzw. Silbernitrat durch den Einsatz von Citraten, wie z.B. TriNatrium-Dihydrat. Die wohl bekanntesten Veröffentlichungen zur Präparation solcher Hydrosole stammen von Lee und Meisel [60] und von Sutherland und Winefordner [105]. Wie bereits in Abschnitt 2.2 beschrieben, zeigen diese Gold- und Silberkolloide spektral unterschiedliche Absorptionsmaxima, die auf eine Anregung von Oberflächenplasmonen zurückzuführen sind. Obwohl Metallkolloide einfach herzustellen sind, eignen sie sich nur bedingt zur Ramanstreulichtverstärkung, da sie mit der Zeit zur Agglomeration neigen und ausfallen. Desweiteren muss eine sehr aufwendige Oberflächenchemie betrieben werden, damit die zu untersuchenden Moleküle an die Kolloide adsorbieren. Die dafür eingesetzten chemischen Substanzen zeigen in der Regel aber einen hohen Störeinfluss in den entsprechenden Ramanspektren. 


\section{Metallische Sol-Gele}

Metallische Sol-Gele sind hybridpolymere Materialen, in denen Gold- bzw. Silberkolloide in einem Gelgerüst mit definierter Porengröße eingeschlossen sind. Das Sol-Gel weist je nach Herstellungsverfahren unterschiedliche Porengrößen auf, wobei die Poren alle miteinander in Verbindung stehen. Moleküle entsprechender Größe können durch diese Poren diffundieren und somit in Kontakt mit den eingeschlossenen Kolloiden treten. In [73] ist beispielhaft ein Sol-Gel-Prozess für die Nutzung in der oberflächenverstärkten Ramanspektroskopie von polyzyklischen aromatischen Kohlenwasserstoffen in Seewasser detailliert beschrieben. Metallische Sol-Gel-Substrate eignen sich zwar wegen ihrer variablen Porengröße zur selektiven oberflächenverstärkten ramanspektroskopischen Untersuchung von Molekülen unterschiedlicher Größe in Lösungen, doch ist die maximale Porengröße begrenzt. Sie sind nicht für Makromoleküle, wie z.B. Proteine, geeignet.

\section{Metallinselfilme}

Metallinselfilme entstehen durch sehr geringe Aufdampfraten von wenigen Pikometern pro Sekunde von Metallen auf Glas- bzw. Quarzglasträgern [57]. Die üblicherweise schlechte Haftung der aufgedampften Metalle auf diesen Trägermaterialien führt aufgrund der Oberflächenspannung des flüssigen Metalls zu kleinen Tröpfchen, die zu den so genannten Inseln zusammenlaufen. Die Durchmesser der Inseln liegen im Bereich weniger Nanometer und sind in der Regel homogen auf dem bedampften Träger verteilt. Aufgrund des fehlenden Haftvermittlers kann bereits das Aufbringen einer flüssigen Probe zur Ablösung der Inseln führen.

\section{Nanostrukturierte Metalloberflächen}

Die vielversprechendsten ramanstreulichtverstärkenden Oberflächen bildet die Gruppe der nanostrukturierten Metalloberflächen. Sie entstehen entweder durch die direkte Strukturierung einer Metalloberfläche oder durch die Bedampfung eines bereits strukturierten Substrates mit dem bevorzugten Metall. Für die direkte Strukturierung von Metallen werden häufig dünne Metallfolien verwendet, die mittels Laserablation [59] oder Ätzen [115] bearbeitet werden und in der Regel unregelmäßige Struktur aufweisen. Für die Herstellung von Oberflächen mit regelmäßigen Strukturen werden im Wesentlichen drei Strategien verfolgt:

- Erzeugung geordneter Monolagen von metallischen Kolloiden [30] auf Glasträgern (s. Abbildung 2.10 (a)).

- Erzeugung geordneter Monolagen von Nanopartikeln, wie Polystyrolkügelchen oder Teflonpartikel [35], die mit einem dünnen Metallfilm bedampft werden (op- 
tional mit anschließender chemischer Entfernung der Nanopartikel [34]) (s. Abbildung $2.10(\mathrm{~b}))$.

- Elektronenstrahllithographisch strukturierte Silizium-Wafer mit anschließender metallischer Bedampfung [66] (s. Abbildung 2.10 (c)).

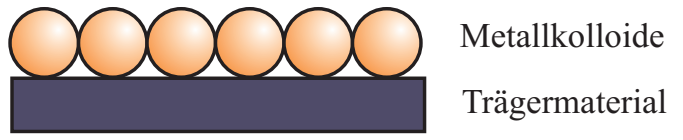

(a)

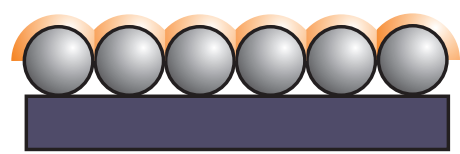

Metallfilm Nanopartikel

Trägermaterial

(b)

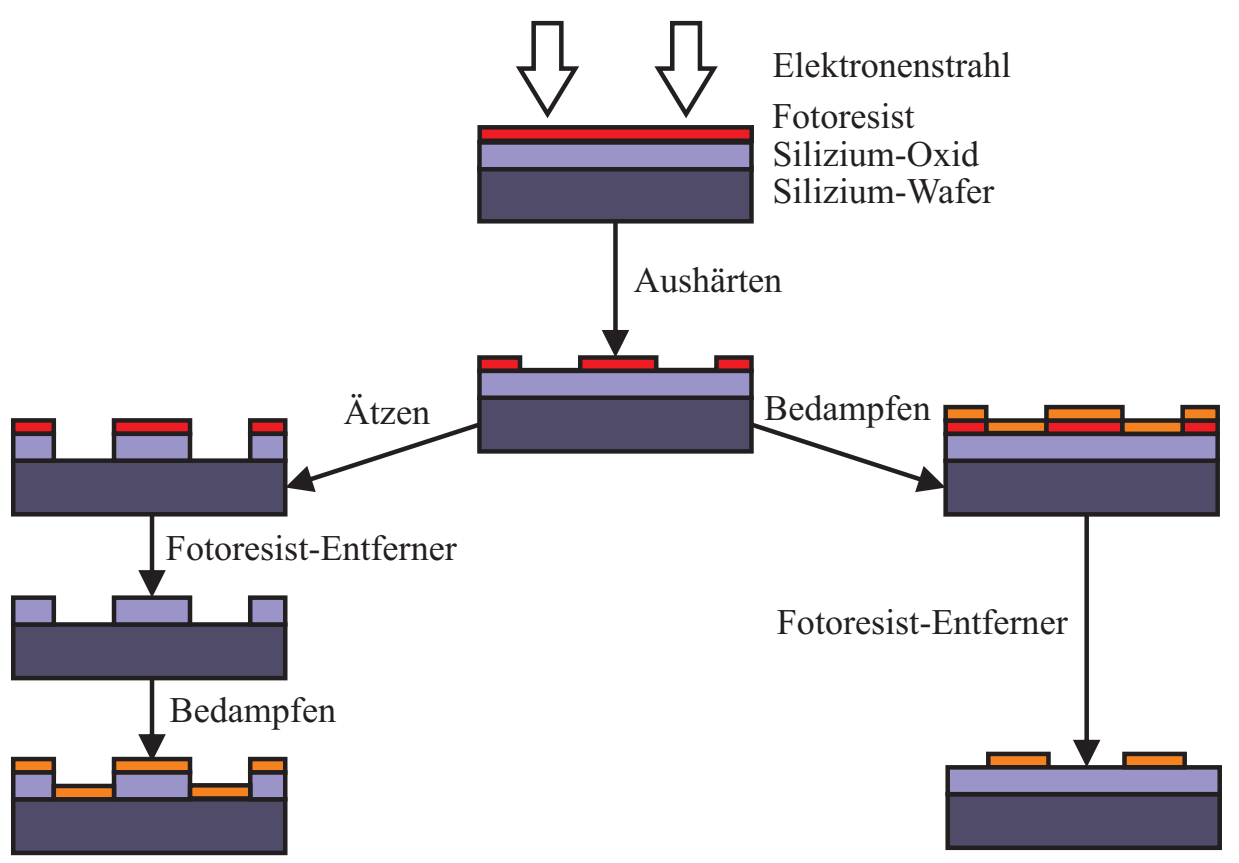

(c)

Abbildung 2.10: Ausgewählte Methoden für die Nanostrukturierung von metallischen Oberflächen.

Der Vorteil dieser Herstellungsmethoden liegt in der räumlichen Homogenität der erzeugten Strukturen, die zu einer hohen Signalreproduzierbarkeit führen. Nachteile dieser Substrate sind jedoch die vielen benötigten Arbeitsschritte und die kostenintensiven lithographischen Strukturierungsverfahren. 


\subsection{Grundlagen der Ramanspektren von Proteinen}

Die Identifizierung und Quantifizierung von Proteinen mit Hilfe der oberflächenverstärkten Ramanspektroskopie setzt die Kenntnis der an der Ramanstreuung beteiligten Moleküleigenschwingungen und deren Gruppenfrequenzen voraus. Dabei spielt nicht nur die chemische Zusammensetzung des Proteins eine große Rolle, sondern auch die für Proteine typische große Strukturvariabilität, die sich in den Ramanspektren widerspiegelt. Daher werden im folgenden Abschnitt die Grundlagen der chemischen Zusammensetzung und die der räumlichen Struktur von Proteinen beschrieben sowie deren charakteristische Ramanbanden.

\subsubsection{Aufbau und Struktur von Proteinen}

Proteine bilden eine der vielfältigsten Stoffklassen der belebten Materie und unterscheiden sich untereinander nicht nur durch ihre Zusammensetzung, sondern vor allem durch ihre strukturellen Eigenschaften. Sie sind Makromoleküle, die aus einer Vielzahl von kleineren Molekülen, den Aminosäuren, aufgebaut sind. Mittels Peptidbindungen sind diese Aminosäuren zu langen Ketten verbunden, die eine Länge von mehreren tausend Stück aufweisen können. Aminosäureketten mit einer Länge von bis zu 100 Aminosäuren werden nach Konvention als Peptide bezeichnet und erst Kettenlängen größer 100 Aminosäuren als Proteine. Aminosäuren sind organische Verbindungen, die mindestens eine Carboxyl- $(\mathrm{COOH})$ und eine Aminogruppe $\left(\mathrm{NH}_{2}\right)$ aufweisen. Derzeit sind beinahe 250 verschiedene Aminosäuren bekannt, von denen nur 22 als Bausteine für Proteine dienen [89]. Sie werden auch als proteinogene Aminosäuren bezeichnet. In Abbildung 2.11 sind exemplarisch die Strukturformeln von drei aromatischen proteinogenen Aminosäuren dargestellt. Deutlich zu erkennen ist die direkte Nachbarschaft der Carboxyl- und Aminogruppe. Alle drei Aminosäuren zeichnen sich insbesondere durch ihre aromatischen Seitenketten (Kohlenstoffring) aus, die intensive Banden im Ramanspektrum von Proteinen aufweisen, vorausgesetzt, dass sie im Protein vorliegen. Unter Abspaltung der OH-Gruppe der Carboxylgruppe und eines Wasserstoffatoms der Aminogruppe gehen Aminosäuren eine Peptidbindung ein und können sich so zu langen Ketten formieren. Dabei entsteht ein Wassermolekül (s. Abbildung 2.12(a)). Diese Peptidbindungen sind in langen Aminosäurenketten sehr häufig vertreten, so dass sie ebenfalls charakteristische Banden im Ramanspektrum von Proteinen zeigen. Diese Banden werden auch als Amid-Banden bezeichnet. Abbildung 2.12(b) zeigt schematisch die drei möglichen Schwingungsmoden der Amid-Banden, die mit Amid-I bis Amid-III gekennzeichnet sind, häufig auch Peptidrückgratschwingungsmoden genannt. 
<smiles>NC(Cc1ccccc1)C(=O)O</smiles>

Phenylalanin (Phe)<smiles>NC(Cc1ccc(O)cc1)C(=O)O</smiles>

Tyrosin (Tyr)

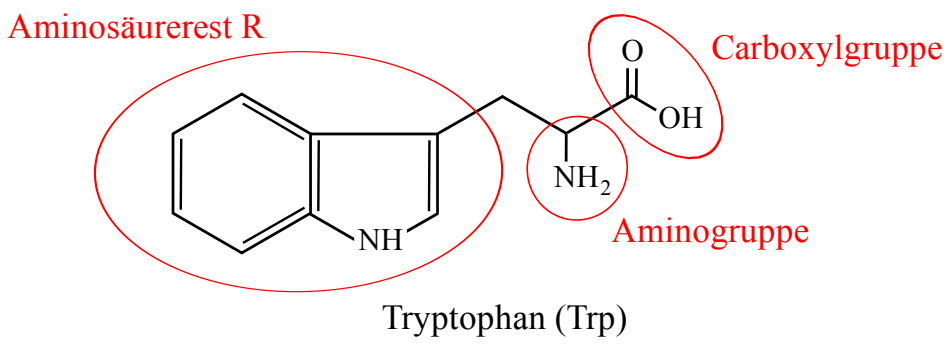

Abbildung 2.11: Strukturformeln aromatischer Aminosäuren.

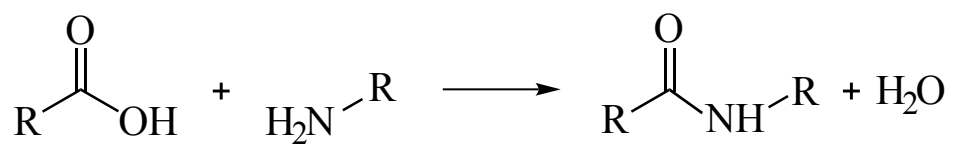

(a) Die Peptidbindung bzw. Amidbildung.<smiles>COC(C)(C)N(C)C</smiles>

Amid - I<smiles>COC(=O)N(C)C</smiles>

Amid - II

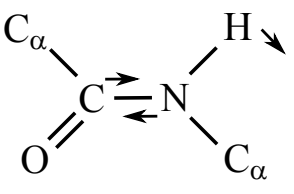

Amid - III

(b) Schwingungsmoden der Amid-Banden.

Abbildung 2.12: Amidbildung und -schwingungsbanden.

Die Amid-I-Bande wird hauptsächlich durch eine CO-Streckschwingung erzeugt, während die Amid-III-Bande durch eine CN-Streckschwingung, gekoppelt mit einer NHBeugeschwingung, zustande kommt. Die Amid-II-Bande ist im Allgemeinen in wässrigen Lösungen nur sehr schwach und kaum nachzuweisen und wird erst durch den Einsatz von schwerem Wasser deutlich ausgeprägter im Ramanspektrum. Da in dieser Arbeit aber nur wässrige Lösungen untersucht werden, soll nicht weiter auf sie eingegangen werden. Desweiteren sind die Amid-Banden von den unterschiedlichen Proteinstrukturen abhängig, die sich in vier Klassen einteilen lassen. 


\section{Primärstruktur}

Die Primärstruktur stellt die lineare Aneinanderreihung der Aminosäuren dar und beschreibt somit die Aminosäuresequenz der Peptidketten, jedoch nicht ihre räumliche Anordnung. In Abbildung 2.13 sind exemplarisch sechs farbig markierte Aminosäuren aneinandergereiht, wobei nur die Kohlenstoffatome und deren Bindungen zu benachbarten Kohlenstoffatomen dargestellt sind.

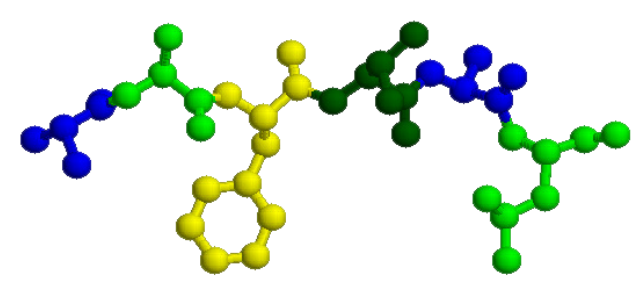

Abbildung 2.13: Kettendarstellung einer Aminosäuresequenz.

\section{Sekundärstruktur}

Unter der Sekundärstruktur von Proteinen werden häufig auftretende räumliche Strukturmuster der Aminosäureketten verstanden. Dabei wird unter folgenden Strukturtypen unterschieden: die $\alpha$-Helix, das $\beta$-Faltblatt, die $\beta$-Schleife und die so genannten „Random-Coil“-Strukturen. Verursacht werden diese räumlichen Strukturen vor allem durch Wasserstoffbrückenbindungen zwischen den Peptidbindungen des Peptidrückgrates.

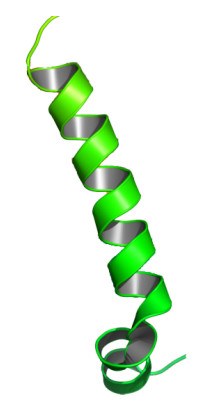

(a) $\alpha$-Helix.

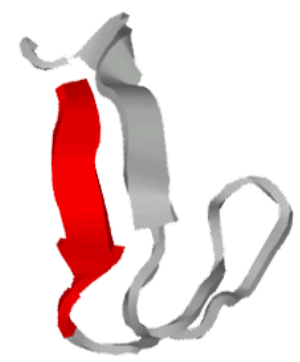

(b) $\beta$-Faltblatt.

Abbildung 2.14: Teilausschnitte aus der Cartoon-Darstellung diverser Proteine. Die $\beta$ Schleife und "Random-Coil"-Struktur sind nicht dargestellt.

\section{Tertiärstruktur}

Die Tertiärstruktur ist der Sekundärstruktur räumlich übergeordnet und wird im Wesentlichen durch Bindungen der Aminosäurereste $R$ verursacht. Neben den van-derWaals Kräften, den bereits erwähnten Wasserstoffbrückenbindungen und den ionischen 
Bindungen sind ebenfalls kovalente Bindungen von Schwefelatomen zweier Cysteinaminosäurereste, die so genannte Disulfidbrücke, an der Strukturgebung beteiligt, sofern das Cystein im Protein vorliegt. In Abbildung 2.15 ist exemplarisch die CartoonDarstellung der Tertiärstruktur des Proteins Rv2991 mit der Kennzeichnung 1RFE aus der PDB - Protein Data Bank [85] dargestellt.

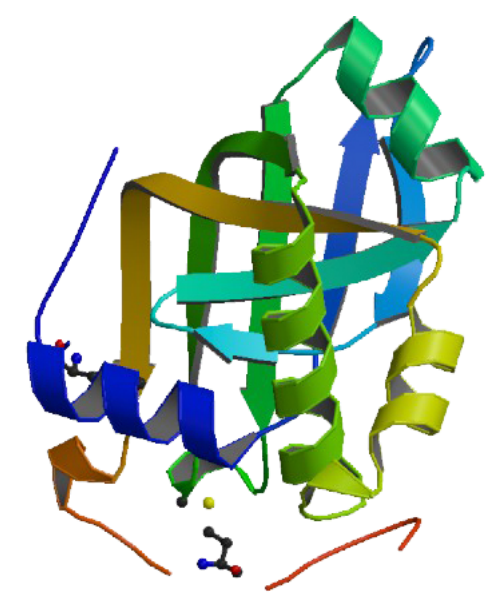

Abbildung 2.15: Protein Rv2991.

\section{Quartärstruktur}

Die durch die Primär-, Sekundär- und Tertiärstruktur beschriebenen Proteine schließen sich häufig noch zu höheren Aggregaten zusammen, wobei deren räumliche Struktur als Quartärstruktur bezeichnet wird und die einzelnen Peptidketten bzw. Proteine als Untereinheiten. Die Proteine bzw. Polypeptidketten sind im Aggregat über Salz- und Wasserstoffbrückenbindungen sowie durch kovalente Bindungen miteinander verknüpft. In Abbildung 2.16 ist exemplarisch die Cartoon-Darstellung der Quartärstruktur des N-Lithocholyl Insulin Proteins mit der Kennzeichnung 1UZ9, ebenfalls der PDB entnommen, dargestellt. Darin sind deutlich drei zueinander symmetrisch angeordnete und identische Untereinheiten zu sehen.

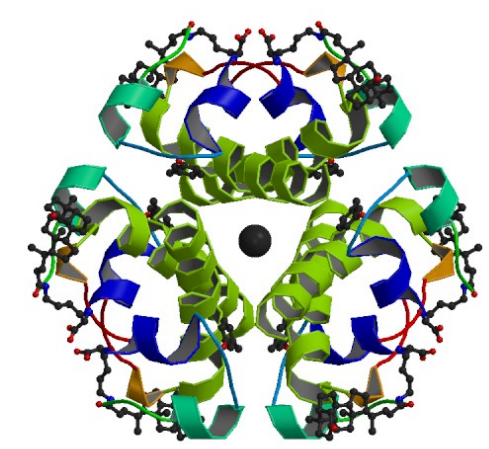

Abbildung 2.16: Protein N-Lithocholyl Insulin. 


\subsubsection{Charakteristische Ramanbanden von Proteinen}

Die Proteinramanbanden werden im Wesentlichen von den Peptidrückgratschwingungen und den Seitenkettenschwingungen der Aminosäuren dominiert. Die Amid-Banden spiegeln dabei die Sekundärstruktur des Proteins wider, während die Banden der Aminosäurereste in den Seitenketten Informationen zu ihrer unmittelbaren Umgebung liefern. Als ein Beispiel wird das Ramanspektrum von Lysozym im Bereich von 600$1800 \mathrm{~cm}^{-1}$ in Abbildung 2.17 gezeigt. Das Spektrum wird im Wesentlichen durch die Amid-I- und Amid-III-Banden der Peptidgruppe sowie durch die aromatischen Seitenketten von Tryptophan, Tyrosin und Phenylalanin und der $\mathrm{CH}_{2}$-Gruppe dominiert. In Tabelle 2.1 sind die mit der Sekundärstruktur des Proteins verknüpften Amid-I- und Amid-III-Ramanbanden aufgelistet. Diese Daten wurden Ramanspektren von Proteinen mit bekannter Sekundärstruktur entnommen, siehe [37] und [112].

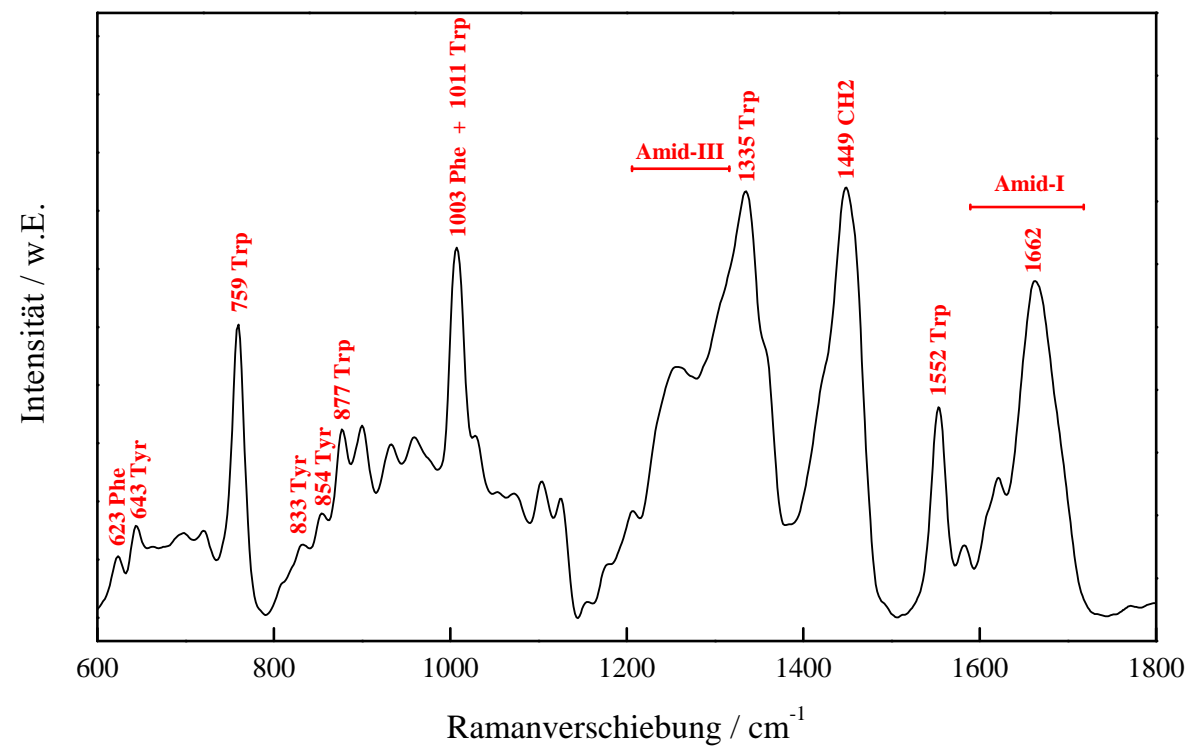

Abbildung 2.17: Ramanspektrum von kristallinem Lysozym, das mit dem in Kapitel 3.1 beschriebenen Ramanspektrometer aufgenommen wurde.

Für den Fall, dass ein Proteinkomplex bzw. mehrere Sekundärstrukturen vorliegen, überlagern sich die einzelnen Amidschwingungsbanden zu relativ breiten Banden. Die in der Tabelle 2.1 angegebenen Ramanverschiebungen sind deshalb keine strikten Wellenzahlangaben, sondern nur Wellenzahlbereiche. Diese werden neben der Überlagerung mehrerer Sekundärstrukturen aber auch maßgeblich von der Stärke der Wasserstoffbrückenbindungen im Bereich der Peptidbindungen bestimmt. 


\begin{tabular}{lll}
\hline Sekundärstruktur & Amid-I $\left(\mathbf{c m}^{-1}\right)$ & Amid-III $\left(\mathbf{c m}^{-1}\right)$ \\
\hline$\alpha$-Helix & $1645-1657(\mathrm{~s})$ & $1260-1300(\mathrm{~g})$ \\
$\beta$-Faltblatt & $1665-1680(\mathrm{~s})$ & $1230-1240(\mathrm{~s})$ \\
Random-Coil & $1660-1665(\mathrm{~m}, \mathrm{~b})$ & $1240-1250(\mathrm{~m})$ \\
\hline
\end{tabular}

Tabelle 2.1: Sekundärstruktur und spektrale Position der Amid-I- und Amid-III-Bande von Proteinen in $\mathrm{H}_{2} \mathrm{O}$; Bandenintensität: (s) stark, (m) mittel, (g) gering und (b) breite Bande.

Neben den Amid-Banden sind weitere Banden des Tyrosins, des Tryptophans und des Phenylalanins im Ramanspektrum des Lysozymkristalls markiert. Im Folgenden werden ihre Interpretationsmöglichkeiten und Bedeutungen für die Charakterisierung eines Proteins und seiner Umgebung vorgenommen. Nicht alle hier aufgezählten Ramanbanden sind im Spektrum des Lysozyms wiederzufinden, dennoch sollen sie der Vollständigkeit halber genannt werden. Auch dabei handelt es sich keineswegs um exakte Wellenzahlangaben. Sie können im Proteinramanspektrum um ca. $5 \mathrm{~cm}^{-1}$ variieren, in Abhängigkeit von der direkten Umgebung der an der Molekülschwingung beteiligten Molekülgruppe. In Abbildung 2.18 sind Ramanspektren der Aminosäuren Phenylalanin, Tyrosin und Tryptophan exemplarisch dargestellt, die in der vorliegenden Arbeit mit dem in Kapitel 3.1 beschriebenen Ramanspektrometer aufgenommen wurden. Die darin vorgenommenen Wellenzahlangaben stimmen mit der Literatur [104] überein.

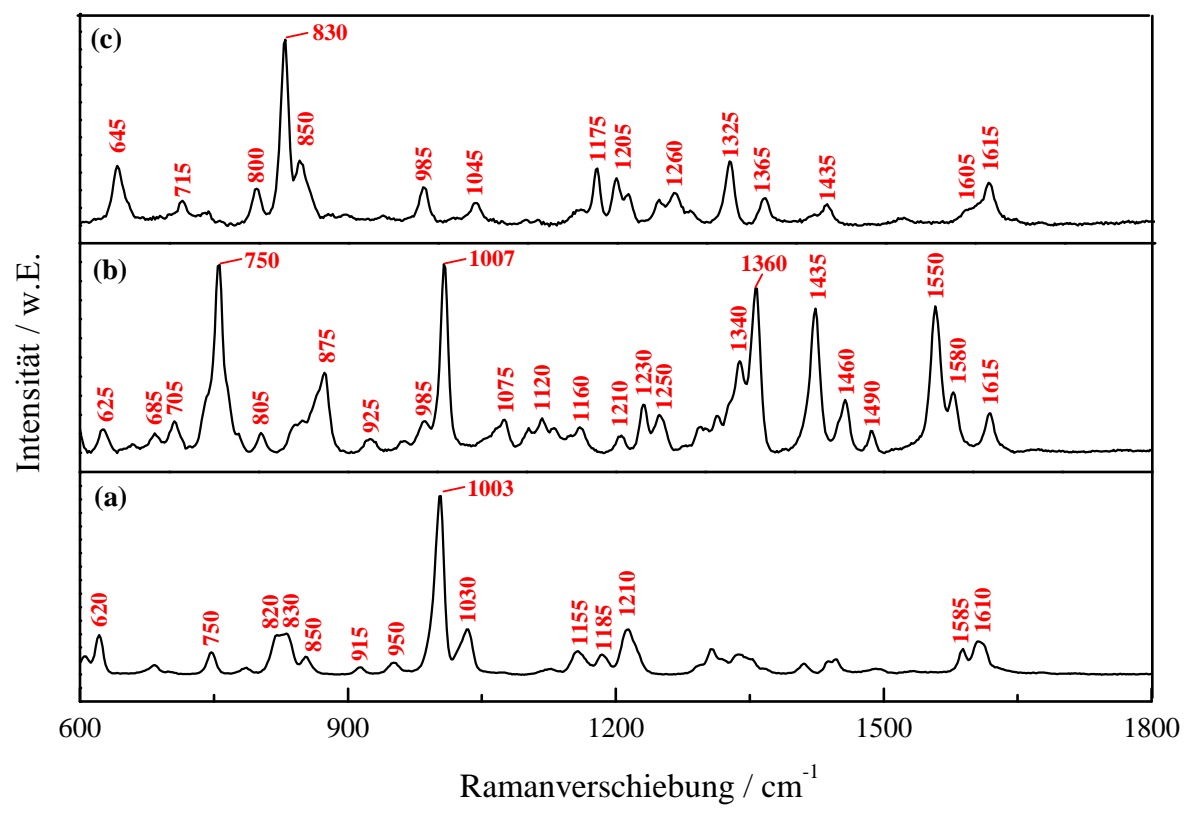

Abbildung 2.18: Ramanspektren von kristallinem (a) Phenylalanin, (b) Tryptophan und (c) Tyrosin. 


\section{Phenylalanin}

Das Phenylalanin zeigt Ramanbanden bei 620, 750, 820, 830, 850, 915, 950, 1003, 1030, 1155, 1185, 1210, 1585 und $1610 \mathrm{~cm}^{-1}$. Die intensivste Bande bei $1003 \mathrm{~cm}^{-1}$ ist unabhängig von der Struktur des Proteins und kann so zur Normierung von Proteinramanspektren herangezogen werden.

\section{Tryptophan}

Das Tryptophan zeigt Ramanbanden bei 625, 685, 705, 750, 805, 875, 925, 985, 1007, 1075, 1120, 1160, 1210, 1230, 1250, 1340, 1360, 1425, 1460, 1490, 1550, 1580, 1605 und $1615 \mathrm{~cm}^{-1}$. Die Banden bei 875,1360 und $1550 \mathrm{~cm}^{-1}$ sind konformationsabhängig und geben Auskunft über die Umgebung der Tryptophanreste. So z.B. gibt die Bande bei $805 \mathrm{~cm}^{-1}$ die Stärke der Wasserstoffbrückenbindung, gebildet aus der NH-Gruppe des Indolrings, wieder, wobei sich die Bande mit abnehmender Bindungsstärke zu kleineren Wellenzahlen verschiebt [70]. Desweiteren ist die Zunahme bzw. Abnahme der Bandenintensität bei $1360 \mathrm{~cm}^{-1}$ ein Marker für die Hydrophobizität der Indolringumgebung. Die Frequenz der Bande bei $1550 \mathrm{~cm}^{-1}$ wird direkt von der Orientierung des Indolrings zum Peptidrückgrat beeinflusst.

\section{Tyrosin}

Das Tyrosin zeigt Ramanbanden bei 645, 715, 800, 830, 850, 985, 1045, 1175, 1205, $1260,1325,1365,1435,1605$ und $1615 \mathrm{~cm}^{-1}$. Die wohl aussagekräftigsten Banden hinsichtlich der Proteinstruktur bildet die Dublette bei 830 und $850 \mathrm{~cm}^{-1}$. Das Intensitätsverhältnis $I_{830} / I_{850}$ beider Banden kann in wässriger Lösung einen Wert zwischen 2,5 und 0,3 annehmen [108] und gibt Auskunft darüber, ob die phenolische Hydroxylgruppe (OH-Gruppe) eine Wasserstoffbrückenbindung mit einem positiven Donor ausbildet und somit oberflächlich lokalisiert ist, oder mit einem negativen Akzeptor eine Wasserstoffbrückenbindung eingeht und somit im inneren hydrophoben Bereich des Proteins lokalisiert ist. Bei der Interpretation der Lokalisierung des phenolischen Tyrosinrestes muss aber unbedingt die Anzahl der Tyrosinmoleküle im Protein berücksichtigt werden, da das Intensitätsverhältnis der Dublette nur eine Mittelung aus allen Tyrosinresten darstellt.

\section{Disulfidgruppe}

Sofern ein Protein Disulfidbrücken aufweist, existiert eine Ramanbande zwischen 510 und $540 \mathrm{~cm}^{-1}$. Sie dient als Indikator für die konformationsabhängige lokale Geometrie der Disulfidbrücken. 


\section{Kapitel 3}

\section{Experimentelle Grundlagen der Ramanstreulichtmessung}

Der Einsatz der Ramanspektroskopie zur Identifizierung und Quantifizierung von Proteinen in physiologisch relevanten Konzentrationsbereichen setzt wegen des lichtschwachen Ramanprozesses grundlegend ein hochempfindliches Ramanspektrometer voraus. Die rasanten technologischen Entwicklungen auf dem Gebiet der Laser, Filter und CCD-Sensoren der letzten Jahre brachten eine Fülle an kommerziell erhältlichen Ramanspektrometern hervor. Zu den wohl leistungsstärksten und anwenderfreundlichsten Ramanspektrometern zählen derzeit die Geräte der Firmen Kaiser Optical Systems, Renishaw und Jobin Ivon, deren Anschaffungskosten im fünf- bis sechsstelligen Eurobereich angesiedelt sind. Es handelt sich beim Großteil dieser Geräte um modifizierte Mikroskope, in denen sowohl ein Laser zur Anregung des Ramanstreulichtes als auch die zur Detektion des Ramanstreulichtes eingesetzten und an Spektrometer gekoppelten CCD-Kameras integriert sind. Darüber hinaus funktioniert ein Großteil dieser Geräte nach dem konfokalen Messprinzip [113]. Damit sind sie in der Lage, Proben bzw. Oberflächen dreidimensional mit einer Auflösung von $1 \mu \mathrm{m}$ sowohl in lateraler als auch in axialer Richtung ramanspektroskopisch zu vermessen. Für die technische Umsetzung des konfokalen Messprinzips werden in der Regel Lochblenden als räumliche Filter eingesetzt, die das im Fokus erzeugte Ramanstreulicht von den Streulichtanteilen der betsrahlten angrenzenden Probenbereiche trennen. Dementsprechend wird nur ein Bruchteil der zur Verfügung stehenden Streulichtintensität für die Detektion genutzt. Um trotz des lichtschwachen Ramanstreuprozesses ausreichende Signalstärken zu erreichen, müssen entweder hohe Laserleistungen eingesetzt und/oder lange Integrationszeiten gewählt werden. Die Laserleistungen der meisten Ramanspektrometer sind wegen der möglichen Zerstörung der Proben auf wenige Milliwatt begrenzt, und die Integrationszeit ist durch den Dynamikbereich der verwendeten CCD-Kameras ebenfalls eingeschränkt. 


\subsection{Aufbau und Charakterisierung eines Ramanspektrometers}

Da ein wesentliches Ziel dieser Arbeit darin besteht, den Einsatzbereich der Ramanspektroskopie auf die Erfassung und Charakterisierung extrem geringer Proteinkonzentrationen zu erweitern, wurde hier ein Ramanspektrometer konstruiert und gebaut, das auf besonders hohen Lichtdurchsatz optimiert wurde (s. Abbildung 3.1 und 3.2). Dabei wurde auf das konfokale Messprinzip verzichtet. Das Ramanspektrometer wurde fast ausschließlich modular mit Komponenten der Mikrobank- und FLS-Schienensysteme der Firma Linos aufgebaut, die ausreichende Justagemöglichkeiten sowie die anwenderfreundliche Integration von Optiken und Filterelementen bieten. Das Ramanspektrometer besteht im Wesentlichen aus vier Baugruppen: dem Diodenlaser, dem Sensorkopf, dem Spektrometer mit hochempfindlicher CCD-Kamera als Detektor und einer Beobachtungsoptik, mit der die nähere Umgebung der punktuellen Messposition überwacht werden kann. Diese Komponenten werden im Folgenden einzeln vorgestellt.

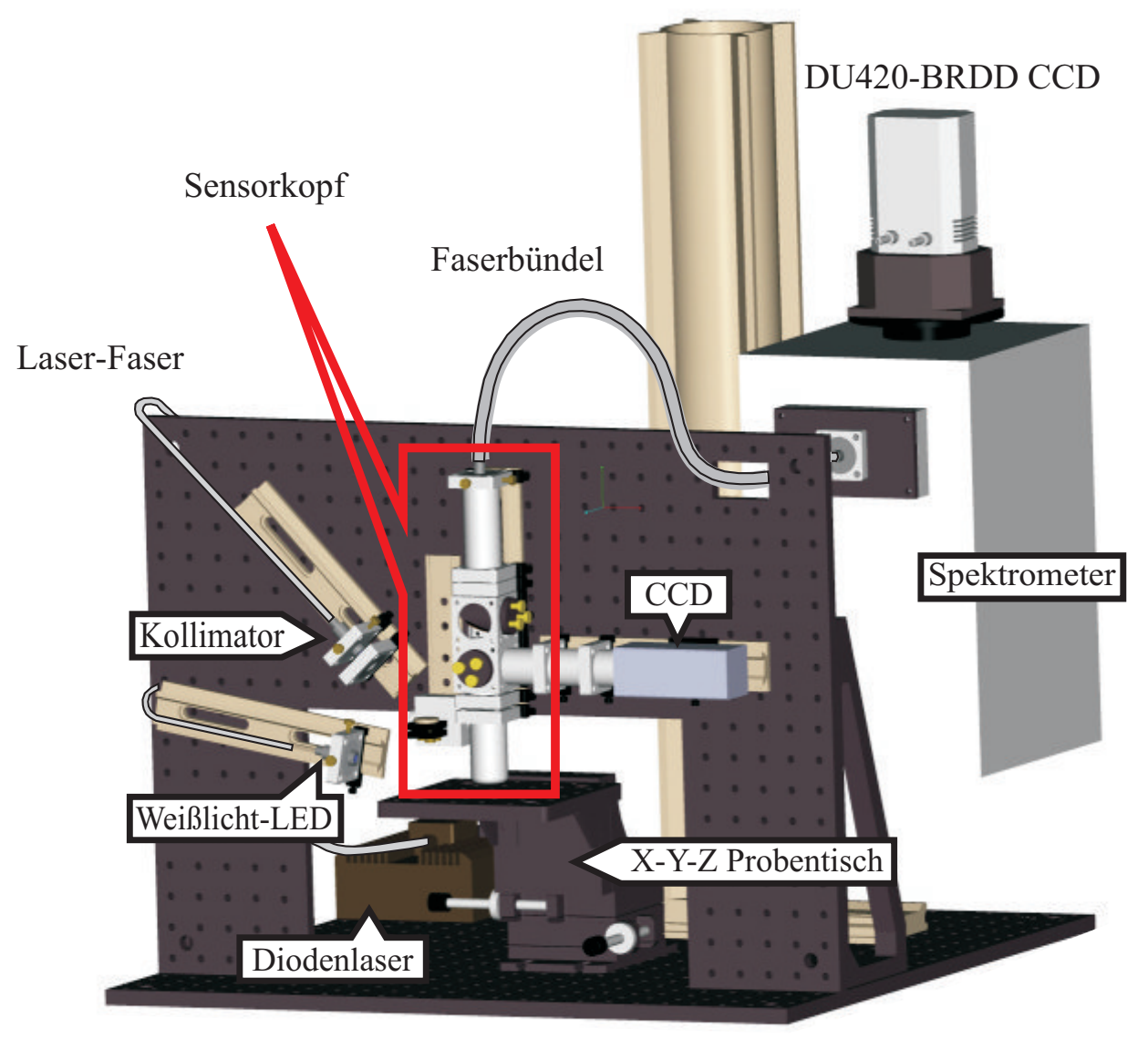

Abbildung 3.1: Dreidimensionale CAD-Darstellung des Ramanspektrometers. 


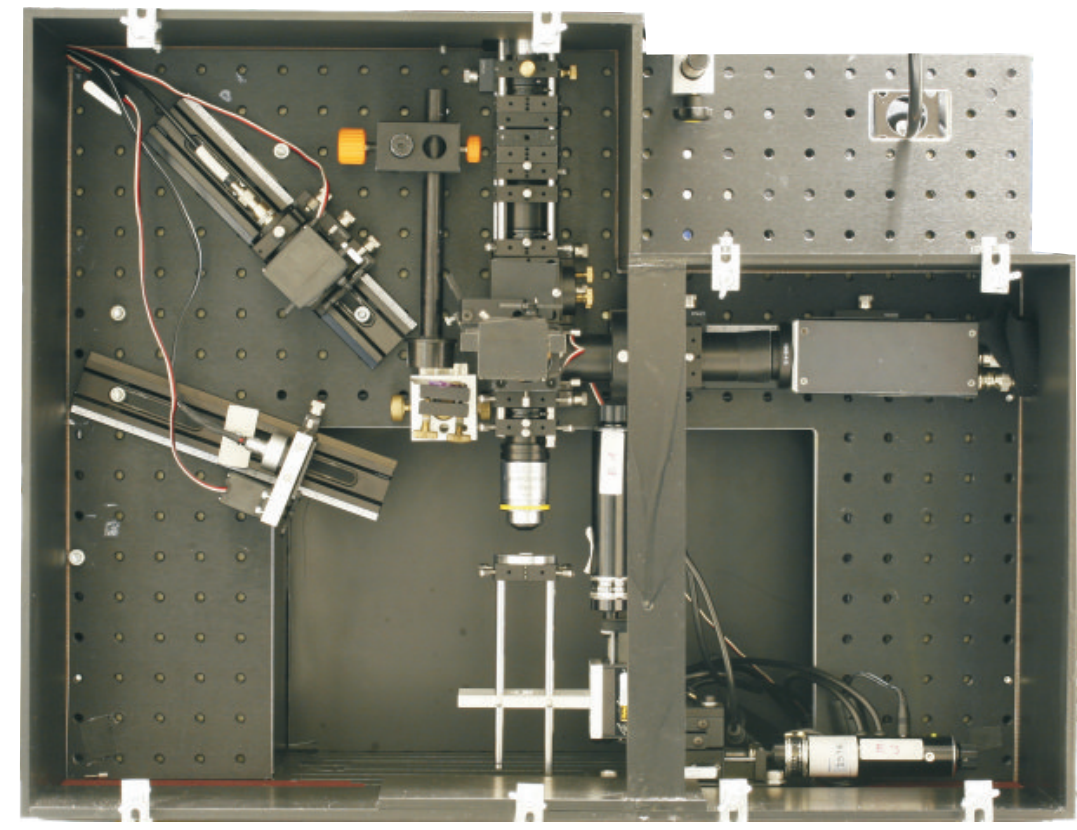

Abbildung 3.2: Foto der Frontansicht des Ramanspektrometers.

\subsubsection{Diodenlaser}

Im Allgemeinen weisen Diodenlaser im Vergleich zu Festkörperlasern deutlich höhere Linienbreiten und eine wesentlich geringere Wellenlängenstabilität auf, so dass sie für die Ramanspektroskopie nur bedingt geeignet sind [6]. Die meisten Diodenlaser, die im sichtbaren bis in den nah-infraroten Spektralbereich emittieren, zeigen teilweise Linienbreiten von mehreren Nanometern, so dass sie nicht dazu geeignet sind, die wesentlich schmaleren Ramanbanden ausreichend aufzulösen. Desweiteren weisen sie in der Regel das so genannte „mode-hopping“ [78] auf. Darunter werden Wellenlängensprünge des emittierten Lichtes verstanden, die mehrere Nanometer betragen können und damit zu willkürlichen Verschiebungen der gemessenen Ramanbanden führen. Unter diesen Umständen können keine reproduzierbaren Ramanspektren aufgenommen werden, so dass sowohl die qualitative als auch die quantitative Analyse von Ramanspektren mit Hilfe chemometrischer Auswertealgorithmen unmöglich ist. Desweiteren spielt die Temperaturregelung ebenfalls eine ganz entscheidende Rolle für die Wellenlängenstabilität, da die verwendeten Halbleitermaterialien in den Diodenlasern empfindlich auf Temperaturveränderungen reagieren und damit eine Verschiebung der Anregungswellenlänge einhergeht. Trotz dieser Umstände, die den Einsatz von Diodenlasern als Anregungslichtquelle in der Ramanspektroskopie erschweren, überzeugen sie vor allem durch ihre geringen Anschaffungskosten, die weit unterhalb von 5000 Euro inklusive Steuereinheiten liegen können. Unabhängig von der Bauart des Lasers spielt insbesondere die 
Wahl der Anregungswellenlänge eine ganz entscheidende Rolle für die Ramanspektroskopie. Aufgrund der reziproken Abhängigkeit der Ramanstreulichtintensität von der vierten Potenz der Anregungswellenlänge (s. Gleichung 2.6) scheinen zunächst kurze Wellenlängen vom sichtbaren bis in den ultravioletten Spektralbereich zur Erzeugung hoher Ramanstreulichtintensitäten geeignet zu sein. Bei der Untersuchung von Biomolekülen führt Anregungslicht im ultravioletten Spektralbereich aufgrund der hohen Photonenenergien jedoch häufig zur Zerstörung bzw. Photodissoziation der angeregten Moleküle. Außerdem werden mit Anregungswellenlängen im ultravioletten bzw. sichtbaren Spektralbereich häufig Fluoreszenzemissionen induziert, die das Ramanstreulicht vollständig überdecken können, wie bereits in Kapitel 2 beschrieben. Aus diesem Grund werden immer häufiger Laserwellenlängen im nah-infraroten Spektralbereich eingesetzt, die einen guten Kompromiss zwischen Effektivität der Anregung von Ramanstreulicht und der Unterdrückung der laserinduzierten Fluoreszenz darstellen.

Der in der vorliegenden Arbeit eingesetzte $785 \mathrm{~nm}$ Luxx-Master (PD-LD) Diodenlaser stellt eine Besonderheit unter den zur Zeit erhältlichen Diodenlasern der Preisklasse bis 2000 Euro dar. Er vereint eine für Diodenlaser außergewöhnlich schmale Linienbreite mit einer Halbwertsbreite von kleiner 0,16 nm laut Herstellerangaben. Außerdem weist er eine hohe Wellenlängenstabilität auf, die mit einem so genannten VolumeBragg-Grating [84] realisiert wird und ist mit einer regelbaren Ausgangsleistung von bis zu maximal $800 \mathrm{~mW}$ ausgestattet. Darüber hinaus verfügt er über eine Temperaturregelung und -überwachung zur weiteren Wellenlängenstabilisierung. Zur Regelung des Diodenlasers wurde in dieser Arbeit eine LDC-3744B Diodenlaser-Steuereinheit (ILX-Lightwave) eingesetzt. Der Diodenlaser ist mit einem fest montierten polymeroptischen Stufenindex-Multimode-Lichtwellenleiter (optische Faser) ausgestattet, der einen Kerndurchmesser von $100 \mu \mathrm{m}$, eine Manteldicke von $12,5 \mu \mathrm{m}$ und eine numerische Apertur von 0,22 aufweist. Das freie Faserende ist mit einem Schrägschliff von $8^{\circ}$ versehen, damit gar kein bzw. nur ein sehr geringer Anteil des an der Faserendfläche reflektierten Laserlichtes direkt in den Diodenlaser zurückreflektiert wird. Sehr hohe Leistungen des reflektierten Lichtes können den Diodenlaser zerstören. Da das Laserlicht entsprechend der numerischen Apertur der Faser divergent austritt, ist die Faser an einen 60-FC-4-A8-07 Kollimator (Schäfter \& Kirchhoff) gekoppelt, der an den $8^{\circ}$ Schrägschliff der Faser angepasst ist und eine Brennweite von $8 \mathrm{~mm}$ aufweist. Darüber hinaus ist er mit einer Antireflexbeschichtung für den Spektralbereich von 650 - $1150 \mathrm{~nm}$ versehen, um den Verlust von Laserleistung bei der Transmission des Laserlichtes durch die Kollimatoroptik auf ein Minimum zu reduzieren. Die Kollimatoroptik erzeugt einen Laserstrahl mit dem Durchmesser von 3,5 mm direkt am Austritt des Kollimators, der sich nach einer Strecke von $20 \mathrm{~cm}$ mit einer Divergenz von 6,25 mrad 
auf ca. $6 \mathrm{~mm}$ verbreitert. Diese Lauflänge entspricht der Strecke, die der Laserstrahl in dem Sensorkopf zurücklegt, bevor er mit einem Mikroskopobjektiv auf die Probe fokussiert wird. Dieser Sensorkopf wird nun im folgenden Abschnitt beschrieben.

\subsubsection{Sensorkopf}

Der Sensorkopf besteht aus einer Anordnung optischer Elemente, die sowohl die Anregung von Ramanstreulicht als auch die Trennung des um Größenordnungen intensiveren Rayleigh- und Oberflächenstreulichtes vom Stokes Ramanstreulicht ermöglicht (s. Abbildung 3.3). Dazu wird zunächst das in der optischen Faser erzeugte Ramanstreulicht sowie eventuell vorhandener breitbandiger Untergrund der Laserstrahlung durch einen $785 \mathrm{~nm}$ Laser-Line Bandpassfilter (Semrock) mit einer Bandbreite kleiner als $3 \mathrm{~nm}$ um einen Faktor von $10^{6}$ (laut Herstellerangaben), einer optischen Dichte von OD6 entsprechend, unterdrückt. Für die Bandbreite von $3 \mathrm{~nm}$ erzielt der Bandpassfilter eine

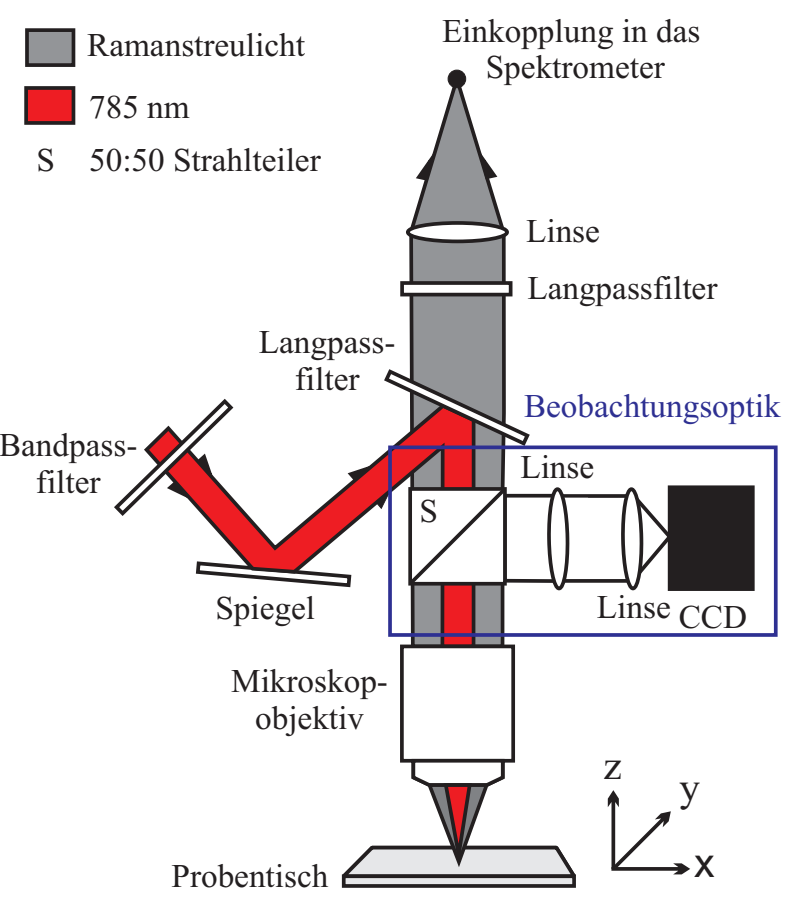

Abbildung 3.3: Schematische Darstellung des Sensorkopfes. Transmission von mehr als $95 \%$. Das kollimierte Laserlicht wird über einen Silberspiegel (Linos) auf einen Razor-Edge $830 \mathrm{~nm}$ Langpassfilter (Semrock) reflektiert. Dieser dielektrische Filter funktioniert wie ein Strahlteiler, indem er das Anregungslicht reflektiert und das zu höheren Wellenlängen verschobene Stokes Ramanstreulicht transmittiert (s. Abbildung 3.4). Er zeichnet sich durch seine Flankensteilheit von 4,2 nm, der hohen Transmission von mehr als $98 \%$ und der Unterdrückung der Streulichtanteile unterhalb von $830 \mathrm{~nm}$ mit einer optischen Dichte von OD6 aus. Die Flankensteilheit errechnet sich aus der spektralen Breite der Flanke, in der die Transmission von $0 \%$ auf den Maximalwert ansteigt. Die Wellenlängenangabe in der Bezeichnung des Langpassfilters gibt die spektrale Position der Flanke für $0 \%$ Transmission bei senkrechter Bestrahlung an. Diese kann durch Verkippen der Flächennormalen des Filters relativ zur Einfallsrichtung des kollimierten Laserlichtes zu kürzeren Wellenlängen verschoben werden (s. Abbildung 3.4). Mit dieser Verkippung wird zum Einen die Einkopplung des Laserlichtes in die Fokussierungsoptik ermöglicht, in diesem Fall ein 10x Plan Apo- 
chromat Mikroskopobjektiv (Zeiss) mit der numerischen Apertur von 0,45, und zum Anderen erlaubt der dielektrische Filter eine kollineare Strahlführung des Laser- und Ramanstreulichtes. Damit wird nur eine Optik für die Anregung und die Kollimation des Ramanstreulichtes benötigt, was enorme Vorteile in der Justage der Strahlführung bringt.

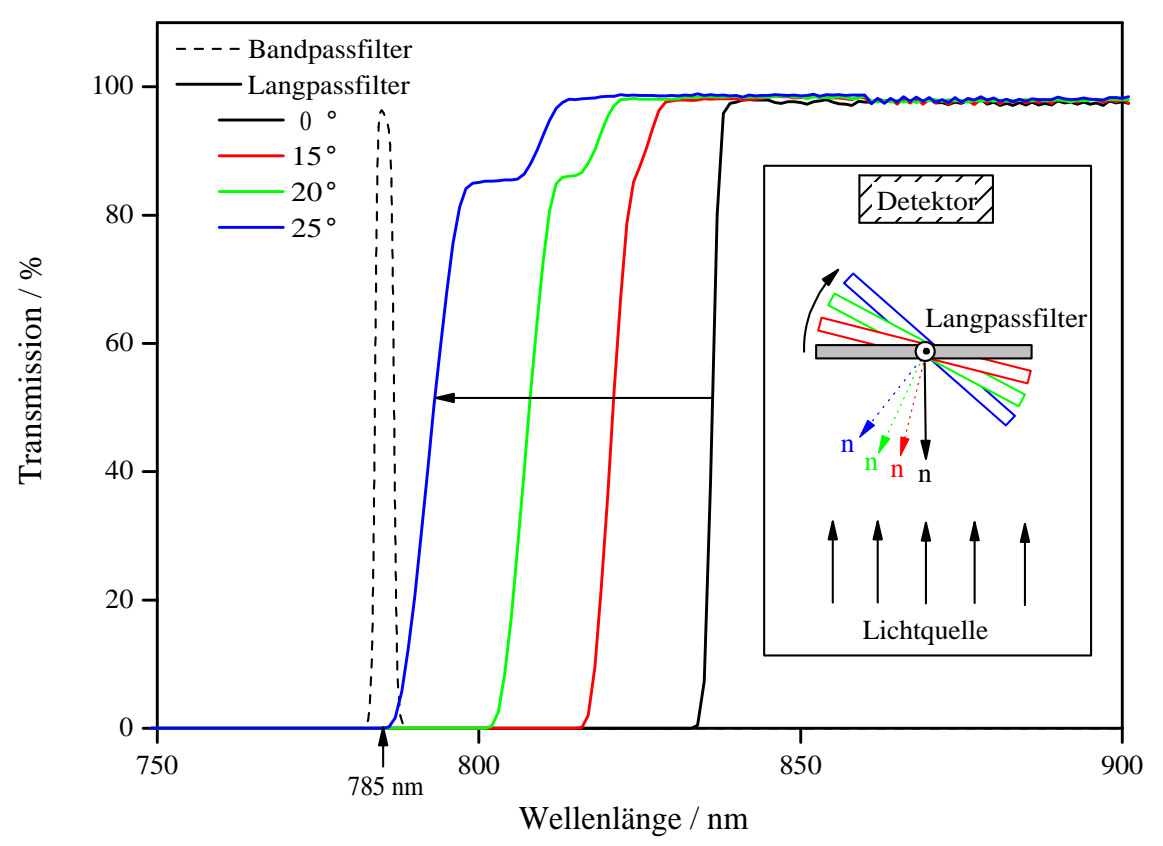

Abbildung 3.4: Transmissionskurven des Langpassfilters für verschiedene Lichteinfallswinkel und des Bandpassfilters, gemessen mit einem Lambda 19 UV/VIS/NIR Spektrometer (Perkin Elmer).

Das im Fokus des Objektivs erzeugte Ramanstreulicht wird durch das Mikroskopobjektiv gesammelt, kollimiert und durch den Langpassfilter transmittiert. Das Rayleighund Oberflächenstreulicht wird jedoch vom Langpassfilter reflektiert, so dass eine effektive Trennung des intensiven Rayleigh- und Oberflächenstreulichtes vom wesentlich schwächeren Ramanstreulicht realisiert wird. Bei der Wahl des Mikroskopobjektivs wurde ein Kompromiss zwischen Arbeitsabstand und numerischer Apertur eingegangen, da mit steigender numerischer Apertur und damit steigender Sammeleffizienz des Mikroskopobjektives in der Regel ein abnehmender Arbeitsabstand einhergeht. Dieser sollte jedoch groß genug sein, um möglichst flexibel in der Wahl der Untersuchungsobjekte zu sein. Der Arbeitsabstand des Mikroskopobjektivs beträgt in diesem Fall $2 \mathrm{~mm}$. Der Durchmesser der Eintrittslinse des verwendeten Mikroskopobjektivs beträgt $14 \mathrm{~mm}$, so dass der gesamte Laserstrahldurchmesser von $6 \mathrm{~mm}$ für die Anregung ausgenutzt wird. Hat das kollimierte Ramanstreulicht den ersten Langpassfilter passiert, folgt ein weiterer Razor-Edge $785 \mathrm{~nm}$ Langpassfilter (Semrock). Er unterdrückt das 
noch verbleibende Rayleigh- und Oberflächenstreulicht ebenfalls mit einer optischen Dichte von OD6.

\subsubsection{Spektrometer und CCD-Kamera}

Die spektrale Auftrennung des Ramanstreulichtes erfolgt über ein abbildendes SpectraPro 300i-P Spektrometer (Acton Research) mit Czerny-Turner Anordnung und einer Brennweite von $f=300 \mathrm{~mm}$ sowie einem Aperturverhältnis von ${ }^{\mathrm{f}} / 4$. Es besteht im Wesentlichen aus einem Eintrittsspalt, zwei konkaven Spiegeln und einem dispersiven Element (Reflexionsgitter), die eine spektrale Trennung des Ramanstreulichtes und die Abbildung auf einem flächigen photoempfindlichen Detektor im Maßstab 1:1 ermöglichen. Die maximale Ausdehnung der fokalen Schärfeebene des Spektrometers beträgt 27 x $14 \mathrm{~mm}$ und wird durch die im Spektrometer eingesetzten, bereits genannten

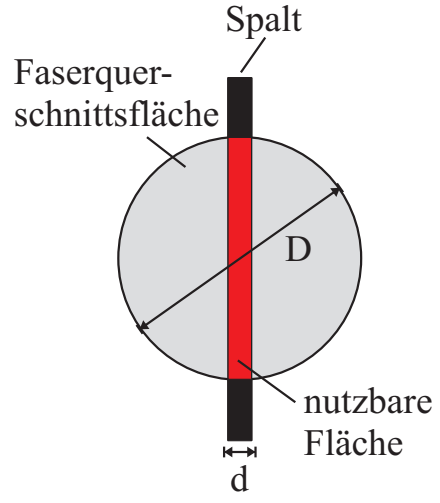

Abbildung 3.5: Schematische Darstellung der effektiven Fläche (rot) für eine Faser mit derselben Querschnittsfläche wie die des Faserbündels bei vergleichbarer Spaltbreite.

Optiken begrenzt. Um bei der Einkopplung des Ramanstreulichtes in das Spektrometer möglichst keine Intensitätsverluste durch den Spalt zu erhalten, wird das Ramanstreulicht über eine Linse mit dem Durchmesser von $22 \mathrm{~mm}$ und der Brennweite von $60 \mathrm{~mm}$ (Linos) in einen faseroptischen Querschnittswandler überführt, der an das Aperturverhältnis des Spektrometers angepasst ist. Dabei handelt es sich um ein optisches Faserbündel, das auf der Sensorkopfseite einen runden Querschnitt und zum Spektrometer hin einen rechteckigen Querschnitt besitzt, der als Spalt dient. Das Faserbündel besteht aus 57 einzelnen WF100/115 P130 Fasern (Ceram Optec) mit dem Kerndurchmesser von $100 \mu \mathrm{m}$, der Manteldicke von $7,5 \mu \mathrm{m}$ und der numerischen

Apertur von 0,14, die an der runden Querschnittsfläche mit einem effektiven Durchmesser von ca. $0,81 \mathrm{~mm}$ verschmolzen und spektrometerseitig linear übereinander angeordnet sind. Daraus ergibt sich eine Spaltbreite von $100 \mu \mathrm{m}$ und eine Spalthöhe von 6,5 mm. Im Gegensatz zur Verwendung einer einzelnen optischen Faser bei vergleichbarer Spaltbreite mit der gleichen Querschnittsfläche wie die des Faserbündels konnte mit dem Faserbündel der Lichtdurchsatz um einen Faktor von 12 gesteigert werden. Zur Veranschaulichung siehe Abbildung 3.5. Die Spalthöhe bzw. die daraus resultierende Anzahl von Fasern im Bündel richtet sich zum Einen nach dem Vergrößerungsmaßstab 
bei der Abbildung des vom Laserstrahlfokus ausgeleuchteten Objektbereichs auf das Faserbündel und zum Anderen nach der Höhe des eingesetzten Detektors.

Mit Hilfe der Gesetze der geometrischen Optik und Abbildung 3.6 lässt sich folgender Zusammenhang für den Vergrößerungsmaßstab M der Abbildung ableiten:

$$
\mathrm{M}=\frac{f_{2}}{f_{1}}=\frac{B_{F}}{B_{B}} .
$$

Für die Anregung ergibt sich unter Verwendung von Gleichung 3.1 mit der Brennweite des Kollimators von $f_{1}=8 \mathrm{~mm}$, dem Faserdurchmesser des Diodenlasers von $B_{F}=100 \mu \mathrm{m}$ und der Brennweite des Mikroskopobjektivs von $f_{2}=16,4 \mathrm{~mm}$ zunächst ein Fokusdurchmesser von $B_{B}=205 \mu \mathrm{m}$. Analog zu dieser Vorgehensweise berechnet sich für die Detektion eine Abbildung des vom Fokus ausgeleuchteten Bereichs auf dem Faserbündel mit einem Durchmesser von $B_{F B}=750 \mu \mathrm{m}$, die vollständig vom Faserbündel erfasst wird.

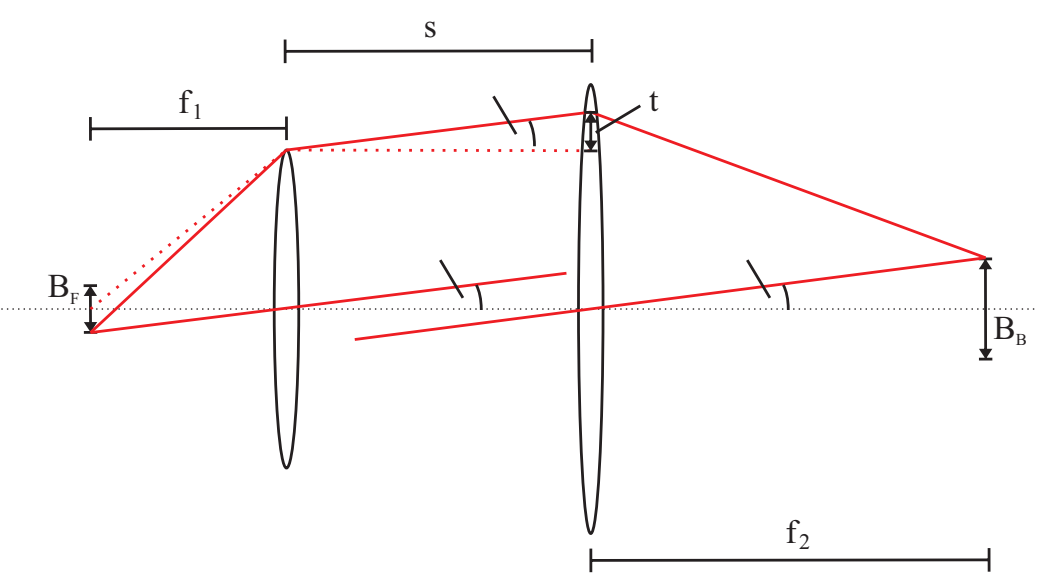

Abbildung 3.6: Schematische Darstellung zur Berechnung des Abbildungsmaßstabes M.

Desweiteren muss neben der Abbildung ebenfalls die Strahlverbreiterung $2 t$, die sich aus dem Abstand $s$ zwischen Eintrittslinse des Mikroskopobjektivs und der Einkoppelungslinse sowie aus der Divergenz $\alpha$ nach $t=s \cdot \tan \alpha$ ergibt (s. Abbildung 3.6), berücksichtigt werden. Der Abstand zwischen den beiden Optikelementen beträgt $s=150 \mathrm{~mm}$, so dass sich mit $\alpha=0,36^{\circ}$ eine Strahlverbreiterung von $2 t=2 \mathrm{~mm}$ errechnet. Damit weist der kollimierte Ramanstreulichtstrahl, der in die Einkopplungslinse einfällt, einen Durchmesser von $16 \mathrm{~mm}$ auf und wird so vollständig von der Linse erfasst und in das Faserbündel fokussiert.

Zur Detektion des Ramanstreulichtes wurde eine auf $-80^{\circ} \mathrm{C}$ heruntergekühlte DU420BRDD CCD-Kamera (Andor) eingesetzt. Ihr CCD-Sensor besteht aus einer flächi- 
gen Anordnung von 1024 x 256 photoempfindlichen Halbleiterelementen der Größe $26 \times 26 \mu \mathrm{m}$, die so genannten Bildelemente (Pixel), über die die Intensität des einfallenden Stokes Ramanstreulichtes integriert wird und mit einem „frame-grabber“, der Schnittstelle zwischen der Kamera und dem Computer, in ein 16-bit Graustufenbild umgewandelt wird. Aus der Anzahl der Bildelemente ergibt sich eine CCD-Sensorfläche von 26,6 x 6,6 mm, die entsprechend der Spalthöhe des Faserbündels und der fokalen Schärfeebene des Spektrometers optimal ausgeleuchtet wird. In Abbildung 3.7 (a) ist exemplarisch das Graustufenbild der Stokes Ramanstreuung für Cyclohexan dargestellt und in (b) das durch das „full-vertical-binning“ erzeugte wellenlängenkalibrierte Ramanspektrum. Sowohl auf das „full-vertical-binning“ als auch auf die Wellenlängenkalibrierung wird weiter unten im Text eingegangen.

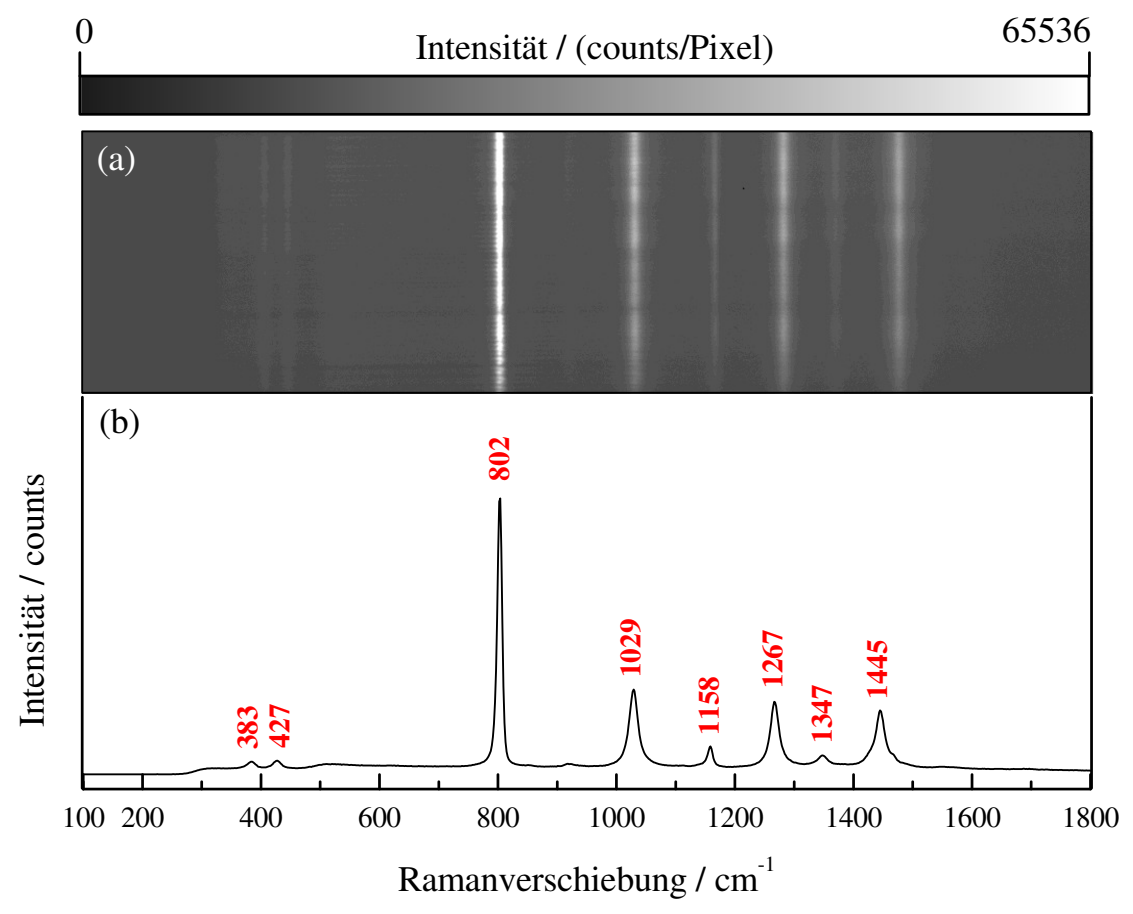

Abbildung 3.7: Ramanspektrum von Cyclohexan im Spektralbereich von $100-1800 \mathrm{~cm}^{-1}$.

(a) 16-bit Graustufenbild der spektralen, entlang des Spalts ortsaufgelösten Ramanstreulichtverteilung. (b) Ramanspektrum nach dem „full-verticalbinning" und der Wellenlängenkalibrierung nach [87].

Als dispersives Element im Spektrometer wurde ein Reflexionsgitter mit 600 Linien pro Millimeter, einer Blazewellenlänge ${ }^{1}$ von $750 \mathrm{~nm}$ und einer reziproken linearen Dispersion von $4,79 \mathrm{~nm} / \mathrm{mm}$ eingesetzt, so dass sich mit der verwendeten CCD-Kamera und einer Spaltbreite von $100 \mu \mathrm{m}$ eine spektrale Auflösung von $0,5 \mathrm{~nm} /$ Pixel ergibt. Bei

\footnotetext{
${ }^{1}$ Wellenlänge, bei der die maximale spektrale Empfindlichkeit des Gitters gegeben ist.
} 
einer Anregungswellenlänge von $785 \mathrm{~nm}$ kann damit ein Spektralbereich von $128 \mathrm{~nm}$ bzw. $1800 \mathrm{~cm}^{-1}$ mit der CCD-Kamera erfasst werden. Aus dem Funktionsprinzip eines CCD-Sensors lassen sich wichtige Kenngrößen für die Detektion lichtschwacher Prozesse ableiten, so dass hier kurz auf die Funktionsweise eingegangen werden soll. Einfallende Photonen lösen in der photoempfindlichen Schicht der Halbleiterelemente Elektronen aus, die für eine bestimmte Zeit, die so genannte Integrationszeit, in dem Halbleiterelement gesammelt, anschließend in ein Ausleseregister zeilenweise verschoben und an den „frame-grabber" übergeben werden. Die Anzahl der Elektronen ist dabei proportional zur Anzahl der auf das Bildelement einfallenden Photonen, wobei die wellenlängenabhängige Quanteneffizienz die Wahrscheinlichkeit angibt, mit der ein Photon ein Elektron herauslöst. Eine weitere wichtige Kenngröße ist der Konversionsfaktor. Er gibt an, wie viele Elektronen zu einem messbaren Impuls führen und beträgt im Fall der DU420-BRDD CCD-Kamera bei der kleinsten Ausleserate von 31 kHz 2 Elektronen pro Impuls. Da der Konversionsfaktor im Allgemeinen mit der Ausleserate zu- und somit die Empfindlichkeit der Kamera abnimmt, wird die DU420-BRDD CCDKamera bei der kleinsten Ausleserate betrieben. Die Anzahl der Impulse, die in der vorliegenden Arbeit mit der Einheit „counts“ versehen ist, wird mit Hilfe des „framegrabbers" in eine Graustufe entsprechender Intensität konvertiert. Die Intensität kann gemäß der 16-bit Werte zwischen 0 und 65536 counts betragen. Dies repräsentiert den Dynamikbereich der CCD-Kamera. Auch dieser stellt eine entscheidende Kenngröße für die Wahl einer CCD-Kamera für die Ramanspektroskopie dar, da für den Fall der simultanen Erzeugung laserinduzierter Fluoreszenz die detektierten Signalintensitäten selbst bei geringen Integrationszeiten den Dynamikbereich der CCD-Kamera schnell übersteigen können. Darüber hinaus muss die Linearität der Impulsanzahl bezüglich der Streulichtintensität gewährleistet sein, damit aus den aufgenommenen Ramanspektren quantitative Rückschlüsse auf die Anzahl der bestrahlten Moleküle möglich sind. Der Hersteller hat die Linearität der DU420-BRDD CCD-Kamera über eine lineare Regression für den gesamten Dynamikbereich zwischen Impulsanzahl und gemessener einfallender Lichtintensität quantifiziert und gibt eine maximale Residue von $1 \%$ an.

Der auf Silizium basierende, rückseitig beleuchtete CCD-Sensor der DU420-BRDD CCD-Kamera erzielt im Vergleich zu den anderen eingesetzten ebenfalls auf Silizium basierenden CCD-Sensor-Technologien die höchsten Quanteneffizienzen, insbesondere im nah-infraroten Spektralbereich (s. Abbildung 3.8). Die Überlegenheit dieser CCDKamera bezüglich der Quanteneffizienz wird durch den Vergleich zu einer herkömmlichen frontseitig beleuchteten CCD-Kamera deutlich. In dem für die Ramanspektroskopie bei einer Anregung mit einer Laserwellenlänge von $785 \mathrm{~nm}$ interessanten Spektralbereich von $785-915 \mathrm{~nm}$ (entspricht $1800 \mathrm{~cm}^{-1}$ ) werden Quanteneffizienzen von 50 
bis $90 \%$ erzielt. Diese sind zwei- bis dreimal höher als bei den herkömmlichen, frontseitig beleuchteten CCD-Sensoren (s. Abbildung 3.8). In Abbildung 3.8 ist außerdem ein Abfall der Quanteneffizienz für beide Kameratypen für Wellenlängen oberhalb von $750 \mathrm{~nm}$ zu erkennen. Der Grund hierfür liegt in der wellenlängenabhängigen Absorption von Silizium, die sich in der Quanteneffizienz widerspiegelt. Aus diesem Grund ist bei der Detektion mit CCD-Kameras der Einsatz von Anregungswellenlängen oberhalb von $785 \mathrm{~nm}$ ungeeignet, da wegen der drastisch abfallenden Quanteneffizienzen der CCD-Kameras das schwache Stokes Ramanstreulicht nicht mehr detektiert werden kann.

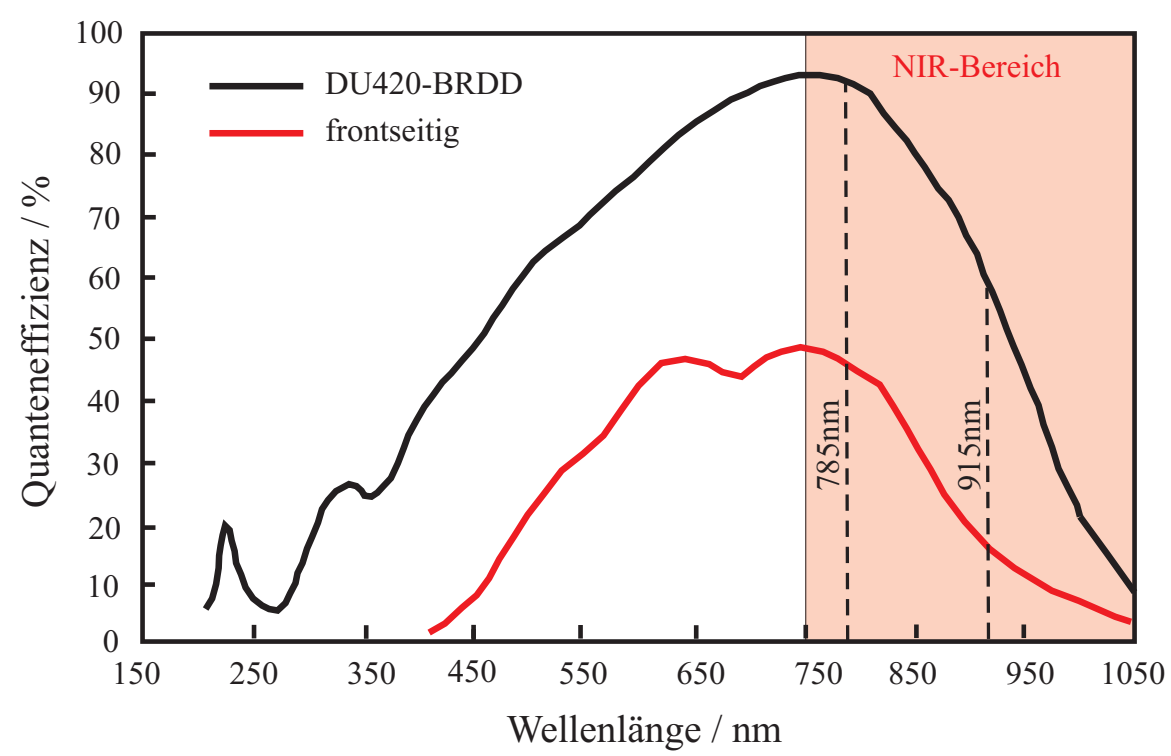

Abbildung 3.8: Vergleich zwischen der wellenlängenabhängigen Quanteneffizienz der DU420BRDD CCD-Kamera mit der einer frontseitig beleuchteten nach [65].

Die hohen Quanteneffizienzen im nah-infraroten Spektralbereich werden durch die so genannte „Deep-Depletion“-Technologie ermöglicht. Dabei handelt es sich um einen Fertigungsprozess, bei dem CCD-Sensoren mit einer wesentlich dickeren photoempfindlichen Silizium-Schicht im Vergleich zu herkömmlichen Verfahren hergestellt werden. Dadurch erhöht sich die Wechselwirkungsstrecke der Photonen in der photoempfindlichen Schicht und somit die Wahrscheinlichkeit, ein Elektron auszulösen.

Einer der großen Nachteile rückseitig bestrahlter CCD-Sensoren besteht in der konstruktiven und destruktiven Interferenz von Licht oberhalb von $650 \mathrm{~nm}$ durch Mehrfachreflexion des Lichtes an der Front- und Rückseite der lichtempfindlichen Siliziumschicht, das so genannte „Etaloning“. Verursacht wird diese Mehrfachreflexion durch eine beim Herstellungsverfahren nach der „Deep-Depletion“-Technologie erzeugten Siliziumoxidschicht direkt vor den Elektroden. Aufgrund des hohen Brechungsindexunterschiedes des Siliziumoxids (Brechungsindex von 1,5) zum Silizium (Brechungsindex von 4) wird 
ein erheblicher Teil des einfallenden Lichtes reflektiert. Für Wellenlängen größer $650 \mathrm{~nm}$ ist Silizium transparent, so dass Licht oberhalb dieser Wellenlänge mehrfach zwischen der Front- und Rückseite der photoempfindlichen Siliziumschicht reflektiert werden kann. Dadurch entstehen signalintensitätsabhängige Wellenmuster, die mit nachträglichen Bildverabeitungsverfahren nicht zu korrigieren sind. Aus diesem Grund kommt bei der DU420-BRDD CCD-Kamera eine neuartige „Fringe Suppression“-Technologie zum Einsatz. Neben einer nah-infraroten Antireflexbeschichtung wird die mit dem Siliziumoxid beschichtete Seite des CCD-Sensors durch ein spezielles Verfahren aufgeraut, wodurch die Reflexion sehr effektiv gestört wird, so dass praktisch kein „Etaloning“ auftritt. Ein weiterer Nachteil der „Deep-Depletion“-Technologie ist das im Vergleich zu frontseitig beleuchteten CCD-Sensoren wesentlich höhere Dunkelstromrauschen. Der Dunkelstrom ist einer von mehreren Effekten, die die Empfindlichkeit des CCD-Sensors begrenzen. Der Dunkelstrom wird allein aufgrund thermischer Anregung von Elektronen ins Leitungsband eines Halbleiterelementes erzeugt. Die Wahrscheinlichkeit für diesen Prozess skaliert einerseits mit der Dicke des CCD-Sensors und andererseits mit der Temperatur.

In Abbildung 3.9 ist das Dunkelstromrauschen der DU420-BRDD CCD-Kamera über die Temperatur aufgetragen und dem Dunkelstromrauschen einer konventionellen frontseitig beleuchteten gegenübergestellt. Im Fall der DU420-BRDD CCD-Kamera beträgt das Dunkelstromrauschen bei einer Kühltemperatur von $-80^{\circ} \mathrm{C} 0,15$ Elektronen pro Pixel und Sekunde, wohingegen die DV401-A CCD-Kamera nur ein Dunkelstromrauschen von 0,007 Elektronen pro Pixel und Sekunde aufweist und damit das Rauschen um zwei Größenordnungen geringer ist.

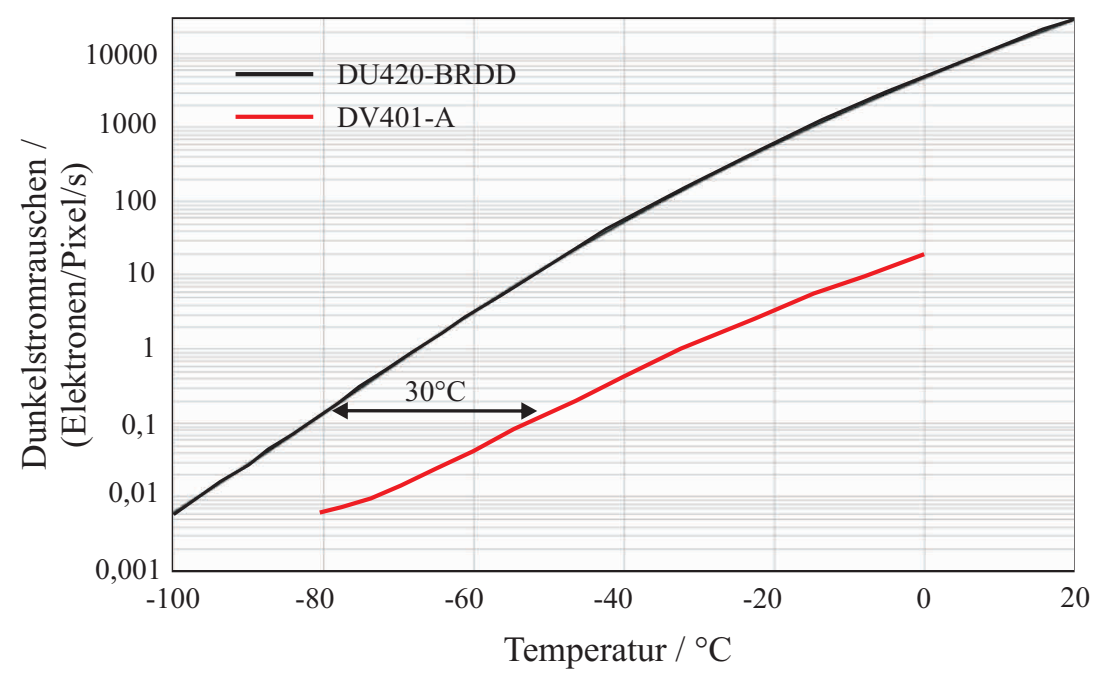

Abbildung 3.9: Vergleich des Dunkelstromrauschens zwischen der DU420-BRDD CCDKamera und der frontseitig beleuchteten DV401-A CCD-Kamera nach [65]. 
Um vergleichbare Dunkelströme zu erzielen, sind bis zu $30^{\circ} \mathrm{C}$ tiefere Kühltemperaturen für die DU420-BRDD CCD-Kamera erforderlich (s. Abbildung 3.9). Umgesetzt werden derart niedrige Kühltemperaturen durch eine interne vierstufige Peltierkühlung, auf der der CCD-Sensor angebracht ist. Das Dunkelstromrauschen $N_{D}$ stellt neben dem Auslese- $N_{A}$ und Signalrauschen $N_{S}$ einen der drei Rauscheffekte dar, die die Empfindlichkeit des CCD-Sensors beeinflussen. Sie gehen bei der Aufnahme von Ramanspektren in das eigentliche Messsignal mit ein und werden in Gleichung 3.2 in einem Gesamtrauschen $N_{K}$ der CCD-Kamera zusammengefasst:

$$
N_{K}=\sqrt{N_{D}^{2}+N_{A}^{2}+N_{S}^{2}}
$$

Um ein möglichst gutes Signal-zu-Rausch-Verhältnis zu gewährleisten, müssen diese Rauschanteile effektiv unterdrückt werden. Da die maximale Kühltemperatur im Fall der DU420-BRDD CCD-Kamera bereits bei $-80^{\circ} \mathrm{C}$ erreicht ist, ist auch keine weitere Optimierung des Dunkelstromrauschens möglich. Anders verhält es sich mit dem Ausleserauschen, das beim Auslesen der Ladungen (Elektronen) und bei der Analog-DigitalWandlung im „frame-grabber“ auftritt und für die DU420-BRDD CCD-Kamera 5 Elektronen pro Pixel bei einer Ausleserate von $31 \mathrm{kHz}$ beträgt. Um diesen Rauschanteil zu minimieren, der bei der zeilenweisen Auslesung in jedes Bildelement mit eingeht, werden in der vorliegenden Arbeit die gesamten 256 vertikalen Halbleiterelemente einer Spalte zunächst im Ausleseregister zusammengefasst (additiv), so dass die gesamten Ladungen nur ein einziges Mal ausgelesen werden. Laut Herstellerangaben beträgt das Ausleserauschen in diesem Fall 10 Elektronen pro Pixel. Darüber hinaus führt dieses so genannte „full-vertical-binning“ zu einer Verbesserung des Signal-zu-Rausch-Verhältnisses um den Faktor $\sqrt{256}=16$, wenn davon ausgegangen wird, dass das Rauschen lediglich aus dem Signalrauschen (statistische Fluktuationen des Photonenflusses) resultiert. Das mittlere Signal nimmt um den Faktor 256 zu, seine Schwankungen aber nur um den Faktor 16.

Da das Ausleseregister beim „full-vertical-binning“ die gesamten Ladungen einer Spalte von Halbleiterelementen speichert, ist dieses mit einer 2 mal höheren Kapazität von $1 \cdot 10^{6}$ Elektronen ausgestattet als die Halbleiterelemente. Diese Kapazitäten werden beim Bildelement als „pixel well depth“ bezeichnet und beim Ausleseregister als „register well depth“. Sie sind ebenfalls ausschlaggebend für den Dynamikbereich der Kamera.

\section{Auflösungsvermögen}

Zur experimentellen Bestimmung des Auflösungsvermögens des Ramanspektrometers wurde ein Argon Pen-Ray-Linienstrahler (L.O.T.) eingesetzt, der mehrere Emissions- 
linien im gewünschten Spektralbereich von 785-915 nm (entsprechend einer Ramanverschiebung von $0-1800 \mathrm{~cm}^{-1}$ ) mit typischen Linienbreiten von kleiner 0,001 nm aufweist. Damit eignet er sich hervorragend für die Messung des Aufösungsvermögens der meisten Spektrometer, da deren Aufösungsvermögen in der Regel deutlich oberhalb der Bandbreite des Linienstrahlers liegen. Die von dem hier eingesetzten Spektrometer gemessene mittlere spektrale Breite der Atomemissionslinien des Pen-Ray-Strahlers beträgt $0,5 \mathrm{~nm} \cong 8 \pm 0,5 \mathrm{~cm}^{-1}$ über den gesamten Spektralbereich von $1800 \mathrm{~cm}^{-1}$ gemittelt und deckt sich mit dem im vorherigen Abschnitt berechneten Auflösungsvermögen. Bei einer Pixelbreite von $26 \mu \mathrm{m}$ und einer Dispersion von 4,79 nm/mm erzielt das Ramanspektrometer eine Auflösung von $1,7 \mathrm{~cm}^{-1} /$ Pixel.

\section{Wellenlängenkalibrierung}

Zur Wellenlängenkalibrierung der detektierten Ramanspektren wurde das Ramanspektrum von Cyclohexan, wie es in Abbildung 3.7 (b) dargestellt ist, aufgenommen. Eine polynomielle Kurvenanpassung 4. Ordnung zwischen den gemessenen CyclohexanRamanbanden und den aus der Literatur [87] bekannten tatsächlichen Ramanverschiebungen ergibt dabei die Kalibrierfunktion, welche multiplikativ auf alle Rohspektren angewendet wurde.

\section{Intensitätskalibrierung}

Zur Korrektur der relativen Intensitäten der Ramanbanden, die empfindlich von den eingsetzten optischen Elementen im Ramanspektrometer und von der spektralen Empfindlichkeit des CCD-Sensors abhängen, wurde das „Standard Reference Material 2241“ (NIST - National Institute of Standards \& Technology) [93] eingesetzt. Hierbei handelt es sich um ein Glas, das bei Anregung mit $785 \mathrm{~nm}$ eine breitbandige Lumineszenz im Bereich von 800-1060 nm (entsprechend einer Ramanverschiebung von 255 bis $3350 \mathrm{~cm}^{-1}$ ) zeigt, deren Intensität mittels eines Weißlichtstandards kalibriert ist. Diese Lumineszenz-Intensität wird als Funktion der Ramanverschiebung durch ein Polynom 5. Grades beschrieben. Durch die Division dieser Funktion mit einem aufgenommenen Lumineszenzspektrum des Glases geht eine intensitätskorrigierende spektrometerspezifische Funktion hervor, die durch einfache Multiplikation auf die gemessenen Ramanspektren angewendet wird. Somit sind die mit dem in dieser Arbeit verwendeten Ramanspektrometer gemessenen Ramanspektren auch quantitativ mit Ramanspektren vergleichbar, die mit anderen Ramanspektrometern aufgenommen wurden, sofern diese ebenfalls einer entsprechenden Intensitätskalibrierung unterzogen wurden. 


\subsubsection{Beobachtungsoptik}

Die Beobachtungsoptik (s. Abbildung 3.3) ermöglicht die visuelle Beobachtung der zu untersuchenden Proben und besteht aus einem 50:50 Strahlteiler (Linos), einem Linsensystem (Tubuslinse 25, Videoadapter 60C 1/2" 0,5x (Zeiss)) und einer CCD-Kamera. Diese optischen Elemente bilden das Sichtfeld des Mikroskopobjektivs auf einen 1/2"CCD-Sensor ab. Im Gegensatz zum fixierten Linsensystem und dem CCD-Sensor ist der Strahlteiler beweglich und kann für die Sicht auf die Probenoberfläche in den Strahlengang des Sensorkopfes eingeführt und für die Ramanstreulichtmessung herausgefahren werden. Mittels einer motorisierten x-y-z-Positioniereinheit T-LA28A (Zaber) mit einem maximalen Verfahrweg von $25 \mathrm{~mm}$ kann die Probe in alle drei Raumrichtungen mit einer lateralen und axialen Genauigkeit von $1 \mu \mathrm{m}$ verfahren werden. Die Beleuchtung des Sichtfeldes wird dabei von einer Weißlicht-LED realisiert, die die Probe von der Seite beleuchtet.

\subsection{Bestimmung der Wellenlängen- und Leistungsstabilität des eingesetzten Diodenlasers}

Im Folgenden werden Messergebnisse präsentiert, die Aussagen bezüglich der Linienbreite und der Wellenlängen- und Leistungsstabilität des Diodenlasers zulassen. Dazu wurde das elastische Oberflächenstreulicht des Lasers bei einer Laserleistung von $100 \mathrm{~mW}$ auf einer hoch reflektierenden Goldoberfläche mit einer Integrationszeit von 1s pro Spektrum über 2 Stunden mit dem Ramanspektrometer aufgezeichnet. In Abbildung 3.10 (rechts) ist sowohl die relative Wellenlängenverschiebung $\Delta \lambda$ der Laserlinie als auch deren Intensität dargestellt. Zur präzisen Bestimmung der Wellenlängenverschiebung der Laserlinie aus den gemessenen Spektren wurde eine Gauss-Funktion an das Profil der Laserlinie angepasst und die spektrale Position des Maximums gegen die Zeit aufgetragen. Damit konnte eine Auflösung der Wellenlängenverschiebung unterhalb des Auflösungsvermögens des Ramanspektrometers von 0,12 nm/Pixel realisiert werden. Deutlich ist eine stetige Zunahme der Wellenlängenverschiebung der Laserlinie mit der Zeit zu sehen, die nach 2 Stunden einen Maximalwert von 0,025 nm erreicht und damit unterhalb des Auflösungsvermögens des Ramanspektrometers liegt. Desweiteren ergibt sich aus dem Intensitätsverlauf der Laserlinie über 2 Stunden eine Leistungsstabilität kleiner $1 \%$ Standardabweichung vom Mittelwert der Einzelmessungen. In Abbildung 3.10 (links) ist der Einfluss der Laserleistung auf die Wellenlängenverschiebung der Laserlinie dargestellt. 

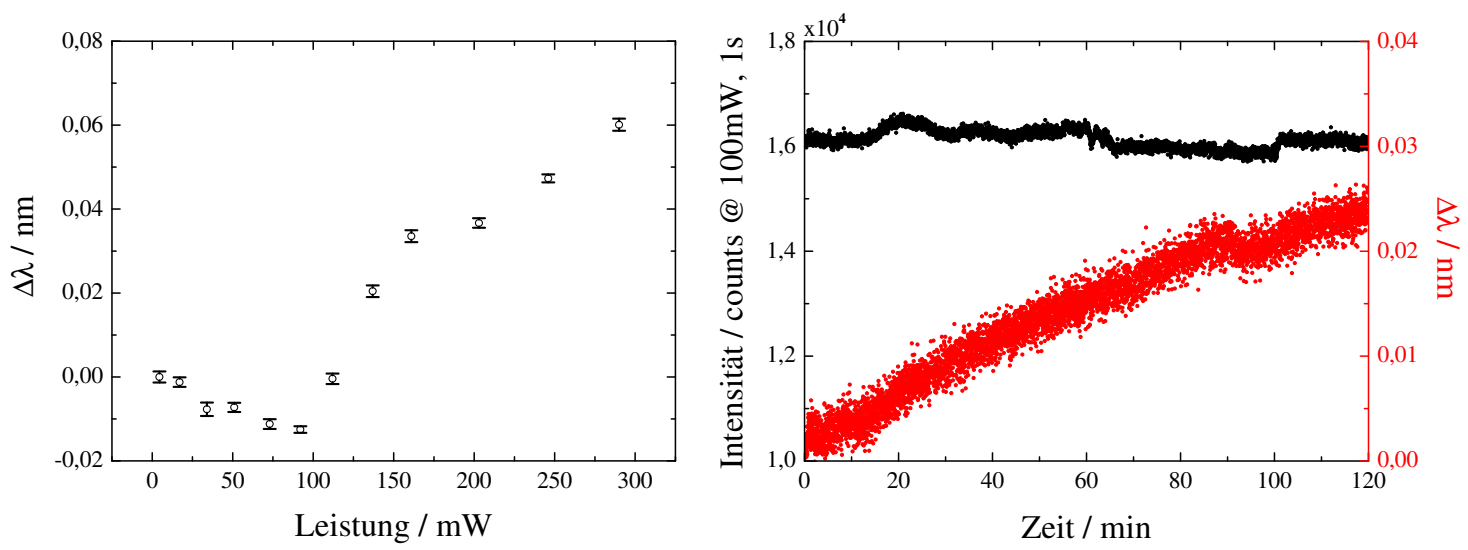

Abbildung 3.10: (Links) Auftragung der Wellenlängenverschiebung $\Delta \lambda$ gegen die eingestellte Laserleistung. Für jede Einstellung der Laserleistung wurden 100 Spektren mit einer Integrationszeit von einer Sekunde pro Spektrum aufgenommen. Die Fehlerbalken geben die Standardabweichung der gemessenen spektralen Linienpositionen an. (Rechts) Auftragung der Laserlinienintensitäten und die Wellenlängenverschiebung der Laserlinie gegen die Zeit bei einer Laserleistung von $100 \mathrm{~mW}$.

Darin ist zu erkennen, dass die Wellenlängenverschiebung zunächst mit der Laserleistung abfällt und ab einer Laserleistung von $100 \mathrm{~mW}$ stetig ansteigt. Die Wellenlängenverschiebung zwischen 0 und $300 \mathrm{~mW}$ Ausgangsleistung beträgt maximal 0,6 nm und liegt somit unterhalb des Aufösungsvermögens des Spektrometers. Sie wird aus diesem Grund im Folgenden vernachlässigt. Die mit der Ausgangsleistung variierende spektrale Verschiebung der Laserlinie ist mit hoher Wahrscheinlichkeit auf nicht ausreichend kompensierte Temperaturänderungen im Diodenlaser während der Laufzeit zurückzuführen.

Die aufgezeichneten Linien des Oberflächenstreulichtes dienten desweiteren nicht nur zur Charakterisierung der Wellenlängen- und Leistungsstabilität des Lasers, sondern wurden auch dazu genutzt, den möglichen Einfluss der Bandbreite der Laserlinie auf die Aufösung der gemessenen Ramanspektren zu untersuchen. Dazu wurde die Halbwertsbreite der Laserlinie aus den Aufzeichnungen ermittelt. Diese beträgt 0,5 nm bzw. $8 \mathrm{~cm}^{-1}$ und spiegelt somit das Auflösungsvermögen des Ramanspektrometers wider. Damit ist das Aufösungsvermögen des Spektrometers der begrenzende Parameter für die Auflösung der Ramanspektren. 


\section{Kapitel 4}

\section{Herstellung und Charakterisierung ramanstreulichtverstärkender Oberflächen}

Die empfindlichste ramanspektroskopische Methode zur Identifizierung und Quantifizierung von Biomolekülen, wie z.B. Proteinen, stellt die oberflächenverstärkte Ramanspektroskopie dar, deren theoretischer Hintergrund bereits in Kapitel 2 beschrieben wurde. Sie liefert in der Regel weit höhere Ramanstreulichtintensitäten als sie mit anderen ramanspektroskopischen Verfahren, wie z.B. der resonanten Ramanspektroskopie oder der kohärenten Anti-Stokes Ramanspektroskopie, zu erreichen sind. Grundlegend für den Einsatz der oberflächenverstärkten Ramanspektroskopie sind Oberflächen aus Edelmetallen, wie beispielsweise Gold oder Silber, die Strukturen in der Größenordnung von einigen Nanometern bis zu wenigen Mikrometern aufweisen. Dazu werden Herstellungsverfahren eingesetzt, wie sie bereits in Kapitel 2 beschrieben wurden. Da nur wenige kommerziell erhältliche ramanstreulichtverstärkende Oberflächen existieren, wurden im Rahmen dieser Arbeit verschiedene Herstellungsverfahren für unterschiedlichste Substrattypen entwickelt und die erzeugten Oberflächen hinsichtlich ihrer Verstärkung und Signalreproduzierbarkeit charakterisiert.

Diese Herstellungsverfahren sowie die damit erzeugten Oberflächen werden im Folgenden vorgestellt. Zur Charakterisierung der generierten Substrattopographien wurden die Rasterkraft- und Elektronenmikroskopie eingesetzt. Für die Untersuchung der Signalreproduzierbarkeit wurde eine Beschichtung mit so genannten ,selbstorganisierenden Molekül-Monolagen“ durchgeführt, die darüber hinaus auch die Berechnung der oberflächenspezifischen Verstärkungsfaktoren, die im Abschnitt 4.2.4 vorgestellt wird, ermöglichen. 


\subsection{Herstellungsverfahren}

Die Herstellungsverfahren der in der vorliegenden Arbeit verwendeten ramanstreulichtverstärkenden Oberflächen lassen sich in drei Kategorien gliedern: die Strukturierung von Silizium-Wafern mit anschließender Goldbedampfung, die Excimerlaserbestrahlung von dünnen Goldschichten und die UV-Nanoimprint Lithographie. Diese Verfahren sollen hier nun vorgestellt werden.

\subsubsection{Strukturierung eines Silizium-Wafers (Klarite ${ }^{\circledR}$-Substrat)}

Das bisher einzige kommerziell erhältliche periodische ramanstreulichtverstärkende Substrat wird unter dem Namen Klarite ${ }^{\circledR}$ von der Firma D3-Technologies vertrieben. Es handelt sich dabei um eine Anordnung pyramidaler Vertiefungen in Silizium, die mit einer ca. $100 \mathrm{~nm}$ dicken Goldschicht bedampft sind. Sie weisen eine Basislänge von $1,4 \mu \mathrm{m}$ und eine Tiefe von $800 \mathrm{~nm}$ auf. In Abbildung 4.1 ist eine elektronenmikroskopische Aufnahme eines Oberflächenausschnittes dieser Klarite ${ }^{\circledR} \_$Oberfläche dargestellt. Für die Herstellung derartiger pyramidaler Strukturen ist ein vierstufiger Prozess notwendig, der in Abbildung 4.2 schematisch dargestellt ist.

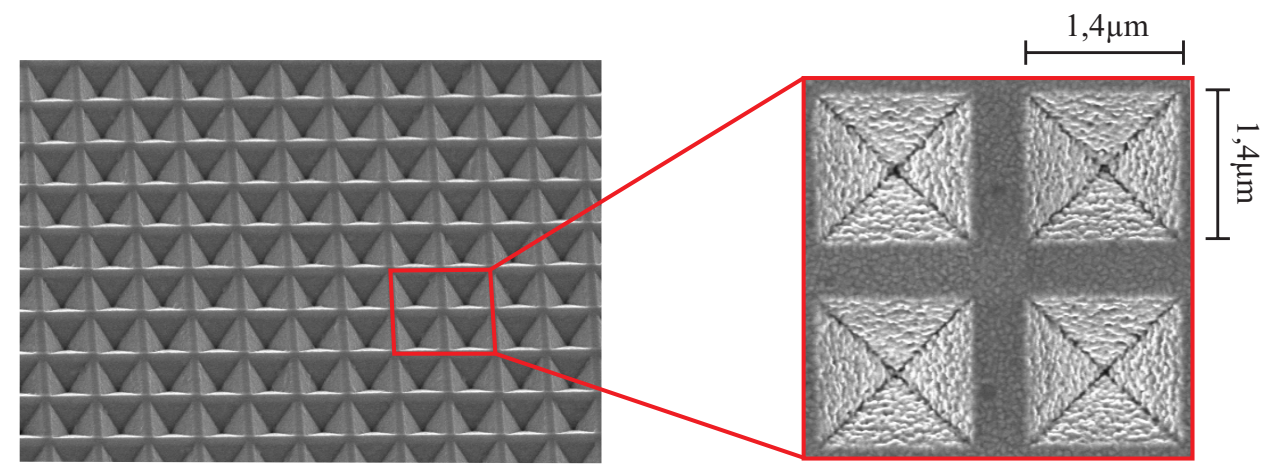

Abbildung 4.1: Elektronenmikroskopische Aufnahme eines Ausschnitts der Klarite ${ }^{\circledR}$ Oberfläche.

Er beginnt mit der thermischen Erzeugung einer Siliziumdioxid-Schicht auf einem (100)orientierten Silizium-Wafer, die im zweiten Schritt durch Maskierung und Laserbestrahlung strukturiert ablatiert wird. Somit ist die Basis der pyramidalen Struktur geschaffen. Im dritten Schritt werden die (100)-orientierten Bereiche des Silizium-Wafers, die frei vom Siliziumdioxid sind, mit einer Kaliumhydroxid-Lösung (KOH) nasschemisch anisotrop geätzt [11]. Dabei entstehen pyramidale Vertiefungen, deren Mantelfächen von den (111)-Kristallebenen des Silizium-Wafers begrenzt werden. Das Verhältnis der Ätzraten beträgt $S i_{(100)} / S i_{(111)} \approx 75$ [101]. Dieses Verfahren ist seit Jahren in der Herstellung photonischer Kristalle etabliert und führt aufgrund der kristallinen Struktur 
des Silizium-Wafers zu Oberflächen mit atomarer Rauigkeit. Daraus entsteht die typische pyramidale Form, die im letzten Schritt mit einer ca. 100 nm dicken Goldschicht bedampft wird.

(1) thermische Oxidation
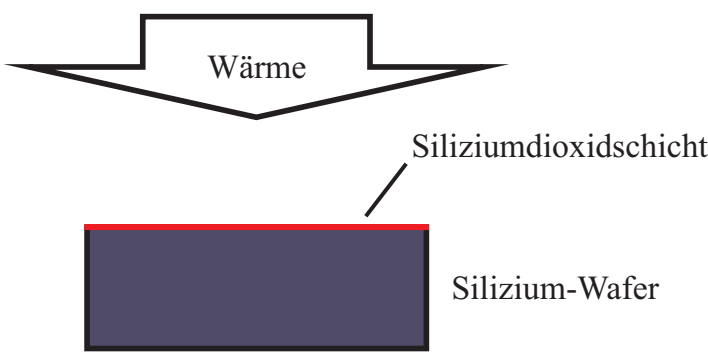

(3) Ätzen

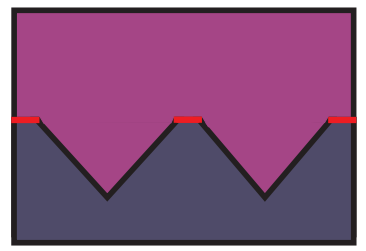

(2) optische Lithographie

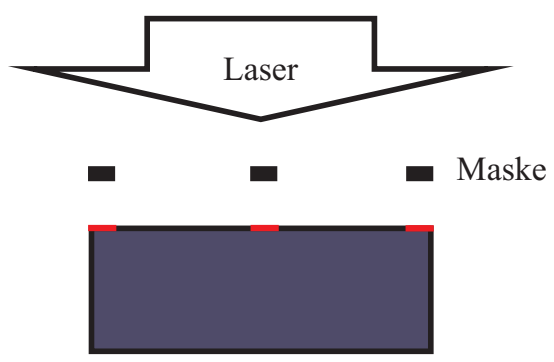

(4) Goldbedampfung

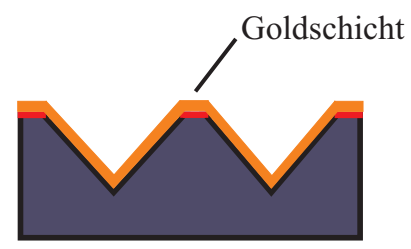

Abbildung 4.2: Schematische Darstellung des vierstufigen Herstellungsprozesses des Klarite ${ }^{\circledR}$-Substrats.

Wie der elektronenmikroskopischen Aufnahme in Abbildung $4.1 \mathrm{zu}$ entnehmen ist, weisen die pyramidalen Strukturen nanoskopisch raue Oberflächen auf, die neben den „hot-spot“-begünstigenden Pyramidenspitzen die Voraussetzung für eine Ramanstreulichtverstärkung schaffen.

Laut Herstellerangaben ist das Klarite ${ }^{\circledR}$ _Substrat für Anregungswellenlängen von $633 \mathrm{~nm}$ und $785 \mathrm{~nm}$ geeignet, was durch die Veröffentlichungen von Perney et al. [88] und Alexander et al. [2] untermauert wird. Sie weisen anhand von Reflektivitätsmessungen des Klarite ${ }^{\circledR}$-Substrats, schematisch in Abbildung 4.3 dargestellt, zwei breitbandige Einbrüche der Reflektivität mit Minima bei $675 \mathrm{~nm}$ und $950 \mathrm{~nm}$ nach. Sie deuten auf die Existenz zweier breitbandiger Plasmonenresonanzen hin, die sich in den Spektralbereich von 785 bis $890 \mathrm{~nm}\left(0\right.$ bis $1600 \mathrm{~cm}^{-1}$ ) erstrecken und somit innerhalb des mit dem Ramanspektrometer detektierten Spektralbereichs liegen. Sie sollten also sowohl die Anregungsstrahlung als auch das emittierte Ramanstreulicht der in der vorliegenden Arbeit untersuchten Biomoleküle für den genannten Spektralbereich verstärken. 


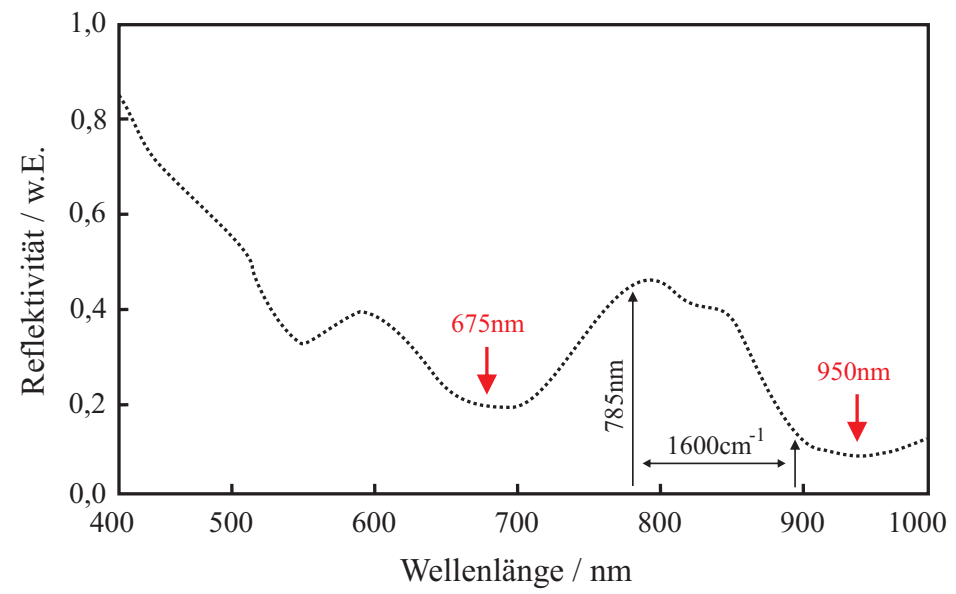

Abbildung 4.3: Schematische Darstellung der von Alexander et al. [2] gemessenen wellenlängenabhängigen Reflektivität des Klarite ${ }^{\circledR}{ }_{-}$Substrats. Die Minima der Reflektivität bei $675 \mathrm{~nm}$ und $950 \mathrm{~nm}$ deuten auf Plasmonenresonanzen hin.

\subsubsection{UV-Nanoimprint Lithographie}

Ein sehr vielversprechendes, kostengünstiges und schnelles Verfahren zur Herstellung reproduzierbarer Oberflächenstrukturen im Nano- bis Mikrometerbereich für den Einsatz in der oberflächenverstärkten Ramanspektroskopie ist die UV-Nanoimprint Lithographie [23]. Sie ist ein Abformungsverfahren, welches eine Übertragung dreidimensionaler Oberflächenstrukturen, die bereits auf einen Stempel aufgebracht wurden, auf verschiedene Substratmaterialien, wie z.B. Silizium-Wafer, Quarzglas oder Metallen, ermöglicht. Diese Substrate werden dazu mit einem UV-aushärtbaren Resist auf Basis von Kunststoff (Methacrylat) mit geringer Viskosität (50 mPas [27]), wie z.B. das Amonil, beschichtet, in den der Stempel eingedrückt wird. Das Stempelmaterial, in das die zu replizierenden Oberflächenstrukturen eingebracht sind, wird dabei so gewählt, dass es transparent für UV-Licht ist, wie z.B. Quarzglas oder bestimmte Polymere, so dass der Resist durch den Stempel hindurch mit Hilfe einer starken UV-Lichtquelle ausgehärtet werden kann. Im letzten Schritt wird der Stempel entfernt und es verbleibt das Negativ der Stempeloberflächenstrukturen im ausgehärteten Resist, die anschlieBend mit einer dünnen Goldschicht bedampft werden. Mit diesem Verfahren können Oberflächenstrukturen mit einer Auflösung von unter $10 \mathrm{~nm}$ repliziert werden. Für ein besseres Verständnis sind die erforderlichen Arbeitsschritte noch einmal in Abbildung 4.4 schematisch dargestellt.

In Kooperation mit der Firma AMO, Gesellschaft für Angewandte Mikro- und Optoelektronik mbH, wurden zwei verschiedene ramanstreulichtverstärkende Substrate mittels des UV-Nanoimprint Verfahrens hergestellt. Dazu wurden zunächst zwei Stem- 
pel mit unterschiedlichen Strukturen angefertigt. Zum Einen wurden per Elektronenstrahllithographie stufenförmige Liniengitterstrukturen mit einer Periode von $500 \mathrm{~nm}$ und einer Gittertiefe von $100 \mathrm{~nm}$ in einem Quarzglasstempel erzeugt und zum Anderen das Negativ der Klarite ${ }^{\circledR}$-Topographie durch Abformung auf einen auf Polymer basierenden Stempel übertragen, der transparent für UV-Licht ist.

(a)

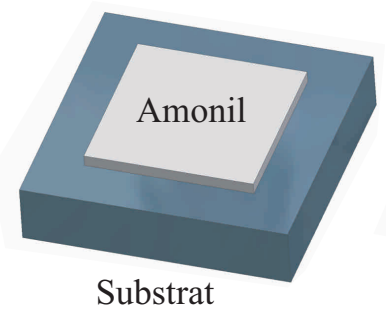

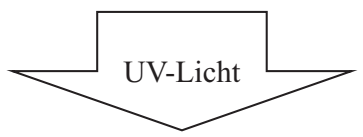

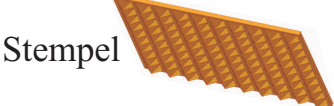

(b)

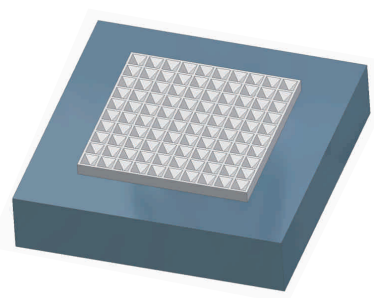

(c)

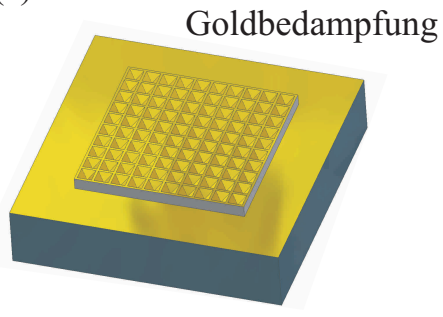

Abbildung 4.4: Schematische Darstellung des 3-stufigen UV-Nanoimprint Lithographie Prozesses (a) - (c).

Anschließend wurden diese Stempel mit dem UV-Nanoimprint Verfahren auf einen mit Amonil beschichteten Silizium-Wafer abgeformt. In den Abbildungen 4.5 und 4.6 sind die hergestellten pyramidalen bzw. Gitterstrukturen mit Hilfe der Rasterkraft- bzw. Elektronenmikroskopie visualisiert.
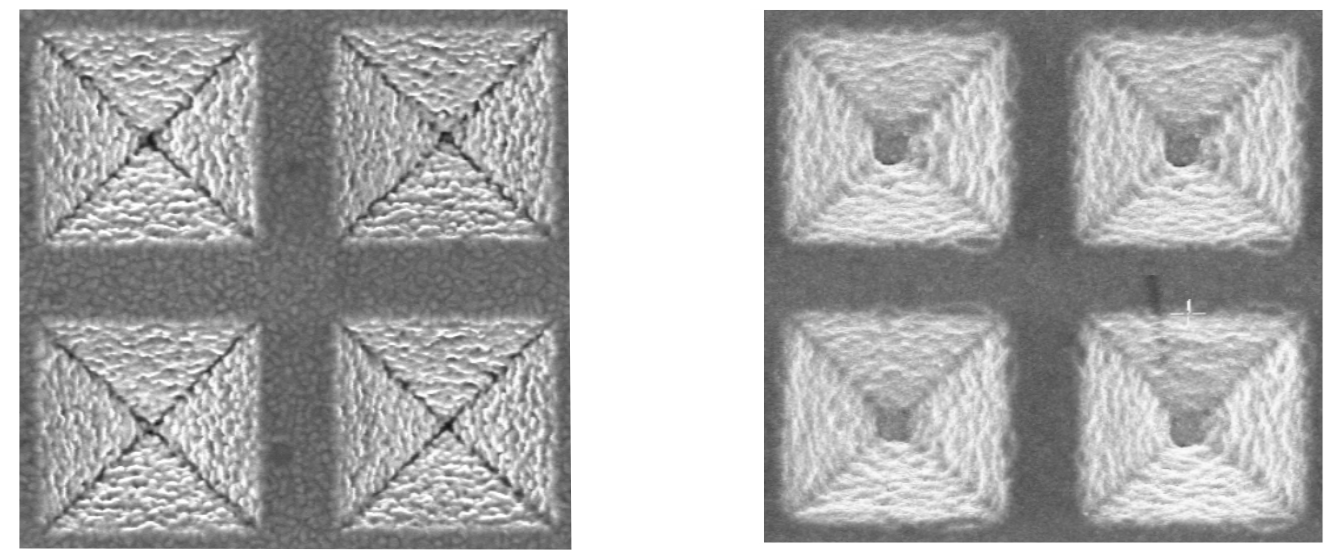

Abbildung 4.5: (Links) Elektronenmikroskopische Aufnahme eines Ausschnitts der Klarite ${ }^{\circledR}$ Oberfläche und (rechts) der replizierten Klarite ${ }^{\circledR}$-Oberfläche. 
Die replizierte Klarite ${ }^{\circledR}$-Oberfläche entspricht bis auf wenige Nanometer exakt der Struktur des Originals. Es sind sogar die feinen Sub-Strukturen der pyramidalen Flächen aufgelöst. Nur die Pyramidenspitze ist wahrscheinlich aufgrund einer unzureichenden Stabilität des Stempels nicht präzise abgeformt.
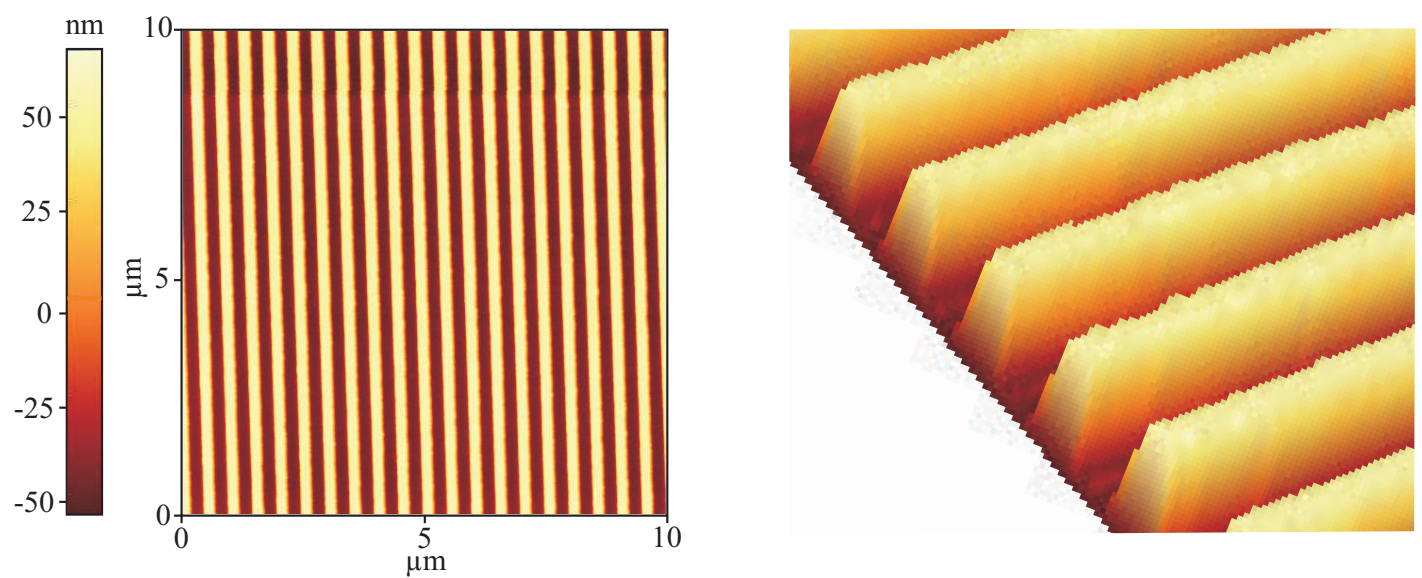

Abbildung 4.6: (Links) Rasterkraftmikroskopische Aufnahmen eines nach dem UV- Nanoimprint Lithographie Verfahren hergestellten Liniengitters, wobei die Höhe falschfarbenkodiert ist. (Rechts) Ausschnitt aus der dreidimensionalen Darstellung der rasterkraftmikroskopischen Aufnahme des Liniengitters.

Die produzierten Liniengitter weisen eine Fertigungsgenauigkeit von kleiner $10 \mathrm{~nm}$ auf und werden daher auch als dispersives Element in Spektrometern verwendet. Das Potential stufenförmiger Liniengitter für die oberflächenverstärkte Ramanspektroskopie wurde bereits ausführlich in der Veröffentlichung von Kahl et al. [39] aus dem Jahre 2000 beschrieben. Daraus geht hervor, dass silberbeschichtete Gitter mit $100 \mathrm{~nm}$ Gittertiefe und $300 \mathrm{~nm}$ Gitterperiode reproduzierbare Verstärkungsfaktoren von bis zu $10^{3}$ bei einer Anregung mit $700 \mathrm{~nm}$ aufzeigen. Da die von AMO angefertigten stufenförmigen Liniengitter eine ähnliche Geometrie aufweisen, sollten sie ebenfalls für die Ramanstreulichtverstärkung geeignet sein.

Um diese Annahme zu überprüfen, wurden die elektrischen Feldverstärkungen für Gitter mit Perioden zwischen 100 und $500 \mathrm{~nm}$ mit Gittertiefen von 25 bis $200 \mathrm{~nm}$ in Kooperation mit Knorr et al. [51] mittels der Software COMSOL Multiphysics simuliert. Das Ergebnis dieser Simulationen ist in Abbildung 4.7 dargestellt. Der Verstärkungsfaktor $\Omega$ errechnet sich dabei gemäß Gleichung 4.1, wobei das elektrische Feld über die Oberfläche $A$ der Einheitszelle, normiert auf die entsprechende Fläche $A_{0}$ ohne Strukturierung, integriert wird:

$$
\Omega=\frac{1}{A_{0}} \int \frac{\left|\vec{E}_{i n d}\right|^{4}}{\left|\vec{E}_{P h}\right|^{4}} d A .
$$


Die vierte Potenz ergibt sich aus der Annahme, dass die Frequenz des eingestrahlten elektrischen Feldes $\left(\nu_{P h}\right)$ sehr nah an der Frequenz des Ramanstreulichtes $\left(\nu_{S}\right)$ liegt. Nach den Ergebnissen aus der Simulation liefern Gitter mit einer Gittertiefe von $100 \mathrm{~nm}$ für alle simulierten Gitterperioden die höchsten Verstärkungsfaktoren von $10^{3}$ bis $10^{4}$. Diese Ergebnisse decken sich mit den Untersuchungen von Kahl et al.. Wie die Berechnung der Verstärkungsfaktoren aus Abschnitt 4.2.4 zeigen wird, stimmen Simulation und Experiment gut überein.
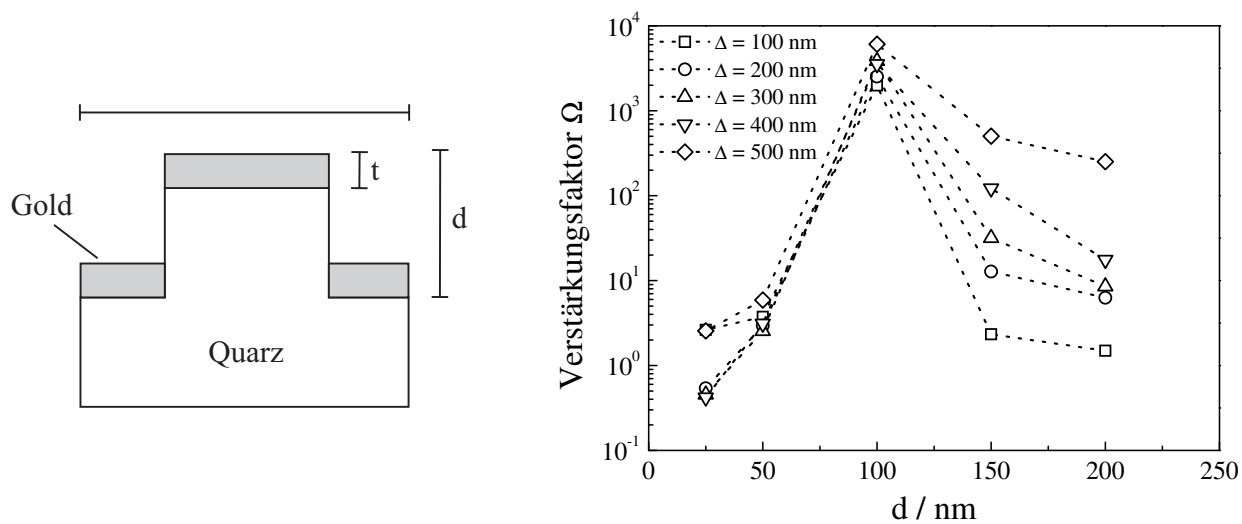

Abbildung 4.7: (Links) Modell der Einheitszelle eines stufenförmigen Gitters mit der Periode $\Delta$, der Gittertiefe $d$ und der Goldschichtdicke $t$. (Rechts) Beziehung zwischen der Ramanstreulichtverstärkung bei einer Anregungswellenlänge von $785 \mathrm{~nm}$ und Gittern mit variierender Periode $\Delta$ und Gittertiefen d.

\subsubsection{UV-Laserbestrahlung dünner Goldschichten}

Im Laufe der vorliegenden Arbeit wurden, basierend auf den Voruntersuchungen von Knorr [50], ramanstreulichtverstärkende Oberflächen mittels Excimerlaserbestrahlung von dünnen, auf Quarzglas aufgedampften Goldschichten hergestellt. In diesen Voruntersuchungen zeigte sich, dass die Einzel- und Mehrfachbestrahlung einer auf Quarzglas aufgedampften Goldschicht von $20 \mathrm{~nm}$ Dicke mit einer Wellenlänge von $193 \mathrm{~nm}$ zur Entstehung annähernd sphärischer Nanopartikel auf der Quarzglasoberfläche führt. Ein wahrscheinliches Erklärungsmodell dafür ist das Aufschmelzen und teilweise Abdampfen der Goldschicht durch den Energieeintrag, die sich aufgrund der Oberflächenspannung zu kleinen Goldkugeln formiert. Knorr wies darüber hinaus eine Abhängigkeit der Partikeldurchmesser von der Goldschichtdicke und den verwendeten Fluenzen nach. Die in Abbildung 4.8 gezeigten elektronenmikroskopischen Aufnahmen machen dies am Beispiel zweier $20 \mathrm{~nm}$ dicken Goldschichten deutlich, die mit einer Wellenlänge von $193 \mathrm{~nm}$ und unterschiedlichen Fluenzen einfach bestrahlt wurden. 

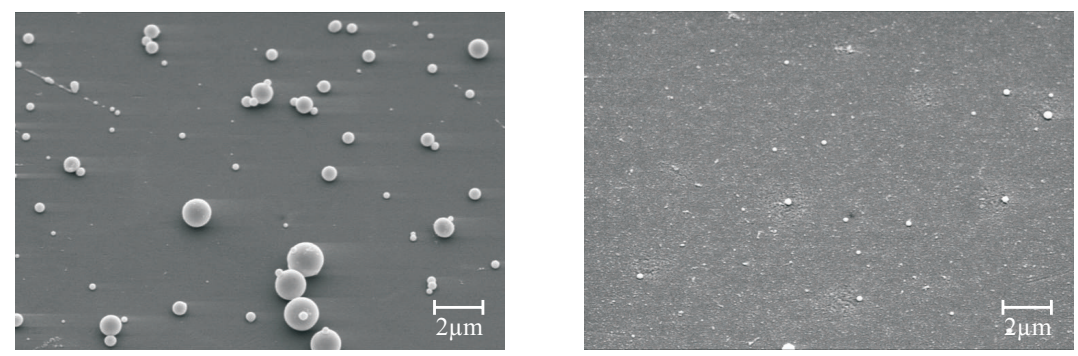

Abbildung 4.8: Elektronenmikroskopische Aufnahme (rechts) der mit $18,5 \mathrm{~mJ} / \mathrm{cm}^{2}$ und (links) der mit $26,5 \mathrm{~mJ} / \mathrm{cm}^{2}$ bestrahlten Goldschicht.

Während mit der Fluenz von 18,5 mJ $/ \mathrm{cm}^{2}$ sphärische Partikel mit Durchmessern von bis zu $2 \mu \mathrm{m}$ erzeugt werden, entstehen bei Bestrahlung mit $26,5 \mathrm{~mJ} / \mathrm{cm}^{2}$ wesentlich kleinskaligere Strukturen im zweistelligen Nanometerbereich. Laut der theoretischen Modelle zur Ramanstreulichtverstärkung sollten die kleinen dichtgepackten Strukturen wegen der sehr viel kleineren interpartikulären Abstände höhere Ramanstreulichtintensitäten zeigen als die großen. Um diesen Sachverhalt zu klären, wurden ramanspektroskopische Untersuchungen von Thiophenol-Monolagen (s. Abschnitt 4.2.1) für eine Serie von Oberflächen aufgenommen, bei denen sowohl die Goldschichtdicke als auch die Fluenz variiert wurden. Abbildung 4.9 zeigt das Ergebnis dieser Messungen.

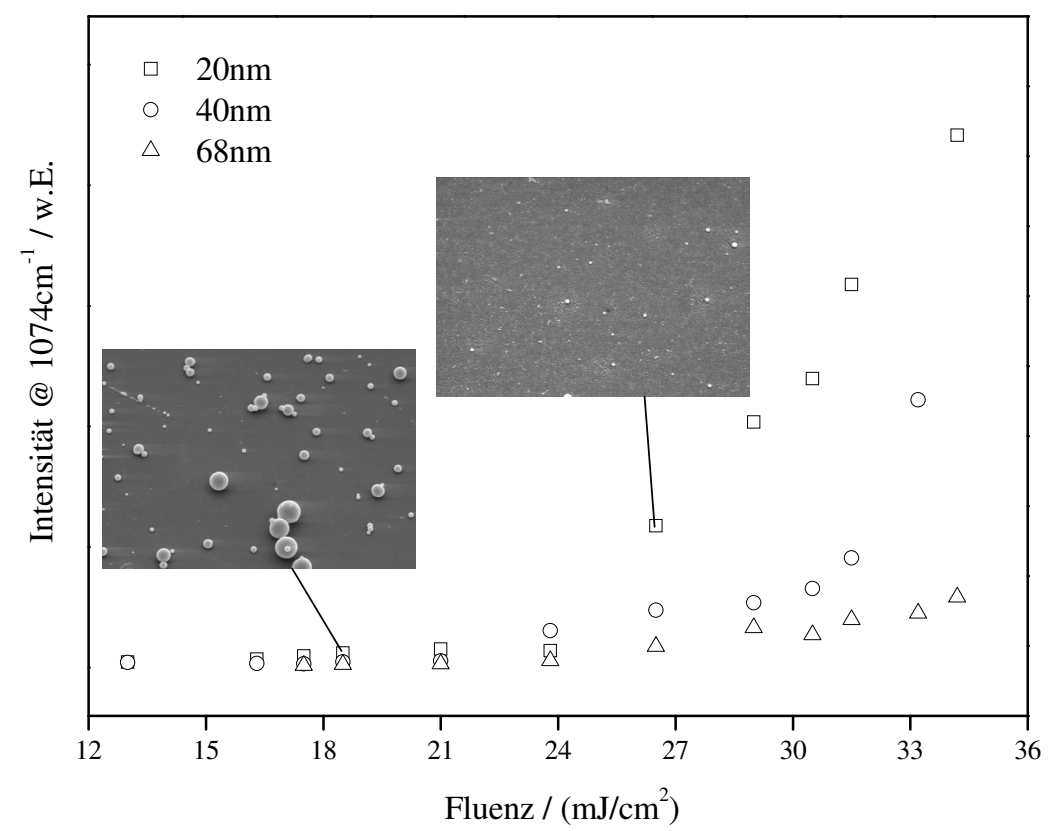

Abbildung 4.9: Auftragung der Ramanstreulichtintensität der Ramanbande bei $1074 \mathrm{~cm}^{-1}$ des Thiophenols gegen die Fluenz für verschiedene Goldschichtdicken, die mit einer Wellenlänge von $193 \mathrm{~nm}$ bestrahlt wurden. Auf das oberflächenverstärkte Ramanspektrum von Thiophenol wird noch in den folgenden Abschnitten eingegangen. 
Wie erwartet, führen die kleinskaligen Strukturen zu deutlich höheren Ramanstreulichtintensitäten als die großskaligen Strukturen.

Basierend auf diesen Ergebnissen wurde eine Reihe von Untersuchungen an Quarzglassubstraten mit variierenden Goldschichtdicken und Bestrahlungswellenlängen eines Excimerlasers hinsichtlich der Ramanstreulichtintensitäten von Thiophenol-Monolagen vorgenommen. Die verwendeten Wellenlängen sind in folgender Tabelle zusammengefasst.

\begin{tabular}{|c|c|c|}
\hline Wellenlänge / nm & Gasfüllung & Fluenz / $\left(\mathrm{mJ} / \mathrm{cm}^{2}\right)$ \\
\hline 193 & Argonfluorid (ArF) & $50-350$ \\
\hline 248 & Kryptonfluorid (KrF) & $100-500$ \\
\hline 308 & Xenonchlorid (XeCl) & $100-350$ \\
\hline 351 & Xenonfluorid (XeF) & $200-700$ \\
\hline
\end{tabular}

Tabelle 4.1: Emissionswellenlängen eines Excimerlasers in Abhängigkeit von der Gasfüllung.

Für die Bestrahlung der Goldschichten wurde ein nichtabbildender Homogenisator eingesetzt, der die für Excimerlaser typischerweise stark ortsabhängigen Intensitäten im rechteckigen Strahlprofil homogenisiert. Die Funktionsweise eines Homogenisators ist in Abbildung 4.10 schematisch dargestellt.

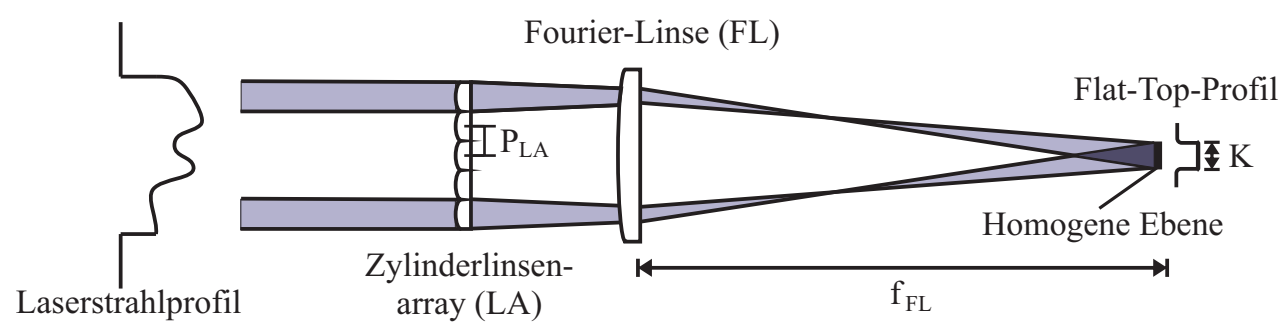

Abbildung 4.10: Schema eines nichtabbildenden Homogenisators.

Ein Linsenarray von gekreuzten Zylinderlinsen teilt zunächst den einfallenden Strahl in kleine Teilstrahlen auf, die über eine sphärische Linse in der Brennebene dieser Linse überlagert werden, wodurch sich ein homogen ausgeleuchtetes Feld ergibt, das so genannte Flat-Top-Profil. Da die Einzellinse eine zweidimensionale Fouriertransformation ausführt, wird sie auch als Fourier-Linse bezeichnet. Der Durchmesser K des Flat-Top-Profils in der Brennebene der Fourier-Linse ergibt sich aus

$$
\mathrm{K}=\left|\frac{P_{L A} \cdot f_{F L}}{f_{L A}}\right|
$$


wobei $P_{L A}$ der Mittenabstand der Zylinderlinsen im Array, $f_{F l}$ die Brennweite der Fourier-Linse und $f_{L A}$ die Brennweite des Linsenarrays ist. Für die Bestrahlung der Oberflächen betrug die Brennweite des Zylinderlinsenarrays $f_{L A}=100 \mathrm{~mm}$, der Mittenabstand der Zylinderlinsen $P_{L A}=2,5 \mathrm{~mm}$ und die Brennweite der Fourier-Linse $f_{F L}=250 \mathrm{~mm}$, so dass die Flat-Top-Profile eine Kantenlänge von ca. $K=6 \mathrm{~mm}$ aufwiesen. In Abbildung 4.11 ist exemplarisch eine Fotografie einer mit unterschiedlichen Fluenzen bestrahlten $20 \mathrm{~nm}$ dicken Goldschicht auf einem Quarzglasträger dargestellt. Die Kantenlänge der bestrahlten Bereiche beträgt in diesem Fall $K=6 \mathrm{~mm}$.

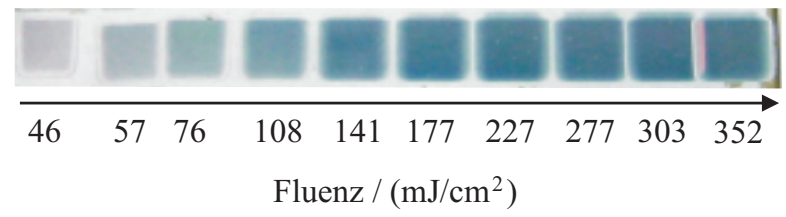

Abbildung 4.11: Strukturierte Goldoberfläche für die Bestrahlungswellenlänge von $193 \mathrm{~nm}$ und variierenden Fluenzen zwischen 46 und $352 \mathrm{~mJ} / \mathrm{cm}^{2}$.

Es ist zu erkennen, dass mit steigender Fluenz eine zunehmende Blauverfärbung der bestrahlten Bereiche eintritt, die auf die durchschnittlichen Größen und Dichten der erzeugten sphärischen Partikel zurückzuführen ist, wie der Diplomarbeit von Knorr [50] entnommen werden kann. Eine derartige Blauverfärbung der Oberflächen wurde auch während dieser Arbeit an allen bestrahlten Goldschichten beobachtet.

Aufschluss über die erzeugten Oberflächenstrukturen geben rasterkraftmikroskopische Aufnahmen, wie sie exemplarisch für den Fall der Laserwellenlänge von $308 \mathrm{~nm}$ und der Fluenz von $227 \mathrm{~mJ} / \mathrm{cm}^{2}$ in Abbildung 4.12 gezeigt werden. Darin sind sphärische Goldpartikel mit Durchmessern im zweistelligen Nanometerbereich zu sehen.
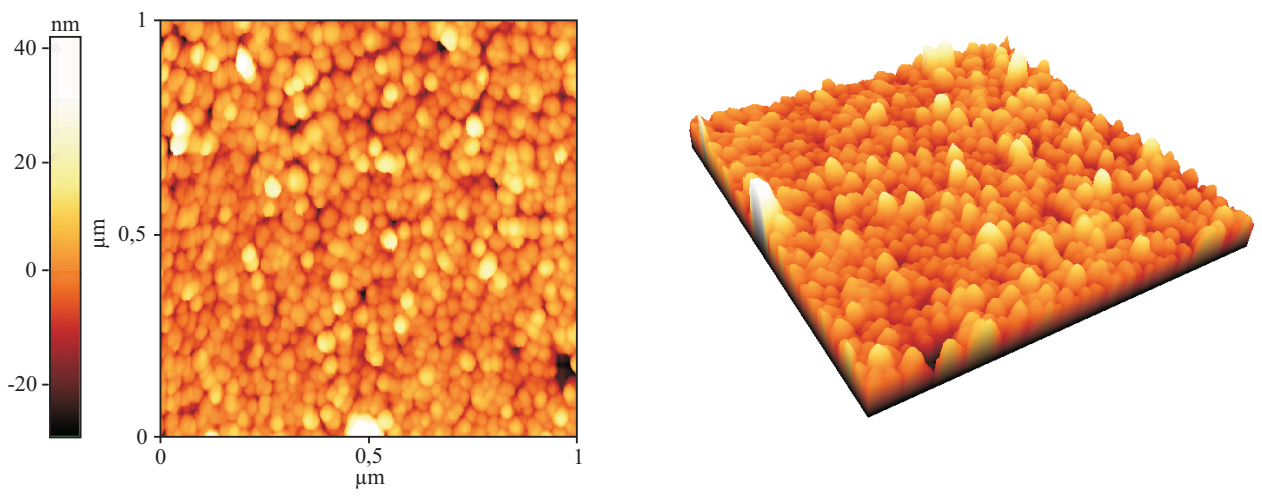

Abbildung 4.12: (Links) Rasterkraftmikroskopische Aufnahme eines Ausschnitts aus der Oberfläche, die durch Bestrahlung einer $20 \mathrm{~nm}$ Goldschicht auf Quarzglas für eine Bestrahlungswellenlänge von $308 \mathrm{~nm}$ und einer Fluenz von $227 \mathrm{~mJ} / \mathrm{cm}^{2}$ erzeugt wurde. (Rechts) Dreidimensionale Darstellung desselben Ausschnitts. 


\subsection{Charakterisierung der erzeugten Oberflächen}

\subsubsection{Experimentelle Grundlagen der Charakterisierung}

Grundlage für reproduzierbare, quantitative oberflächenverstärkte Ramanstreulichtmessungen sind Oberflächen, die eine möglichst geringe ortsabhängige Ramanstreulichtschwankung aufzeigen. Dazu ist allerdings die räumliche Homogenität der Oberflächenstrukturen Voraussetzung, die jedoch in vielen Fällen, abhängig vom jeweiligen Herstellungsverfahren, kaum erfüllt werden kann. Eine experimentelle Herangehensweise zur Bestimmung der örtlichen Ramanstreulichtschwankungen stellt die Beschichtung der Oberflächen mit einer sich selbstorganisierenden Molekül-Monolage (Self-Assembling Monolayer, SAM) dar [100]. Für gewöhnlich zeigen diese Monolagen eine regelmäßige Ausrichtung der Moleküle, so dass ortsabhängige Ramanstreulichtschwankungen direkt auf die Inhomogenitäten der Oberflächen zurückzuführen sind und nicht durch örtliche Anhäufungen adsorbierter Moleküle beeinflusst werden.

\section{Beschichtung mit selbstorganisierenden Molekül-Monolagen}

Für die Beschichtung von metallischen Oberflächen werden in der Regel organische Verbindungen, wie die Alkanthiole, eingesetzt, die eine bzw. mehrere Thiolgruppen (SH) als funktionelle Gruppe aufweisen. Die hohe Affinität dieser Thiolgruppen zu Edelmetallen, wie zum Beispiel Gold, führt zur spontanen Adsorption, indem die Thiolgruppen über das Schwefelatom unter Abspaltung von Wasserstoff eine kovalente Bindung mit der Oberfläche eingehen. Dabei entstehen in der Regel hochgeordnete MolekülMonolagen von Alkanthiolen.

Aus einer Vielzahl kommerziell erhältlicher Alkanthiole wurde das Thiophenol für die Untersuchung der ortsabhängigen Ramanstreulichtschwankungen ausgewählt, welches zu den einfachsten strukturierten aromatischen Alkanthiolen zählt. Es zeichnet sich darüber hinaus vor allem durch seine Langzeitstabilität auf Goldoberflächen von mehreren Tagen aus und weist einen natürlich hohen Ramanstreuquerschnitt auf. Erste ausführliche ramanspektroskopische Untersuchungen von selbstorganisierten MolekülMonolagen auf Basis von Alkanthiolen finden sich in der Veröffentlichung von Sandroff und Herschbach [97] aus dem Jahre 1982. Aus ihren Untersuchungen geht hervor, dass sich Alkanthiole senkrecht zur Oberfläche anordnen, wie es am Beispiel von Thiophenol schematisch in Abbildung 4.13 angedeutet ist. Dieses Ergebnis wird jedoch kontrovers diskutiert und ist gemäß der Veröffentlichung von Wan et al. [110] aus dem Jahre 2000 nicht zutreffend. Deren Untersuchungen zeigen auf, dass der Benzolring des Thiophenolmoleküls unter einem Winkel von $30^{\circ}$ zur Oberflächennormalen geneigt ist und sich damit eine Bedeckung der Oberfläche mit Thiophenol von 0,709 $\mathrm{nmol} / \mathrm{cm}^{2}$ errechnet. 
(a)

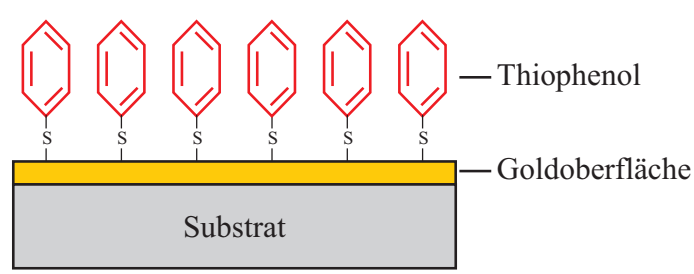

(b)

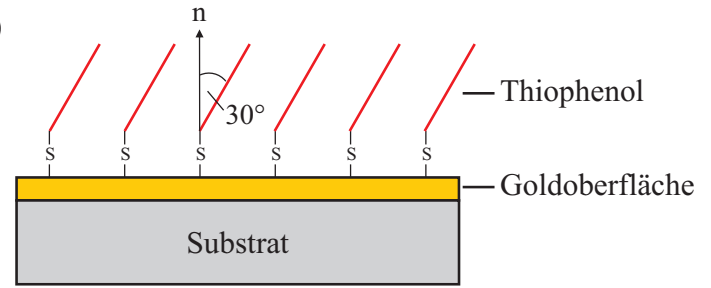

Abbildung 4.13: Ausbildung einer Thiophenol-Monolage auf einer Goldoberfläche. (a) Nach Sandroff et al. ordnen sich die Thiophenol-Moleküle senkrecht zur Oberfläche an. (b) Nach Wan et al. ist der Benzolring des Thiophenols um $30^{\circ}$ zur Flächennormalen n geneigt.

In Abbildung 4.14 (a) ist das oberflächenverstärkte Ramanspektrum einer Thiophenol-Monolage dargestellt, das auf dem kommerziell erhältlichen Klarite ${ }^{\circledR}$ _Substrat aufgenommen wurde. Diesem Spektrum ist das nicht oberflächenverstärkte Ramanspektrum einer 99,9\%'igen Thiophenol-Lösung gegenübergestellt. Bedingt durch die Adsorption des Thiophenols an die Oberfläche, tauchen im oberflächenverstärkten Ramanspektrum drei sehr intensive Ramanbanden bei $1000 \mathrm{~cm}^{-1}, 1025 \mathrm{~cm}^{-1}$ und $1074 \mathrm{~cm}^{-1}$ auf, die im Ramanspektrum der Lösung gar nicht bzw. nur schwach ausgeprägt sind.

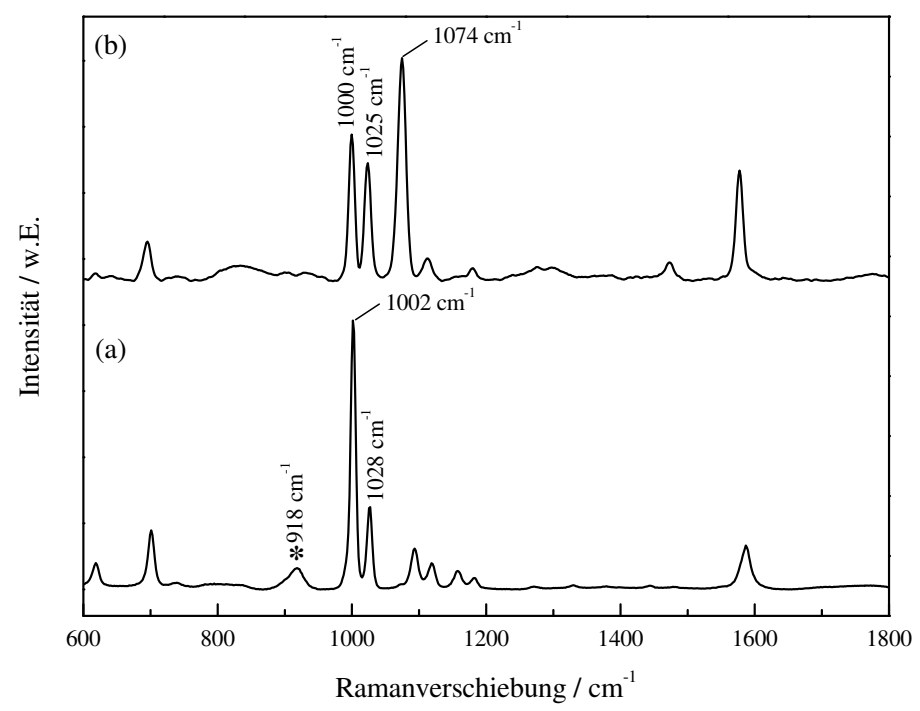

Abbildung 4.14: Vergleich des Ramanspektrums der Thiophenol-Lösung (a) mit dem oberflächenverstärkten Ramanspektrum (b).

Außerdem fällt auf, dass im Gegensatz zum Ramanspektrum des flüssigen Thiophenols die Ramanbande bei $918 \mathrm{~cm}^{-1}$ im oberflächenverstärkten Ramanspektrum fehlt. Diese ist auf die SH-Deformationsschwingung des Thiophenol-Moleküls im ungebundenen Zustand zurückzuführen, die aufgrund der kovalenten Bindung des Schwefelatoms bei der Adsorption des Thiophenols an die Oberfläche nicht mehr existent ist. Daher ist sie 
ein sicheres Indiz für die Ausbildung einer einzigen Lage von Thiophenol-Molekülen. Bei mehr als nur einer Lage müsste die Ramanbande präsent sein.

Am Beispiel des oberflächenverstärkten Ramanspektrums von Thiophenol bestätigt sich das in Kapitel 2 beschriebene Ladungstransfer-Modell, das aufgrund der Bindung des Thiophenols an die Oberfläche weitere bzw. spektral verschobene Ramanbanden vorhersagt. Die Entstehung eines Ladungstransfer-Komplexes kann damit als Ursache für die Verschiebung der Ramanbanden bzw. die Entstehung weiterer Ramanbanden angesehen werden.

Für die Beschichtung der Oberflächen mit Thiophenol wurde eine $10 \mathrm{mM}$ ThiophenolLösung in hoch reinem unvergälltem Ethanol (Sigma-Aldrich) hergestellt. Das verwendete Thiophenol (Sigma-Aldrich) wies eine Reinheit von 99,9\% auf. In dieser Lösung wurden die Oberflächen für maximal 10 Minuten aufbewahrt, anschließend mit Ethanol über eine Zeitspanne von mehreren Sekunden gespült und unter Atmosphäre getrocknet, gemäß der Veröffentlichung von Wan et al. Damit konnte gewährleistet werden, dass sich keine ungebundenen Thiophenolmoleküle während des Trocknens auf der Oberfläche befanden. Beim Umgang mit dem hoch toxischen Thiophenol muss sowohl der Hautkontakt als auch das Einatmen vermieden werden.

Unmittelbar nach der Beschichtung der Oberflächen mit Thiophenol wurden an mehreren Orten auf der Oberfläche Ramanstreulichtmessungen durchgeführt. Die gemessenen ortsabhängigen Ramanstreulichtintensitäten setzen sich dabei aus zwei Anteilen zusammen: ein Anteil, der unmittelbar auf die Inhomogenitäten der Oberflächen zurückzuführen ist und ein weiterer Anteil, der von der Positionierung der Oberfläche im Laserfokus abhängt. Diese Abhängigkeit resultiert daraus, dass der Sensorkopf konstruktionsbedingt (insbesondere durch die Faserkopplung) einen leicht konfokalen Charakter besitzt. Ändert sich während des lateralen Abrasterns der Oberfläche der Abstand der Oberfläche zum Sensorkopf, so ergibt sich eine Variation der detektierten Signalintensität. Da eine leichte Schrägstellung der Oberfläche in Bezug auf die Translationsebene nicht ausgeschlossen werden kann, muss dieser Effekt mit in die Überlegungen einbezogen werden. Beim Verfahren über mehrere Millimeter kann sich die Oberfläche also vertikal im Laserstrahlfokus verschieben und eine Variation der Signalintensität bewirken. Um diesen Anteil der Signalschwankungen auf ein Minimum zu reduzieren, wurde eine Methode zur visuellen Justierung des Ramanspektrometers auf reproduzierbare maximale Ramanstreulichtintensitäten angewandt, die im folgenden Abschnitt beschrieben wird. 


\section{Methode zur visuellen Justierung des Ramanspektrometers auf maximale Ramanstreulichtintensitäten}

Die in das Ramanspektrometer integrierte Beobachtungsoptik (s. Abbildung 3.3) dient nicht nur zur Visualisierung der Oberflächen, sondern wird auch zur reproduzierbaren Positionierung der Oberflächen im Laserfokus des Mikroskopobjektivs genutzt. Um den Ort maximaler Signalausbeute im Laserfokus zu lokalisieren, wurden oberflächenverstärkte Ramanspektren eines mit Thiophenol-Molekülen beschichteten Klarite ${ }^{\circledR}$ Substrates für verschiedene Abstände $\Delta z$ zwischen dem Mikroskopobjektiv und der Oberfläche aufgenommen. Abbildung 4.15 (rechts) zeigt die gemessenen, normierten Werte des Integrals ${ }^{1}$ über die intensive Ramanbande bei $1074 \mathrm{~cm}^{-1}$ des oberflächenverstärkten Ramanspektrums von Thiophenol (s. Abbildung 4.15 (links)). Dabei wird der Abstand mit der höchsten Ramanstreulichtintensität mit $\Delta z=0$ bezeichnet.
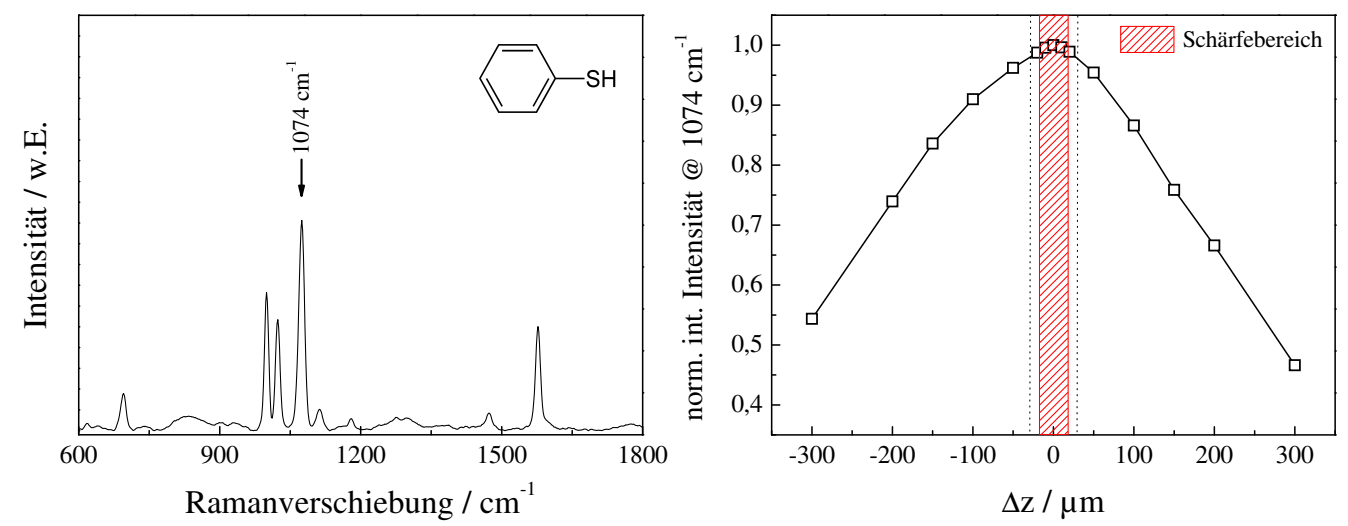

Abbildung 4.15: (Links) Oberflächenverstärktes Ramanspektrum von Thiophenol nach Basislinienkorrektur. Die Strukturformel von Thiophenol ist ebenfalls mit eingezeichnet. (Rechts) Auftragung der normierten integralen Intensität der $1074 \mathrm{~cm}^{-1}$ Ramanbande des Thiophenols für verschiedene Abstände $\Delta z$. Der Tiefenschärfebereich der Beobachtungsoptik ist rot schraffiert dargestellt. Die gepunkteten Linien markieren den Bereich annähernd konstanter maximaler Ramanstreulichtintensität.

Es ist $\mathrm{zu}$ erkennen, dass die Signalintensität bis $\mathrm{zu}$ einem Abstand von $\Delta z \approx \pm 25 \mu \mathrm{m}$ annähernd konstant bleibt (2\% Standardabweichung) und erst für größere Abstände abfällt. Entsprechend dieser Ergebnisse wird die Beobachtungsoptik für den Abstand $\Delta z=0$ auf die Oberfläche scharfgestellt. Der Tiefenschärfebereich der Beobachtungsoptik beträgt etwa $\Delta z \approx \pm 15 \mu \mathrm{m}$ und ist deutlich kleiner als der Abstand $\Delta z \approx \pm 25 \mu \mathrm{m}$, für den konstante Ramanstreulichtintensitäten gemessen werden. Damit liefert die Positionierung der Oberfläche in den Tiefenschärfebereich der Beob-

\footnotetext{
${ }^{1}$ Das Integral über ausgewählte Ramanbanden wird als Maß für die Signalintensität gewählt und in der vorliegenden Arbeit mit dem Ausdruck int. Intensität abgekürzt.
} 
achtungsoptik reproduzierbare Ramanstreulichtintensitäten für verschiedene Messorte mit einer Standardabweichung von maximal $2 \%$.

\subsubsection{Vergleich der ortsabhängigen Ramanstreulichtschwankungen}

Für die Bestimmung der oberflächenspezifischen Ramanstreulichtschwankungen wurden zwischen 5 und 15 Positionen auf den Oberflächen angefahren und Ramanspektren der zuvor aufgebrachten Thiophenol-Monolagen mit 1s Integrationszeit und $50 \mathrm{~mW}$ Laserausgangsleistung aufgenommen. Die Standardabweichung der an verschiedenen Positionen gemessenen Ramanstreulichtintensitäten untereinander wird dabei als Maß für die Ramanstreulichtschwankung betrachtet.

\section{Klarite ${ }^{\circledR}$-Substrat}

Abbildung 4.16 zeigt die integrale Intensität der Ramanbande bei $1074 \mathrm{~cm}^{-1}$ des Thiophenols für verschiedene Positionen auf der originalen und replizierten Klarite ${ }^{\circledR}$-Oberfläche. Beide Oberflächen weisen nahezu die gleichen Intensitäten und Standardabweichungen von $5 \%$ auf.

Um sicher ausschließen zu können, dass durch den Energieeintrag während der Bestrahlung der Oberflächen mit der Anregungswellenlänge $785 \mathrm{~nm}$ Thiophenolmoleküle aus der Monolage thermisch desorbieren und damit zeitabhängige Ramanstreulichtintensitäten auftreten, wurden an jeder Position 100 Spektren zeitlich direkt hintereinander aufgenommen. Dabei ergaben sich Standardabweichungen von weniger als $2 \%$ über die Zeit, so dass von keinem kurzfristigen Einfluss der Anregungsstrahlung auf die Thiophenol-Monolage für die Ausgangsleistung von $50 \mathrm{~mW}$ auszugehen ist.
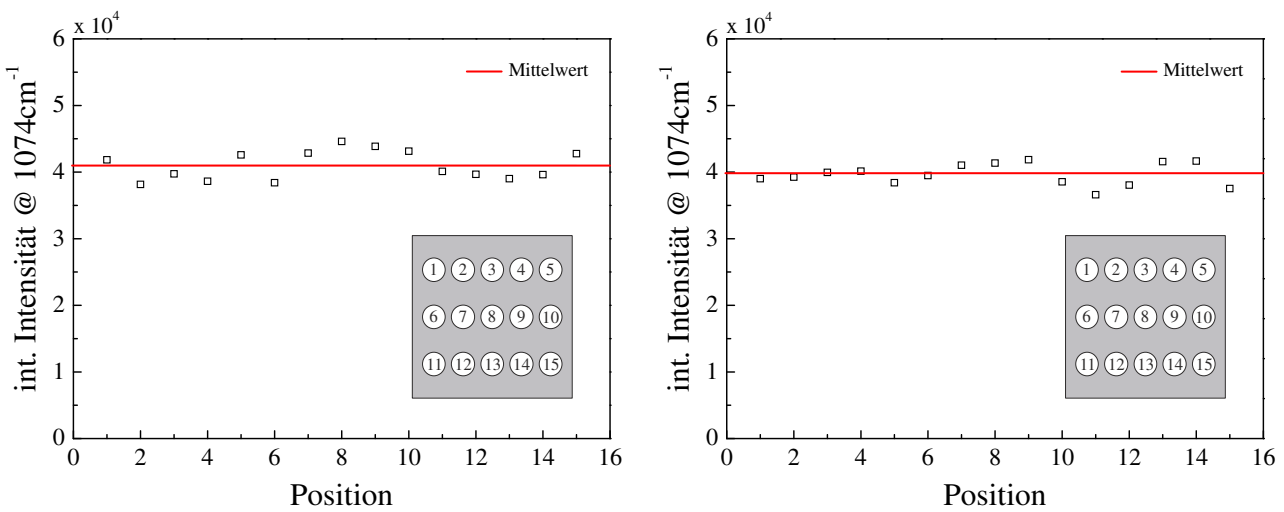

Abbildung 4.16: Vergleich der ortsabhängigen Ramanstreulichtintensitäten gemessen auf dem originalen Klarite ${ }^{\circledR}$-Substrat (links) mit dem mit der UV-Nanoimprint Lithographie reproduzierten Klarite ${ }^{\circledR}$-Substrat (rechts) für 15 verschiedene Positionen auf der Oberfläche. Die Verteilung der gemessenen Positionen ist jeweils den kleinen Abbildungen zu entnehmen. 
Das Ergebnis, dass die auf den replizierten Klarite ${ }^{\circledR}$ _Oberflächen gemessenen Ramanstreulichtintensitäten und deren örtlich gemittelten Standardabweichungen mit denen der originalen Klarite ${ }^{\circledR}$ _Oberfläche übereinstimmen, zeigt deutlich das Potential der UV-Nanoimprint Lithographie für die Abformung bereits bestehender ramanstreulichtverstärkender Oberflächen auf, wobei zu bemerken ist, dass die fehlerhaften Pyramidenspitzen auf der replizierten Klarite ${ }^{\circledR}$ _Oberfläche (s. Abbildung 4.5) keinen messbaren Einfluss auf die Ramanstreulichtintensitäten zeigen.

\section{Gitterstrukturen}

Ein weiteres ramanstreulichtverstärkendes Substrat, das mittels UV-Nanoimprint Lithographie hergestellt wurde, ist das stufenförmige Gitter. Es weist gegenüber dem Klarite ${ }^{\circledR}$-Substrat leicht höhere Ramanstreulichtintensitäten auf bei deutlich geringerer Standardabweichung der Signalintensitäten von nur $1 \%$. Es zeigt die niedrigsten Ramanstreulichtschwankungen aller vermessenen Substrate und sollte daher die reproduzierbarsten Ergebnisse in Hinblick auf die Identifizierung bzw. Quantifizierung von Proteinen liefern. Da während

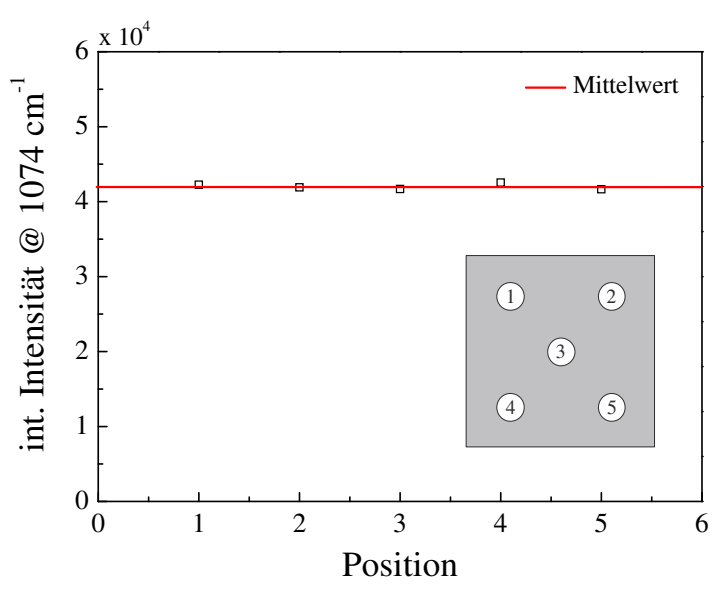

Abbildung 4.17: Auftragung der integralen Intensität der Ramanbande des Thiophenols bei $1074 \mathrm{~cm}^{-1}$ für 5 verschiedene Positionen. dieser Arbeit jedoch nur eine sehr geringe Anzahl von Gittern zur Verfügung stand, konnten keine weiterführenden Untersuchungen hinsichtlich der Proteinidentifizierung bzw. -quantifizierung mit diesen Substraten stattfinden.

\section{Laserbestrahlte Goldschichten}

Die Ergebnisse der Ramanstreulichtmessungen an den Goldschichten, die mit unterschiedlichen Wellenlängen eines Excimerlasers einmalig bestrahlt wurden, sind in Abbildung 4.18 zusammengefasst. Eine Mehrfachbestrahlung der Goldschichten führte im Vergleich zum Einzelschuss zu sehr geringen bzw. zu gar keinen Ramanstreulichtverstärkungen, so dass diese Ergebnisse in Abbildung 4.18 nicht mit aufgenommen wurden. Bereits in der Arbeit von Knorr wurde ein ähnliches Verhalten festgestellt.

Für die Laserbestrahlung mit der Wellenlänge $193 \mathrm{~nm}$ wurde nur eine $20 \mathrm{~nm}$ dicke Goldschicht vermessen, da aus der Voruntersuchung von Knorr (s. Abbildung 4.9) hervorging, dass sie die höchsten Ramanstreulichtintensitäten liefert. Die Ramanstreu- 
lichtintensitäten sind beinahe über den gesamten vermessenen Fluenzbereich konstant, zeigen aber bei $107 \mathrm{~mJ} / \mathrm{cm}^{2}$ ein Maximum. Darüber hinaus weist der Kurvenverlauf keinerlei Ähnlichkeit zu dem in Abbildung 4.9 auf, was sicherlich darauf zurückzuführen ist, dass hier zusätzlich ein Homogenisator verwendet und wesentlich höhere Fluenzen gewählt wurden. Hinsichtlich der Ramanstreulichtintensitäten ist hervorzuheben, dass sie im konstanten Bereich um einen Faktor 2 und im Maximum um einen Faktor 4 höher ausfallen als beim Klarite ${ }^{\circledR}$-Substrat. Dennoch liegen die für die einzelnen Fluenzen ermittelten Standardabweichungen, die im Kurvenverlauf durch die Fehlerbalken angedeutet sind, teilweise bei über $15 \%$ und weisen starke Schwankungen untereinander auf. Dies ist auf die, im Vergleich zum Klarite ${ }^{\circledR}$-Substrat oder dem Liniengitter, wesentlich größeren räumlichen Inhomogenitäten der Oberflächen zurückzuführen.

Ähnlich hohe Ramanstreulichtintensitäten zeigen auch die Messungen der mit $248 \mathrm{~nm}$ bestrahlten Goldschichten auf, wobei keine Systematik in den fluenz- und schichtdickenabhängigen Ramanstreulichtintensitäten zu sehen ist. Ebenfalls liegen sehr hohe Standardabweichungen von bis zu $50 \%$ vor, die zudem untereinander stark variieren, was wahrscheinlich auf örtliche Inhomogenitäten der Oberflächenstrukturen zurückzuführen ist.

Die höchsten Ramanstreulichtintensitäten und die geringsten Streulichtschwankungen im Vergleich zu den anderen laserbestrahlten Substraten liefern die mit $308 \mathrm{~nm}$ bestrahlten Substrate. Sie weisen zum Einen Ramanstreulichtintensitäten auf, die teilweise 20 mal höher sind als beim Klarite ${ }^{\circledR}$-Substrat, und zum Anderen Standardabweichungen, die für alle Fluenzen kleiner $7 \%$ sind.

Die Kurvenverläufe der gemessenen Ramanstreulichtintensitäten für die mit $351 \mathrm{~nm}$ bestrahlten Goldschichten zeigen alle, bis auf die $20 \mathrm{~nm}$ Goldschicht, eine stetige Zunahme mit steigender Fluenz, wobei aber hohe Unregelmäßigkeiten sowohl im Kurvenverlauf als auch in den Standardabweichungen vorliegen. Desweiteren weisen die Standardabweichungen, die für alle Fälle oberhalb von $10 \%$ liegen, starke Fluktuationen untereinander auf.

Zusammenfassend ist zu bemerken, dass die laserbestrahlten Oberflächen zwar deutlich höhere Ramanstreulichtintensitäten liefern als die regelmäßigen Strukturen, wie das Klarite ${ }^{\circledR}$ - bzw. Gittersubstrat, jedoch ebenfalls auch deutlich höhere Standardabweichungen zeigen. Diese spiegeln die erzeugten unregelmäßigen Strukturen wider. Einzige Ausnahme sind die mit $308 \mathrm{~nm}$ bestrahlten Oberflächen, die Standardabweichungen von kleiner $7 \%$ und zudem die höchsten Ramanstreulichtintensitäten aufweisen. Aus diesem Grund wurden rasterkraftmikroskopische Aufnahmen dieser Oberflächen angefertigt und hinsichtlich der erzeugten Strukturen ausgewertet. 


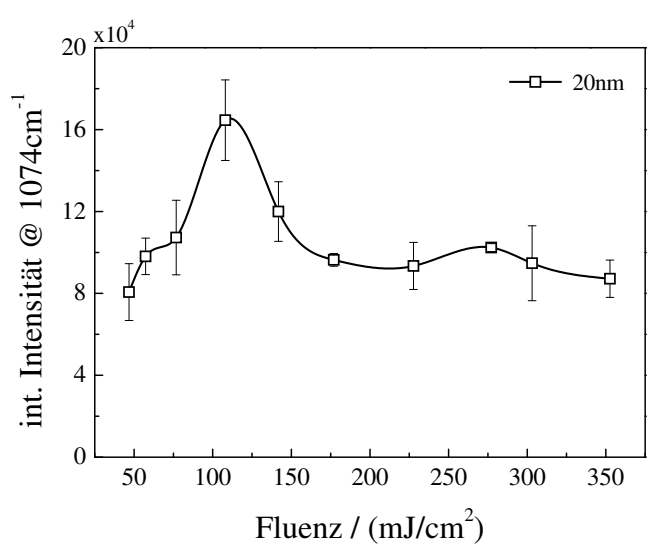

(a)

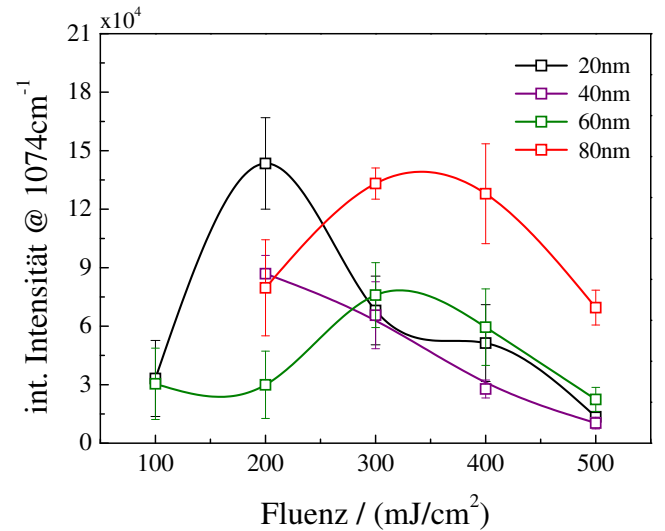

(b)

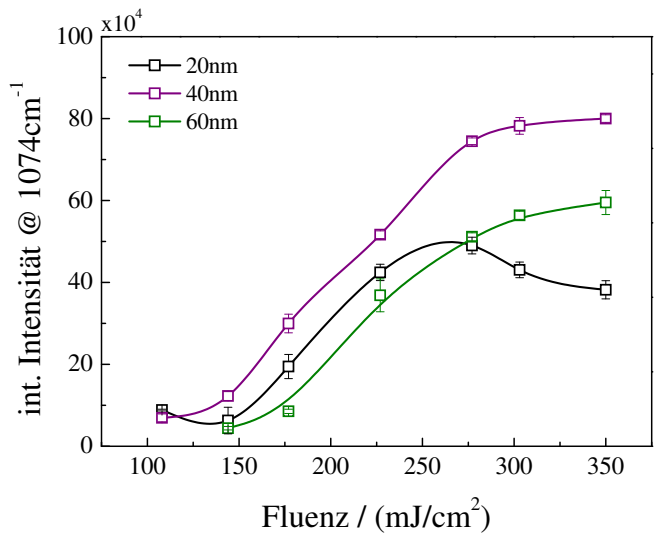

(c)

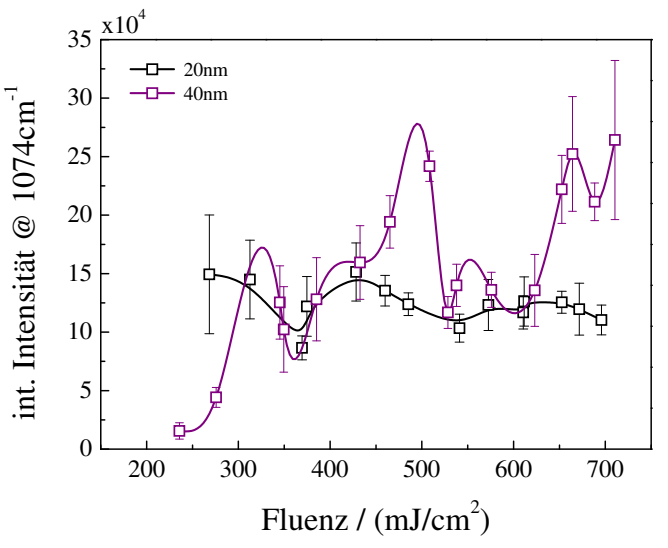

(d)

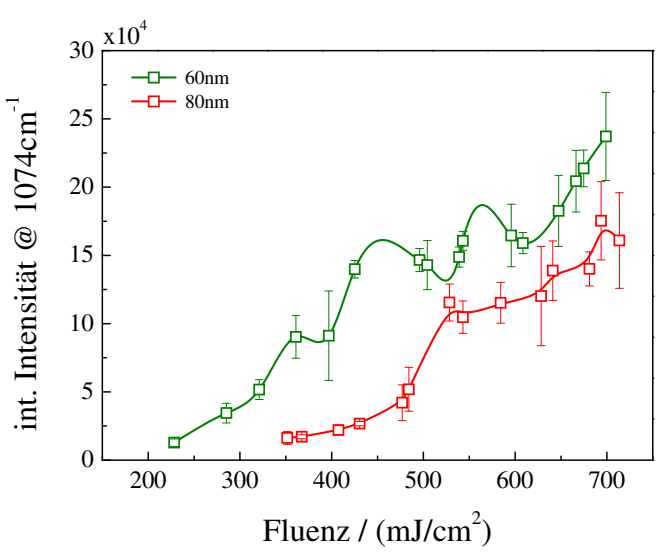

(e)

Abbildung 4.18: Auftragung der integralen Intensitäten der Ramanbande bei $1074 \mathrm{~cm}^{-1}$ des Thiophenols gegen die Fluenzen für (a) $193 \mathrm{~nm}-$ (b) $248 \mathrm{~nm}$ - (c) $308 \mathrm{~nm}-$ (d) und (e) $351 \mathrm{~nm}$-Laserbestrahlung. Die Fehlerbalken geben dabei die Standardabweichung der Ramanstreulichtintensitäten an, die an 15 Positionen auf den jeweiligen Oberflächen gemessen wurden, gemäß der Vorgehensweise wie beim Klarite ${ }^{\circledR}$-Substrat. 


\subsubsection{Topographische Charakterisierung laserbestrahlter Goldschichten}

Zur topographischen Charakterisierung der mit $308 \mathrm{~nm}$ Laserwellenlänge bestrahlten dünnen Goldschichten wurde ein XE-150 Rasterkraftmikroskop (PSIA) verwendet, das mit einem hochauflösenden AR5-NCHR Cantilever (Park Systems) ausgerüstet war. Der Durchmesser der Spitze des Cantilevers betrug $4 \mathrm{~nm}$, so dass die bereits aus elektronenmikroskopischen Aufnahmen abgeschätzten Strukturgrößen hinreichend präzise vermessen werden konnten. Trotz des hohen Aspektverhältnisses von 7:1 des eingesetzten Cantilevers zeigen jedoch einige rasterkraftmikroskopische Aufnahmen Artefakte auf, die keine Auswertung zulassen. Diese Bildartefakte entstehen bei Höhenunterschieden in der Oberflächenstruktur, die so groß sind, dass sie nicht mehr mit dem Rasterkraftmikroskop aufgelöst werden können.

In den Abbildungen 4.19 und 4.20 (links) sind exemplarisch die rasterkraftmikroskopischen Aufnahmen der bestrahlten Oberflächen für den Fall der 20 nm Goldschicht dargestellt. Die Aufnahmen zeigen jeweils einen $1 \mu \mathrm{m}^{2}$ großen Oberflächenausschnitt, in dem die gemessenen Höhen falschfarbenkodiert sind. Bei den Fluenzen von $141 \mathrm{~mJ} / \mathrm{cm}^{2}$ und $177 \mathrm{~mJ} / \mathrm{cm}^{2}$ sind neben den kleinen Partikeln im zweistelligen Nanometerbereich auch sehr viel größere Partikel zu sehen, die, wie bereits geschildert, trotz des hohen Aspektverhältnisses des Cantilevers nicht ausreichend aufgelöst werden können. Auf der rechten Seite der Abbildungen sind zusätzlich die Höhenverteilungen und das so genannte „Bearing-Ratio“ [75] aufgetragen. Darunter wird grundsätzlich das Integral über die Höhenverteilung der Oberfläche verstanden, das in diesem Fall den prozentualen Anteil von Bildpunkten widerspiegelt, deren Höhen unterhalb der repräsentativen Höhe liegen. Das „Bearing-Ratio“ wird typischerweise als Graph dargestellt, in dem die Abszisse die repräsentative Höhe unterhalb der maximalen Höhe und die Ordinate den prozentualen Anteil an Bildpunkten mit der repräsentativen Höhe angibt. Es reflektiert die Rauigkeit der Oberfläche und liefert laut Nowicki [75] deutlich präzisere Aussagen bezüglich der Rauigkeit als die arithmetische Rauigkeitsbestimmung durch den RMS (Root-Mean-Square). Darüber hinaus deutet die Kurvenform des „Bearing-Ratios“ die Topographie der Oberfläche an.

Den Höhenverteilungen aus Abbildung 4.19 und 4.20 ist zu entnehmen, dass bei kleinen Fluenzen (141 und $177 \mathrm{~mJ} / \mathrm{cm}^{2}$ ) vereinzelt große Partikel entstehen, die bei den anderen verwendeten Fluenzen nicht mehr beobachtet werden konnten. Mit diesen Fluenzen werden Partikel mit Partikelhöhen im Bereich zwischen 10 und $70 \mathrm{~nm}$ erzeugt, die eine Normalverteilung um 30 bis $40 \mathrm{~nm}$ aufweisen. 

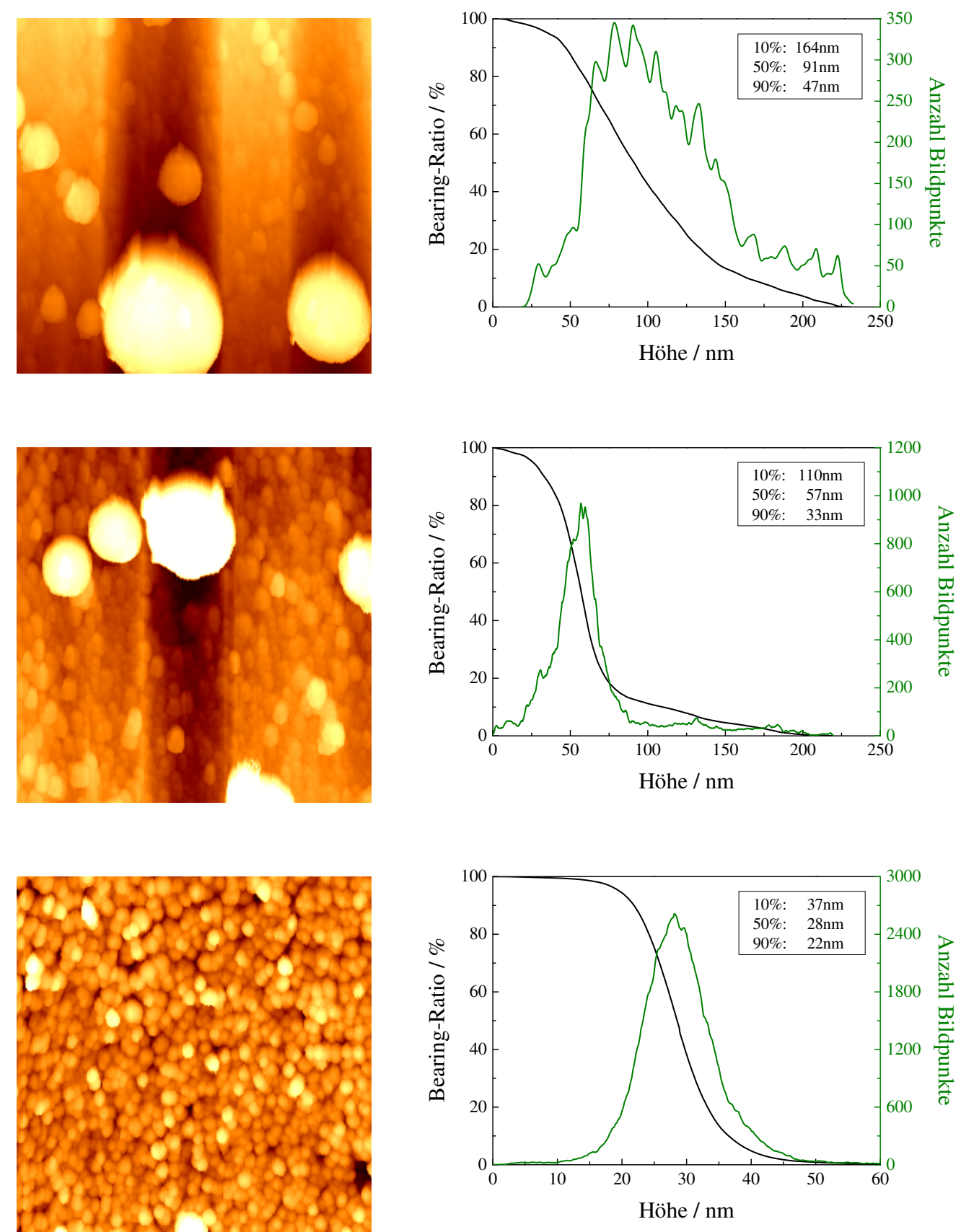

Abbildung 4.19: (Links) Rasterkraftmikroskopische Aufnahme und (rechts) die Höhenverteilung und die Auftragung des „Bearing-Ratio“. (Oben) $141 \mathrm{~mJ} / \mathrm{cm}^{2}$, (Mitte) $177 \mathrm{~mJ} / \mathrm{cm}^{2}$, (Unten) $227 \mathrm{~mJ} / \mathrm{cm}^{2}$. 

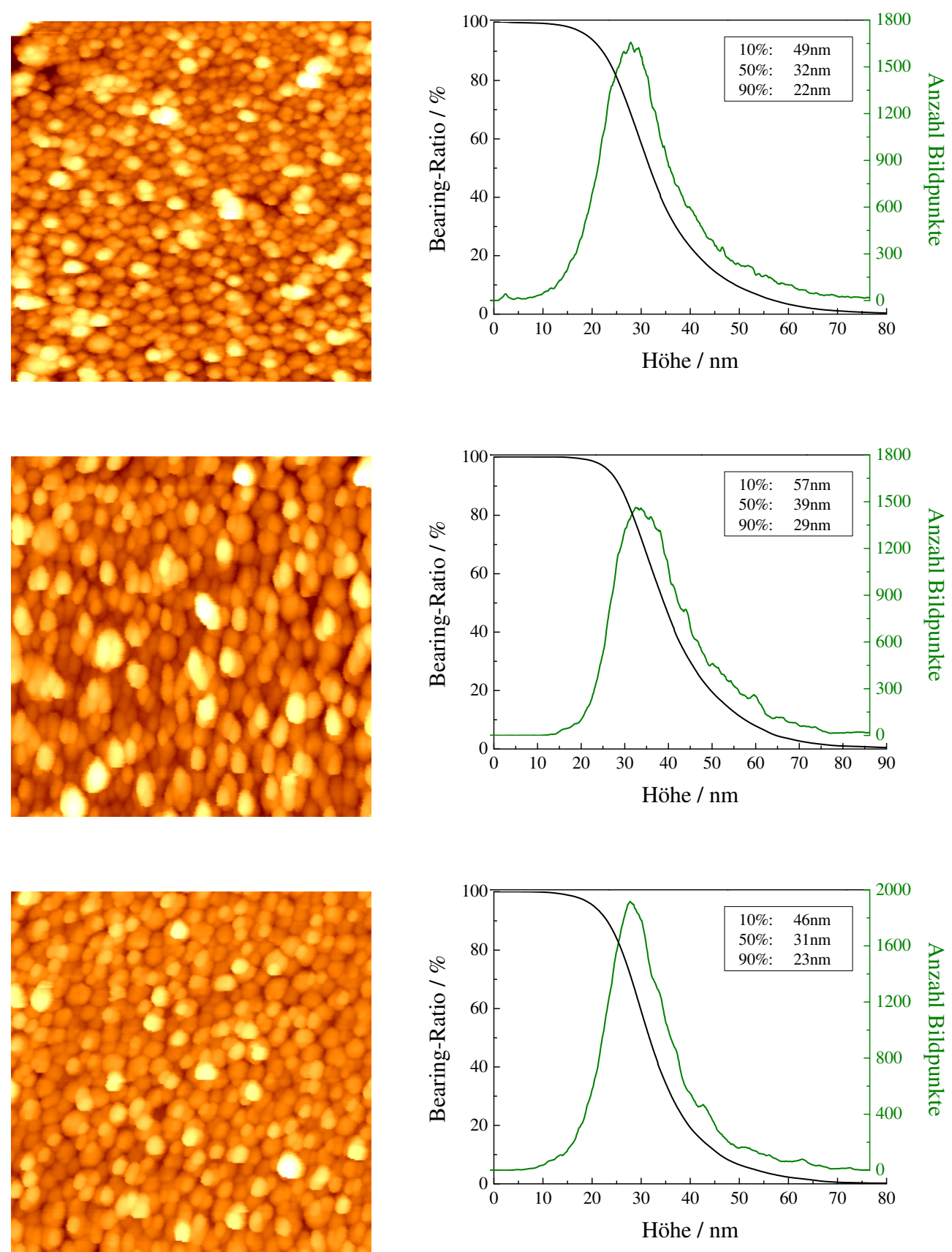

Abbildung 4.20: (Links) Rasterkraftmikroskopische Aufnahme und (rechts) die Höhenverteilung und die Auftragung des „Bearing-Ratio“. (Oben) $277 \mathrm{~mJ} / \mathrm{cm}^{2}$, (Mitte) $308 \mathrm{~mJ} / \mathrm{cm}^{2}$, (Unten) $350 \mathrm{~mJ} / \mathrm{cm}^{2}$. 
Desweiteren ist aus den rasterkraftmikroskopischen Aufnahmen nicht zu erkennen, ob unter den dargestellten Topographien noch weitere Partikelschichten verborgen sind. Um diese Fragestellung zu klären, wurde eine elektronenmikroskopische Aufnahme des Querschnitts eines Substrates erstellt (s. Abbildung 4.21). Aus dieser Aufnahme geht zum Einen hervor, dass nur eine Lage von Goldpartikeln durch die Laserbestrahlung entsteht und zum Anderen, dass ovale Goldpartikel mit einem Achsenverhältnis von ungefähr 1,5:1 vorliegen.

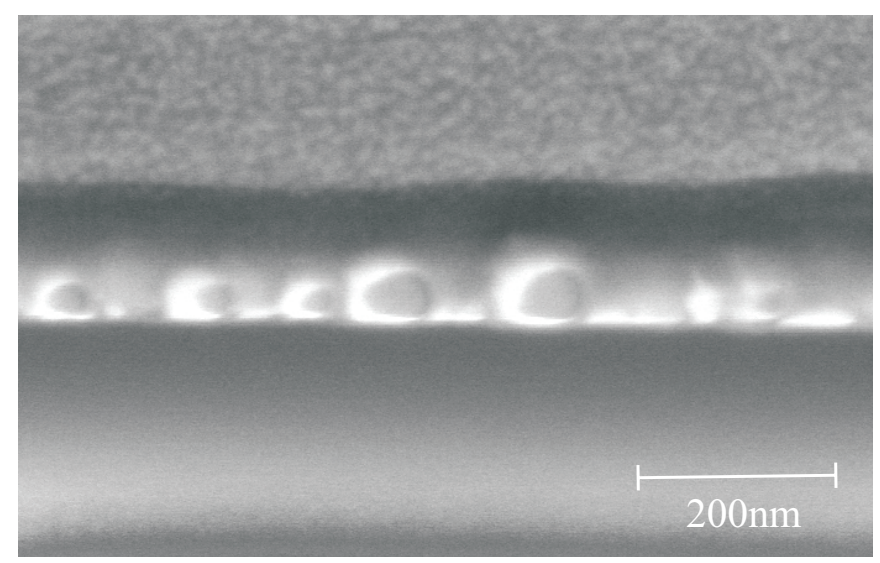

Abbildung 4.21: Elektronenmikroskopische Aufnahme des Querschnitts einer bestrahlten Oberfläche. Dazu wurde die Oberfläche mit einer Platinschicht bedampft und mit einem Ionenstrahl geschnitten.

Obwohl die Häufigkeitsverteilungen der Partikelhöhen auf den Oberflächen sehr ähnlich sind, zeigen die gemessenen Ramanstreulichtintensitäten, die bereits in Abbildung 4.18 (c) dargestellt sind, eine Abhängigkeit von der Fluenz auf. Um eine Korrelation zwischen beiden Parametern feststellen zu können, wurden die Ramanstreulichtintensitäten den durch das „Bearing-Ratio“ erfassten mittleren Partikelhöhen für $10 \%, 50 \%, 90 \%$ aller Bildpunkte in Abbildung 4.22 (links) gegenübergestellt. Ana$\log$ zu dieser Vorgehensweise wurden auch die durch Laserbestrahlung einer $40 \mathrm{~nm}$ dicken Goldschicht erzeugten Partikelverteilungen ausgewertet und zum Vergleich in Abbildung 4.22 (rechts) dargestellt. Darin ist eine qualitative Korrelation zwischen der Partikelhöhe und der Ramanstreulichtintensität für beide Goldschichten zu erkennen. Die Höhenverteilungen der bestrahlten $40 \mathrm{~nm}$ Goldschichten weisen im Vergleich zu den mit $20 \mathrm{~nm}$ dicken Goldschichten hergestellten Nanostrukturen bis zu ca. $20 \mathrm{~nm}$ höhere Partikel auf, die zu höheren Ramanstreulichtintensitäten führen. 

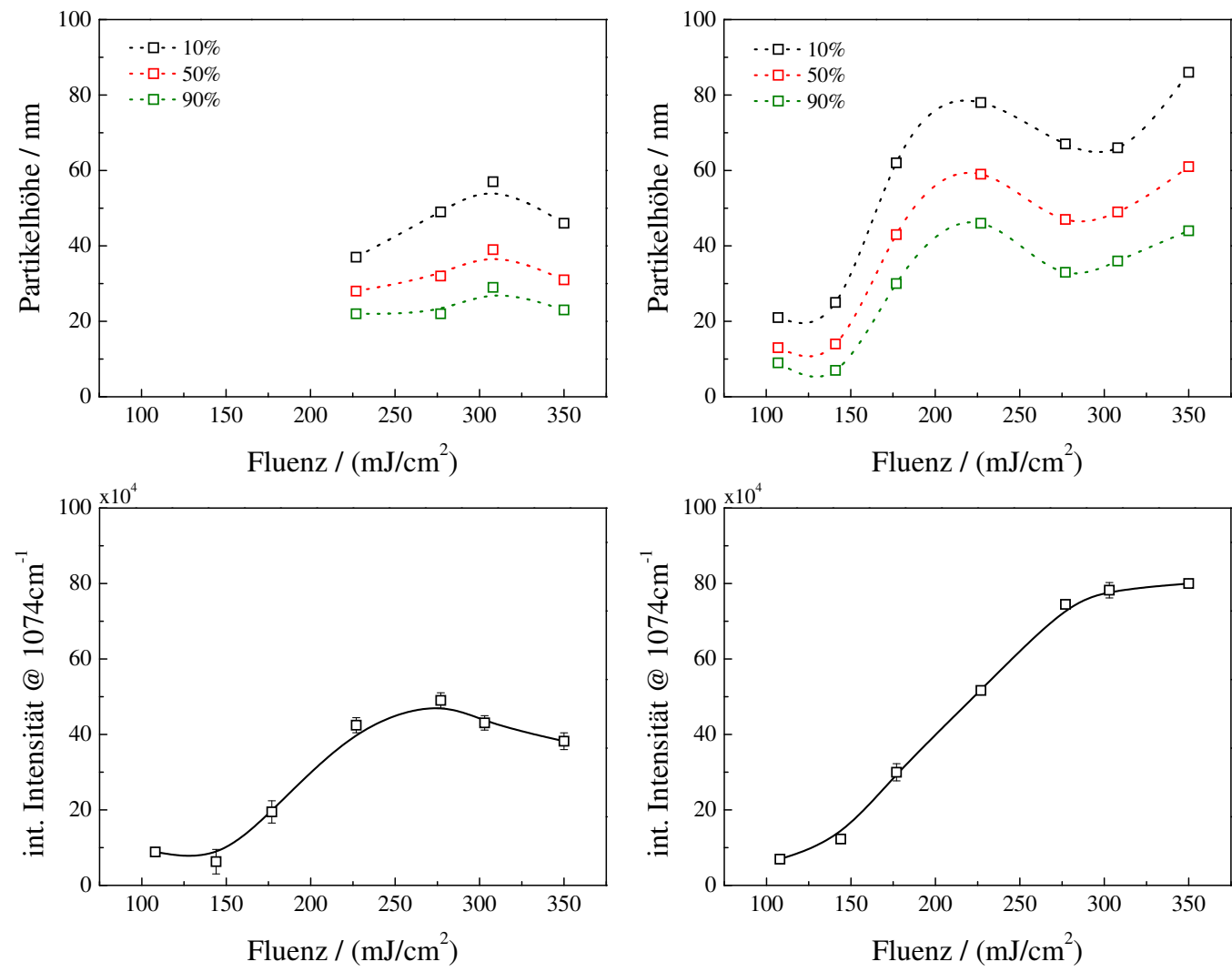

Abbildung 4.22: (Oben) Auftragung der Partikelhöhen in Abhängigkeit von der Fluenz für eine $20 \mathrm{~nm}$ dicke Goldschicht (links) und eine $40 \mathrm{~nm}$ dicke Goldschicht (rechts). Jeweils darunter die Auftragung der dazugehörigen integralen Ramanstreulichtintensitäten gegen die Fluenz.

Wie das folgende Rechenbeispiel demonstriert, können die erhöhten Ramanstreulichtintensitäten lediglich aus einer Erhöhung der Anzahl adsorbierter ThiophenolMoleküle aufgrund der größeren Oberfläche herrühren. Beispielsweise ergeben sich bei der Fluenz von $308 \mathrm{~mJ} / \mathrm{cm}^{2}$ integrale Signalintensitäten von $45 \cdot 10^{4}$ für die bestrahlte $20 \mathrm{~nm}$ Goldschicht und $78 \cdot 10^{4}$ für die bestrahlte $40 \mathrm{~nm}$ Goldschicht, wobei ein mittlerer Partikelhöhenzuwachs von $40 \mathrm{~nm}$ auf $50 \mathrm{~nm}$ für $50 \%$ aller Bildpunkte festgestellt werden kann. Vorausgesetzt, dass die Partikel näherungsweise kugelförmig sind, ergibt sich durch den Partikelhöhenzuwachs von $10 \mathrm{~nm}$ eine 1,6 mal größere bestrahlte Oberfläche, d.h. es können ebenfalls 1,6 mal so viele Thiophenol-Moleküle adsorbieren. Daher sollten auch die Ramanstreulichtintensitäten zwischen den beiden Oberflächen ungefähr um diesen Faktor auseinanderliegen, was durch die Messergebnisse bestätigt wird.

An diesem Beispiel wird deutlich, dass die Anzahl adsorbierter Moleküle direkt mit der Topographie der Oberflächen verknüpft ist, so dass sie einen wesentlichen Bestandteil in der Berechnung von Verstärkungsfaktoren darstellt. Weitere Faktoren sind die 
Laserleistung, die Integrationszeit und die Anzahl der bestrahlten Moleküle, die sich im Messvolumen befinden. Erst unter Berücksichtigung dieser Faktoren können die auf unterschiedliche Art und Weise hergestellten ramanstreulichtverstärkenden Oberflächen hinsichtlich ihrer Verstärkungseigenschaften direkt miteinander verglichen werden.

\subsubsection{Berechnung der Verstärkungsfaktoren}

Für die Berechnung von Verstärkungsfaktoren wurde die Methode von McFarland et al. [69] eingesetzt. Der Verstärkungsfaktor lässt sich dadurch berechnen, indem die auf der nanostrukturierten Oberfläche gemessene Ramanstreulichtintensität einer Thiophenol-Ramanbande, in diesem Fall die Bande bei $1074 \mathrm{~cm}^{-1}$, mit der Intensität der Ramanbanden des flüssigen Thiophenols verglichen wird. Unter der Voraussetzung, dass die Ramanstreulichtintensität auf die Laserleistung und die Integrationszeit normiert ist, lässt sich der Verstärkungsfaktor nach

$$
\Omega=\frac{N_{F} \cdot I_{O}}{N_{O} \cdot I_{F}} \cdot \frac{1}{G}
$$

berechnen, wobei $N_{F}, N_{O}$ die Anzahl der bestrahlten Moleküle im flüssigen Thiophenol beziehungsweise auf der Oberfläche ist, und $I_{F}$ und $I_{O}$ die dazugehörigen spontanen beziehungsweise oberflächenverstärkten Ramanstreulichtintensitäten beschreiben. Der Faktor $G$ beschreibt die Zunahme der Oberfläche nanostrukturierter Substrate im Vergleich zu einer Oberfläche mit atomarer Rauigkeit. Während die Anzahl der Thiophenol-Moleküle auf einer Goldoberfläche mit atomarer Rauigkeit nach Wan et al. mit $0,709 \mathrm{nmol} / \mathrm{cm}^{2}$ bekannt ist, ist zunächst die Größe des Messvolumens, das vom Laserspotdurchmesser vorgegeben wird, unbekannt. Es ist daher notwendig, den effektiven Laserspotdurchmesser auf der Oberfläche experimentell zu bestimmen. Dies wurde mit der so genannten Knife-Edge Methode [44] durchgeführt. Sie ist eine schnelle und präzise Methode zur Bestimmung des Querschnitts von Laserstrahlen mit einem gaussförmigen Profil und benötigt dafür eine scharfe Kante, z.B. eine Rasierklinge, eine Verfahreinheit mit einstellbarer Schrittweite im Mikrometerbereich und ein Leistungsmessgerät, die wie in Abbildung 4.23 (a) angeordnet sind. Während die Klinge, die anfänglich den gesamten Laserstrahl blockiert, senkrecht zur Ausbreitungsrichtung des Laserstrahls inkrementell aus dem Strahl herauswandert, zeichnet ein Leistungsmessgerät die Laserleistung auf. Im Falle eines Gaussprofils lässt sich der funktionelle Zusammenhang des detektierten Leistungsverlaufs $P(x)$ über eine Fehlerfunktion (erf $)$ herstellen (s. Gleichung 4.4), die durch das einfache Ableiten in eine Gaussfunktion $P^{\prime}(x)$ übergeht. $P_{0}$ beschreibt dabei die Ausgangsleistung und $r$ den Radius, bei dem 
die auf Eins normierte Funktion $P^{\prime}(x)$ auf $1 / e^{2}$ in der Gausskurve abgefallen ist.

$$
P(x)=P_{0} r \sqrt{\frac{\pi}{8}} \operatorname{erf}\left(\frac{\sqrt{2} x}{r}\right)
$$

Abbildung 4.23 (b) stellt den Leistungsverlauf einer am Ramanspektrometer durchgeführten Knife-Edge Messung dar.

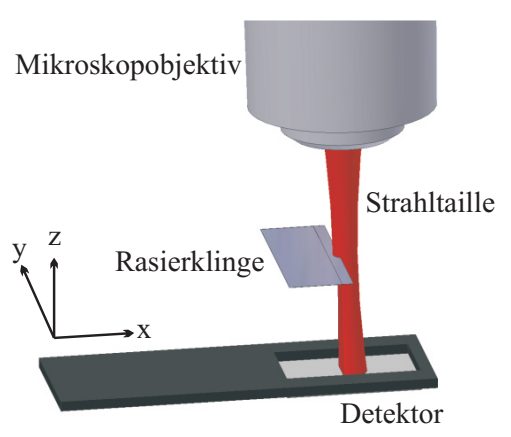

(a) Typischer Aufbau für die Knife-Edge Messung.

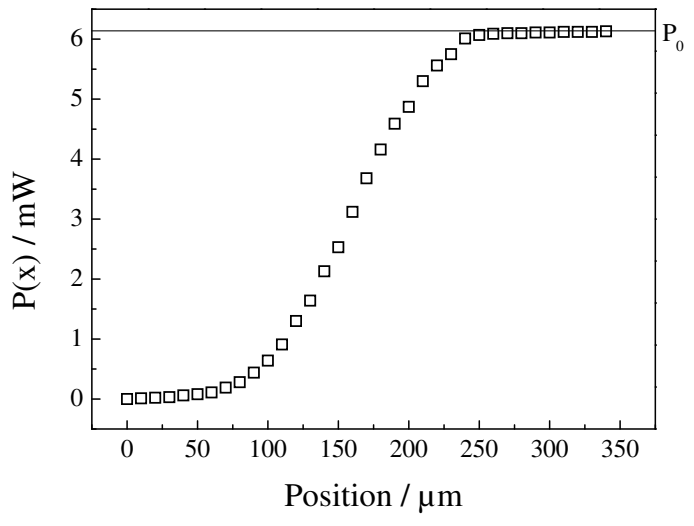

(b) Leistungsverlauf $P(x)$.

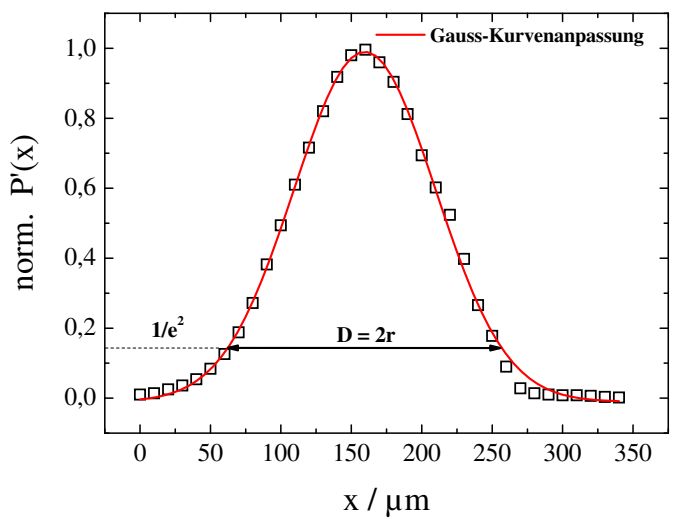

(c) 1. Ableitung von $P(x)$.

Abbildung 4.23: Vorgehensweise zur Bestimmung des effektiven Laserspotdurchmessers $D$.

Es ist der erwartete Funktionsverlauf $P(x)$ zu erkennen. Die Ausgangsleistung beträgt in diesem Fall 6,2 $\mathrm{mW}$ und die Schrittweite $10 \mu \mathrm{m}$. Der Kurvenverlauf der 1. Ableitung wird geglättet, damit kleine Schwankungen im Kurvenverlauf unterdrückt werden. Dazu wird ein Algorithmus eingesetzt, der die 1. Ableitung des Mittelwertes zweier benachbarter Datenpunkte i ausführt und von folgendem funktionalen Zusammenhang ist:

$$
P^{\prime}(x)=\frac{d P(x)}{d x}=\frac{1}{2}\left(\frac{P_{i+1}-P_{i}}{x_{i+1}-x_{i}}+\frac{P_{i}-P_{i-1}}{x_{i}-x_{i-1}}\right) .
$$

In Abbildung 4.23 (c) ist der auf Eins normierte Kurvenverlauf der ersten Ableitung 
von $P(x)$ dargestellt, der mit einer Gaussfunktion angepasst ist. Daraus ergibt sich ein Laserspotdurchmesser von $\mathrm{D}=203 \mu \mathrm{m}$. Um den Einfluss möglicher Fehlerquellen in dem Verfahren zu minimieren, wurde die Messung zwei weitere Male durchgeführt. Daraus resultierte ein mittlerer effektiver Laserspotdurchmesser von $\mathrm{D}=217 \pm 15 \mu \mathrm{m}$, der sich mit den Berechnungen aus Kapitel 3.1 Abschnitt 3.1.3 deckt.

Die Ramanstreulichtmessung im flüssigen Thiophenol wurde in einer Quarzglasküvette mit einer Schichtdicke von $100 \mu \mathrm{m}$ durchgeführt. Unter der Annahme eines zylindrischen Messvolumens mit einem Durchmesser, der dem des Laserspots entspricht, resultiert ein zum Signal beitragendes Volumen von 3,6 nl. Mit der Dichte $\rho_{T h}=1,08 \mathrm{~g} / \mathrm{cm}^{-3}$ und der molaren Masse $\mathrm{M}_{T h}=110,18 \mathrm{~g} / \mathrm{mol}$ von Thiophenol berechnet sich eine Molekülanzahl von $N_{F}=2,1 \cdot 10^{16}$. Unter Berücksichtigung des Platzbedarfes von $0,709 \mathrm{nmol} / \mathrm{cm}^{2}$ der Thiophenol-Moleküle auf einer Goldoberfläche mit atomarer Rauigkeit und des Laserspotdurchmessers geht eine zum Signal beitragende Molekülanzahl von $N_{O}=1,6 \cdot 10^{11}$ hervor. Sowohl der berechnete Faktor $G$ als auch alle weiteren relevanten Informationen sowie die berechneten Verstärkungsfaktoren sind in der folgenden Tabelle für die Klarite ${ }^{\circledR}$ _Oberfläche, das Liniengitter und die mittels 308 nm Excimerlaserbestrahlung erzeugte Oberfläche bei der Fluenz von $350 \mathrm{~mJ} / \mathrm{cm}^{2}$ zusammengefasst. Im Fall der laserbestrahlten Oberfläche wurde für die Berechnung von $G$ eine dicht gepackte Lage von Halbkugeln mit dem Radius $R$ in erster Näherung angenommen, so dass für $G=2 \pi R^{2} /(2 R)^{2}=\pi / 2$ resultiert.

\begin{tabular}{ccccc}
\hline Oberfläche & & $G$ & $I_{O}$ (int. Intensität @ $\left.1074 \mathrm{~cm}^{-1}\right)$ & $\Omega$ \\
\cline { 1 - 1 } \cline { 5 - 6 } Klarite $^{\circledR}$ & & 1,24 & $4,1 \cdot 10^{4}$ & \\
Gitter & 1,4 & $4,2 \cdot 10^{4}$ & \\
Laserbestrahlung & $\frac{\pi}{2}$ & $8 \cdot 10^{5}$ & $2,2 \cdot 10^{5}$ \\
\hline
\end{tabular}

Tabelle 4.2: Zusammenstellung der für die Berechnung der Verstärkungsfaktoren benötigten Parameter sowie die Verstärkungsfaktoren.

Desweiteren wurde $I_{F}$ anhand der Ramanstreulichtmessung vom flüssigen Thiophenol in der Küvette zu $I_{F}=17,5 \cdot 10^{3}$ in Einheiten der integralen Intensität ermittelt. Wie der Tabelle 4.2 entnommen werden kann, erzielt die durch Laserbestrahlung erzeugte Oberfläche den höchsten Verstärkungsfaktor, der eine Größenordnung über dem der anderen Substrate liegt. Ein Vergleich dieses Verstärkungsfaktors mit der Literatur ist derzeit nicht möglich, da bisher noch keine Veröffentlichungen von vergleichbaren Oberflächen für ramanspektroskopische Anwendungen bei einer Anregungswellenlänge von $785 \mathrm{~nm}$ ausfindig gemacht werden konnten. Häufig sind Verstärkungsfaktoren von Silberinselfilmen dokumentiert, wie beispielsweise in der Veröffentlichung von Weitz [111], oder in seltenen Fällen auch von Goldinselfilmen [103], die jedoch wesent- 
lich kleinskaligere Strukturgrößen von bis zu maximal $10 \mathrm{~nm}$ im Durchmesser aufweisen. Für diese unregelmäßigen Strukturen werden Verstärkungsfaktoren zwischen $10^{5}$ und $10^{7}$ angegeben.

\subsection{Fazit}

In diesem Kapitel wurden unterschiedliche Verfahren zur Herstellung ramanstreulichtverstärkender Oberflächen vorgestellt. Dabei wurden die erzeugten Oberflächen zum Einen durch rasterkraft- bzw. elektronenmikroskopische Aufnahmen topographisch charakterisiert und zum Anderen hinsichtlich Signalreproduzierbarkeit und Verstärkungsfaktor mittels selbstorganisierter Thiophenol-Monolagen untersucht.

Dabei zeigt sich, dass vor allem die Oberflächen mit den regelmäßigen Strukturen, wie die des originalen und replizierten Klarite ${ }^{\circledR}$-Substrats sowie die des Liniengitters, sehr gute Signalreproduzierbarkeiten mit ortsabhängigen Signalschwankungen kleiner $5 \%$ Standardabweichung aufweisen bei Verstärkungsfaktoren in der Größenordnung von $10^{5}$. Darüber hinaus zeigen die Ergebnisse der oberflächenverstärkten Ramanstreulichtmessungen an einer Thiophenol-Monolage auf dem Liniengitter Verstärkungsfaktoren, die etwas höher ausfallen als die mit der Simulation vorhergesagten. Eine mögliche Erklärung stellt die Tatsache dar, dass bei der Simulation mit einem idealen stufenförmigen Liniengitter gerechnet wurde und somit weder die Parameter Oberflächenrauigkeit noch das exakte Profil des Liniengitters in die Simulation einflossen. Eine weitere Erklärung für die Differenz der Verstärkungsfaktoren könnte der chemische Verstärkungseffekt sein, der ebenfalls nicht mit in der Simulation berücksichtigt wurde. Untersuchungen mit denselben Versuchsbedingungen auf einer mit Thiophenol beschichteten Goldoberfläche mit atomarer Rauigkeit zeigten aber auf, dass der chemische Verstärkungseffekt keinen messbaren Einfluss auf den Verstärkungsfaktor hat, da kein Ramanstreulicht vom Thiophenol detektiert werden konnte. Aus diesem Grund kann der elektromagnetische Verstärkungseffekt als der dominierende Faktor für die Ramanstreulichtverstärkung angesehen werden.

Bei der Berechnung der Verstärkungsfaktoren fällt auf, dass sowohl das Klarite ${ }^{\circledR}$ Substrat als auch das Liniengitter-Substrat beinahe identische Verstärkungsfaktoren bei ebenfalls fast identischer Molekülanzahl aufweisen, obwohl sie völlig unterschiedliche Topographien besitzen. Zwar wird die Topographie durch den Faktor $G$ in Gleichung 4.2 zur Berechnung des Verstärkungsfaktors berücksichtigt, jedoch ist darin nicht die räumliche Ausdehnung der Feldverstärkungen enthalten sowie deren Lokalisierung auf der Oberfläche. Damit ist die Anzahl der Moleküle im Bereich maximaler Feldstärken unbekannt. 
Die elektrischen Felderhöhungen sind wahrscheinlich zum Einen in den interpartikulären Bereichen der durch Laserbestrahlung erzeugten Nanostrukturen und zum Anderen in den Pyramidenspitzen und „Kanten“ der Klarite ${ }^{\circledR}$ - bzw. Gitterstrukturen bevorzugt lokalisiert. Die Reichweite der Felderhöhungen korreliert dabei mit den gemessenen Plasmonenresonanzen im Nah- und Fernfeld [95], so dass sich die Reichweite der Feldverstärkungen der untersuchten Oberflächen untereinander stark unterscheiden können.

Daher ist das Ergebnis, dass die Verstärkungsfaktoren des Klarite ${ }^{\circledR}$ und Gittersubstrats beinahe identisch sind, ein komplexes Zusammenspiel aus vielen Faktoren. Demnach kann aufgrund der Lokalisierung der elektrischen Feldverstärkungen und deren Reichweiten eine Abhängigkeit zwischen dem Verstärkungsfaktor und der Größe der bestrahlten Moleküle angenommen werden. Denn je größer ein Molekül ist, desto kleiner ist das Verhältnis zwischen der Anzahl der Moleküle und der von ihnen eingenommene Raum, in dem die Feldverstärkungen auftreten.

Unter dieser Voraussetzung relativieren sich die in der Literatur angegebenen hohen Verstärkungsfaktoren von bis zu 14 Größenordnungen, wie im Fall der in Kapitel 2 bereits erwähnten Veröffentlichung von Kneipp et al.. In diesen Untersuchungen wurden die Ramanstreulichtmessungen beinahe lokal im Bereich maximaler Feldverstärkungen, in den so genannten „hot-spots“, mittels eines sehr kleinen Fokus von nur ca. $1 \mu \mathrm{m}$ Durchmesser durchgeführt. Unter diesen Bedingungen ist der berechnete Verstärkungsfaktor gegenüber konventionellen Ramanstreulichtmessungen nicht über den typischerweise einige hundert Mikrometer großen Laserfokus auf der Oberfläche örtlich gemittelt, sondern beschränkt sich auf einen Bruchteil davon. Aus diesem Grund bestimmt die Dichte der lokalisierten Bereiche, in denen Feldverstärkungen auftreten, in entscheidendem Maße den berechneten Verstärkungsfaktor.

So zeigen beispielsweise die mit dem Excimerlaser bestrahlten Oberflächen höhere Verstärkungsfaktoren auf, da sie eine sehr dichte Anhäufung von Goldpartikeln mit geringen interpartikulären Abständen von wenigen Nanometern aufweisen, wie den rasterkraftmikroskopischen Aufnahmen zu entnehmen ist. Laut Theorie (s. Kapitel 2) sind insbesondere die sehr geringen interpartikulären Abstände für hohe Feldverstärkungen verantwortlich.

Der Großteil der mittels Laserbestrahlung erzeugten Nanostrukturen weist sehr hohe ortsabhängige Signalschwankungen von teilweise bis zu $50 \%$ Standardabweichung auf. Derart hohe Standardabweichungen sind mit hoher Wahrscheinlichkeit auf eine inhomogene Verteilung und Größe der erzeugten Partikel zurückzuführen. Eine ausführliche rasterkraftmikroskopische Untersuchung der erzeugten Nanostrukturen wurde aufgrund des unverhältnismäßigen zeitlichen Messaufwands und der Vielzahl an generier- 
ten Oberflächen lediglich auf die Oberflächen, die mit der Wellenlänge von $308 \mathrm{~nm}$ bestrahlt wurden, beschränkt. Sie weisen sowohl sehr hohe Verstärkungsfaktoren als auch gute Signalreproduzierbarkeiten im Vergleich zu den anderen durch Laserbestrahlung erzeugten Oberflächentopographien auf. Die Gründe für dieses Ergebnis sind sicherlich vielfältig und zur Zeit nicht vollständig verstanden, doch liefern die elektronenstrahlmikroskopischen Aufnahmen der durch $308 \mathrm{~nm}$ Laserwellenlänge erzeugten Nanostrukturen aufschlussreiche Hinweise. Beinahe alle rasterkraftmikroskopische Aufnahmen zeigen mittlere Partikelhöhenverteilungen, die sich nur wenig voneinander unterscheiden. Desweiteren korrelieren die fluenzabhängigen Ramanstreulichtintensitäten mit der Partikelgröße, und zwar unmittelbar mit der Oberfläche, unter Vernachlässigung der damit einhergehenden möglichen Variation der Anzahl von „hot-spots“.

Ein großer Vorteil der durch Laserbestrahlung erzeugten Oberflächen liegt im Herstellungsverfahren, bei dem lediglich die Bestrahlung einer dünnen Goldschicht mit einem einzigen Laserpuls ausreicht und nicht wie die meisten anderen Verfahren mehrere aufwendige Arbeitsschritte benötigt.

Trotz dieser vielversprechenden Voraussetzungen wurde in dieser Arbeit auf den Einsatz laserbestrahlter Oberflächen für die Identifizierung und Quantifizierung von Proteinen verzichtet, da die Einflussfaktoren auf die erzeugten Strukturen derzeit noch nicht ausreichend untersucht sind. Dazu gehört u.a. die für ältere Generationen von Excimerlasern, wie sie in der vorliegenden Arbeit verwendet wurden, typische Leistungsschwankung von $10 \%$ Standardabweichung. Außerdem ist bisher ungeklärt, warum die Wellenlänge von $308 \mathrm{~nm}$ zu Oberflächen mit hoher Signalreproduzierbarkeit und hohen Verstärkungsfaktoren führt.

Aufgrund der nicht vollständig verstandenen Prozesse bei der Herstellung der durch Laserbestrahlung erzeugten ramanstreulichtverstärkenden Oberflächen sowie der nur begrenzten Anzahl der durch die UV-Nanoimprint Lithographie hergestellten Substrate, wurden diese in der vorliegenden Arbeit nicht für die Identifizierung und Quantifizierung von Proteinen eingesetzt, sondern nur das kommerziell erhältliche Klarite ${ }^{\circledR}$ Substrat. Es lag zum Zeitpunkt der quantitativen und qualitativen Untersuchungen von Proteinen in dieser Arbeit eine ausreichende Stückzahl dieser Susbtrate vor. 


\section{Kapitel 5}

\section{Ramanstreulichtmessungen an klinisch relevanten Proteinlösungen}

In diesem Kapitel werden Konzentrationsmessungen von wässrigen Lösungen klinisch relevanter Biomoleküle, wie sie beispielsweise in der Körperflüssigkeit Blut vorliegen, mit Hilfe der Ramanspektroskopie vorgestellt. Diese Messungen sollen aufzeigen, ob mit dem selbstentwickelten Ramanspektrometer Nachweisgrenzen erreicht werden können, die in physiologisch relevanten Konzentrationsbereichen liegen. Desweiteren dienen diese Messungen als Vergleichskriterium für die in dieser Arbeit durchgeführten quantitativen Ramanstreulichtmessungen von Biomolekülen, wobei der Schwerpunkt auf den Proteinen lag. Aus einer Fülle von mehreren Hundert verschiedener im Blut enthaltener Biomoleküle wurden exemplarisch die Glukose, das Cholesterin und die Proteine Albumin und $\gamma$-Globulin (Sigma-Adlrich) ausgewählt und in Wasser gelöst. Wasser eignet sich besonders gut als Lösungsmittel, da sein Ramanspektrum in dem so genannten „finger-print“ Bereich durch die intermolekularen Wechselwirkungen [12] sehr schwach und breitbandig ist. Zudem ist Wasser der Hauptbestandteil des Blutes (prozentualer Anteil ca. 90\%) und ist somit ein realitätsnahes Lösungsmittel.

Im Allgemeinen treten bei der Anregung biologischer Moleküle im sichtbaren Spektralbereich häufig laserinduzierte Fluoreszenzen [26] auf, da viele biologische Moleküle so genannte Fluorophore besitzen. Dabei handelt es sich um Molekülgruppen, die zur Fluoreszenz angeregt werden können. Diese Fluoreszenzintensitäten sind jedoch häufig um etliche Größenordnungen höher als die des schwachen Ramanstreulichtes, so dass die schwachen Ramanbanden von den Fluoreszenzbanden teilweise vollständig überlagert werden und nicht mehr detektierbar sind. Aus diesem Grund wurden die erwähnten biologischen Moleküle in der vorliegenden Arbeit mit einer Wellenlänge von $785 \mathrm{~nm}$ angeregt, da die Effizienz der Fluoreszenzanregung bei dieser Wellenlänge wesentlich kleiner im Vergleich zu kürzeren Anregungswellenlängen ist (s. Kapitel 2).

Für die Umsetzung der quantitativen Ramanstreulichtmessungen wurden wässrige Stammlösungen der bereits erwähnten Biomoleküle angefertigt und in einer Konzentrationsreihe bis unterhalb der physiologischen Konzentrationsbereiche im Blut eines 
gesunden Menschen, die in Tabelle 5.1 aufgelistet sind, verdünnt. Im Fall des Cholesterins wurde das Lösungsmittel Methanol (Sigma-Aldrich) verwendet, da das Cholesterin in Wasser nicht löslich ist. Im Blut liegt es als Lipoprotein vor, das sich aus einem Cholesterin-Molekül und einer Hülle aus Lipiden und Eiweissen zusammensetzt. Erst durch den Einsatz von Methanol können Lösungen von Cholesterin in physiologisch relevanten Konzentrationsbereichen realisiert werden.

\begin{tabular}{|c|c|c|c|c|}
\hline & \multicolumn{2}{|c|}{ Konzentrationsbereich } & \multirow[t]{2}{*}{ molare Masse/kDa } & \multirow[t]{2}{*}{ Dichte/(g/l) } \\
\hline & Untere Grenze & Obere Grenze & & \\
\hline Albumin & $500 \mu \mathrm{mol} / \mathrm{l}$ & $700 \mu \mathrm{mol} / \mathrm{l}$ & 66,3 & 1364 \\
\hline$\gamma$-Globulin & $35 \mu \mathrm{mol} / 1$ & $80 \mu \mathrm{mol} / 1$ & 157 & 1353 \\
\hline Glukose & $3,5 \mathrm{mmol} / \mathrm{l}$ & $6 \mathrm{mmol} / \mathrm{l}$ & 0,18 & 1562 \\
\hline Cholesterin & $3 \mathrm{mmol} / \mathrm{l}$ & $5,6 \mathrm{mmol} / \mathrm{l}$ & 0,386 & 1070 \\
\hline
\end{tabular}

Tabelle 5.1: Physiologische Konzentrationsbereiche von Albumin, $\gamma$-Globulin, Glukose und Cholesterin im menschlichen Blut eines gesunden Menschen [77].

\subsection{Experimenteller Aufbau}

Für die Streulichtmessungen wurde der Sensorkopf gemäß Abbildung 5.1 modifiziert, so dass die Lösungen in einer handelsüblichen verschließbaren Quarzglasküvette (Starna) mit der Wandstärke von $1 \mathrm{~mm}$ und der Schichtdicke von $1 \mathrm{~cm}$ vermessen werden konnten. Die eingesetzte Küvette zeichnete sich vor allem durch die Reinheit des zum Bau verwendeten Quarzglases (Suprasil) aus, das zu deutlich geringeren Querempfindlichkeiten im Ramanspektrum der un-

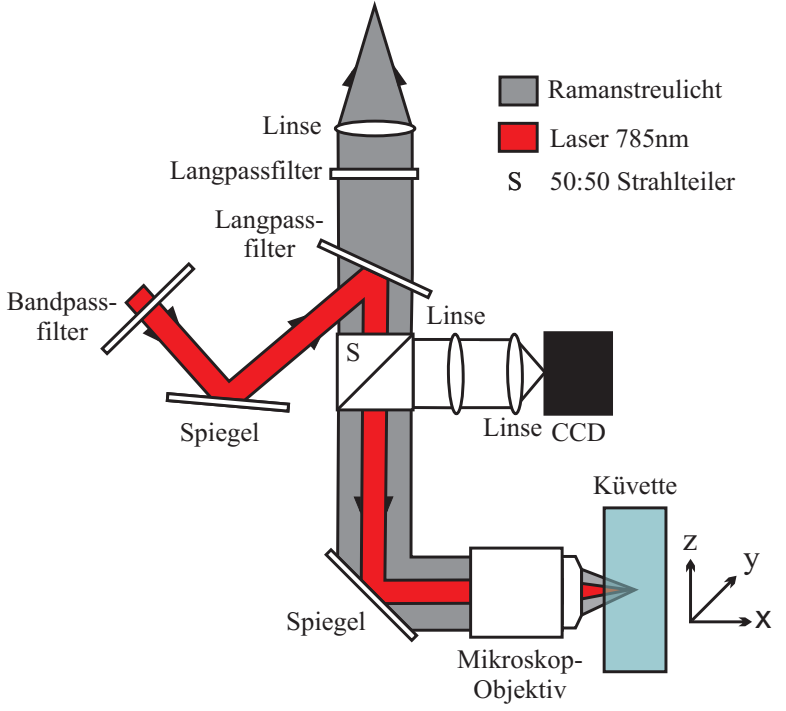

Abbildung 5.1: Schematsiche Darstellung des veränderten Sensorkopfes für die Ramanstreulichtmessung in wässrigen Lösungen. zu herkömmlichen Gläsern führte. Einflüsse auf die Ramanstreulichtmessung, wie die Absorption der Moleküle bzw. die Streulichtverluste durch eine Trübung der Lösungen, konnten durch gezielte Positionierung der Fokusebene in unmittelbarer Nähe zur inneren Wandung der Küvette auf ein Minimum reduziert werden. 
In Abbildung 5.2 sind exemplarisch die Ramanrohspektren von Wasser (links) und einer $600 \mu \mathrm{M}$ wässrigen Albumin-Lösung (rechts) dargestellt. Die farbig gekennzeichneten Felder in den Ramanspektren zeigen ungewöhnliche Intensitätseinbrüche auf, die auf den $830 \mathrm{~nm}$-Langpassfilter im Sensorkopf zurückzuführen sind. Der eingesetzte Langpassfilter weist s- und p-polarisationsabhängige Transmissionseigenschaften auf, die neben der filtertypischen Transmissionskante bei $300 \mathrm{~cm}^{-1}$ (grünes Feld) zu einer weiteren Transmissionskante im Ramanspektrum führen (rotes Feld, dazu siehe auch Abbildung 3.4 in Abschnitt 3.1.2).
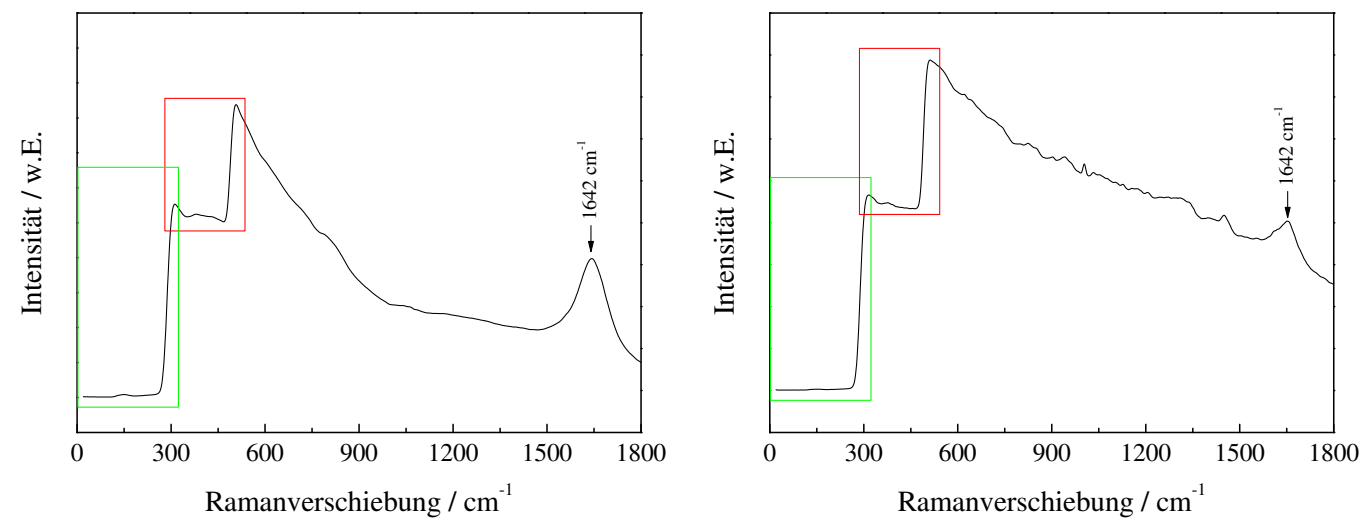

Abbildung 5.2: (Links) Ramanspektrum von Wasser. (Rechts) Ramanspektrum von einer $600 \mu \mathrm{M}$ Albumin-Lösung.

Diese Transmissionskanten stellten aber kein Hindernis für die Auswertungen der Ramanspektren dar, weil die meisten Ramanbanden von Biomolekülen zwischen 600 und $1800 \mathrm{~cm}^{-1}$ liegen und damit nicht von diesen Transmissionskanten betroffen sind.

Im Vergleich beider Ramanspektren fallen sowohl die sehr geringen Bandenintensitäten des Albumins als auch die stark unterschiedlichen Intensitätsverläufe auf. Im Ramanspektrum des Wassers ist im Wesentlichen die Ramanbande von Wasser bei $1642 \mathrm{~cm}^{-1}$ [12] und ein breiter unspezifischer Untergrund zu sehen. Dieser ist auf Streulichtanteile zurückzuführen, die zum Einen aus den optischen Komponenten im Sensorkopf und zum Anderen aus dem Quarzglas der Küvette herrühren. Im Ramanspektrum des Albumins sind neben der ausgeprägten Ramanbande des Wassers bei $1642 \mathrm{~cm}^{-1}$ zusätzlich die dazu im Vergleich sehr viel schwächeren Albumin-Ramanbanden zu erkennen. Die auffälligen großen Unterschiede zwischen den Intensitätsverläufen des Wassers und der wässrigen Albumin-Lösung sind mit hoher Wahrscheinlichkeit auf die Anregung von laserinduzierter breitbandiger Fluoreszenz der aromatischen Aminosäuren Tryptophan, Tyrosin und Phenylalanin des Proteins Albumin zurückzuführen, wodurch die Subtraktion des Wasser-Ramanspektrums vom Albumin-Ramanspektrum zur Auflösung der schwachen Albumin-Ramanbanden ungeeignet ist. 
Eine effektive Methode zur Unterdrückung spektraler breitbandiger Untergründe, wie sie überwiegend von der laserinduzierten Fluoreszenz herrühren, stammt von C.A. Lieber und A. Mahadevan-Jansen [61], die einen Algorithmus zur automatischen Basislinienkorrektur entwickelt haben. Er zeichnet sich gegenüber den bisherigen und häufig eingesetzten Verfahren, wie die 1. und 2. Ableitung, die Wavelet-Transformation oder die manuelle Frequenzfilterung dadurch aus, dass die Ramanbanden nicht deformiert werden, keine Artefakte auftauchen und keine Informationsverluste durch falsche Frequenzangaben wie bei der Frequenzfilterung stattfinden. Da beinahe alle in der vorliegenden Arbeit untersuchten biologischen Moleküle mit einem breitbandigen unspezifischen Untergund behaftet waren, bot die auf der polynomiellen Kurvenanpassung basierende automatische Basislinienkorrektur eine schnelle und präzise sowie reproduzierbare Methode zur Reduzierung des Spektrums auf die reinen Ramanbanden. Dieser Algorithmus wird wegen seiner hohen Relevanz für die quantitative Analyse von biologischen Molekülen im folgenden Abschnitt näher beschrieben und wurde für die Auswertung der Ramanspektren in Matlab implementiert (Matlabskript s. Anhang 8).

\subsection{Datenvorbehandlung}

Die automatische Basislinienkorrektur basiert auf der polynomiellen Kurvenanpassung n-ter Ordnung des Ramanspektrums nach der Methode des kleinsten Fehlerquadrates, wobei diese Methode allein aber keine effiziente Unterdrückung des breitbandigen Untergrundes darstellt, da nur die Differenz zwischen der angepassten Funktion und dem gemessenen Spektrum minimiert wird. Diese Differenz beinhaltet aber beide Informationen, sowohl die der schmalen Ramanbanden als auch die des breiten Untergrundes. Daher wird die polynomielle Kurvenanpassung zunächst dahingehend modifiziert, dass alle Datenpunkte der angepassten Funktion, die oberhalb der Intensitätswerte des Ramanspektrums liegen, automatisch diesen Intensitätswerten zugeordnet werden. Diese Prozedur wird mit den jeweils modifizierten Spektren bei konstant gehaltener polynomieller Ordnung so oft wiederholt, bis nur noch die geeignete Basislinie verbleibt. Erfahrungsgemäß sind dazu in der Regel bis zu 200 Wiederholungen notwendig. Zum besseren Verständnis sind in Abbildung 5.3 (a) die polynomiell angepasste Funktion am Ramanspektrum der $600 \mu \mathrm{M}$ Albumin-Lösung und in (b) die modifizierte angepasste Funktion, sowie die aus 200 Wiederholungen resultierende Basislinie dargestellt. Durch die Subtraktion der Basislinie vom Ramanspektrum wird der breitbandige Untergrund entfernt. Die Wahl der polynomiellen Ordnung ist keineswegs willkürlich, sondern muss jeweils an die Komplexität des Ramanspektrums angepasst werden und erfordert ein gewisses Maß an Erfahrung bei der Interpretation von Ramanspektren. 


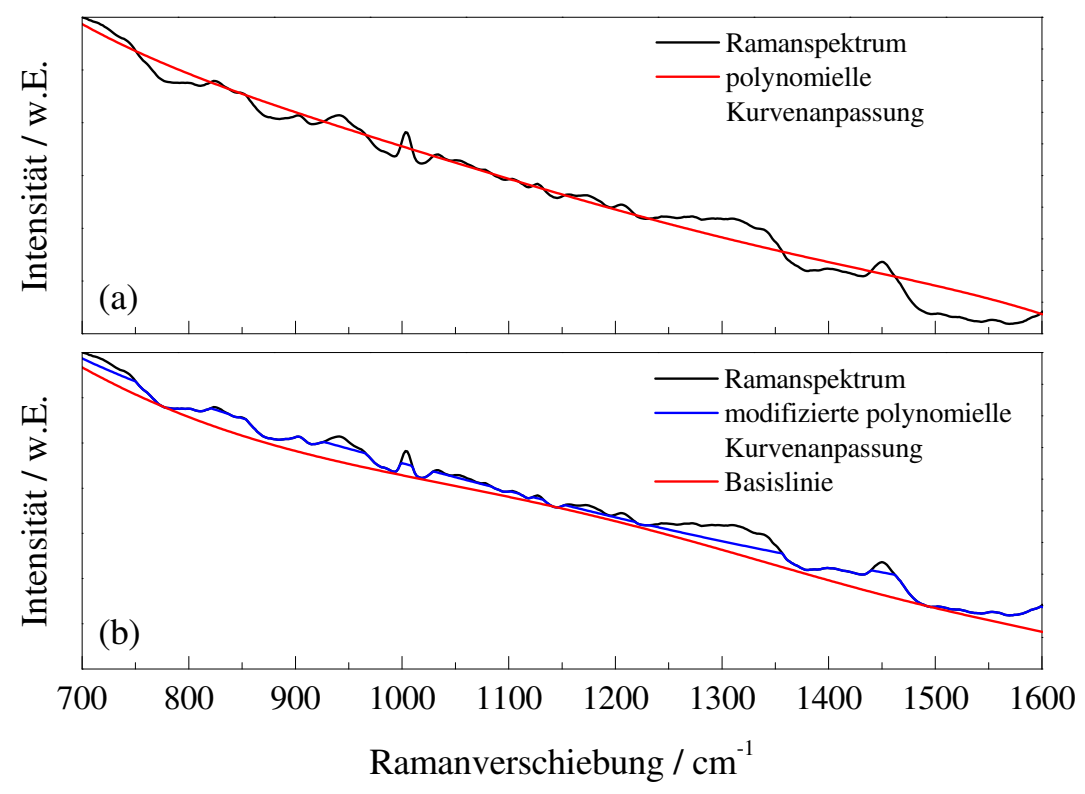

Abbildung 5.3: (a) Ramanspektrum der $600 \mu \mathrm{M}$ Albumin-Lösung zwischen 700 und $1600 \mathrm{~cm}^{-1}$ und die polynomiell angepasste Funktion 5. Ordnung. (b) Ramanspektrum der $600 \mu \mathrm{M}$ Albumin-Lösung zwischen 700 und $1600 \mathrm{~cm}^{-1}$, sowie eine modifizierte polynomiell angepasste Funktion als auch die nach 200 Wiederholungen erzeugte Basislinie.

\subsection{Konzentrationsmessungen und Nachweisgrenzen}

Nach Abzug des breitbandigen Untergrundes vom Ramanspektrum der $600 \mu \mathrm{M}$ Albumin-Lösung mit Hilfe der Basislinienkorrektur geht das in Abbildung 5.4 (links) gezeigte Ramanspektrum hervor, das nun deutlich die gut aufgelösten Ramanbanden des Albumins zeigt, die Grundlage für alle weiteren Berechnungen sind.

Um quantitative Aussagen bezüglich der Konzentrationen treffen zu können, wurden die gemessenen Ramanspektren des Albumins mit Hilfe einer automatisch generierten Basislinie unter Voraussetzung eines Polynoms 5. Ordnung zunächst vorbehandelt (s. Abbildung 5.4 (links)) und anschließend die Ramanbande des Phenylalanins bei $1003 \mathrm{~cm}^{-1}$ zur Konzentrationsbestimmung herangezogen. Dazu wurde an dieser Ramanbande zusätzlich eine Basislinienkorrektur mittels einer linearen 2-Punkt Kurvenanpassung vorgenommen (s. Abbildung 5.4 (links)), um den nach der ersten Basislinienkorrektur noch verbleibenden Untergrund im spektralen Bereich der Ramanbande zu eliminieren (s. Abbildung 5.4 (rechts)). Darauffolgend wurde das Integral über diese Ramanbande berechnet, die so genannte integrale Intensität, und gegen die eingestellte molare Konzentration aufgetragen (s. Abbildung 5.5). In der Regel werden Ramanspektren durch die Integration über einzelne Ramanbanden quantitativ ausgewertet. 

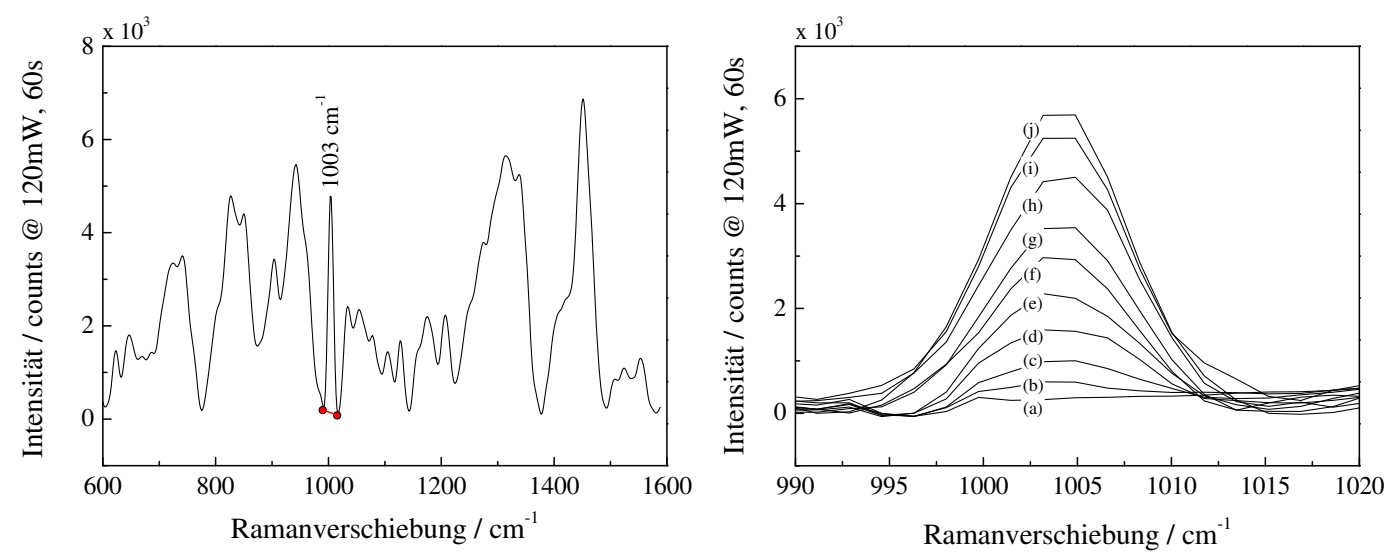

Abbildung 5.4: (Links) Ramanspektrum einer wässrigen Albumin-Lösung nach Abzug der Basislinie. (Rechts) Ramanbande des Phenylalanins bei $1003 \mathrm{~cm}^{-1}$ für verschiedene Albumin-Konzentrationen von (a) $0 \mu \mathrm{mol} / \mathrm{l}$ - (j) $600 \mu \mathrm{mol} / \mathrm{l}$ nach Abzug einer weiteren Basislinie (lineare 2-Punkt Kurvenanpassung).

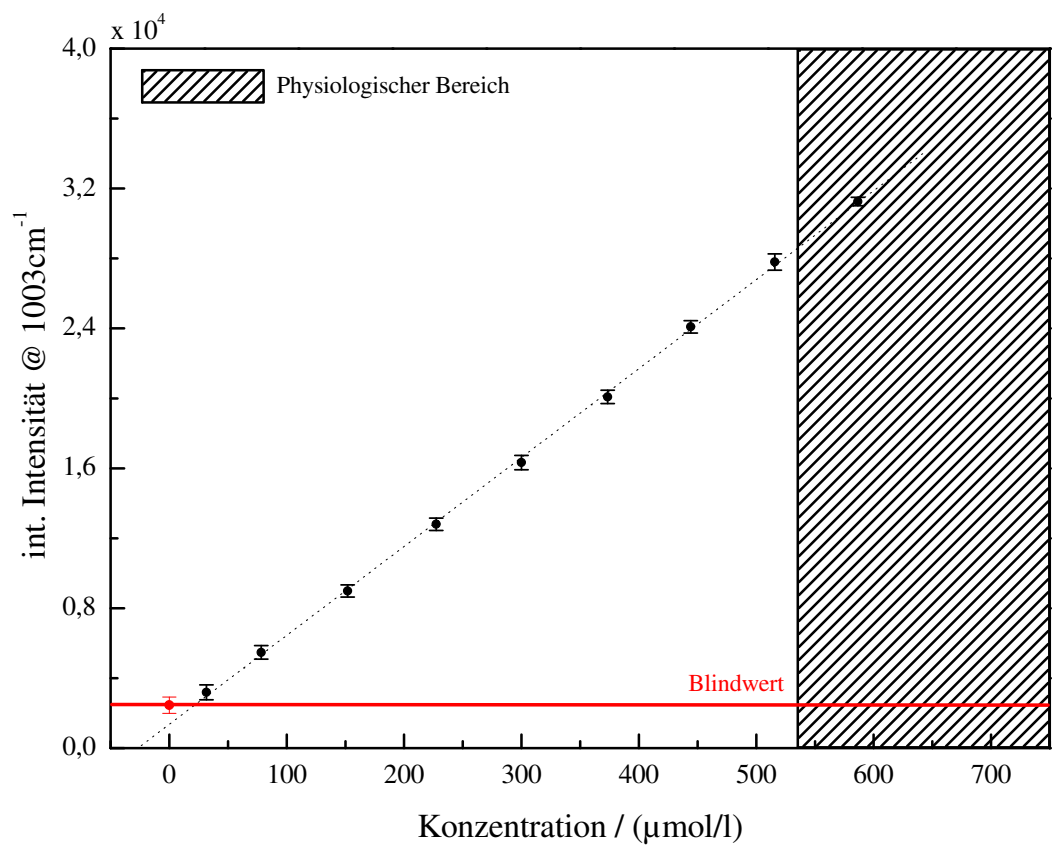

Abbildung 5.5: Auftragung der über fünf unabhängige Messungen gemittelten integralen Intensität der Phenylalanin-Ramanbande bei $1003 \mathrm{~cm}^{-1}$ gegen die molare Konzentration des Albumins. Die Fehlerbalken geben dabei die Standardabweichung der fünf unabhängigen Einzelmessungen an.

Für die Bestimmung der Nachweisgrenze wurde eine direkte Blindwertmethode nach [19] angewendet. Dazu wurden fünf unabhängige Ramanstreulichtmessungen einer Blindlösung durchgeführt. Unter einer Blindlösung wird das Lösungsmittel ohne Zugabe des Analyten verstanden. Die gemessenen Ramanspektren wurden analog zu der 
bereits beschriebenen Vorgehensweise mit einer Basislinie korrigiert und die berechneten integralen Intensitäten anschließend gemittelt sowie die Standardabweichung $\sigma$ der Einzelmessungen bestimmt. Die Nachweisgrenze NWG geht aus folgender Gleichung hervor

$$
\mathrm{NWG}=3,3 \cdot \frac{\sigma}{m}
$$

wobei $m$ die Steigung aus der linearen Regression der konzentrationsabhängigen integralen Intensitäten oberhalb des Blindwertes angibt. Der Blindwert entspricht dem Mittelwert der integralen Intensitäten bei $1003 \mathrm{~cm}^{-1}$.

Der lineare Zusammmenhang in Abbildung 5.5 zwischen der eingestellten Konzentration und der integralen Intensität oberhalb des Blindwertes bestätigt die durch Gleichung 2.6 vorhergesagte Proportionalität der Ramanstreulichtintensität zur Teilchenkonzentration. Die Nachweisgrenze beträgt im Fall von Albumin $29 \mu \mathrm{mol} / \mathrm{l}$ und liegt damit sogar weit unterhalb des physiologischen Konzentrationsbereichs im Blut eines gesunden Menschen.

Analog zu dieser Vorgehensweise wurden auch die Ramanspektren von $\gamma$-Globulin, Glukose und Cholesterin ausgewertet. Diese Ergebnisse sind in Abbildung 5.6 dargestellt. Aufgrund der stark ausgeprägten Ramanbande des Wassers bei $1642 \mathrm{~cm}^{-1}$ lieferte die automatische Basislinienkorrektur im Fall der wässrigen Lösungen nur im Spektralbereich von 600 bis $1600 \mathrm{~cm}^{-1}$ unter der Voraussetzung einer polynomiell angepassten Funktion 5. Ordnung gute Ergebnisse. Im Fall der Cholesterin-Lösungen stand für die Konzentrationsbestimmung nur ein spektraler Bereich von 600 bis $900 \mathrm{~cm}^{-1}$ zur Verfügung, da die im Vergleich zum Cholesterin sehr intensiven Ramanbanden des Methanols oberhalb von $900 \mathrm{~cm}^{-1}$ zu einer Sättigung des CCD-Sensors führten.

Die in Abbildung 5.6 dargestellte Abhängigkeit der gemessenen Ramanstreulichtintensitäten ausgewählter Ramanbanden von der eingestellten molaren Konzentration zeigt den geforderten linearen Zusammenhang, der sich ebenfalls in jedem Fall bis weit unterhalb des physiologisch relevanten Konzentrationsbereiches erstreckt. Die daraus berechneten Nachweisgrenzen sind in Tabelle 5.2 zusammengefasst.

\begin{tabular}{lc}
\hline & Nachweisgrenze \\
\cline { 2 - 2 } Albumin & $29 \mu \mathrm{mol} / \mathrm{l}$ \\
$\gamma$-Globulin & $13 \mu \mathrm{mol} / 1$ \\
Glukose & $3 \mathrm{mmol} / 1$ \\
Cholesterin & $0,24 \mathrm{mmol} / 1$ \\
\hline
\end{tabular}

Tabelle 5.2: Berechnete Nachweisgrenzen. 

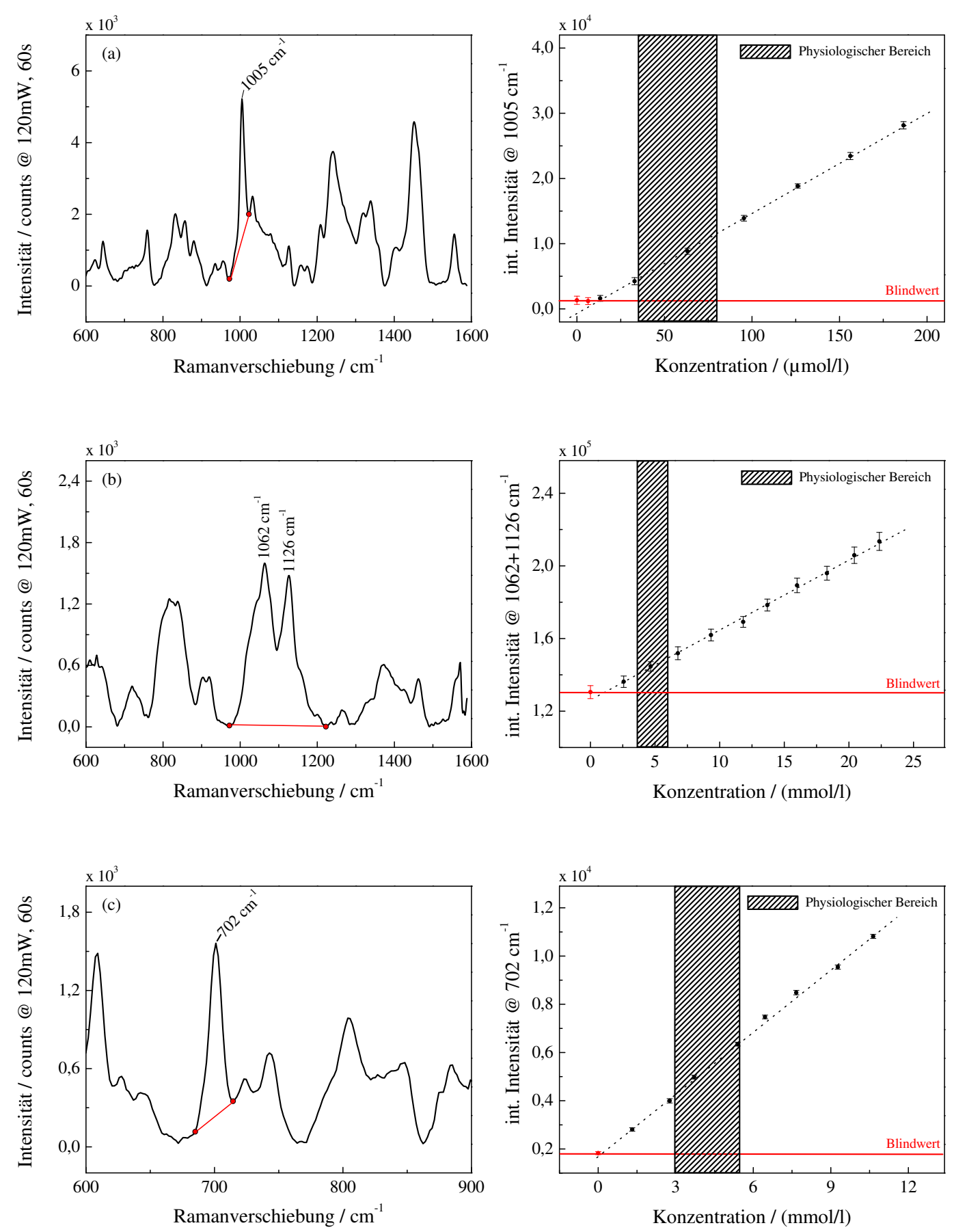

Abbildung 5.6: (Links) Ramanspektren wässriger Lösungen von (a) $\gamma$-Globulin, (b) Glukose und (c) Cholesterin nach Abzug einer Basislinie. (Rechts) Auftragung der über fünf unabhängige Einzelmessungen gemittelten integralen Intensitäten gegen die molare Konzentration. Die Fehlerbalken geben die Standardabweichungen der fünf unabhängigen Einzelmessungen an. 


\subsection{Fazit}

Die berechneten Nachweisgrenzen zeigen eindrucksvoll die Leistungsfähigkeit des in dieser Arbeit entwickelten Ramanspektrometers zur Detektion von ausgewählten Biomolekülen. Die nachgewiesenen Konzentrationen erstrecken sich sogar in allen Fällen bis unterhalb des physiologisch relevanten Konzentrationsbereichs eines gesunden Menschen. Diese Moleküle können natürlich nicht repräsentativ für die Gesamtheit aller im Blut enthaltenen Moleküle sein, da viele der physiologisch relevanten Konzentrationsbereiche um etliche Größenordnungen unterhalb der hier vorgestellten Bereiche liegen. Eine ausführliche Übersicht der physiologischen Konzentrationsbereiche der Hauptbestandteile von Blut bietet das Informationsblatt der Universitäts-Klinik Göttingen "Hinweise für Laboruntersuchungen - Referenzintervalle für Erwachsene" [77].

Wie aber können die bisher ermittelten Nachweisgrenzen mit den momentan zur Verfügung stehenden technischen Möglichkeiten deutlich verbessert werden? Dazu gibt es in der Regel zwei Möglichkeiten: die Erhöhung der Laserleistung und die Erhöhung der Integrationszeiten. Während zu hohe Laserleistungen die Moleküle jedoch zerstören können, ist die maximale Integrationszeit durch die Dynamik der Kamera begrenzt. Da fast alle in der vorliegenden Arbeit untersuchten biologischen Moleküle mit einem breitbandigen Fluoreszenzuntergrund behaftet waren, konnte eine maximale Integrationszeit von einer Minute nicht überschritten werden.

Einen Ausweg hieraus bietet der Einsatz von so genannten Flüssigkernhohlwellenleitern. Darunter werden Kapillaren verstanden, die mit der zu untersuchenden wässrigen Lösung gefüllt werden und durch Ausnutzen der Totalreflexion die Wechselwirkungstrecke zwischen Analyt und Anregungsstrahlung deutlich erhöhen. Im folgenden Abschnitt wird der Einsatz von Flüssigkernhohlwellenleitern anhand der Proteine Albumin und $\gamma$-Globulin zur Herabsetzung der bisher erreichten Nachweisgrenzen exemplarisch vorgestellt und die Möglichkeiten und Grenzen dieser Nachweistechnik evaluiert. 


\section{Kapitel 6}

\section{Ramanstreulichtmessungen an Proteinlösungen in Hohlwellenleitern}

Der Einsatz von Flüssigkernhohlwellenleitern als Probenkammer zur Erhöhung der Ramanstreulichtausbeute bzw. zur Steigerung des Signal-zu-Rausch-Verhältnisses wurde bereits in den frühen 70'er Jahren von Walrafen und Stone [109] demonstriert. Dazu wurden Quarzglaskapillaren von mehreren Metern Länge verwendet, die mit Benzol gefüllt waren und zu einer 3000-fachen Verstärkung der Ramanstreulichtintensität des Benzols gegenüber einer konventionellen Probenanordnung (Küvette) führten. Die Tatsache, dass die optische Leitfähigkeit der Quarzglaskapillaren nur für diejenigen Flüssigkeiten gewährleistet werden kann, die die Bedingungen für die Totalreflexion der Anregungsstrahlung und des Ramanstreulichtes an der Innenfläche des Hohlwellenleiters erfüllen, begrenzt die Anwendungsmöglichkeiten auf Flüssigkeiten, deren Brechungsindizes oberhalb des Brechungsindexes der Quarzglaskapillare $n_{Q}=1,46$ liegen. Damit scheidet Wasser mit einem Brechungsindex von $n_{W}=1,33$ als Lösungsmittel aus, wodurch besonders biologische Anwendungen zunächst keinen Zugang zu derartigen Probenkammern fanden.

Heutzutage sind auf Teflon basierte, kopolymere und flexible Kapillaren mit Brechungsindizes zwischen $n_{\text {Teflon }}=1,31$ und $n_{\text {Teflon }}=1,29$ unter dem Namen TeflonAF 1600 bzw. Teflon-AF 2400 bei der Firma DuPont erhältlich. Eine Beschreibung der Fabrikation und Charakterisierung derartiger Teflon-AF Kapillaren findet sich in der Veröffentlichung von Altkorn et al. [3] aus dem Jahre 1997.

Um Teflon-AF Kapillaren effektiv zur Erhöhung der Ramanstreulichtausbeute nutzen zu können, müssen diverse Anforderungen an das verwendete Ramanspektrometer gestellt und die physikalischen Grundlagen der verwendeten Kapillaren geklärt werden. Sowohl die Anforderungen als auch die physikalischen Grundlagen werden in diesem Abschnitt anhand von Ramanstreulichtmessungen aufgezeigt und darüber hinaus die Ergebnisse der quantitativen Ramanstreulichtmessungen der Proteine Albumin und $\gamma$-Globulin mit der konventionellen Probenandordnung, realisiert mittels einer Quarzglasküvette (s. Kapitel 5.1), verglichen. 


\subsection{Vorüberlegungen}

Das Vorgehen bei der quantitativen Ramanstreulichtmessung wässriger Lösungen in Teflon-AF Kapillaren unterscheidet sich erheblich von dem in der Küvette. Denn wegen der im Vergleich zur Küvette wesentlich größeren Wechselwirkungsstrecke zwischen der Lösung und der Anregungsstrahlung ist der Zusammenhang zwischen Konzentration und Ramanstreulichtintensität direkt von den Absorptionseigenschaften der Lösung abhängig und nicht mehr linear. Um diese Linearität wieder herstellen zu können, müssen die spektralen Absorptionseigenschaften der wässrigen Lösungen sowohl für die Anregungswellenlänge als auch für die der Ramanbanden bekannt sein bzw. gemessen werden.

Altkorn et al. [4] entwickelten dementsprechend ein theoretisches Modell, das die in einer Teflon-AF Kapillare gemessene absorptionsabhängige Ramanstreulichtintensität $P_{R}$ für Detektionssysteme, die in Rückwärtsstreuung arbeiten, nach folgender Gleichung vorhersagt:

$$
P_{R}\left(\nu_{S}\right) \approx c\left(\frac{1-e^{-\left(\mu_{L}+\mu_{S}+2 \mu_{T}\right) L}}{\mu_{L}+\mu_{S}+2 \mu_{T}}\right) \frac{A P_{L} \sigma}{m_{0}} .
$$

$P_{R}\left(\nu_{S}\right)$ ist die Ramanstreulichtintensität bei der Stokeschen Ramanverschiebung $\nu_{S}, c$ die Konzentration der Lösung, $L$ die Länge der Teflon-AF Kapillare, $\mu_{L}$ der Absorptionskoeffizient der wässrigen Lösung bei der Laserwellenlänge, $\mu_{S}$ der Dämpfungskoeffizient bei der Wellenlänge der entsprechenden Ramanverschiebung, $\mu_{T}$ der effektive Verlustkoeffizient, der den Einfluss von Störstellen innerhalb der Teflon-Kapillare auf die Ramanstreulichtintensität beschreibt, $P_{L}$ die Laserleistung, $m_{0}$ das Molekulargewicht, $\sigma$ der Ramanstreuquerschnitt eines einzelnen Moleküls und $A$ eine dimensionslose systemspezifische Konstante.

Unter der Voraussetzung, dass die Parameter $\mu_{L}, \mu_{S}$ und $\mu_{T}$ bekannt sind, lässt sich aus Gleichung 6.1 die gemessene Ramanstreulichtintensität $P_{\text {korr }}$ für alle Konzentrationen durch Umformung nach

$$
P_{k o r r}\left(\nu_{S}\right)=P_{R}\left(\nu_{S}\right) \cdot\left(\frac{\mu_{L}+\mu_{S}+2 \mu_{T}}{1-e^{-\left(\mu_{L}+\mu_{S}+2 \mu_{T}\right) L}}\right)=c \cdot \frac{A P_{L} \sigma}{m_{0}}
$$

korrigieren. Demnach korreliert die korrigierte Ramanstreulichtintensität $P_{\text {korr }}\left(\nu_{S}\right)$ linear mit der Konzentration $c$ für konstante Anregungsleistungen $P_{L} \cdot \mu_{L}$ und $\mu_{S}$ können mit Hilfe von Transmissionsmessungen breitbandigen Lichtes in der Teflon-AF Kapillare nach dem Lambert Beerschen Gesetz für beliebige Wellenlängen $\lambda$ nach

$$
P_{M}(\lambda)=P_{0}(\lambda) C e^{-\mu(\lambda) L}=P_{0}(\lambda) C e^{-\left(\mu_{W}(\lambda)+\mu_{M}(\lambda)+\mu_{T}\right) L}
$$


berechnet werden. $P_{M}$ beschreibt dabei die gemessene wellenlängenabhängige Intensität des Lichtes nach der Transmission durch die Kapillare, $P_{0}(\lambda)$ die eingekoppelte wellenlängenabhängige Weißlichtintensität, $C$ eine systemspezifische Verlustkonstante und $\mu$ einen Dämpfungsterm, der sich aus der Summe der Dämpfunsgsterme $\mu_{W}$ für das Wasser, $\mu_{M}$ für die untersuchten Moleküle und $\mu_{T}$ für den Verlust durch diffuse Streuung an der Innenseite der Kapillare zusammensetzt.

Eine Transmissionsmessung von reinem Wasser, wobei

$$
\mathrm{P}_{W}(\lambda)=P_{0}(\lambda) C e^{-\left(\mu_{W}(\lambda)+\mu_{T}\right) L}
$$

gilt und der Literaturwert für den wellenlängenabhängigen Absorptionskoeffizienten von Wasser $\mu_{W}$, der der Veröffentlichung von Kou et al. [53] entnommen werden kann, ermöglichen dann die Berechnung von $\mu_{L}$ bzw. $\mu_{S}$ durch die Verhältnisbildung der transmittierten Intensität der Anregungswellenlänge für eine Füllung mit reinem Wasser $\left(P_{W}(\lambda)\right)$ und eine Füllung mit der zu untersuchenden Lösung $\left(P_{M}(\lambda)\right)$.

$$
\begin{aligned}
\frac{P_{W}(\lambda)}{P_{M}(\lambda)}=e^{-\mu_{M}(\lambda) L} \quad \text { mit } \quad \mu(\lambda)=\mu_{W}(\lambda)+\mu_{M}(\lambda) \\
\\
\Longrightarrow \quad \mu_{L, S}=\mu_{W}+\frac{1}{L} \ln \left(\frac{P_{W}}{P_{M}}\right)
\end{aligned}
$$

Das Einsetzen der nach dieser Methode ermittelten Dämpfungsterme $\mu_{L, S}$ in Gleichung 6.2 führt zu den absorptionskorrigierten Ramanstreulichtintensitäten $P_{\text {korr }}\left(\nu_{S}\right)$ (s. Gleichung 6.7), ohne den Term $2 \mu_{T}$, da die Störstellen jeweils in den Termen $\mu_{L, S}$ bei der Berechnung mit berücksichtigt wurden.

$$
P_{\text {korr }}\left(\nu_{S}\right)=P_{R}\left(\nu_{S}\right) \cdot \overbrace{\left(\frac{\mu_{L}+\mu_{S}}{1-e^{\left[-\left(\mu_{L}+\mu_{S}\right) L\right]}}\right)}^{\text {Korrekturterm }}
$$

Basierend auf diesem theoretischen Modell wurde ein experimenteller Aufbau zur simultanen Ramanstreulicht- und Transmissionsmessung umgesetzt. Dieser wird nachfolgend vorgestellt.

\subsection{Experimenteller Aufbau}

Für die Ramanstreulichtmessungen in den Teflon-AF Kapillaren wurde das Ramanspektrometer zum Einen mit einer Fluidikzelle erweitert, in die die Teflon-Kapillaren integriert waren und zum Anderen eine spezielle Anordnung optischer Elemente für Transmissionsmessungen in der Teflon-AF Kapillare, wie in Abbildung 6.1 gezeigt, realisiert. Die Fluidikzelle, die in Abbildung 6.2 schematisch dargestellt ist, diente als 
Schnittstelle zwischen dem Ramanspektrometer und der Kapillare, indem sie über ein Quarzglasfenster den optischen Zugang des Ramanspektrometers zur Kapillare gewährleistete und darüber hinaus das Zu- bzw. Abführen der zu untersuchenden Lösungen ermöglichte. Die Fluidikzelle setzt sich aus einer Bodenplatte aus Plexiglas, einem $125 \mu \mathrm{m}$ dicken Abstandshalter aus Mylarfolie, der die Kanalgeometrie für die Zu- und Abführung der Lösungen vorgibt, und einer Deckplatte aus Quarzglas zusammen, die miteinander verklebt wurden.

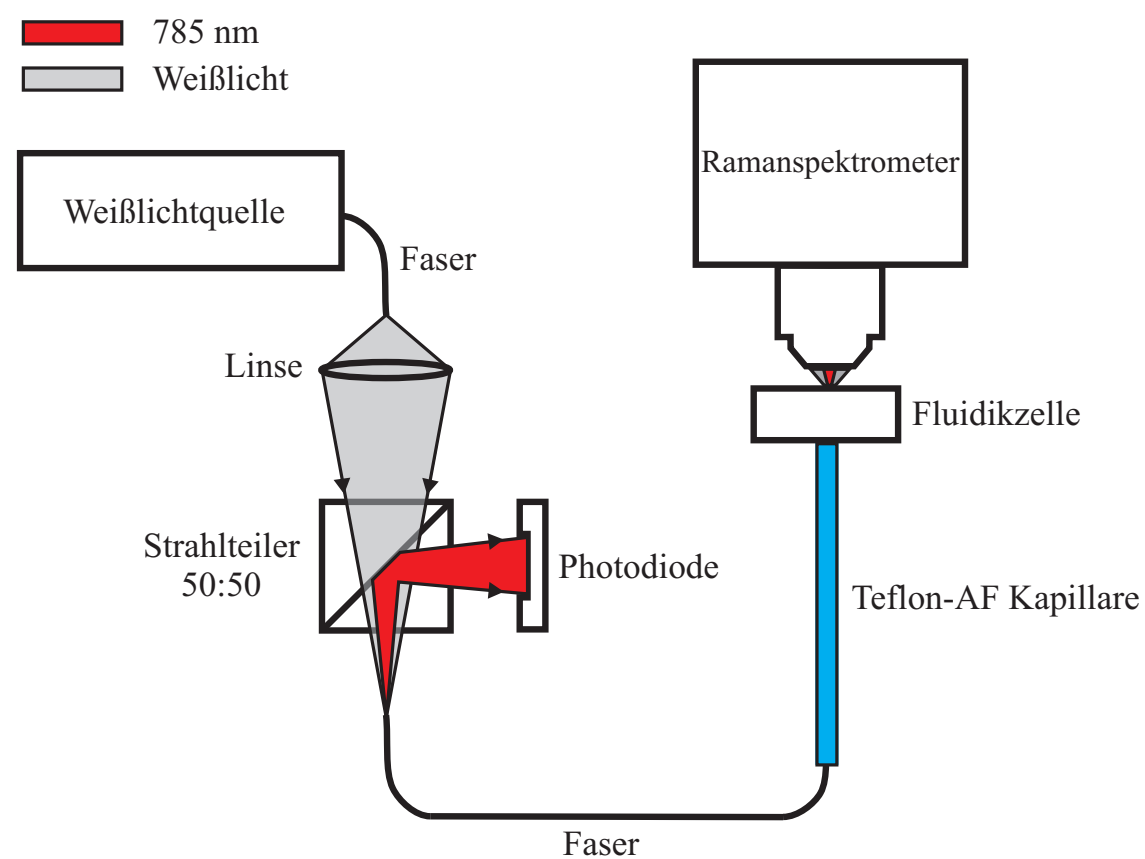

Abbildung 6.1: Schematische Darstellung des kombinierten Raman- und Absorptionsspektroskopie Systems.
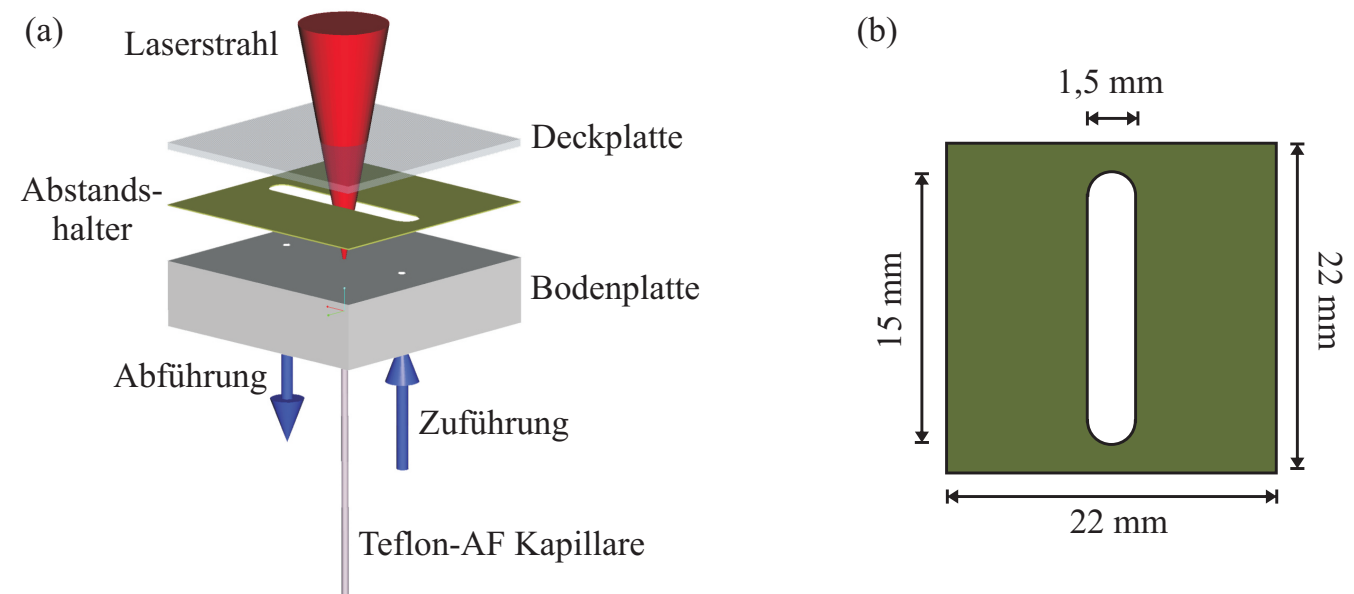

Abbildung 6.2: (a) 3-dimensionale CAD-Darstellung der Fluidikzelle. (b) Geometrie des Fluidikkanals im Abstandshalter. 
Die beiden verwendeten Teflon-AF Kapillaren stammen von Biogeneral, Inc., sind aus dem Material Teflon-AF 2400 mit dem Brechungsindex $n_{T}=1,29$ gefertigt und weisen zum Einen einen Innendurchmesser von $250 \mu \mathrm{m}$ und einen Außendurchmesser von $510 \mu \mathrm{m}$ und zum Anderen einen Innendurchmesser von $610 \mu \mathrm{m}$ und einen Außendurchmesser von $810 \mu \mathrm{m}$ auf. Den Transport der wässrigen Lösung in die Fluidikzelle und damit in die Kapillare übernahm eine PHD Infusion (Harvard Apparatus) Spritzenpumpe.

Für die Transmissionsmessungen wurde in die der Ramanspektrometer abgewandten Öffnung der Kapillare eine Faser hineingeschoben. Diese war an den Innendurchmesser der Kapillare angepasst und stellte die Schnittstelle für die Transmissionsmessungen dar. Dazu wurde die durch die wässrige Lösung transmittierte Anregungsstrahlung mit Hilfe der Faser über einen Strahlteiler auf eine photonenempfindliche Orion-PD (Ophir) Diode abgelenkt und die Leistung, die dem Term $P_{M}\left(\lambda_{L}\right)$ bei der Anregungswellenlänge $\lambda_{L}$ entspricht, während der Ramanstreulichtmessung aufgezeichnet. Diese Ergebnisse dienten zur Berechnung von $\mu_{L}$ nach Gleichung 6.5.

Um ebenfalls die wellenlängenabhängige Dämpfung des Ramanstreulichtes $\mu_{S}$ bestimmen zu können, wurde breitbandiges Weißlicht der Halogenlampe HL-2000 (Avantes) in umgekehrter Richtung über eine Linse durch den Strahlteiler hindurch in die Faser eingekoppelt. Das durch die Kapillare transmittierte Weißlicht wurde unmittelbar nach jeder Ramanstreulichtmessung von dem Ramanspektrometer erfasst und das Weißlichtspektrum ebenfalls nach Gleichung 6.5 zur Berechnung von $\mu_{S}$ herangezogen.

\section{Optimierung der Einkoppelungs- und Sammeleffizienzen}

Eine zentrale Rolle für die effiziente Nutzung von Teflon-AF Kapillaren spielt der kritische Winkel $\Theta_{k r i t}$ bei der Totalreflexion von Anregungsstrahlung und Ramanstreulicht. Dieser folgt dem „Snellius‘schen Brechungsgesetz“ und lässt sich nach folgender Gleichung berechnen

$$
\Theta_{k r i t}=\arcsin \left(\frac{n_{T}}{n_{M}}\right)
$$

wobei $n_{T}$ und $n_{M}$ die Brechungsindizes des Teflon-AFs und der wässrigen Lösung beschreiben. Demzufolge kann eine Wellenleitung nur für Ausbreitungswinkel kleiner $\Theta_{k r i t}$ stattfinden. Die Überschreitung des kritischen Winkels würde bei der Einkoppelung der Anregungsstrahlung zu erheblichen Leistungsverlusten führen, wodurch nur noch ein geringer Anteil der ursprünglich zur Verfügung stehenden Leistung zur Anregung des Ramanstreulichtes ausgenutzt würde. Mit dem Brechungsindex $n_{T}=1,29$ der TeflonAF 2400 Kapillare und unter Voraussetzung wässriger Lösungen mit dem Brechungsindex von Wasser $n_{M}=1,33$ errechnet sich ein kritischer Winkel von $\Theta_{\text {krit }}=76^{\circ}$. Daraus 
folgt für den maximal möglichen Ausbreitungswinkel $\psi_{k r i t}=90^{\circ}-\Theta_{k r i t}=14^{\circ}$ der Anregungsstrahlung bzw. des Ramanstreulichtes in der Kapillare (s. Abbildung 6.3). Damit ist die notwendige Bedingung für eine optimale Einkoppelung des Laserlichtes in das Mikroskopobjektiv gegeben.

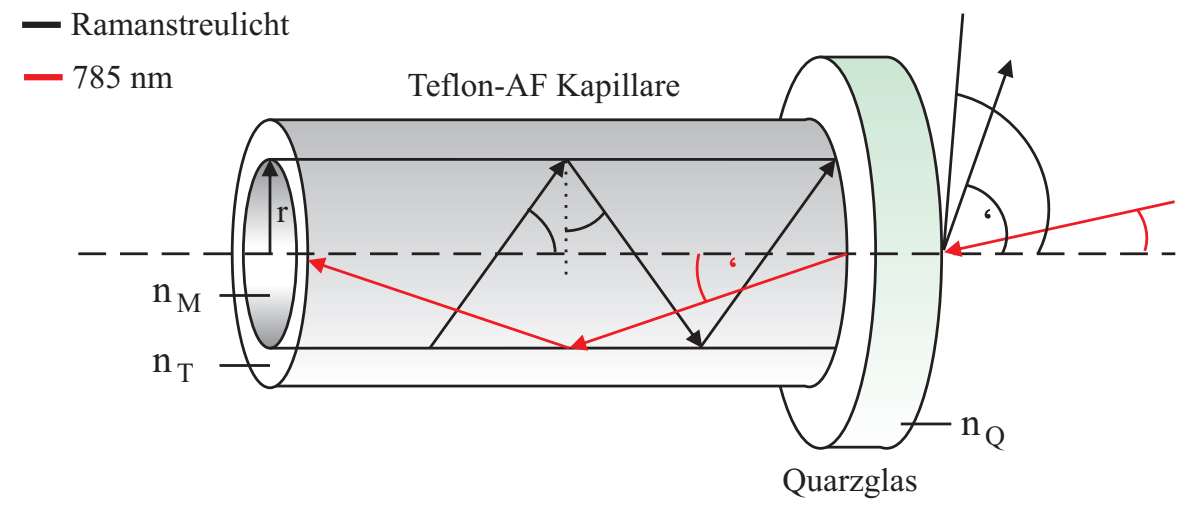

Abbildung 6.3: Schematische Darstellung eines Ausschnitts aus der Kapillare.

Die Messung des Austrittswinkels der Anregungsstrahlung aus dem Mikroskopobjektiv ergab einen Winkel von $\beta=7,5^{\circ}$, so dass sich unter Berücksichtigung des Brechungsindexes von Quarzglas $n_{Q}=1,46$ nach dem Snellius'schen Gesetz ein maximaler Ausbreitungswinkel von $\beta^{\prime}=5,5^{\circ}<\psi_{k r i t}$ für die Anregungsstrahlung innerhalb der Kapillare errechnete. Damit wurde eine effiziente Einkoppelung der Anregungsstrahlung gewährleistet.

Analog zu dieser Vorgehensweise ergab sich für das Ramanstreulicht ein Abstrahlwinkel von $\psi^{\prime}=18,8^{\circ}$ von der Fluidikzelle in die Luft hinein und lag damit unterhalb des Akzeptanzwinkels $\gamma$ des Mikroskopobjektivs. Dieser berechnete sich nach

$$
\mathrm{NA}_{M O}=n_{L} \sin \gamma
$$

zu $\gamma=26,7^{\circ}$, wobei $n_{L}=1$ den Brechungsindex der Luft und $\mathrm{NA}_{M O}=0,45$ die numerische Apertur des Mikroskopobjektivs darstellt. Damit wurde auch eine maximale Sammeleffizienz des Ramanstreulichtes durch das Mikroskopobjektiv gewährleistet.

\subsection{Voruntersuchungen}

\subsubsection{Bestimmung des optimalen Kapillardurchmessers und der Kapillarlänge}

Um die optimalen Bedingungen für die Ramanstreulichtmessungen an wässrigen Proteinlösungen zu schaffen, wurden zunächst die Parameter, wie die maximale zur Ramanstreulichtintensität beitragende Kapillarlänge und der Einfluss des Kapillarinnendurch- 
messers untersucht. Dafür standen zwei unterschiedliche Teflon-AF 2400 Kapillaren zur Verfügung, eine mit $250 \mu \mathrm{m}$ Innendurchmesser und $510 \mu \mathrm{m}$ Außendurchmesser, sowie eine mit $610 \mu \mathrm{m}$ Innendurchmesser und $810 \mu \mathrm{m}$ Außendurchmesser. Beide Kapillaren besaßen eine Länge von $600 \mathrm{~mm}$.

Um den Einfluss des Kapillarinnendurchmessers auf die Ramanstreulichtintensität zu ermitteln, wurden Ramanspektren eines 5 Volumen-prozentigen Ethanol-Wassergemisches mit beiden Kapillaren aufgenommen und auf Anregungsstrahlungsintensität und Integrationszeit normiert. Dabei zeigte sich, dass die Kapillare mit dem kleineren Innendurchmesser $25 \%$ höhere Ramanstreulichtintensitäten erbrachte als die mit dem größeren. Dieser Sachverhalt ist nicht sofort einsichtig, da mit der Zunahme des Innendurchmessers einer Kapillare ebenfalls eine deutliche Zunahme des bestrahlten Volumens und somit der Ramanstreulichtintensität einhergeht. Eine der möglichen Ursachen für dieses entgegengesetzte Verhalten kann die durch eine schlechte Fertigung der Kapillare bedingte Rauigkeit auf der Kapillarinnenseite sein. Diese führt unmittelbar zu hohen Streuverlusten. Eine weitere Ursache stellt sicherlich der Durchmesser der Kapillare dar. Mit ihm skaliert die Querschnittsfläche der Kapillare quadratisch, aus der das Ramanstreulicht austritt. Wie bereits in Kapitel 3.1 geschildert, berechnet sich der Vergrößerungsmaßstab des Sensorkopfes zu $M=3,66$, so dass die Abbildung des Kapillarquerschnitts der Kapillare mit dem Innendurchmesser von $610 \mu \mathrm{m}$ auf der Faserbündeleintrittsfläche einen Durchmesser von ca. 2,4 mm aufweist. Der effektive Durchmesser des Faserbündels beträgt aber 0,81 mm, so dass nur 1/9 der gesamten Ramanstreulichtintensität detektiert werden kann. Für den Fall der Kapillare mit dem kleineren Kapillarinnendurchmesser von $250 \mu \mathrm{m}$ ergibt sich eine Abbildung mit dem Durchmesser von $915 \mu \mathrm{m}$, so dass fast die gesamte emittierte Ramanstreulichtintensität detektiert wird.

Mit der Tatsache, dass die Kapillare mit dem kleineren Innendurchmesser von $250 \mu \mathrm{m}$ höhere Ramanstreulichtintensitäten liefert, wurde diese ausschließlich für alle weiteren Ramanstreulichtmessungen verwendet. Dazu zählten neben den Konzentrationsmessungen an wässrigen Proteinlösungen außerdem die Bestimmung der maximalen zur Ramanstreulichtintensität beitragenden Kapillarlänge. Im Idealfall sollte möglichst die gesamte zur Verfügung stehende Kapillarlänge zur Erzeugung von detektierbarem Ramanstreulicht beitragen.

Zur Vermessung der zum Signal beitragenden Kapillarlänge, im Folgenden als effektive Länge $L_{\text {eff }}$ bezeichnet, wurde eine optische WF 200/220P Faser (CeramOptec) mit dem Kerndurchmesser von $200 \mu \mathrm{m}$, der Mantelbreite von $10 \mu \mathrm{m}$ und der numerischen Apertur von NA = 0,22 (für Luft) in die mit einem 5 Volumen-prozentigen Ethanol-Wassergemisch gefüllte Kapillare bis vor die Öffnung der Kapillare innerhalb 
der Fluidikzelle geschoben und schränkte damit die für die Ramanstreulichtmessung zur Verfügung stehende Kapillarlänge zu Beginn auf $0 \mathrm{~mm}$ ein. Zur schrittweisen Vergrößerung der zur Ramanstreulichterzeugung beitragenden Kapillarlänge wurde die optische Faser aus der Kapillare in äquidistanten Schritten herausgezogen und simultan Ramanstreulichtmessungen für das 5 Volumen-prozentige Ethanol-Wassergemisch durchgeführt. Abbildung 6.4 stellt die Ergebnisse dieser Messungen dar, wobei der von Altkorn vorhergesagte monoexponentielle Verlauf der rückgestreuten Ramanstreulichtintensität nach Gleichung 6.1 bestätigt wird. Da ab einer Länge von $250 \mathrm{~mm}$ augenscheinlich keine merkliche Erhöhung der Ramanstreulichtintensität zu erkennen ist, wird diese Länge als effektive Länge $L_{e f f}=250 \mathrm{~mm}$ abgeschätzt. Damit ist die Gesamtlänge der untersuchten Teflon-AF Kapillare von $600 \mathrm{~mm}$ ausreichend, um auch die maximal mögliche Ramanstreulichtintensität zu detektieren.
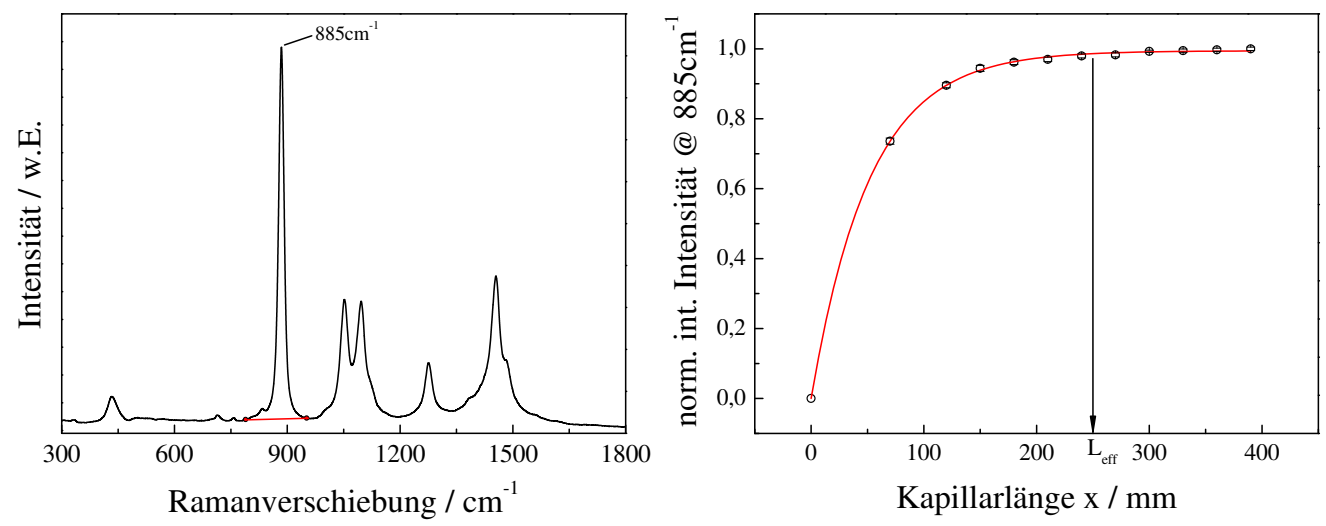

Abbildung 6.4: (Links) Ramanspektrum von Ethanol, das in der Kapillare gemessen wurde. (Rechts) Auftragung der normierten integralen Intensität der $885 \mathrm{~cm}^{-1}$ Ramanbande des Ethanols gegen die Kapillarlänge und Anpassung einer Exponentialfunktion (rot) nach Altkorn [5]. Die Fehlerbalken geben die Standardabweichungen von fünf unabhängigen Einzelmessungen an.

\subsubsection{Bestimmung des Reflexionskoeffizienten}

Ein weiterer ganz entscheidender Parameter für eine optimale Ramanstreulichtausbeute ist der so genannte Reflexionskoeffizient $R$ der Kapillarinnenwand. Dabei handelt es sich um eine Kenngröße, die den Verlust der Anregungsstrahlung bzw. des Ramanstreulichtes durch diffuse Streuung bei der Reflexion an der Innenseite der Kapillarwand beschreibt. $R$ kann Werte zwischen Null und Eins annehmen, wobei Eins für eine verlustfreie Reflexion steht. Um diesen Reflexionskoeffizienten bestimmen zu können, wurde eine von Qi et al. [90] speziell dafür vorgestellte experimentelle Methode mit dem Ramanspektrometer umgesetzt. Die Anregungsstrahlung wurde dazu 
zunächst aus dem Mikroskopobjektiv mittels der bereits für die Absorptionskorrektur verwendeten optischen Faser auf der der Fluidikzelle gegenüberliegenden Öffnung in die mit Wasser gefüllte Teflon-Kapillare geführt. Dann wurde die optische Faser bis zur Kapillaröffnung innerhalb der Fluidikzelle geschoben und die integrale Intensität der Rayleighbande mit dem Ramanspektrometer gemessen, während die optische Faser in äquidistanten Abständen $\Delta x$ aus der Kapillare herausgezogen wurde. Abbildung 6.5 zeigt den ermittelten Verlauf der Anregungsstrahlungsintensität $P(x)$ normiert auf die Eingangsintensität $P(x=0)$ der Anregungsstrahlung. Qi et al. formulierten folgenden Ausdruck zur Vorhersage des gezeigten Kurvenverlaufs:

$$
\frac{P(x)}{P(x=0)}=e^{-\mu_{W} x} \cdot \frac{2}{(\ln (R / d) \Theta x)^{2}} \cdot\left(e^{(\ln (R / d) \Theta x)}(\ln (R / d) \Theta x-1)+1\right) .
$$

Dabei beschreibt $\Theta$ den maximalen Ausbreitungswinkel der Anregungsstrahlung in der Teflon-AF Kapillare, $\mu_{W}$ den Absorptionskoeffizienten von Wasser und $d$ den Innendurchmesser der Kapillare. Der maximale Ausbreitungswinkel $\Theta$ des aus der Einkopplungsfaser austretenden Lichts errechnet sich für Wasser mit dem Brechungsindex von $n_{W}=1,33$ über $\Theta=\arcsin \left(1 / n_{W} \cdot \sqrt{n_{\text {Kern }}^{2}-n_{\text {Mantel }}^{2}}\right)$ zu NA $=0,165$, woraus sich ein maximaler Ausbreitungswinkel von $\Theta=9,5^{\circ}$ für die Anregungsstrahlung innerhalb der Kapillare ergibt. Laut Herstellerangaben wird die numerische Apertur der Faser für Luft mit NA $=1 / n_{L} \cdot \sqrt{n_{\text {Kern }}^{2}-n_{\text {Mantel }}^{2}}=0,22$ und $n_{L}=1$ angegeben.

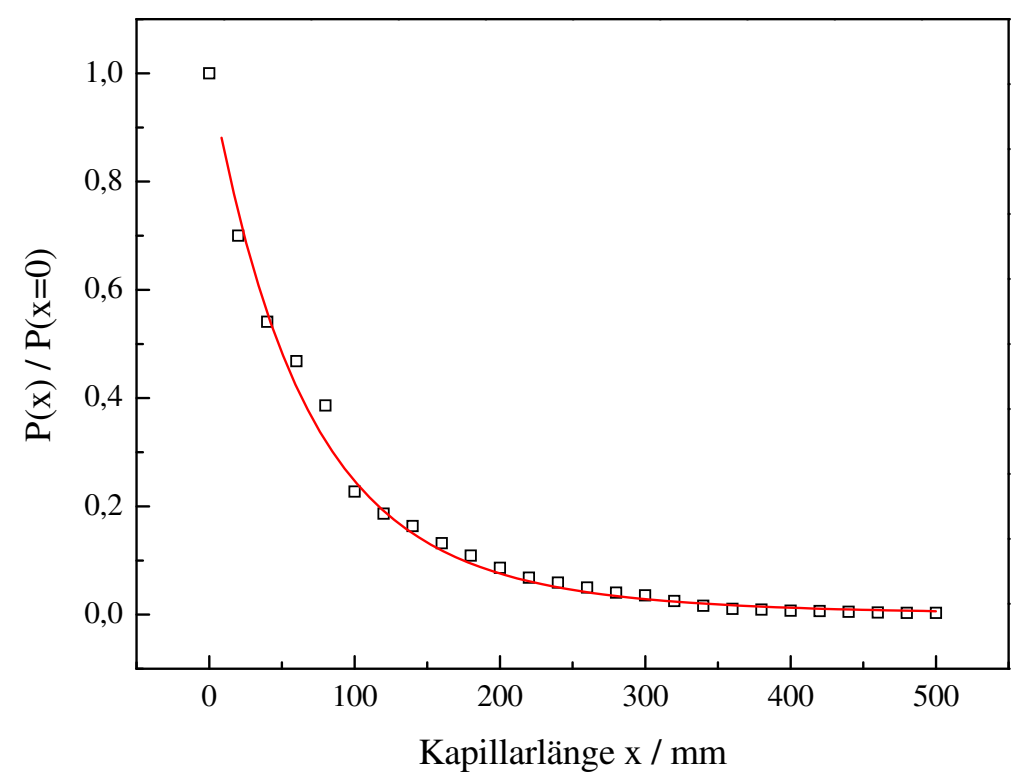

Abbildung 6.5: Messung des Reflexionskoeffizienten $R$ der Teflon-AF Kapillare durch Anpassung der gemessenen Strahlungsleistung $P(x)$ nach Gleichung 6.10 (rote Linie) . 
Durch die Anpassung der Datenpunkte nach Gleichung 6.10 ergibt sich ein Reflexionskoeffizient von $R=0,89 \pm 0,03$. Dieser liegt deutlich unterhalb von Eins und steht für hohe Streuverluste, denn im Falle von $R=0,96$ würde sich die Ramanstreulichtintensität nach Gleichung 6.10 im Vergleich zu $R=0,89$ bereits um einen Faktor von 3 erhöhen.

\subsubsection{Erprobung der Absorptionskorrektur}

Um die Anwendbarkeit der Absorptionskorrektur nach Gleichung 6.7 zur Wiederherstellung des durch die Absorption gestörten linearen Zusammenhangs zwischen Ramanstreulichtintensität und molarer Konzentration zu überprüfen, wurden wässrige Glaubersalzlösungen mit unterschiedlichen Konzentrationen hergestellt, Raman- und Weißlichtspektren dieser Lösungen aufgenommen und diese nach dem bereits beschriebenen Verfahren zur Absorptionskorrektur ausgewertet. Das Ramanspektrum von Glaubersalz eignet sich dazu besonders gut, da sein Ramanspektrum im Wesentlichen eine starke Ramanbande bei $983 \mathrm{~cm}^{-1}$ aufweist, die sich spektral deutlich von den charakteristischen Ramanbanden des Teflon-AF bei 715, 757 und $832 \mathrm{~cm}^{-1}$ abhebt (s. Abbildung 6.6). Dazu wurde die integrale Intensität der stark ausgeprägten Ramanbande des Glaubersalzes bei $983 \mathrm{~cm}^{-1}$ sowohl ohne als auch mit der Absorptions korrektur gegen die molare Konzentration aufgetragen und auf Eins normiert (s. Abbildung 6.7).

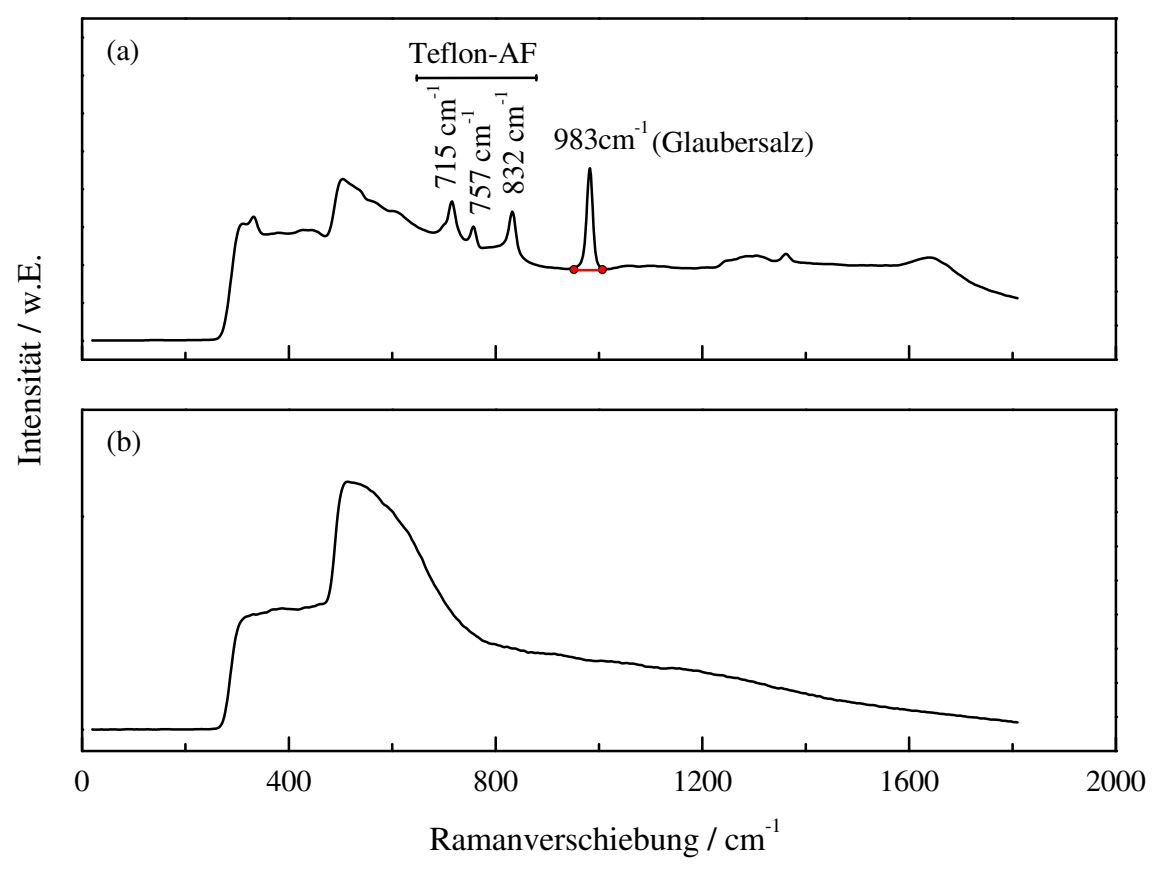

Abbildung 6.6: (a) Ramanspektrum einer $100 \mu \mathrm{M}$ Glaubersalzlösung. (b) Dazugehöriges Weißlichtspektrum. 
Um zu zeigen, dass die mit der Absorptionskorrektur vorbehandelten Daten mit einer präziseren Ausgleichsgeraden angepasst werden können als die unbehandelten Daten, wurde für beide Fälle eine lineare Regression durchgeführt und daraus die Verfahrensstandardabweichung $\sigma_{V e r}$ nach Gleichung 6.11 berechnet, wobei $\mathrm{m}$ die Steigung der angepassten Geraden und $\sigma_{R}$ die Reststandardabweichung (Maß für die Streuung der Residuen) beschreibt.

$$
\sigma_{V e r}=\frac{\sigma_{R}}{m}
$$

Die Verfahrensstandardabweichung ist laut [29] ein gütebestimmender Kennwert für die Präzision einer linearen Kurvenanpassung. Für den Fall der Datenauswertung mit der Absorptionskorrektur errechnet sich eine Verfahrensstandardabweichung von $\sigma_{V e r}=0,35$ mit Hilfe der linearen Regression und im Fall der nicht vorbehandelten Daten eine Verfahrensstandardabweichung von $\sigma_{V e r}=0,98$. Damit kann eindeutig gezeigt werden, dass die Absorptionskorrektur zu einem präziseren linearen Zusammenhang zwischen der Konzentration und der Ramanstreulichtintensität führt.

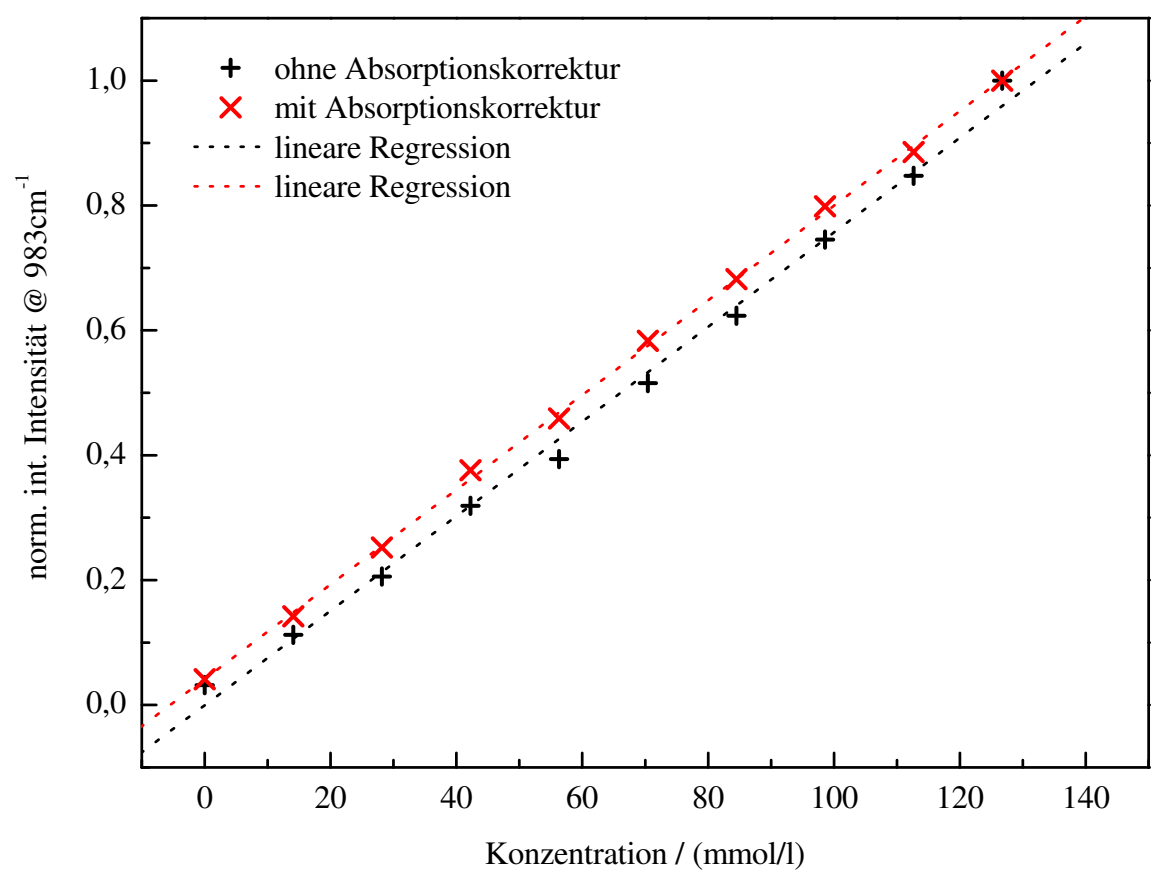

Abbildung 6.7: Auftragung der normierten integralen Intensität der Ramanbande des Glaubersalzes bei $983 \mathrm{~cm}^{-1}$ gegen die normierte molare Konzentration für den Fall ohne und mit Absorptionskorrektur.

Der Literaturwert des Absorptionskoeffizienten von Wasser $\mu_{W}=4,191 / \mathrm{m}$ zur Berechnung der Absorptionskoeffizienten $\mu_{L, S}$ des Glaubersalzes nach Gleichung 6.5 bei der Wellenlänge $\lambda=850 \mathrm{~nm}$ (entspricht der Ramanbande bei $983 \mathrm{~cm}^{-1}$ ) wurde ebenfalls der Veröffentlichung von Kou et al. [53] entnommen. 


\subsection{Konzentrationsmessungen}

Nachdem die Absorptionskorrektur erfolgreich am Beispiel wässriger Glaubersalzlösungen demonstriert wurde, werden nun die Konzentrationsmessungen an wässrigen Albumin und $\gamma$-Globulin Lösungen vorgestellt. Die Ramanspektren wurden dazu neben der Absorptionskorrektur analog zu der Vorgehensweise wie bei der Küvettenmessung (s. Kapitel 5.1) ausgewertet und die Ergebnisse in den Abbildungen 6.8 und 6.9 für Albumin und in den Abbildungen 6.10 und 6.11 für $\gamma$-Globulin dargestellt. Darin sind zum Einen die vom Teflon-AF dominierten Spektren zu sehen, in denen sich die Konzentrationsvariationen der einzelnen proteinspezifischen Ramanbanden nur in wenigen spektralen Bereichen äußern, die nicht vom Ramanspektrum des Teflon-AFs überlagert sind. Zum Anderen sind die absorptionskorrigierten integralen Intensitäten (korr. int. Intensität) ausgewählter Ramanbanden dargestellt, die den geforderten linearen Zusammenhang aufweisen. In Tabelle 6.1 sind die ermittelten Nachweisgrenzen, die berechneten Verstärkungsfaktoren und die Korrekturfaktoren zusammengefasst. Die Verstärkungsfaktoren ergeben sich dabei aus dem Verhältnis der auf Laserleistung und Integrationszeit normierten integralen Ramanbandenintensitäten vergleichbarer Konzentrationen, die sowohl in der Küvette als auch in der Teflon-AF Kapillare gemessen wurden.

\begin{tabular}{lccccc}
\hline & Nachweisgrenze & & Verstärkungsfaktor & & Korrekturfaktor \\
\cline { 2 - 2 } Albumin & $10,6 \mu \mathrm{mol} / 1$ & & $\approx 50(@ 31 \mu \mathrm{mol} / \mathrm{l})$ & & 8,3 \\
-Globulin & $3,8 \mu \mathrm{mol} / 1$ & & $\approx 60(@ 13 \mu \mathrm{mol} / \mathrm{l})$ & & 10 \\
\hline
\end{tabular}

Tabelle 6.1: Nachweisgrenzen, Verstärkungs- und Korrekturfaktoren. Die für die Brechnung der Verstärkungsfaktoren berücksichtigte Konzentration ist in Klammern angegeben.

Es zeigt sich eine Verbesserung in der Nachweisempfindlichkeit, da die Nachweisgrenzen um ca. einen Faktor von 3 gegenüber denen aus der Küvettenmessung herabgesetzt werden konnten. Desweiteren ermöglicht die Teflon-AF Kapillare eine fünfzig- bis sechzigfach höhere Ramanstreulichtausbeute gegenüber der Küvette. Diese Verstärkungsfaktoren decken sich in der Größenordnung mit denen aus der Veröffentlichung von Qi et al. [90] und Altkorn et al. [4]. Unter Berücksichtigung der in Abschnitt 6.3.2 gezeigten Abschätzung, dass sich die Ramanstreulichtintensität um einen Faktor von 3 erhöht, wenn der ermittelte Reflexionskoeffizient der verwendeten Kapillare nicht $R=0,89$ sondern $R=0,96$ beträgt, würde sich sogar ein Verstärkungsfaktor von ca. 150 bis 180 ergeben. 


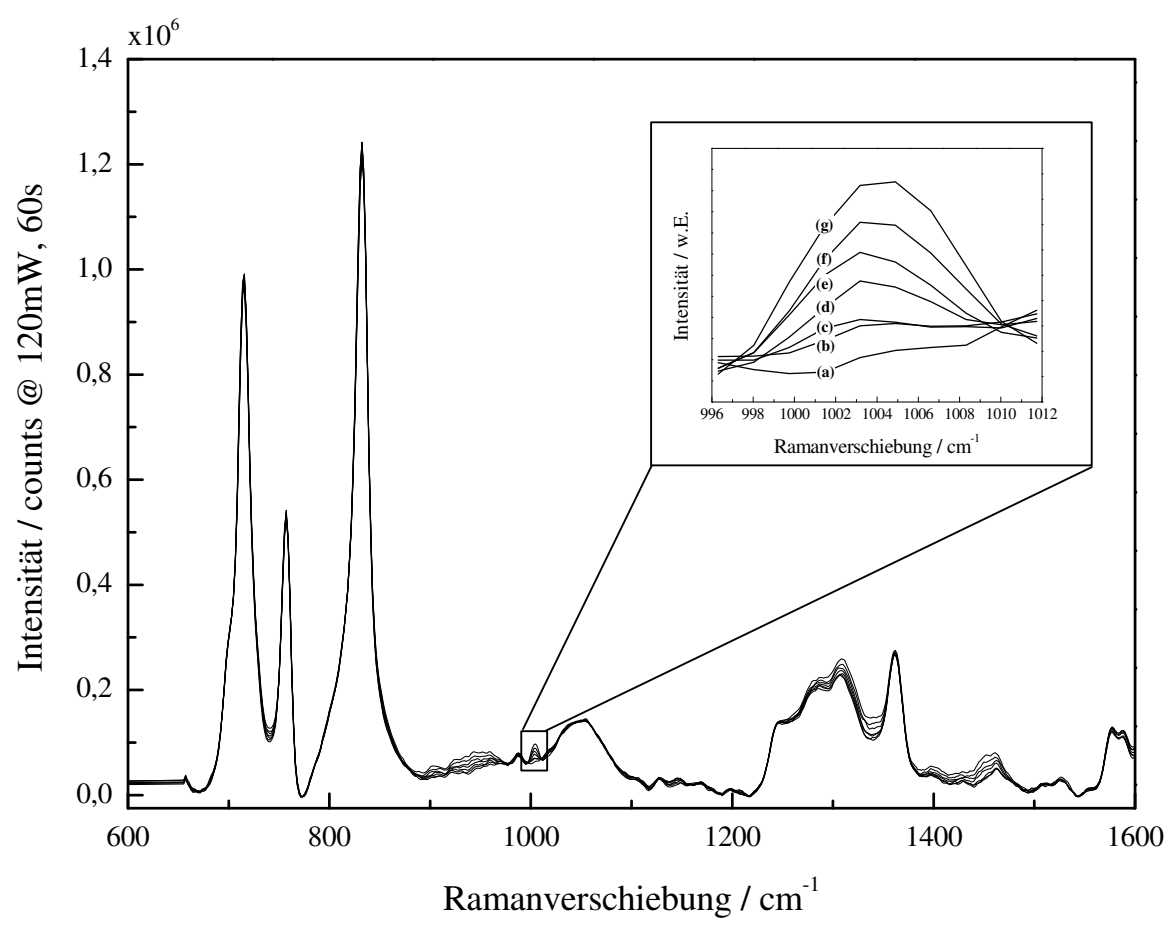

Abbildung 6.8: Ramanspektren der wässrigen Albumin-Lösungen für den molaren Konzentrationsbereich von (a) 0 bis (g) $31 \mu \mathrm{mol} / \mathrm{l}$.

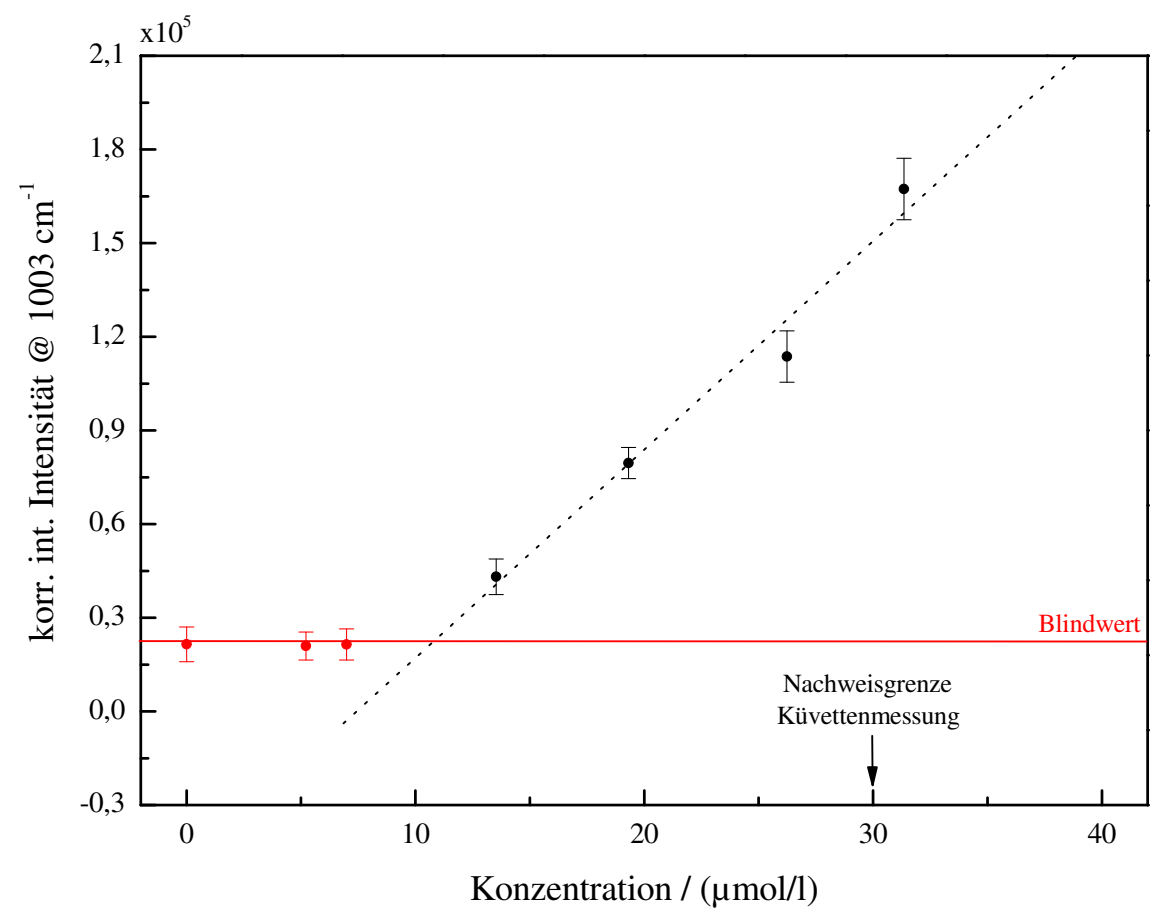

Abbildung 6.9: Auftragung der korrigierten integralen Intensität der Ramanbande bei $1003 \mathrm{~cm}^{-1}$ gegen die molare Konzentration. 


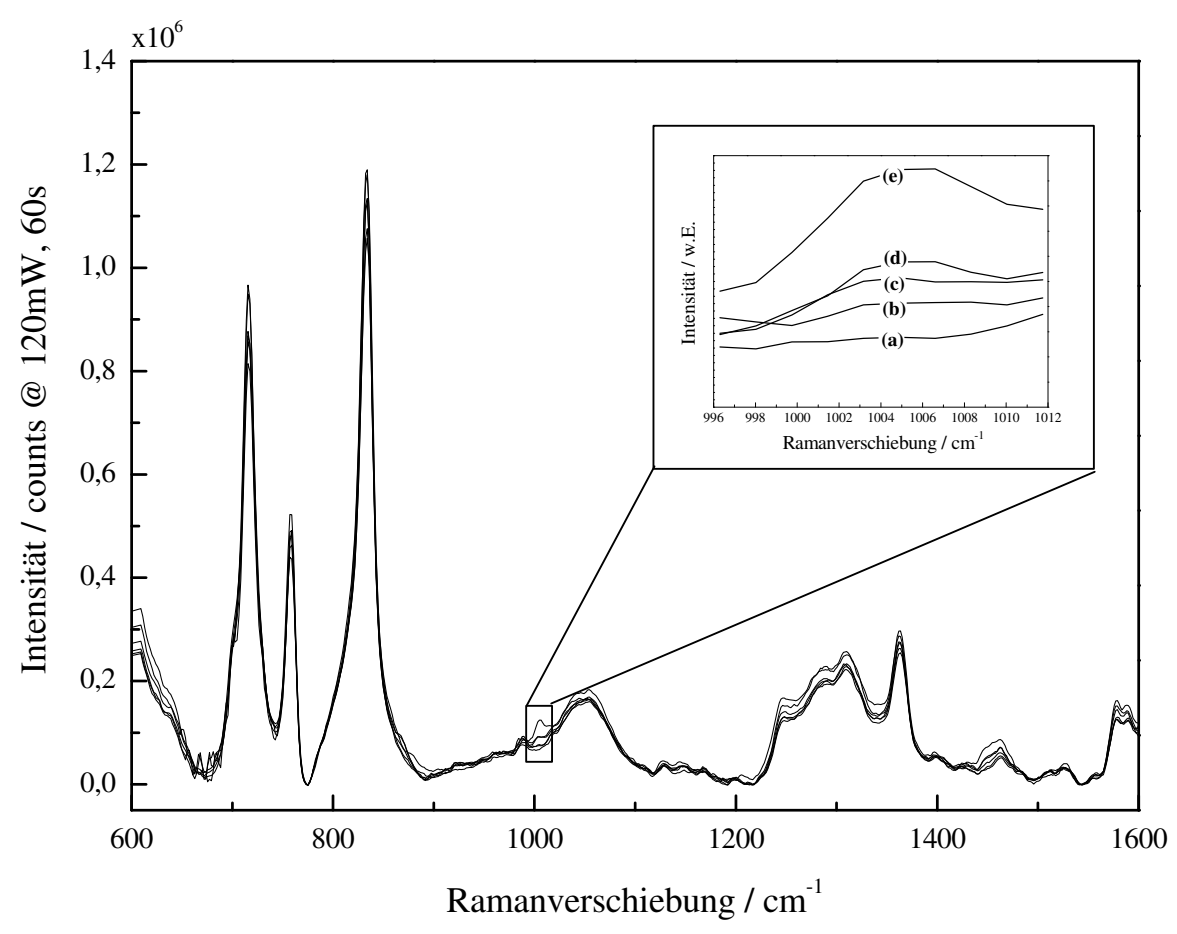

Abbildung 6.10: Ramanspektren der wässrigen $\gamma$-Globulin-Lösungen für den molaren Konzentrationsbereich von (a) 0 bis (e) $13 \mu \mathrm{mol} / 1$.

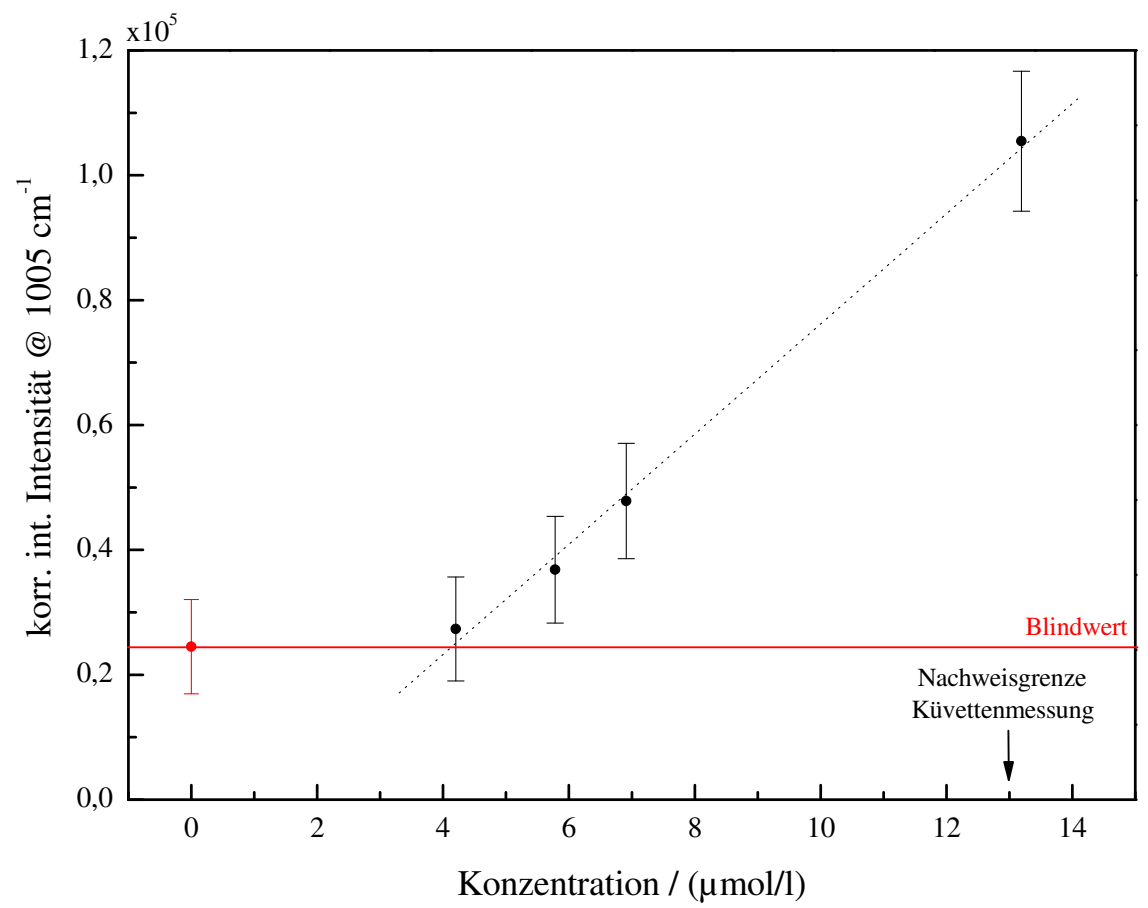

Abbildung 6.11: Auftragung der korrigierten integralen Intensität der Ramanbande bei $1005 \mathrm{~cm}^{-1}$ gegen die molare Konzentration. 


\subsection{Fazit}

Der Einsatz von Teflon-AF Kapillaren konnte erfolgreich zur Senkung der Nachweisgrenze wässriger Proteinlösungen gegenüber standardisierten Probenkammern, wie die der Küvette, demonstriert werden. Dazu wurde die üblicherweise von der Absorption der wässrigen Lösung abhängige Ramanstreulichtintensität ebenfalls erfolgreich korrigiert und eine fünfzig bis sechzigfach höhere Ramanstreulichtausbeute gegenüber der Küvette ermittelt. Dabei ist jedoch zu berücksichtigen, dass sich die Ramanstreulichtausbeute aus einer Multiplikation der tatsächlich gemessenen Ramanstreulichtintensitäten mit dem durch die Absorptionsmessungen ermittelten Korrekturfaktoren (s. Gleichung 6.7) ergibt. Da es sich lediglich um eine Multiplikation der gemessenen Ramanstreulichtintensitäten mit dem Korrekturfaktor handelt, ist die gegenüber der Küvette deutlich erhöhte Ramanstreulichtausbeute nicht zwangsläufig mit einer wesentlichen Verbesserung der Nachweisempfindlichkeit verbunden. Denn die Nachweisgrenze ergibt sich nur aus den nicht absorptionskorrigierten Ramanstreulichtintensitäten und den aus den Einzelmessungen ermittelten Standardabweichungen des Blindwertes. Damit führt der Einsatz der Teflon-AF Kapillare effektiv lediglich zu einer ca. sechsfach höheren Ramanstreulichtausbeute, wodurch es zur Absenkung der Nachweisgrenze kommt.

Desweiteren zeigen alle Spektren sehr dominante Ramanbanden des Teflon-AF's im Spektralbereich von 650 bis $900 \mathrm{~cm}^{-1}$, die für hohe Integrationszeiten und/oder Laserleistungen zwangsläufig zu einer Sättigung des CCD-Sensors führen und damit in diesem Fall keine Informationen aus diesen spektralen Bereichen für die Bestimmung extrem geringer Konzentrationen genutzt werden können.

Angesichts dieser angesprochenen Tatsachen ist abzuwägen, ob sich der Einsatz von Hohlwellenleitern auf Basis von Teflon-AF für die Detektion wässriger Proteinlösungen und der mit der Absorptionskorrektur verbundene experimentelle Aufwand für eine derart geringfügig verbesserte Nachweisempfindlichkeit rechtfertigt.

Dennoch ist hervorzuheben, dass mit Hilfe der Teflon-AF Kapillaren eine Erhöhung der Nachweisempfindlichkeit erreicht werden konnte bei deutlich geringeren Probenvolumina als bei der Küvettenmessung. Das Volumen für die effektive Länge der TeflonAF Kapillare betrug gegenüber dem Volumen der Küvette von $3 \mathrm{ml}$ lediglich $122 \mu \mathrm{l}$, worin einer der ganz entscheidenden Vorteile in der Verwendung von Teflon-AF Hohlwellenleitern liegt, nämlich die Möglichkeit, ramanspektroskopische Untersuchungen an sehr geringen Probenmengen durchführen zu können. 


\section{Kapitel 7}

\section{Oberflächenverstärkte Ramanstreu- lichtmessungen an Proteinen}

Die Quantifizierung und Identifizierung von sehr geringen Proteinkonzentrationen mittels der oberflächenverstärkten Ramanspektroskopie setzt neben den Anforderungen an die dafür eingesetzten Oberflächen, wie die Signalreproduzierbarkeit und Signalverstärkung, vor allem die Anlagerung einer ausreichenden zum Signal beitragenden Anzahl von Proteinen in unmittelbarer Nähe zu den ramanstreulichtverstärkenden Nanostrukturen voraus. Der Grund dafür sind die bereits in Kapitel 2 beschriebenen sehr kurzreichweitigen elektrischen Feldverstärkungen $\left(\propto 1 / d^{12}\right)$ der ramanstreulichtverstärkenden Oberflächen, so dass nur die der Oberfläche am nächsten gelegenen Moleküle die höchsten elektrischen Feldverstärkungen erfahren („first-layer“-Effekt). Aus diesem Grund korreliert die oberflächenverstärkte Ramanstreulichtintensität mit der Molekülbelegung der eingesetzten Oberflächen [81], wobei dieser Zusammenhang durch unterschiedliche Adsorptions-Isothermen für beliebige Adsorbate in Flüssigkeiten und Gasen in Abhängigkeit von der Adsorbatkonzentration beschrieben werden kann [14]. Diese Adsorptions-Isothermen fassen im Allgemeinen das Adsorptionsverhalten von Molekülen auf Oberflächen zusammen.

Eine in der oberflächenverstärkten Ramanspektroskopie häufig eingesetzte Adsorptions-Isotherme ist die Langmuir-Isotherme [58], die das mathematisch einfachste Modell zur Beschreibung des Zusammenhangs zwischen oberflächenverstärkter Ramanstreulichtintensität und Adsorbatkonzentration darstellt. Sie beruht auf der Annahme, dass die oberflächenverstärkte Ramanstreulichtintensität mit der konzentrationsabhängigen Adsorbatbelegung der Oberfläche korreliert, so dass mit zunehmenden Adsorbatkonzentrationen die Ramanstreulichtintensität zunächst monoton anwächst. Ist diejenige Adsorbatkonzentration erreicht, für die eine vollständige Belegung der Oberfläche (Monolage) vorliegt, führt eine Erhöhung der Adsorbatkonzentration wegen der nur sehr kurzreichweitigen elektrischen Feldverstärkungen der Oberflächen zu keinem weiteren Anstieg der Ramanstreulichtintensität. Diese nimmt somit für alle darüberliegenden Adsorbatkonzentrationen einen konstanten Wert an. Auf die mathematische 
Beschreibung der Langmuir-Isotherme wird in Abschnitt 7.4.1 noch näher eingegangen.

Seit den anfänglichen Untersuchungen von Otto et al. [81] bezüglich der von der Molekülbedeckung der Oberflächen abhängigen oberflächenverstärkten Ramanstreulichtintensität und vielen darauffolgenden Untersuchungen wiesen insbesondere Aroca et al. [10] anhand gemischter Monolagen von wohldefinierten Molekülkonzentrationen nach, dass auch gestapelte Monolagen, die sich bis zu $10 \mathrm{~nm}$ weit von der Oberfläche erstrecken, ebenfalls von den elektrischen Feldverstärkungen erfasst werden können. Damit wurde einerseits die Existenz eines Reichweiten-Effektes der elektrischen Feldverstärkung experimentell nachgewiesen und andererseits die Langmuir-Isotherme zur Beschreibung der konzentrationsabhängigen oberflächenverstärkten Ramanstreulichtintensität von Adsorbaten in solchen Fällen in Frage gestellt. Hingegen zeigten Loo et al. [64], dass die Langmuir-Isotherme für Konzentrationsbereiche unterhalb derjenigen, die zu einer Monolagenbedeckung der Oberfläche führt, ein gültiges Beschreibungsmodell darstellt.

Aufgrund der Tatsache, dass eine ausreichende zum Ramanstreulichtsignal beitragende und vor allem bekannte Anzahl von Zielmolekülen auf den ramanstreulichtverstärkenden Oberflächen adsorbiert sein muss, damit eine Quantifizerung durchgeführt werden kann, wurde in der vorliegenden Arbeit eine Methode zur gezielten Aufbringung wohldefinierter Volumina wässriger Proteinlösungen entwickelt. Diese Methode stellt die Grundlage für die Quantifizierung mit Hilfe der oberflächenverstärkten Ramanspektren von ausgewählten Proteinen dar und wird im nächsten Abschnitt beschrieben. Darauffolgend werden die auf Klarite ${ }^{\circledR}{ }_{-}$Substraten gemessenen oberflächenverstärkten Ramanspektren ausgewählter Proteine im Femtomol-Bereich vorgestellt und der Einfluss des reinen Substrat-Ramanspektrums auf diese Messungen diskutiert. Dafür werden sowohl orts- als auch zeitabhängige Ramanstreulichtmessungen des reinen Klarite ${ }^{\circledR}$-Substrates präsentiert und Hinweise auf einen Einzelmolekülnachweis diskutiert. Basierend auf diesen Untersuchungen werden konzentrationsabhängige Ramanstreulichtmessungen von Proteinen auf dem Klarite ${ }^{\circledR}$-Substrat dargestellt und der durch die Langmuir-Isotherme beschriebene funktionelle Zusammenhang zwischen der gemessenen Ramanstreulichtintensität und der Konzentration auf diese Messergebnisse übertragen und diskutiert. Darüber hinaus findet anhand der auf dem Klarite ${ }^{\circledR}$ Substrat gemessenen Ramanspektren eine Abschätzung des Verstärkungsfaktors statt. Anschließend wird mit Hilfe der Haupt-Komponenten-Analyse („Principal-ComponentAnalysis“ - PCA) die Fragestellung verfolgt, wie die Identifizierung ausgewählter Proteine auf den Klarite ${ }^{\circledR}$-Substraten mittels der oberflächenverstärkten Ramanspektroskopie realisiert werden kann. 


\subsection{Proteinanlagerung auf Oberflächen}

Wie bereits beschrieben, spielt insbesondere die Adsorption einer ausreichenden zum Signal beitragenden Anzahl von Proteinen in unmittelbarer Nähe zu den ramanstreulichtverstärkenden Nanostrukturen eine zentrale Rolle. Im Fall von wässrigen Lösungen mit sehr geringen Proteinkonzentrationen kann dies sehr effektiv durch die tropfenweise Auftragung der Proteinlösung auf die ramanstreulichtverstärkenden Oberflächen mit anschließender Verdampfung des Lösungsmittels realisiert werden, ohne dabei auf aufwendige chemische Modifikationen der Oberflächen zurückgreifen zu müssen. Durch das Verdampfen des Lösungsmittels lagern sich die in dem Tropfen vorliegenden Proteinmoleküle auf der Oberfläche an, so dass die unmittelbare Nähe dieser Moleküle zu den ramanstreulichtverstärkenden Nanostrukturen gewährleistet wird und darüber hinaus sogar eine Aufkonzentrierung der Moleküle stattfindet. Dieser Aufkonzentrierungseffekt wird vor allem in der „Drop-coating-deposition Raman spectroscopy“ (DCDR) genutzt [117, 20, 79]. Nach dem Verdampfen des Lösungsmittels liegt eine ringförmige Anhäufung der Proteine auf der Oberfläche vor, die einem Kaffeeringmuster (s. Abbildung 7.1) gleicht.

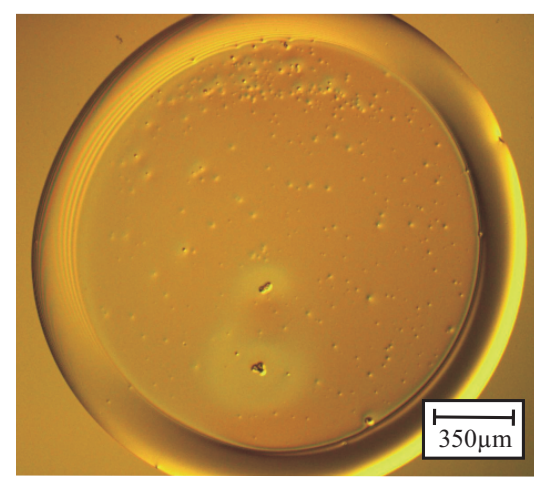

Abbildung 7.1: Fotografie eines Ringmusters, erzeugt durch Verdampfen von $0,5 \mu \mathrm{l}$ einer wässrigen $60 \mu \mathrm{M}$ Albuminlösung auf einer unstrukturierten Goldoberfläche.

Dieses Ringmuster entsteht durch einen Kapillarfluss, bei dem während des Verdunstens das Lösungsmittel aus dem Innenbereich des Tropfens in die Außenbereiche bis hin zur Kontaktline des Tropfens mit der Oberfläche strömt und dabei die Moleküle von innen nach außen transportiert [16]. Diese Moleküle sind nach der vollständigen Verdampfung des Lösungsmittels in Form eines Ringmusters auf der Oberfläche konzentriert. Das Potential der Aufkonzentrierung von Proteinmolekülen durch das Verdampfen des Lösungsmittels und die damit einhergehende Erhöhung der Signalintensität wird durch die in Abbildung 7.2 vorgestellten Ramanstreulichtmessungen deutlich. Dazu wurde ein Tropfen mit dem Volumen von $0,5 \mu \mathrm{l}$ einer $60 \mu \mathrm{M}$ wässrigen Albuminlösung manuell auf 
eine unstrukturierte Goldoberfläche mit Hilfe einer Pipette (Eppendorf) aufgebracht und nach anschließender Verdampfung des Lösungsmittels Ramanstreulichtmessungen bei konstanter Integrationszeit und Laserleistung von unterschiedlichen Positionen im Ringmuster durchgeführt (s. Abbildung 7.2).

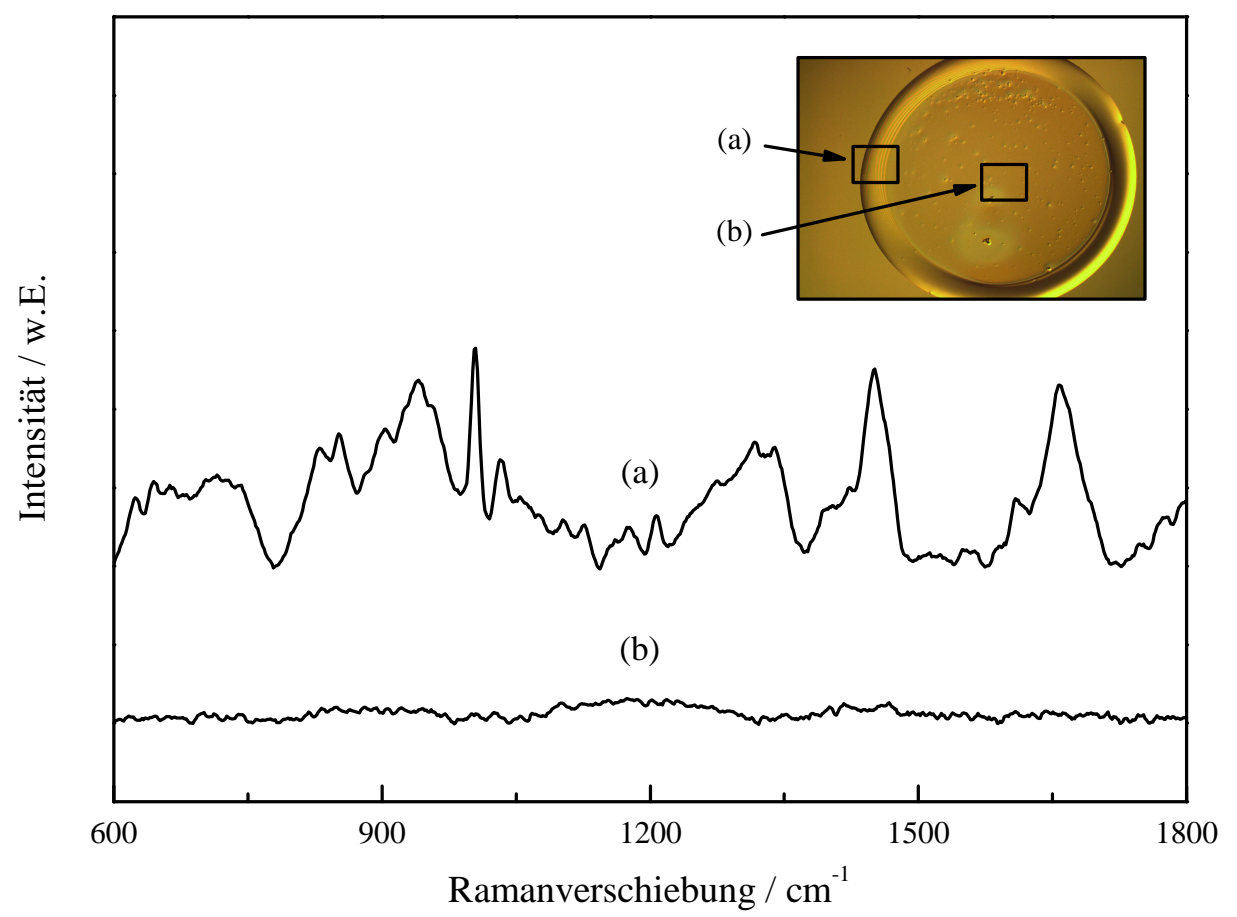

Abbildung 7.2: Ramanstreulichtmessungen an unterschiedlichen Positionen auf einem Ringmuster von $0,5 \mu \mathrm{l}$ einer $60 \mu \mathrm{M}$ Albuminlösung. (a) Im inneren Bereich des Rings und (b) auf dem Ring.

Während in der vom Ring eingeschlossenen Fläche kein Ramanstreulicht des Albumins detektiert werden kann, führt die Aufkonzentrierung zu einer erheblichen Steigerung der Signalintensität und zu einem Ramanspektrum, in dem die Ramanbanden des Albumins sehr gut aufgelöst sind. Der Übersicht halber wurden die mit einer Basislinie korrigierten Spektren jeweils mit einem additiven Versatz in der Intensität verschoben. Damit ist eindeutig gezeigt, dass sich der Großteil der Moleküle auf dem Ring befindet. Dabei kann aber keine Abschätzung der Molekülanzahl auf dem Ring und in der vom Ring eingschlossenen Fläche wegen der mit der Aufkonzentrierung einhergehenden Mehrschichtenbelegung der Moleküle im Ring vorgenommen werden. Dennoch ist in Abbildung $7.1 \mathrm{zu}$ sehen, dass die vom Ring eingeschlossene Fläche mit Molekülen bedeckt ist, was insbesondere durch die wesentlich rauere Oberflächenstruktur dieses Bereiches im Vergleich zu der reinen Goldoberfläche außerhalb des Ringmusters hervorgeht. Diese Aussage wird durch die rasterkraftmikroskopischen Aufnahmen von Ringmustern verschiedener Proteinlösungen aus der Veröffentlichung von Ortiz et al. [79] untermau- 
ert. Während die Aufkonzentrierung zu einer deutlichen Steigerung der Signalintensität führt, ist eine quantitative Analyse nicht unmittelbar mit den Ramanspektren möglich, wie anhand der Abbildung 7.3 ersichtlich wird.

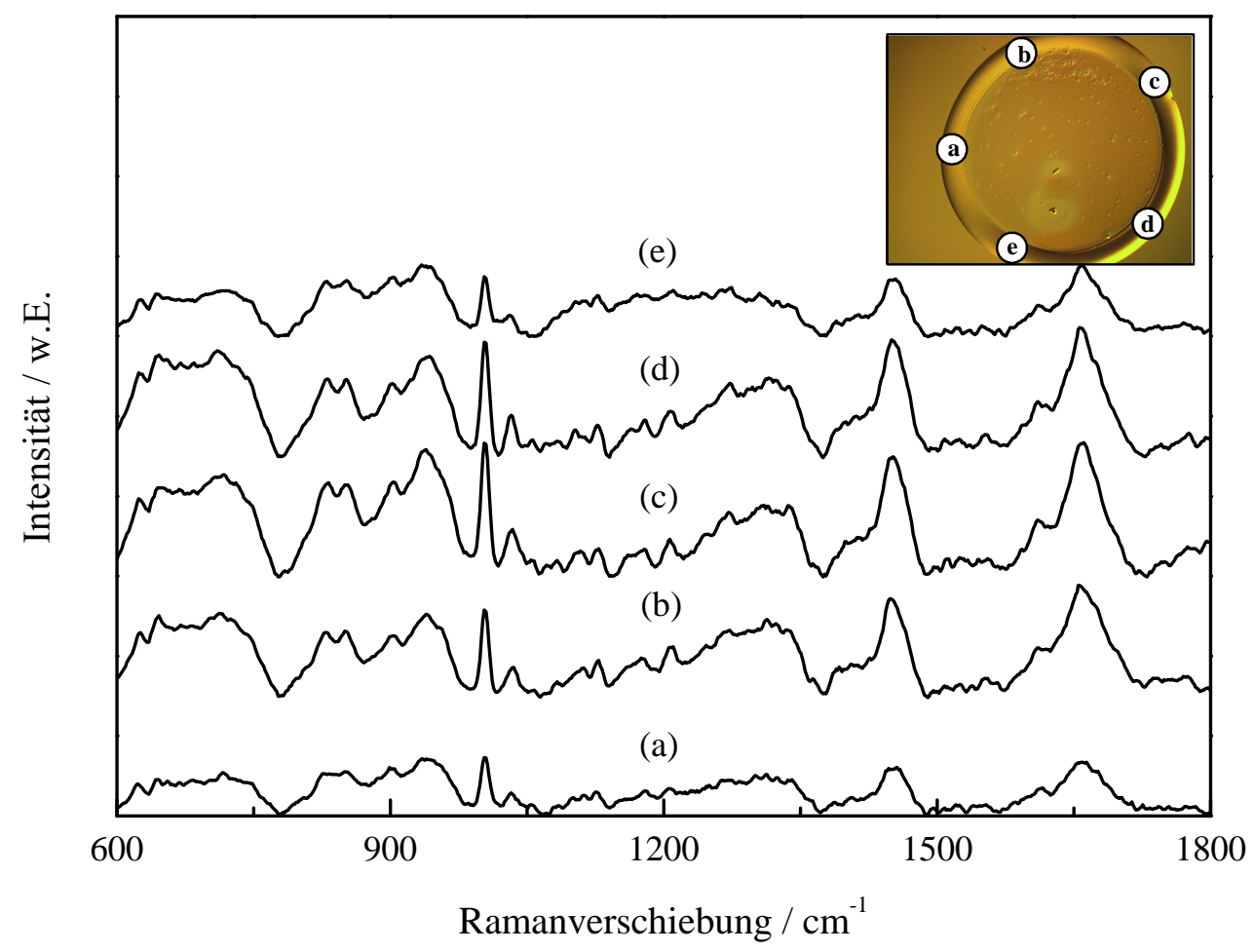

Abbildung 7.3: Ramanstreulichtmessungen an unterschiedlichen Positionen eines Ringmusters von $0,5 \mu \mathrm{l}$ einer $60 \mu \mathrm{M}$ Albuminlösung für verschiedene Positionen auf dem Ring (a)-(e).

Sie zeigt fünf mit einer Basislinie korrigierten Ramanspektren, die an verschiedenen Positionen auf dem bereits in Abbildung 7.2 vorgestellten Ringmuster aufgenommen wurden. Die Ramanspektren sind der Übersicht halber mit einem additiven Versatz in der Intensität dargestellt. Die Ringbreite betrug im Mittel ca. $170 \mu \mathrm{m}$, so dass die gesamte Ringbreite vom effektiven Laserspotdurchmesser des Ramanspektrometers erfasst wurde. Deutlich sind die hohen Intensitätsschwankungen der einzelnen Ramanbanden für die gemessenen Positionen auf dem Ring zu erkennen, die von Spektrum zu Spektrum bis zu $60 \%$ betragen können und mit hoher Wahrscheinlichkeit auf eine inhomogene Verteilung der Moleküle in dem Ringmuster zurückzuführen sind.

Neben den ortsabhängigen Signalschwankungen führt das manuelle Pipettieren ebenfalls zu sichtbaren Variationen der aufgetragenen Volumina, die sich in Abbildung 7.4 anhand der unterschiedlichen Ringbreiten (B) und -durchmesser (D) äußern, womit zwangsläufig hohe Ramanstreulichtintensitätsschwankungen von Ringmuster zu Ringmuster zu erwarten sind. 

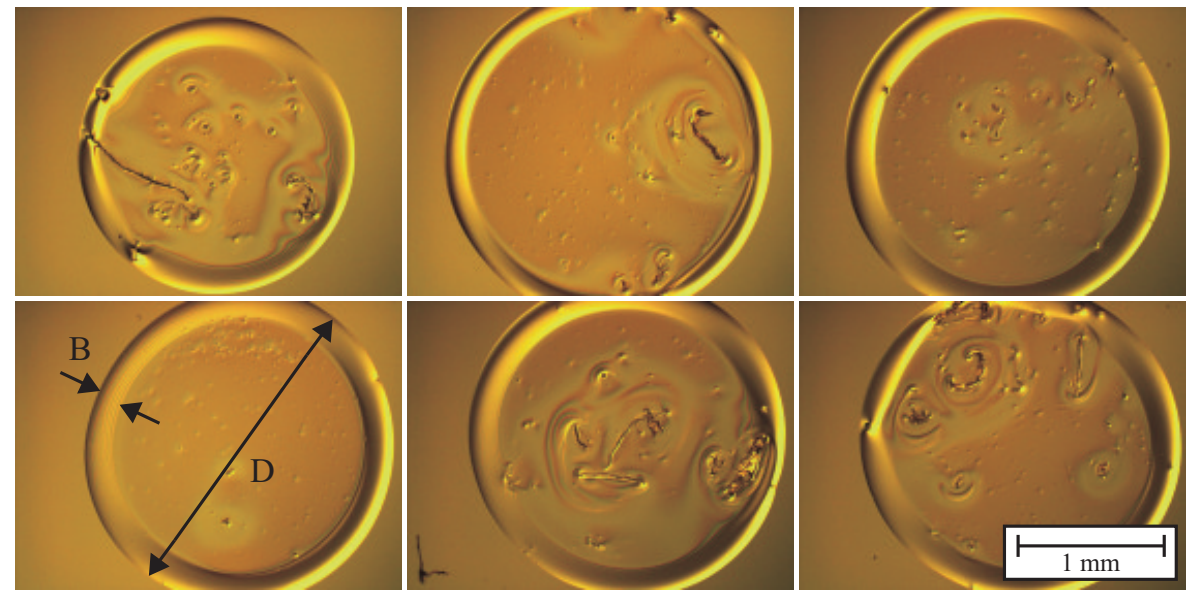

Abbildung 7.4: Fotos von sechs Ringmustern von $0,5 \mu \mathrm{l}$ einer $60 \mu \mathrm{M}$ Albuminlösung nach manueller Pipettierung und anschließender Verdampfung des Lösungsmittels.

Aufgrund dieser Tatsache, die die quantitative Ramanstreulichtmessung an den Ringmustern erschwert, wurde in der vorliegenden Arbeit eine automatische NP1.2 Pipettiereinheit der Firma GeSim zur Auftragung von Tropfen mit reproduzierbarem Volumen auf Oberflächen eingesetzt. Diese Pipettiereinheit ist ein Robotiksystem, welches mit einer piezoelektrischen Pipette ausgerüstet ist und Tropfen berührungsfrei dosiert. Diese Piezotechnologie erlaubt die Auftragung von Tropfen mit Volumina von minimal $0,06 \mathrm{nl}$ bis maximal 0,4 nl auf Oberflächen bei einer Frequenz von bis zu $1000 \mathrm{~Hz}$ und wird vor allem zur Herstellung von dichtgepackten Protein-Arrays eingesetzt [7]. Die Pipettiereinheit arbeitet in einem dreistufigen Pipettierzyklus (s. Abbildung 7.5), bei dem zunächst eine Probenentnahme mit der Pipette in der Regel aus standardisierten „Micro-Well“ Platten erfolgt.

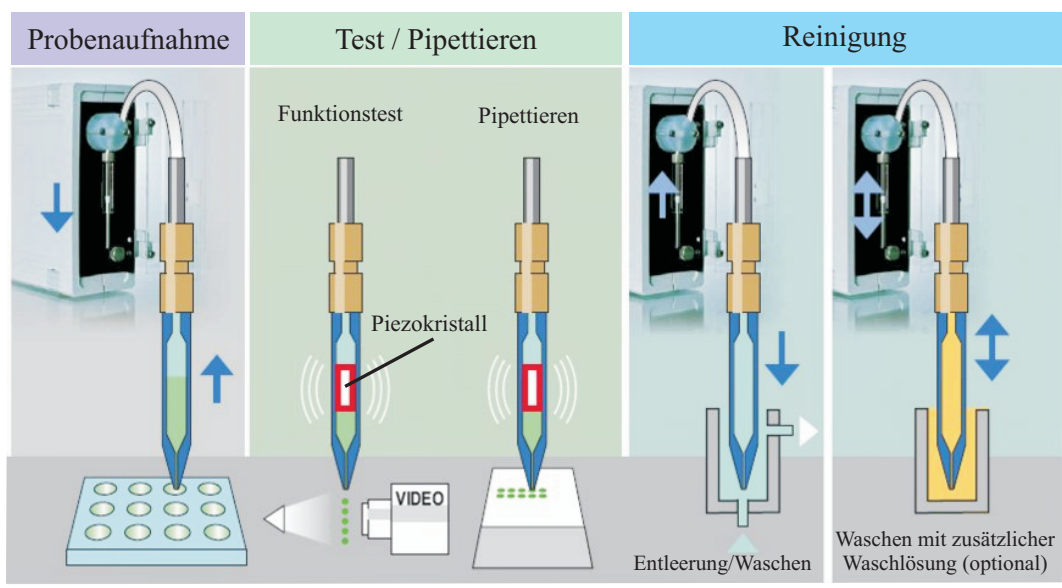

Abbildung 7.5: Schematische Darstellung des dreistufigen Pipettierzyklus des Nanoplotters NP1.2. 
Anschließend wird ein Funktionstest mit Hilfe einer Stroboskopkamera durchgeführt, in der sowohl die Tropfenerzeugung als auch die Flugbahn der Tropfen kontrolliert werden kann. Nach erfolgreichem Funktionstest wird der Tropfen auf die gewünschten Positionen auf der Oberfläche aufgebracht. Um bei einer weiteren direkt darauffolgenden Probenentnahme eine Kontamination mit dem bereits verwendeten Probenmaterial in der Pipette zu vermeiden, wird die Pipette im letzten Schritt des Pipettierzyklus entleert, mit Wasser gespült und von außen ebenfalls mit Wasser gereinigt. Die Dosierung der Tropfen wurde in der vorliegenden Arbeit mittels einer Nanopipette mit einem minimalen Tropfenvolumen von 0,16 nl und einem maximalen von 0,40 $\mathrm{nl}$ dosiet. Mittels eines Piezokristalls, der in der Pipette integriert ist, konnte durch Anlegen einer Spannung computergesteuert das Tropfenvolumen für Spannungen zwischen 60 und $90 \mathrm{~V}$ variiert werden, wobei ein lineares Verhalten zwischen dem dosierten Volumen und der Spannung besteht (s. Abbildung 7.6).

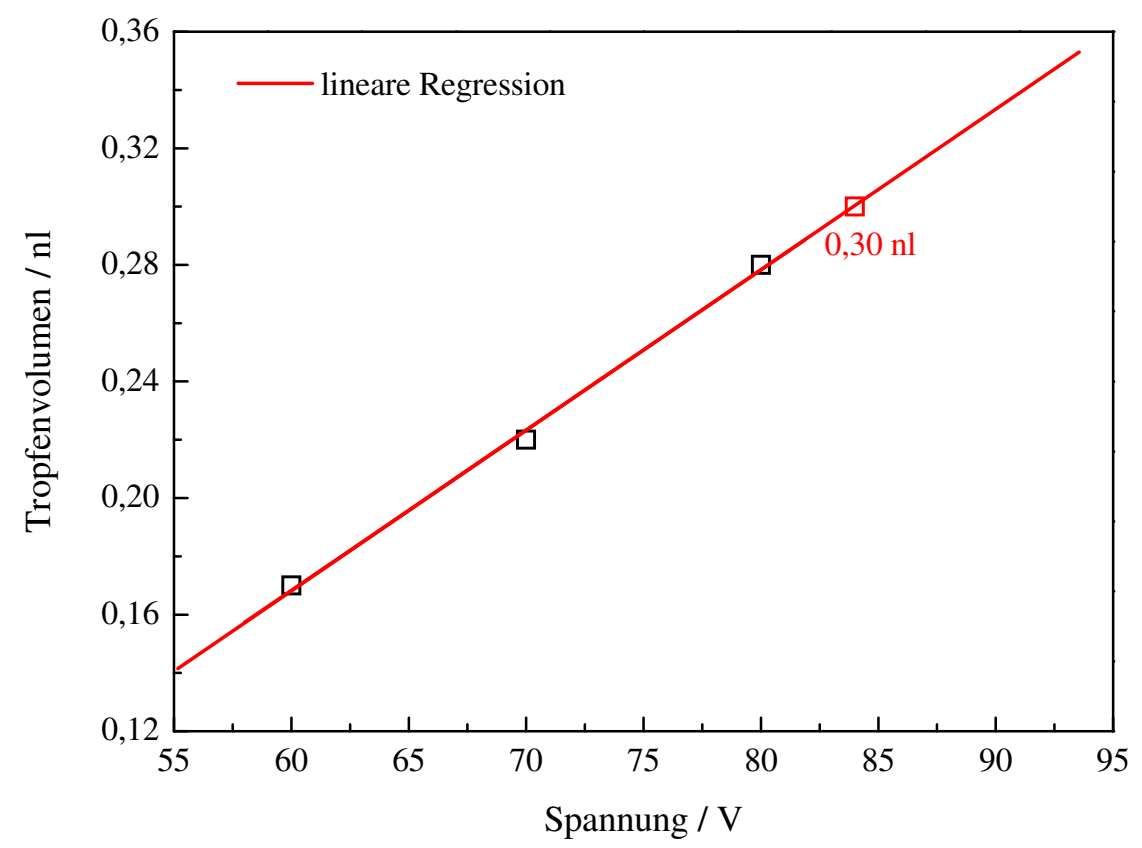

Abbildung 7.6: Auftragung des Tropfenvolumens der eingesetzten Nanopipette gegen die angelegte Spannung.

Spannungen oberhalb bzw. unterhalb dieses Bereiches ermöglichten in der vorliegenden Arbeit für die verwendeten Analytkonzentrationen entweder keine Tropfenerzeugung oder nur eine unzureichende, bei der simultan eine Vielzahl wesentlich kleinerer Tropfen, die so genannten „Satelliten“, entstehen (s. Abbildung 7.7) und damit das dosierte Volumen stark schwankt. Dabei zeigte sich, dass eine Spannung von 85 V Tropfen ohne Satelliten und mit optimalen senkrechten Flugbahnen erzeugte. Die in Abbildung 7.6 dargestellten Tropfenvolumina für die Spannungen von 60, 70 und $80 \mathrm{~V}$ sind Angaben 
des Herstellers. Für die Bestimmung des bei der Spannung von $85 \mathrm{~V}$ abgegebenen Tropfenvolumens wurde eine lineare Regression dieser Angaben durchgeführt und mittels der Regressionsgeradengleichung ein Tropfenvolumen von 0,30 nl berechnet.
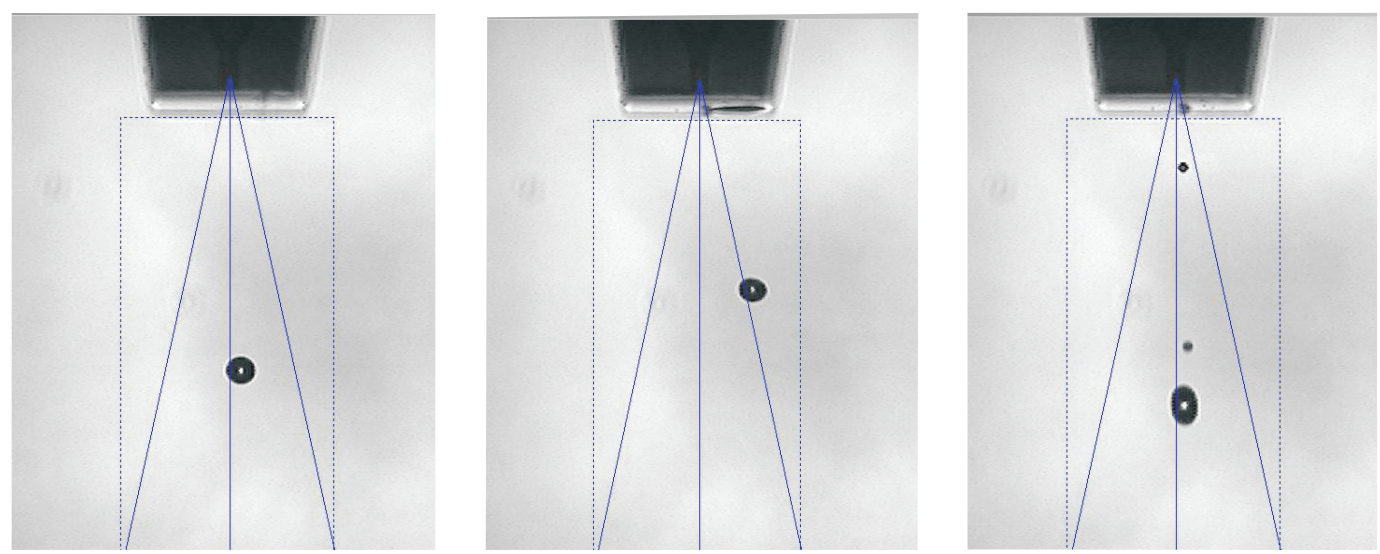

Abbildung 7.7: Fotografien des stroboskopischen Funktionstests für (links) $85 \mathrm{~V}$ und optimaler Tropfenerzeugung (Mitte) $50 \mathrm{~V}$ und schlechter Tropfenflugbahn und (rechts) $100 \mathrm{~V}$ mit Satelliten.

Laut Herstellerangaben [25] ermöglicht die eingesetzte Nanopipette eine Volumendosierung mit einer Genauigkeit von kleiner 5\% Standardabweichung gemessen über 10 Tropfen einer wässrigen Lösung und stellt zur Zeit technologisch die präziseste Dosierungstechnologie dar.

Zur Überprüfung der Herstellerangaben wurden drei Untersuchungen zur experimentellen Bestimmung der Volumenreproduzierbarkeit der Nanopipette durchgeführt. In der ersten Untersuchung wurden sowohl 10 Ringmuster mit jeweils einem Tropfenvolumen von 0,3 nl als auch 10 Ringmuster mit einer zunehmenden Anzahl von Tropfen pro Ringmuster einer wässrigen $60 \mu \mathrm{M}$ Albuminlösung auf einer unstrukturierten Goldoberfläche erzeugt. Die Tropfen wurden mit einer Frequenz von $100 \mathrm{~Hz}$ appliziert. Die nach dem Verdampfen des Lösungsmittels verbleibenden Ringmuster wurden anschließend mittels eines Axiostar Mikroskops (Zeiss) mit angeflanschter Infinity 3 CCD-Kamera (Lumenera) aufgenommen sowie die Ringdurchmesser D mit einem Bildbearbeitungsprogramm bestimmt. Das Ergebnis dieser Messungen ist in Abbildung 7.8 dargestellt. Daraus geht hervor, dass der Ringdurchmesser mit steigender Anzahl von Tropfen pro Ringmuster deutlich zunimmt, wohingegen die mit nur einem Tropfen erzeugten Ringmuster einen nahezu konstanten Ringdurchmesser aufweisen. Für den zweiten Fall ergibt sich ein mittlerer Ringdurchmesser von $123 \pm 2 \mu \mathrm{m}$ mit einer Standardabweichung von kleiner $2 \%$ vom Mittelwert der Ringdurchmesser und spiegelt somit die hohe Reproduzierbarkeit des applizierten Volumens wider. 


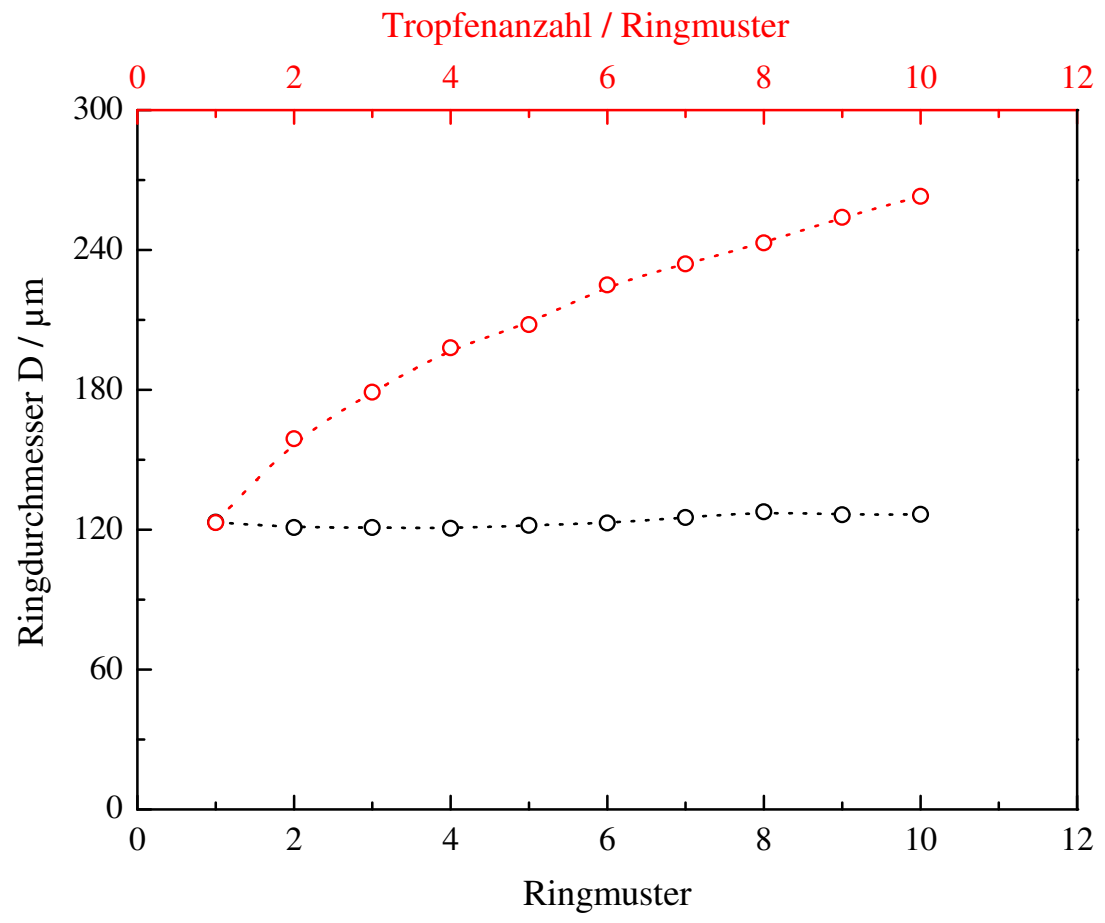

Abbildung 7.8: Auftragung der gemessenen Ringdurchmesser D.

In der zweiten Messreihe wurde der Einfluss der Konzentration und somit der Viskosität der Probenlösung auf das dosierte Tropfenvolumen untersucht, indem jeweils fünf Ringmuster wässriger Albuminlösungen mit Konzentrationen zwischen $13 \mu \mathrm{mol} / 1$ und $60 \mu \mathrm{mol} / 1$ ebenfalls auf einer unstrukturierten Goldoberfläche erzeugt wurden und analog zur ersten Untersuchung sowohl die Ringdurchmesser als auch zusätzlich die Ringbreite B bestimmt wurden. Das Ergebnis dieser Messungen ist in Abbildung 7.9 dargestellt. Daraus geht hervor, dass der Ringdurchmesser D über den gesamten Konzentrationsbereich mit $\mathrm{D}=122 \pm 2 \mu \mathrm{m}$ konstant bleibt, während die Ringbreite B linear mit der Konzentration ansteigt. Die mittlere Standardabweichung des Ringdurchmessers D liegt über dem gesamten gemessenen Konzentrationsbereich - ebenfalls wie bei der ersten Untersuchung - unterhalb von $2 \%$. Damit ist der Einfluss der Viskosität auf die dosierten Volumina für den vorgestellten Fall zu vernachlässigen. Der für die Ringmustervermessung verwendete Konzentrationsbereich des Albumins orientierte sich dabei an dem für die oberflächenverstärkte Ramanstreulichtmessung eingesetzten Konzentrationsbereich, der im noch folgenden Abschnitt 7.4.2 beschrieben wird.

Neben der reproduzierbaren Volumendosierung liegt ein ganz entscheidender Vorteil bei der Verwendung der Pipettiereinheit NP1.2 darin, dass die erzeugten Proteinringmuster kleiner sind als der effektive Laserspotdurchmesser des eingesetzten Ramanspektrometers. Somit ist die exakte Anzahl der zum Ramanstreulichtsignal beitragenden Moleküle im effektiven Laserspotdurchmesser bekannt. 


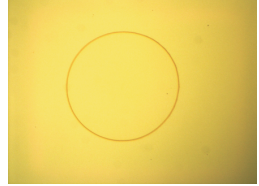

$13 \mu \mathrm{mol} / 1$

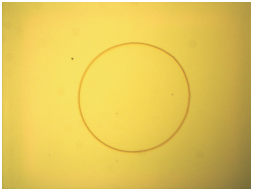

$17 \mu \mathrm{mol} / 1$

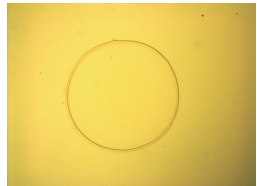

$24 \mu \mathrm{mol} / 1$

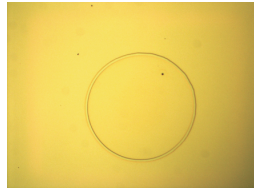

$40 \mu \mathrm{mol} / 1$

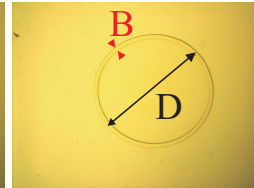

$60 \mu \mathrm{mol} / 1$

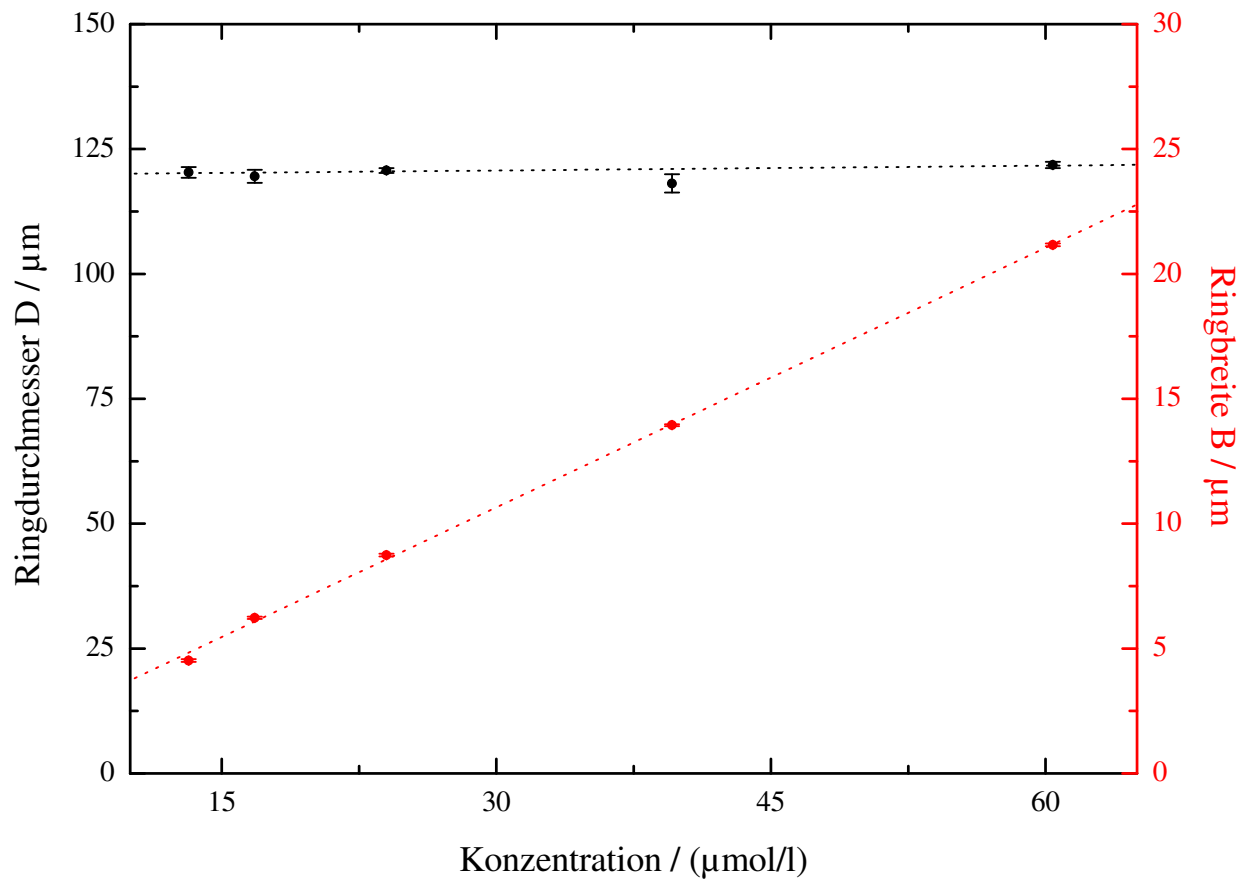

Abbildung 7.9: (Oben) Mikroskopische Aufnahmen von Ringmustern wässriger Albuminlösungen mit verschiedenen Konzentrationen bei einem dosierten Tropfenvolumen von 0,3 nl. (Unten) Auftragung der gemessenen Ringdurchmesser D und Ringbreiten B gegen die Konzentration der Albuminlösungen. Die Fehlerbalken geben die Standardabweichungen des Ringdurchmessers und der Ringbreite von fünf verschiedenen Ringmustern bei konstanter Albuminkonzentration an.

Demzufolge sollte sich eine Änderung des dosierten Volumens und somit der zum Signal beitragenden Molekülanzahl direkt in der Ramanstreulichtintensität äußern, da die anregende Strahlung erfahrungsgemäß bis zu $2 \mathrm{~mm}$ tief in biologische Proben eindringen kann und im Fall der sehr viel kleineren Ringhöhen alle Molekülschichten im Ring gleichermaßen zum Signal beitragen sollten.

Um diese Annahme zu untermauern, wurden in einer dritten Untersuchung fünf Ringmuster mit einer wässrigen $60 \mu \mathrm{M}$ Albuminlösung erzeugt und ramanspektroskopisch vermessen. Dazu wurde der effektive Laserspotdurchmesser jeweils fünfmal mit Hilfe der Beobachtungsoptik auf das Ringmuster zentriert, Ramanspektren aufgenommen, mit einer Basislinie korrigiert und die gemittelte integrale Intensität der Ramanbande des Albumins bei $1003 \mathrm{~cm}^{-1}$ gegen die Anzahl der Ringmuster aufgetragen (s. Abbil- 
dung 7.10). Die Fehlerbalken geben dabei die Standardabweichung der gemittelten Einzelmessungen an. Diese Standardabweichungen sind in jedem Fall kleiner als $2 \%$ vom Mittelwert der Einzelmessungen und geben den systematischen Fehler der Ramanstreu-

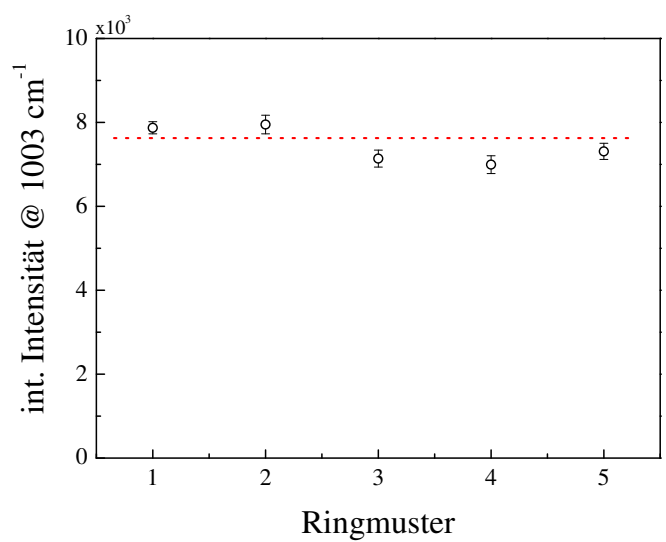

Abbildung 7.10: Auftragung der integralen Intensität der Ramanbande des Albumins bei $1003 \mathrm{~cm}^{-1}$ gegen die Anzahl der Ringmuster. lichtmessungen an, der auf die subjektive visuelle Zentrierung des effektiven Laserspots auf das Ringmuster durch den Experimentator zurückzuführen ist. Die Schwankung der über die Anzahl der Ringmuster gemittelten mittleren integralen Intensitäten beträgt $5 \%$, so dass unter Berücksichtigung der Standardabweichung der Einzelmessungen eine Reproduzierbarkeit der Volumendosierung von ca. $3 \%$ abgeschätzt werden kann. Sie stimmt mit denen der ersten beiden Untersuchungen überein, so dass insgesamt von einer Volumenreproduzierbarkeit von ca. 3\% ausgegegangen werden kann. Diese liegt im Bereich der vom Hersteller angegebenen Standardabweichung von $5 \%$.

Um bei derart geringen Molekülanzahlen in der vorliegenden Arbeit eine ausreichende Signalstärke zu erzielen, wurden die Ramanspektren bei einer Laserleistung von $50 \mathrm{~mW}$ und einer Integrationszeit von $60 \mathrm{~s}$ aufgenommen und zur Verbesserung des Signal-zu-Rausch Verhältnisses jeweils 5 Ramanspektren akkumuliert, woraus eine gesamte Integrationszeit von 300 s resultiert.

\subsection{Oberflächenverstärkte Ramanspektren ausgewählter Proteine}

In diesem Abschnitt werden oberflächenverstärkte Ramanspektren der Proteine Albumin, Insulin und Lysozym (Sigma-Aldrich), die auf Klarite ${ }^{\circledR}$-Substraten gemessen wurden sowie deren quantitative als auch qualitative Analyse in den folgenden Abschnitten vorgestellt. Diese Proteine decken eine große Spanne des molekularen Gewichtes von Proteinen ab. In Abbildung 7.11 sind die auf dem Klarite ${ }^{\circledR}$-Substrat gemessenen Ramanspektren der Ringmuster eines Volumens von $0,3 \mathrm{nl}$ einer wässrigen $18 \mu \mathrm{M} \mathrm{Al}$ buminlösung, $350 \mu \mathrm{M}$ Insulinlösung und $600 \mu \mathrm{M}$ Lysozymlösung sowie das Ramanspektrum des reinen Klarite ${ }^{\circledR}$-Substrates, im Folgenden mit Blindwertspektrum bezeichnet, dargestellt. Die dafür verwendeten Proteinkonzentrationen richteten sich nach den im 
noch folgenden Abschnitt 7.4.2 ermittelten nachweisbaren Konzentrationsbereichen dieser Proteine. Der Übersicht halber sind die Spektren in Abbildung 7.11 versetzt dargestellt. Daraus geht hervor, dass sich die Spektren kaum vom Blindwertspektrum des Klarite ${ }^{\circledR}$-Substrats unterscheiden. Damit liegt ein dominanter Quereinfluss des Blindwertspektrums in den Ramanspektren der Proteine vor.

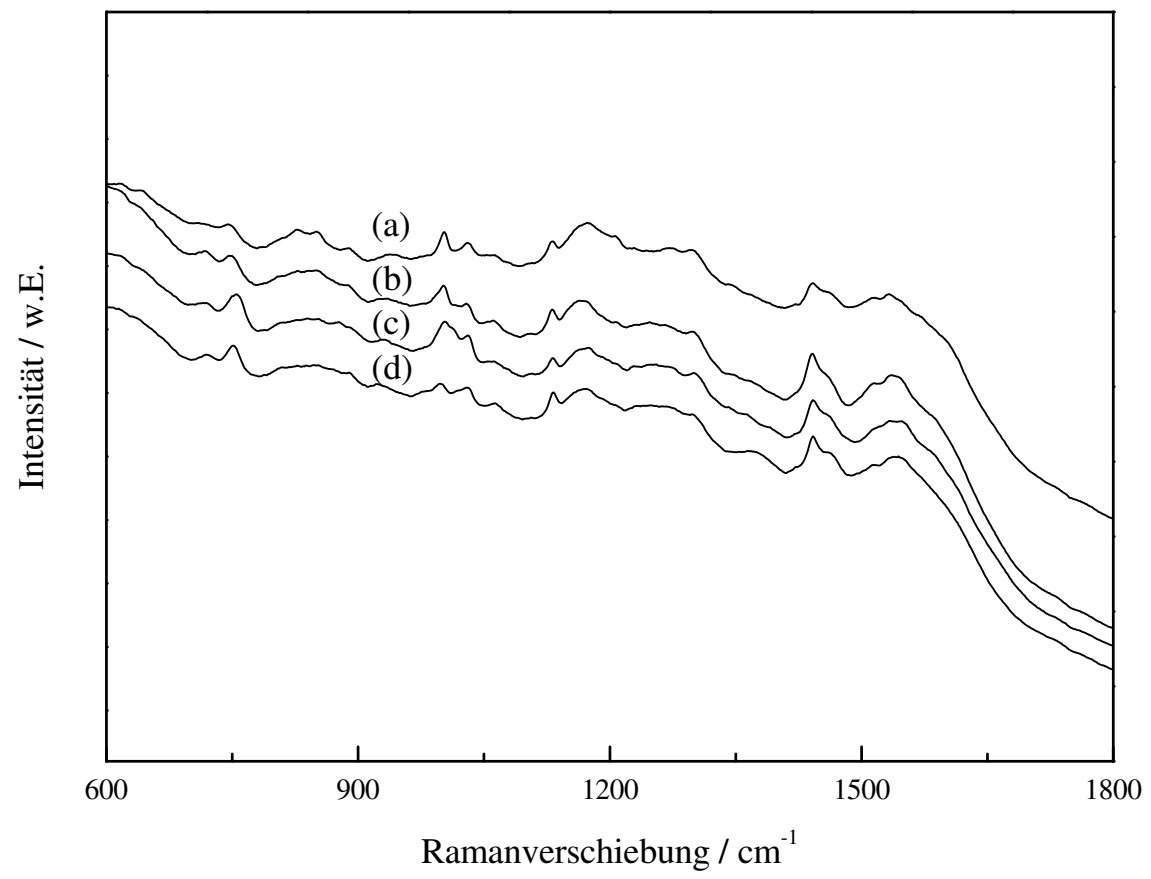

Abbildung 7.11: Oberflächenverstärkte Ramanspektren von Ringmustern einer wässrigen (a) $600 \mu \mathrm{M}$ Lysozymlösung, (b) $18 \mu \mathrm{M}$ Albuminlösung, (c) $350 \mu \mathrm{M}$ Insulinlösung und (d) Blindwertspektrum.

Das Blindwertspektrum auf dem unstrukturierten Bereich des Klarite ${ }^{\circledR}$-Substrates unterschied sich deutlich von demjenigen, welches auf dem strukturierten Bereich gemessen wurde und entspricht einer Null-Linie. Damit ist das Blindwertspektrum auf dem strukturierten Bereich der Klarite ${ }^{\circledR}$-Oberfläche mit hoher Wahrscheinlichkeit auf ein oberflächenverstärktes Ramanspektrum von Molekülen zurückzuführen, die aus einer Kontamination während des Herstellungsprozesses resultieren. Ein sicheres Indiz dafür sind die relativ scharfen spektralen Strukturen des Blindwertspektrums. Aus diesem Grund wurde Rücksprache mit der Herstellerfirma D3-Technologies gehalten, und es wurde mitgeteilt, dass eine mögliche Kontamination nicht ausgeschlossen werden kann. Bei der Kontamination handelte es sich nicht um einen Einzelfall, sondern Entsprechendes wurde auf allen eingesetzten Substraten festgestellt, die aus völlig unterschiedlichen Chargen stammten. Eine ausführliche ramanspektroskopische Untersuchung des zeitlichen und örtlichen spektralen Verhaltens des strukturierten Bereiches der Klarite ${ }^{\circledR}$ Substrate wird in Abschnitt 7.3 vorgestellt. 


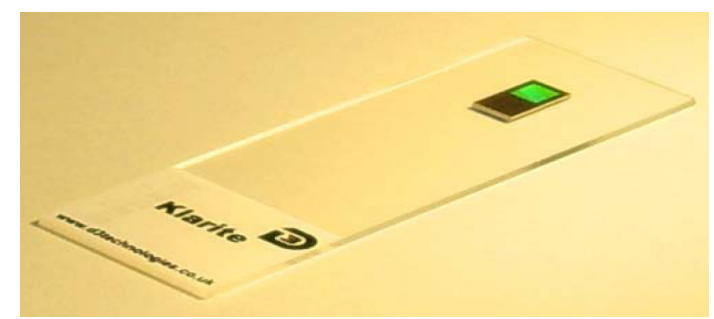

Abbildung 7.12: Foto eines Klarite ${ }^{\circledR}$-Substrats, das auf einem Objektträger befestigt ist. Der grünlich wirkende Bereich markiert die nanostrukturierte Oberfläche, die von einer unstrukturierten Goldoberfläche umgeben ist.

Um trotz des dominanten Blindwertspektrums die Ramanbanden der Proteine auflösen zu können, wurde das Blindwertspektrum vom Proteinramanspektrum subtrahiert und an dem resultierenden Spektrum anschließend eine automatische Basislinienkorrektur durchgeführt. Die Ergebnisse dieser Datenvorbehandlung sind exemplarisch in den Abbildungen 7.13, 7.14 und 7.15 zusammengefasst.

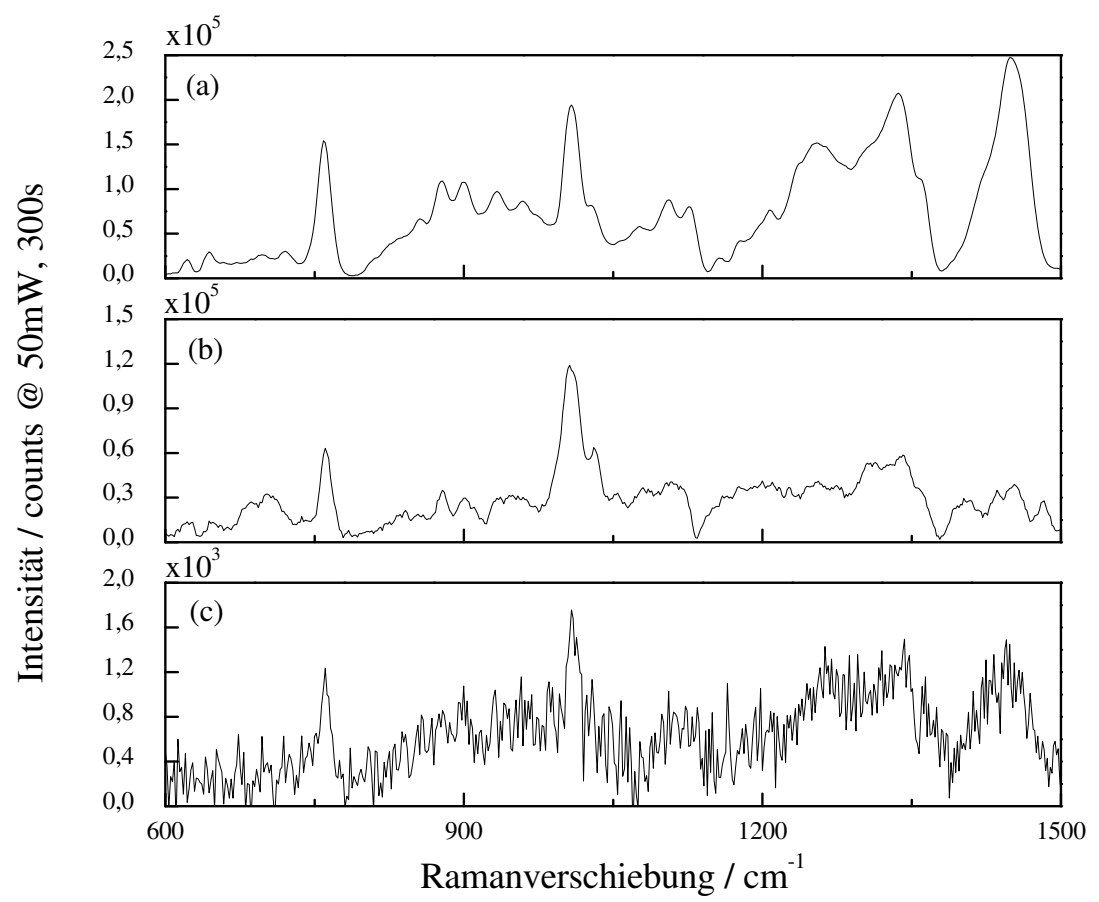

Abbildung 7.13: (a) Ramanspektrum von kristallinem Lysozym mit Basislinienkorrektur. (b) oberflächenverstärktes Ramanspektrum des Ringmusters einer $600 \mu \mathrm{M}$ Lysozymlösung nach Abzug des Blindwertspektrums mit darauffolgender Basislinienkorrektur. (c) Nicht oberflächenverstärktes Ramanspektrum eines Ringmusters der $600 \mu \mathrm{M}$ Lysozymlösung, gemessen auf einer unstrukturierten Goldoberfläche. 


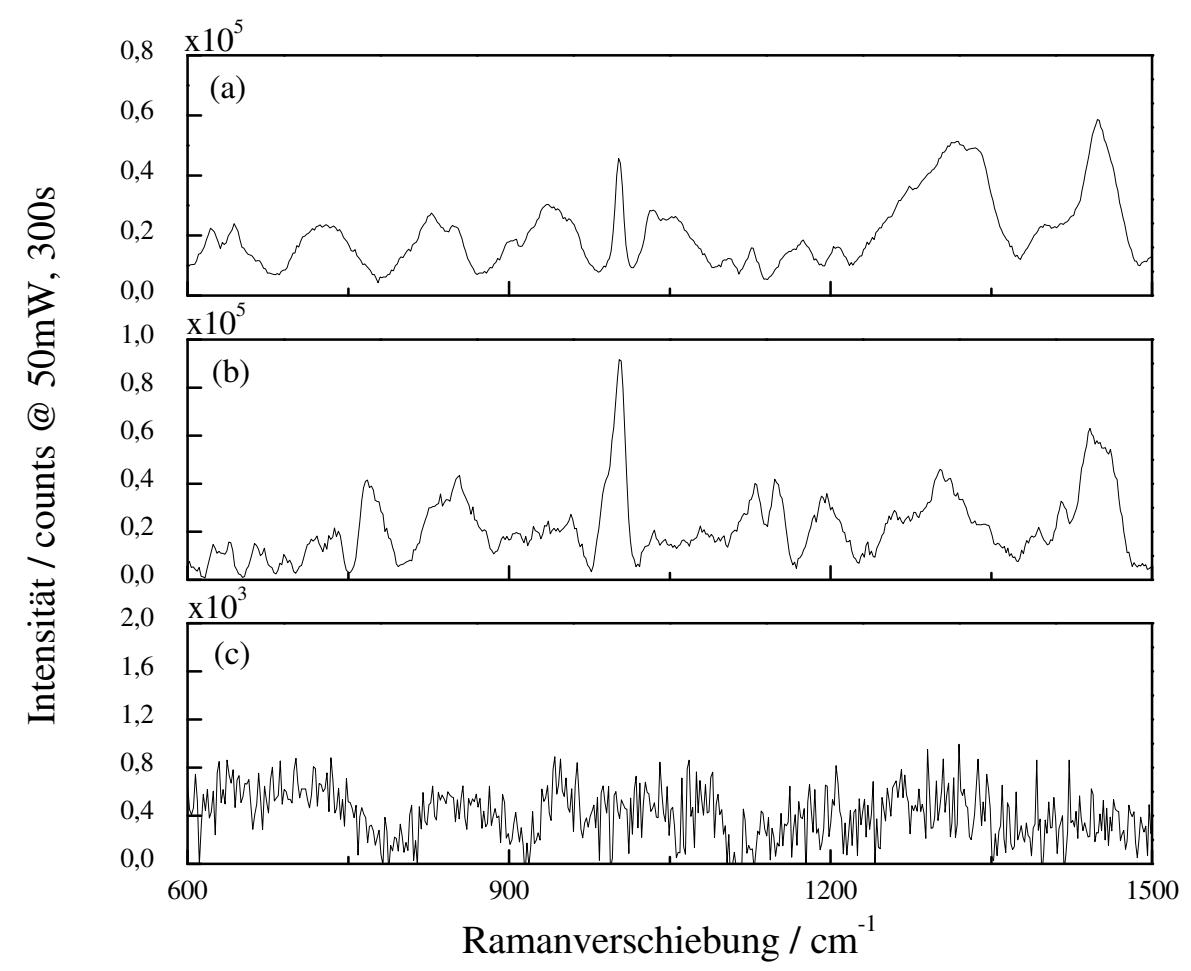

Abbildung 7.14: (a) Ramanspektrum von kristallinem Albumin mit Basislinienkorrektur. (b) Oberflächenverstärktes Ramanspektrum des Ringmusters einer $18 \mu \mathrm{M}$ Albuminlösung nach Abzug des Blindwertspektrums mit darauffolgender Basislinienkorrektur. (c) Nicht oberflächenverstärktes Ramanspektrum des Ringmusters der $600 \mu \mathrm{M}$ Albuminlösung, gemessen auf einer unstrukturierten Goldoberfläche.

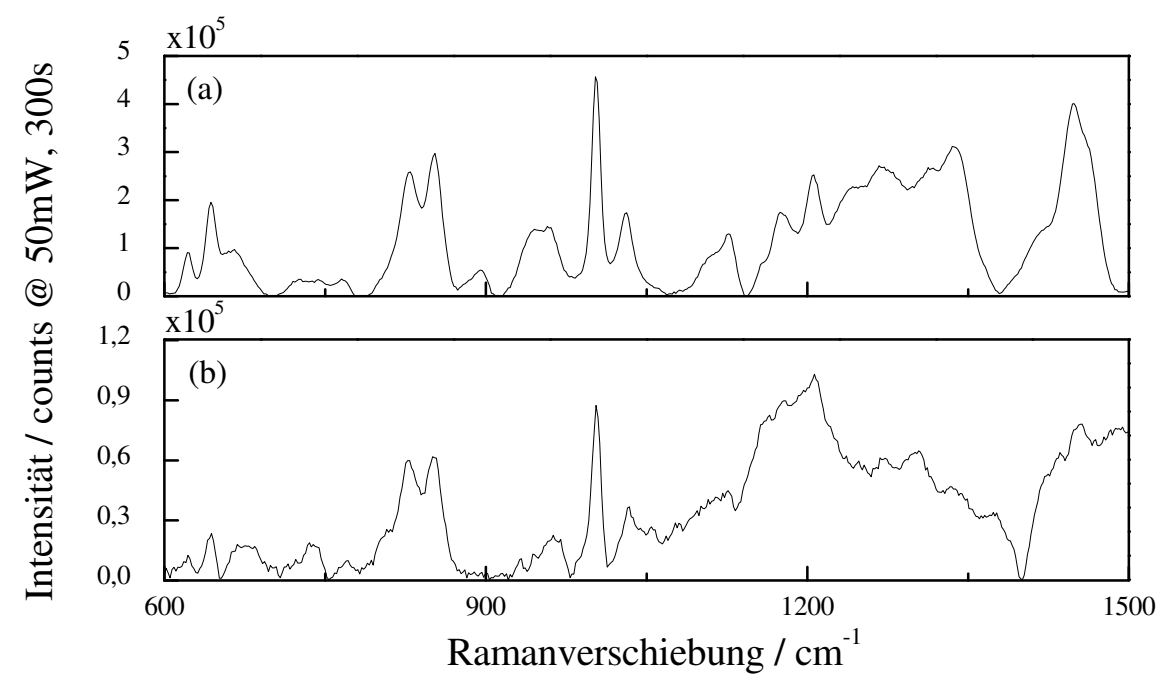

Abbildung 7.15: (a) Ramanspektrum von kristallinem Insulin mit Basislinienkorrektur. (b) Oberflächenverstärktes Ramanspektrum des Ringmusters einer $350 \mu \mathrm{M}$ Insulinlösung nach Abzug des Blindwertspektrums mit darauffolgender Basislinienkorrektur. 
Um sicherzustellen, dass die vorbehandelten Spektren den Proteinsspektren entsprechen, wurden zusätzlich die Ramanspektren der Proteine in kristalliner Form gemessen. Diese sind ebenfalls in den vorherigen Abbildungen dargestellt.

Desweiteren wurden Ramanspektren von Ringmustern mit denselben Proteinkonzentrationen von Albumin und Lysozym auf dem unstrukturierten Bereich des Klarite ${ }^{\circledR}$ _ Substrates bei gleicher Integrationszeit und Laserleistung aufgenommen, damit ein direkter Vergleich zwischen dem nicht oberflächenverstärkten und dem oberflächenverstärkten Ramanspektrum bei konstanten Versuchsbedingungen möglich ist. Diese Spektren sind ebenfalls in den Abbildungen 7.13 und 7.14 mit aufgenommen. Um bei den Ramanstreulichtmessungen auf der unstrukturierten Oberfläche bei diesen Konzentrationen ausreichend Signal zu erhalten, wurde eine Integrationszeit von $20 \mathrm{~s}$ und eine Laserleistung von $50 \mathrm{~mW}$ gewählt und über 15 Ramanspektren akkumuliert. Mit diesen Einstellungen wurden ebenfalls die oberflächenverstärkten Ramanstreulichtmessungen durchgeführt.

Im direkten Vergleich der Spektren wird das Potential der Ramanstreulichtverstärkung durch den Einsatz von Klarite ${ }^{\circledR}$-Substraten deutlich. Zum Einen zeigen die oberflächenverstärkten Ramanspektren charakteristische Ramanbanden der Proteine, was durch den Vergleich mit den Ramanspektren der kristallinen Proteine gezeigt wird. Zum Anderen wird eine erhebliche Steigerung des Signal-zu-Rausch-Verhältnisses sowie um ca. 2 Größenordnungen höhere Ramanstreulichtintensitäten erzielt im Vergleich zu den Ramanspektren auf der unstrukturierten Goldoberfläche. Diese Verstärkung des Ramanstreulichtes ist aber keinesfalls mit dem Verstärkungsfaktor gleichzusetzen. Denn unter Berücksichtigung der nur sehr kurzreichweitigen Feldverstärkungen werden mit sehr hoher Wahrscheinlichkeit nur diejenigen Moleküle von den Feldverstärkungen erfasst, die unmittelbar auf der Oberfläche aufliegen. Damit trägt nur ein sehr viel kleinerer Anteil von der gesamten Molekülanzahl im Ringmuster zur gemessenen oberflächenverstärkten Ramanstreulichtintensität bei. Im Fall der Ringmuster auf der unstrukturierten Goldoberfläche aber tragen alle Moleküle gleichermaßen zum Signal bei. Da in der vorliegenden Arbeit ungeklärt ist, in welcher Art und Weise sich die Proteine auf der Oberfläche durch das Verdampfen des Lösungsmittels anlagern, ist keine exakte Bestimmung des Verstärkungsfaktors über eine bekannte Anzahl von Molekülen unmittelbar auf der Oberfläche, analog zu Kapitel 4, möglich, sondern nur eine grobe Abschätzung. In Abschnitt 7.4.3 wird eine Abschätzung der mit dem Klarite ${ }^{\circledR}$ Substrat erzielten Verstärkungsfaktoren für Proteine vorgenommen.

Obwohl in dieser Arbeit mögliche Strukturveränderungen der Proteine bei der Anlagerung auf der Oberfläche nach dem Verdampfen des Lösungsmittels nicht untersucht werden konnten, liefern die IR-spektroskopischen Untersuchungen von Oberg et al. [76] 
an dünnen Proteinfilmen lediglich einige Hinweise darauf, dass die Proteine nach dem Verdampfen des Lösungsmittels weitgehend hydratisiert bleiben, wobei der Grad der Hydratisierung von dünnen Proteinschichten in einer Studie von Ortiz et al. [80] mit Hilfe der DCDR untersucht wurde. Aussagen über die strukturellen Veränderungen konnten auch hier nicht getroffen werden.

Die oberflächenverstärkten Spektren der Proteine aus den Abbildungen 7.13, 7.14 und 7.15 stimmen für den Spektralbereich von 600 bis $1100 \mathrm{~cm}^{-1}$ gut mit denen der kristallinen Form der Proteine überein, was auf einen konstanten Verstärkungsfaktor über diesen Spektralbereich hindeutet. Diese Beobachtung deckt sich mit den Untersuchungen von Drachev et al. [17], allerdings wurden in dieser Untersuchung so genannte „adaptive plasmonische Nanostrukturen“ eingesetzt. Im Vergleich zu den in Kapitel 4 beschriebenen Thiophenol-Monolagen weisen die oberflächenverstärkten Ramanspektren der Proteine keine messbaren Verschiebungen in den Ramanbanden gegenüber den nichtoberflächenverstärkten Ramanspektren auf. Dies weist darauf hin, dass die mit der Chemisorption einhergehende Ausbildung eines Ladungstransferkomplexes als möglicher Verstärkungseffekt ausgeschlossen werden kann und lediglich der elektromagnetische Verstärkungseffekt für die Ramanstreulichtverstärkung verantwortlich ist.

Desweiteren fällt in den oberflächenverstärkten Ramanspektren der Proteine auf, dass oberhalb von $1100 \mathrm{~cm}^{-1}$ starke Unterschiede zu den Ramanspektren der kristallinen Proteine vorliegen. Oberhalb von $1100 \mathrm{~cm}^{-1}$ liegen die Amid-I und Amid-III Ramanbanden, die Auskunft über die Struktur der Proteine geben (s. Kapitel 2). Da in der vorliegenden Arbeit ungeklärt ist, wie sich die Proteinstrukturen beim Verdampfen des Lösungsmittels verhalten, können die spektralen Unterschiede von einer strukturellen Veränderung des Proteins herrühren. Eine weitere mögliche Erklärung stellen zeitabhängige und ortsabhängige Schwankungen des Blindwertspektrums vom Klarite ${ }^{\circledR}$-Substrat dar, die sich in den oberflächenverstärkten Ramanspektren der Proteine widerspiegeln. Szeghalmi et al. [106] wiesen derartige Schwankungen bereits auf Klarite ${ }^{\circledR}$-Substraten nach. Zur Untersuchung dieses Einflusses auf die Proteinramanspektren wurden sowohl zeit- als auch ortsabhängige Ramanstreulichtmessungen des reinen Klarite ${ }^{\circledR}$-Substrates durchgeführt, die im nächsten Abschnitt vorgestellt werden. 


\subsection{Zeit- und ortsabhängige Messungen des Blindwertspektrums}

Für die Untersuchung des zeitlichen Verhaltens des Blindwertspektrums des Klarite ${ }^{\circledR}$ Substrates wurden 600 Spektren mit jeweils 1s Integrationszeit bei einer Laserleistung von $50 \mathrm{~mW}$ direkt aufeinanderfolgend an demselben Ort auf der Oberfläche gemessen. Die Rohspektren sind in Abbildung 7.16 dargestellt. Daraus geht hervor, dass ca. $90 \%$ der gemessenen Blindwertspektren unverändert bleiben, während die restlichen $10 \%$ zeitabhängige Fluktuationen in Form stark ausgeprägter Ramanbanden überwiegend im Wellenzahlbereich um $1550 \mathrm{~cm}^{-1}$ herum aufweisen und vereinzelt im Wellenzahlbereich um $1000 \mathrm{~cm}^{-1}$. Abbildung 7.17 zeigt zwei Ausschnitte aus der gemessenen Zeitreihe, in denen stark ausgeprägte Ramanbanden in kurzen Zeitintervallen (kleiner 10 s) auftauchen. Derartige stark zeitlich fluktuierende ausgeprägte Ramanbanden sind vielfach in der Literatur $[54,67,56]$ dokumentiert und werden häufig einem Einzelmolekülnachweis zugeschrieben.

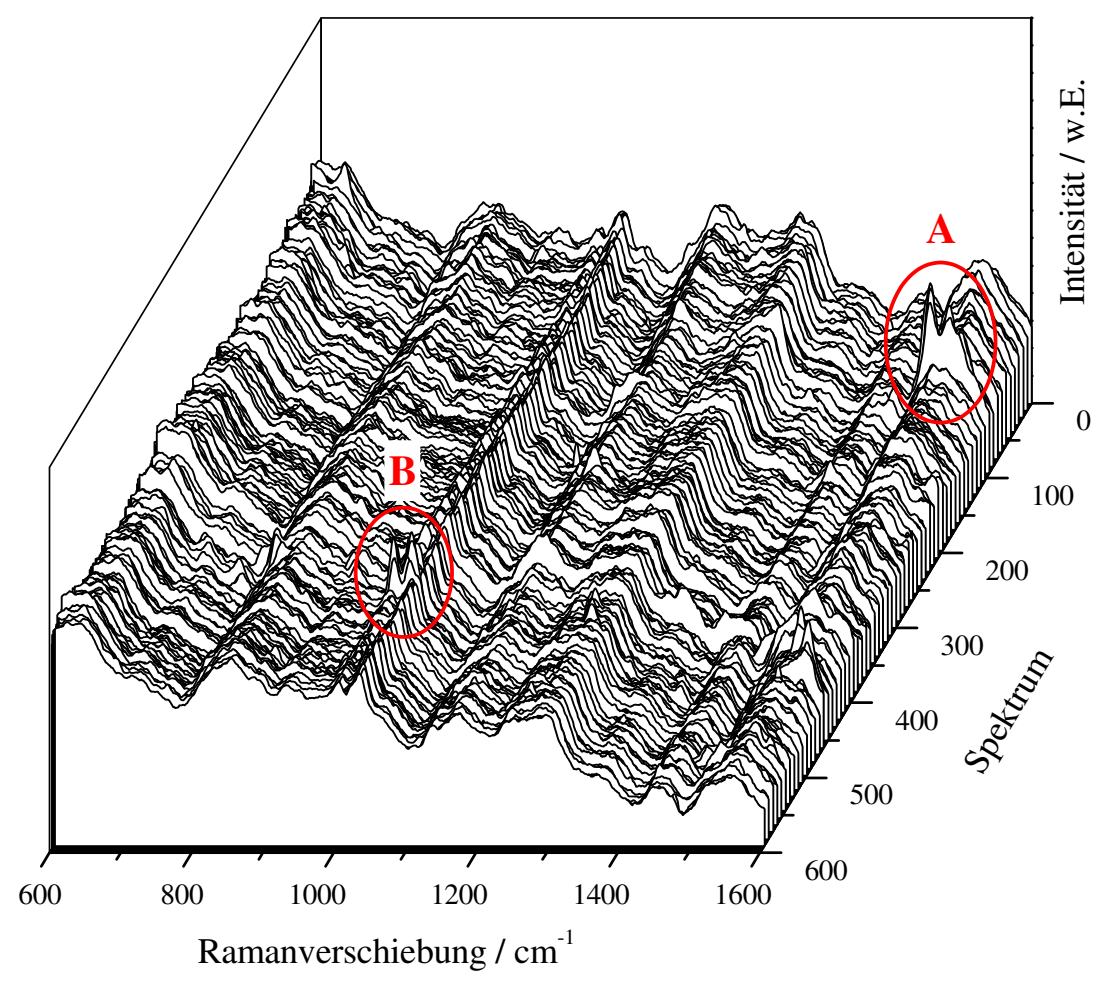

Abbildung 7.16: Zeitreihe des Blindwertspektrums vom Klarite ${ }^{\circledR}$-Substrat.

Diese Studien werden derzeit jedoch noch kontrovers diskutiert, da der zugrundeliegende chemische und physikalische Ursprung nicht vollständig verstanden ist. Ein Großteil dieser Studien wurde allerdings nicht auf den reinen ramanstreulichtverstärkenden 
Oberflächen durchgeführt, sondern nur auf mit Adsorbaten beschichteten. Diese Studien führen die kurzzeitigen Fluktuationen auf eine thermische Aktivierung des Adsorbates zurück, wodurch eine thermische Diffusion oder eine Neuorientierung des Adsorbats auf der Oberfläche stattfindet und damit zeitlich korrelierende Änderungen im Ramanspektrum auftauchen. Da das Ramanspektrum des reinen Klarite ${ }^{\circledR}$-Substrats im Mittel einen strukturierten Kurvenverlauf aufweist (s. Abbildung 7.17), wie er typischerweise von Molekülen herrührt, stellt dieser Effekt eine mögliche Erklärung dar.
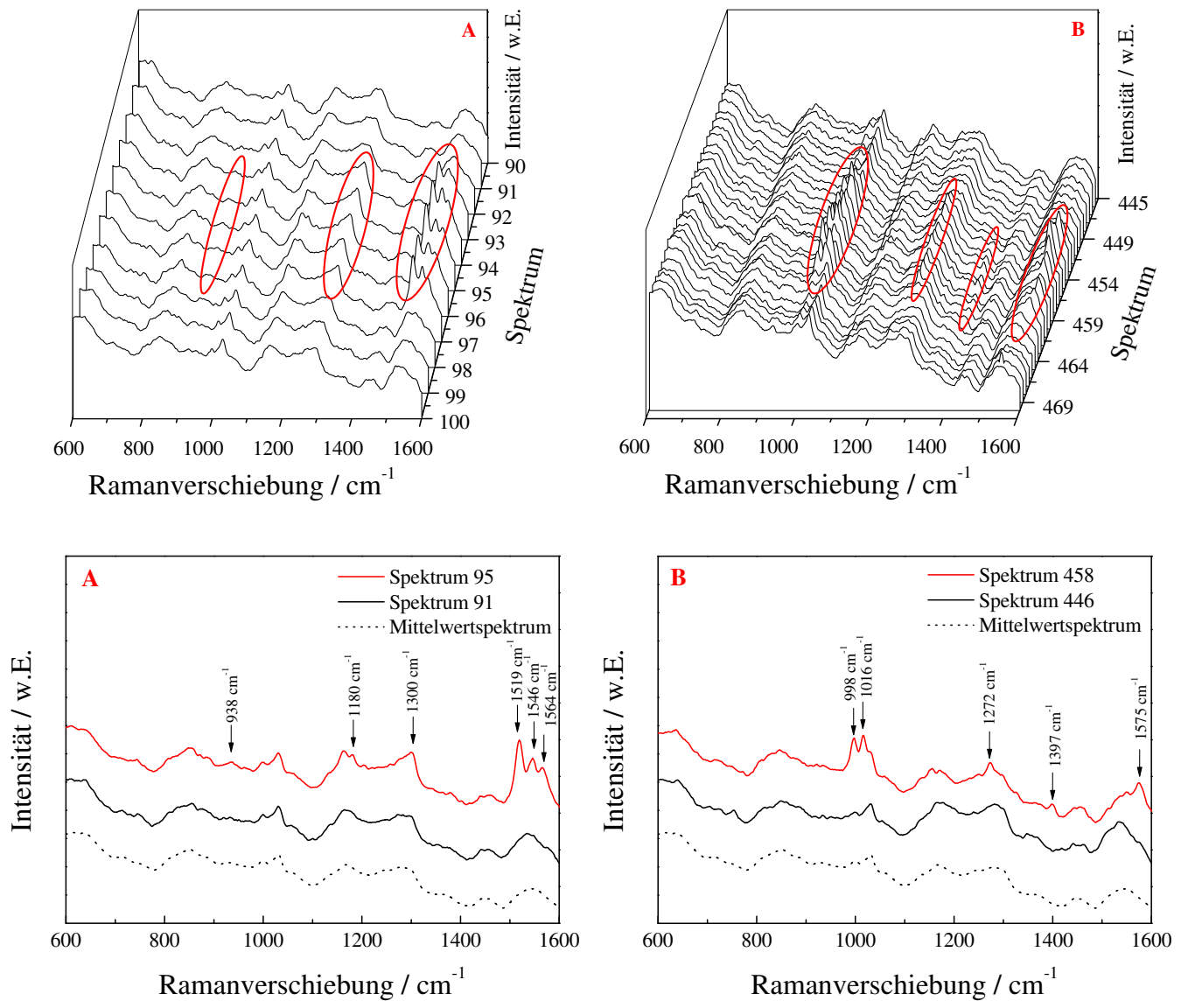

Abbildung 7.17: (Oben) Ausschnitte aus der Zeitreihe der gemessenen Blindwertspektren. (Unten) Vergleich einzelner Blindwertspektren mit dem zeitlich gemittelten. Die temporär auftretenden Ramanbanden, die nicht im zeitlich gemittelten Blindwertspektrum auftauchen, sind gekennzeichnet. Der Übersicht halber wurden die Spektren additiv in der Intensität verschoben.

Eine weitere Erklärung für das temporäre Auftreten von Ramanbanden im Ramanspektrum des Klarite ${ }^{\circledR}$-Substrats ist möglicherweise die ebenfalls häufig in der Literatur erwähnte nanoskopische Bewegung von Molekülen oder Molekülanhäufungen in und aus den so genannten „hot-spots“ [55]. Die Moleküle können dabei über die Umgebungsluft auf die Oberflächen übertragen werden. Die „hot-spots“ werden in den 
Pyramidenspitzen und -kanten des Klarite ${ }^{\circledR}$-Substrates vermutet [74]. Gemessen an der großen Anzahl von Veröffentlichungen, deren Motivation die Aufklärung des physikalischen und chemischen Ursprungs zeitlich fluktuierender oberflächenverstärkter Ramanspektren ist, stellt die zeitabhängige Untersuchung des Blindwertspektrums des Klarite ${ }^{\circledR}$-Substrats in der vorliegenden Arbeit nur eine sehr begrenzte Studie dar. Dennoch deuten die Ergebnisse der Zeitreihe an, dass eventuell ein Einzelmolekülnachweis vorliegen könnte.

In der vorliegenden Arbeit wurden Integrationszeiten von 300 s für die ramanspektroskopische Untersuchung der Proteinringmuster unterschiedlicher Konzentrationen gewählt, so dass sich die Frage stellt, ob die gemessenen kurzzeitig auftretenden Ramanbanden des Blindwertspektrums ebenfalls bei einer Integrationszeit von $300 \mathrm{~s}$ in den Blindwertspektren zu beobachten sind. Um diese Fragestellung zu beantworten, werden in Abbildung 7.17 beispielhaft Blindwertspektren mit und ohne zeitliche Fluktuationen dargestellt und mit dem über 300 s zeitlich gemittelten Blindwertspektrum verglichen. Dabei zeigt sich, dass das zeitlich gemittelte Blindwertspektrum im Wesentlichen dem Kurvenverlauf der nicht von den Fluktuationen betroffenen Einzelblindwertspektren entspricht. Damit sind diese spektralen Fluktuationen bei der gewählten Integrationszeit vernachlässigbar.

Um den Einfluss der ortsabhängigen Ramanstreulichtschwankung zu ermitteln, wurden an 60 verschiedenen Positionen auf dem reinen nanostrukturierten Klarite ${ }^{\circledR}$-Substrat Ramanspektren mit einer Integrationszeit von ebenfalls 300 s und einer Laserleistung von $50 \mathrm{~mW}$ aufgenommen. Die Positionen wurden dabei so gewählt, dass sie in äquidistanten Abständen über die gesamte nanostrukturierte Oberfläche des Klarite ${ }^{\circledR}$ Substrates verteilt waren. Abbildung 7.18 (links) zeigt die gemessenen Ramanspektren, wobei jedes Spektrum einer Position auf dem Klarite ${ }^{\circledR}$-Substrat entspricht. Daraus geht hervor, dass insbesondere oberhalb von $1100 \mathrm{~cm}^{-1}$ deutliche Unterschiede in den Ramanspektren zu erkennen sind, wobei sich aber nur in weniger als $1 \%$ der Fälle ausgeprägte Ramanbanden zeigen. Dies ist auch nicht verwunderlich, da jede bei der Aufnahme temporär erscheinende Ramanbande durch die gewählte hohe Integrationszeit gemittelt wird. Dennoch fallen insbesondere die hohen spektralen Unterschiede oberhalb von $1100 \mathrm{~cm}^{-1}$ auf, deren Ursachen unbekannt sind. In diesem Spektralbereich liegen vor allem Schwingungsmoden der $\mathrm{CH}_{3}$ - und $\mathrm{CH}_{2}$-Bindungen sowie der CCund CO-Bindungen. Abschließend ist zu bemerken, dass sich in den ortsabhängigen Ramanstreulichtmessungen bei einer Integrationszeit von 300 s spektrale Veränderungen von Ort-zu-Ort insbesondere im Spektralbereich oberhalb von $1100 \mathrm{~cm}^{-1}$ zeigen. Diese Beobachtung deckt sich mit den oberflächenverstärkten Ramanstreulichtmessungen eines Pilzgeflechtes auf dem Klarite ${ }^{\circledR}$-Substrat von Szeghalmi et al. [106]. Die 
Ortsabhängigkeit der gemessenen Spektren wird durch Abbildung 7.18 deutlich. Darin wird das zeitlich gemittelte mit dem örtlich gemittelten Ramanspektrum verglichen, wobei sich insbesondere spektrale Unterschiede oberhalb von $1100 \mathrm{~cm}^{-1}$ zeigen, gemäß der ortsabhängigen Einzelmessungen.
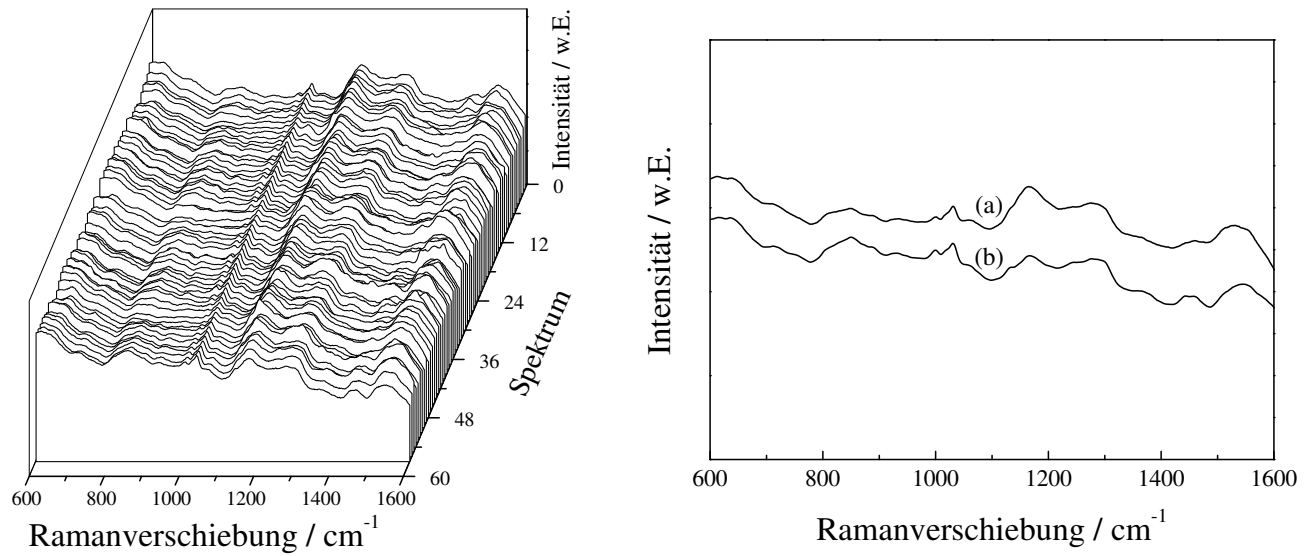

Abbildung 7.18: (Links) Ortsabhängige Blindwertspektren des Klarite ${ }^{\circledR}$-Substrates. (Rechts) Vergleich des zeitlich (a) und örtlich (b) gemittelten Blindwertspektrums. Der Übersicht halber wurden die Spektren additiv in der Intensität verschoben.

\subsection{Quantifizierung von Proteinen auf dem Klarite ${ }^{\circledR}$-Substrat}

In diesem Abschnitt werden konzentrationsabhängige oberflächenverstärkte Ramanspektren der bereits erwähnten Proteine Albumin, Lysozym und Insulin sowie der Aminosäure Tryptophan vorgestellt, die auf dem Klarite ${ }^{\circledR}$-Substrat gemessen wurden. Grundlegend für die quantitative Vermessung ihrer Ringmuster ist die Zentrierung des Laserfokus auf die Ringmuster, die visuell vom Experimentator durchgeführt wird. Damit ist ein Entscheidungskriterium für die Wahl der Konzentrationsbereiche der zu untersuchenden Moleküle gegeben, denn es können nur diejenigen Ringmuster zur Ramanstreulichtmessung herangezogen werden, die mittels der Beobachtungsoptik noch mit dem menschlichen Auge wahrgenommen werden können. Deshalb wurden die Konzentrationen sukzessiv so lange reduziert, bis die entsprechenden Ringmuster nicht mehr mit Hilfe der Beobachtungsoptik zu erkennen waren und somit die untere Grenze der Konzentrationsbereiche festgelegt wurde. Die obere Grenze der Konzentrationsbereiche wurde empirisch bestimmt, indem die Konzentrationen jeweils so hoch gewählt wurden, dass oberhalb eines bestimmten Konzentrationsbereiches kein 
signifikanter Anstieg des Ramanstreulichtes gemessen werden konnte. Analog zu der Vorgehensweise wie in Kapitel 5.1 ergibt sich die Konzentrationsabhängigkeit der gemessenen Ramanstreulichtintensitäten aus der Berechnung der integralen Intensitäten charakteristischer Ramanbanden, die gegen die Konzentration aufgetragen werden. Im Gegensatz zu der in den Kapiteln 5.1 und 6 beschriebenen Datenvorbehandlung wurde in diesem Abschnitt zunächst eine Subtraktion des Blindwertspektrums des Klarite ${ }^{\circledR}$ Substrates von den Proteinramanspektren durchgeführt und erst dann das resultierende Spektrum mit einer Basislinie korrigiert. Der Grund für diese Subtraktion ist die bereits in Abschnitt 7.2 gezeigte Überlagerung der Proteinramanspektren von dem Blindwertspektrum des Klarite ${ }^{\circledR}$-Substrates.

Bevor diese Ergebnisse jedoch präsentiert werden, soll zunächst ein kurzer Einblick in die der Langmuir-Isotherme zugrundeliegenden theoretischen Erklärungsmodelle gegeben werden, da sich während dieser Arbeit gezeigt hat, dass sich der funktionelle Zusammenhang auf die Konzentrationsreihen übertragen lässt.

\subsubsection{Analogie zur Langmuir-Isotherme}

Die Adsorption von Molekülen aus Gasen und Flüssigkeiten auf Oberflächen ist ein Phänomen, das prinzipiell durch zwei Modelle beschrieben werden kann: die physische Adsorption (Physisorption) und die chemische Adsorption (Chemisorption). Bei der Physisorption adsorbieren die Moleküle durch physikalische Kräfte auf einer Oberfläche und nicht durch chemische Bindungen. Zu diesen Kräften gehören beispielsweise die London'schen Dispersionskräfte, die eine elektrostatische Wechselwirkung zwischen induzierten, fluktuierenden Dipolen beschreibt. Die Chemisorption ist im Unterschied zur Physisorption eine Form der Adsorption, bei der das Adsorbat durch chemische Bindungen an die Oberfläche gebunden wird. Beispielsweise chemisorbiert das in Kapitel 4 beschriebene Thiophenol über die Ausbildung einer kovalenten Bindung zwischen dem Schwefelatom der Thiolgruppe und der Goldoberfläche. Beide Adsorptionsmodelle können jeweils durch eine Adsorptions-Isotherme charakterisiert werden, die die Bedeckung der Oberfläche $\zeta(c)$ als Funktion der Konzentration $c$ des Adsorbats beschreibt.

$\mathrm{Zu}$ den weitläufig bekanntesten Adsorptions-Isothermen zählen die Slygin-Frumkin Isotherme, die Brunauer-Emmet-Teller Isotherme, die Freundlich-Isotherme und die Langmuir-Isotherme $[9,58]$, benannt nach Irving Langmuir aus dem Jahre 1916. Sie gehört zu den mathematisch einfachsten Beschreibungsmodellen und findet besonders dann Anwendung, wenn sich der Konzentrationsbereich des Adsorbats bis maximal zu der Ausbildung einer Monolage erstreckt. Für dieses Adsorptionsmodell kann folgende 
Reaktionsgleichung angenommen werden

$$
O+M_{A d s} \underset{K_{-}}{\stackrel{K_{+}}{\rightleftharpoons}} O+M_{D e s}
$$

wobei $M_{A d s}$ die Adsorption der Moleküle auf der Oberfläche $O$ und $M_{\text {Des }}$ die Desorption der Moleküle von der Oberfläche beschreiben. Die Adsorptionsrate ist dabei proportional zu der Konzentration $c$ des Adsorbates und der Zahl der freien Plätze $(1-\zeta)$ auf der Oberfläche mit der Proportionalitätskonstanten $K_{+}$. Umgekehrt ist die Desorptionsrate proportional zur Bedeckung der Oberfläche $\zeta$ mit der Proportionalitätskonstanten $K_{-}$. Für ein Gleichgewicht dieser Adsorptionsraten gilt

$$
K_{+} c \cdot(1-\zeta)=K_{-} c \cdot \zeta
$$

so dass durch Auflösung dieser Gleichung nach der Bedeckung $\zeta$ folgender Zusammenhang mit der Langmuir-Konstanten $K=\mathrm{K}_{+} / \mathrm{K}_{-}$besteht:

$$
\zeta=\frac{K c}{1+K c} .
$$

Im Fall von oberflächenverstärkten Ramanstreulichtmessungen, bei denen die Reichweite der Feldverstärkung maximal eine Monolage erfasst, ist die maximale Signalstärke $I_{M a x}$ dann erreicht, wenn die Oberfläche vollständig mit einer Monolage bedeckt und somit die Bedeckung maximal ist $\left(\zeta=\zeta_{\text {Max }}\right)$. Wird die Oberflächenbedeckung derart gewählt, dass $\zeta_{\operatorname{Max}}=1$ ist, gilt folgender Zusammenhang zwischen der Ramanstreulichtintensität $I$ und der Bedeckung $\zeta$ :

$$
\frac{I}{I_{\operatorname{Max}}}=\frac{\zeta}{\zeta_{\operatorname{Max}}} .
$$

Daraus lässt sich Gleichung 7.3 folgendermaßen formulieren

$$
I=I_{M a x} \frac{K c}{1+K c}
$$

und gibt somit die Abhängigkeit der oberflächenverstärkten Ramanstreulichtintensität I von der Konzentration $c$ des jeweiligen Adsorbates in der Lösung bzw. im Gas an.

\subsubsection{Konzentrationsmessungen}

Die Voraussetzung für die Anwendbarkeit der Langmuir-Isotherme zur Beschreibung der konzentrationsabhängigen oberflächenverstärkten Ramanstreulichtintensität besteht in dem Gleichgewicht der Adsorption und Desorption der Moleküle auf der Oberfläche, das durch die Langmuir-Konstante $K$ ausgedrückt wird. 
Diese Bedingung kann in der vorliegenden Arbeit aber nicht erfüllt werden, da die Erzeugung der Ringmuster durch Verdampfung des Lösungsmittels zu einer zwangsläufigen Anlagerung der Moleküle auf der Oberfläche führt. Wie jedoch die nun folgenden Ergebnisse der oberflächenverstärkten Ramanstreulichtmessungen der Proteine Albumin, Lysozym und Insulin und der Aminosäure Tryptophan (s. Abbildung 7.19) zeigen, lassen sich dennoch die konzentrationsabhängigen Ramanstreulichtintensitäten durch denselben funktionellen Zusammenhang, wie er durch die Langmuir-Isotherme beschrieben wird, anpassen. Dabei wird nun nicht weiter der Begriff der Konzentration verwendet, sondern zu der Molekülanzahl $N_{M}$ übergegangen. Diese lässt sich über Gleichung 7.6 aus der Konzentrationsangabe der Proteinlösungen $c$, der Avogadrozahl $N_{A}$ und dem dosierten Volumen $V$ pro Ringmuster berechnen.

$$
N_{M}=c V N_{A}
$$

Durch die Bestimmung der zum Signal beitragenden Molekülanzahl wird das Potential der oberflächenverstärkten Ramanspektroskopie zur Detektion geringster Proteinmengen deutlich, die, wie Abbildung 7.19 zeigt, im Femtomol-Bereich $\left(\approx 10^{8}\right.$ Moleküle) liegen. Daraus resultiert eine Nachweisempfindlichkeit, die sehr nah an diejenige heranreicht, die in der Proteinanalytik durch den Einsatz von Fluoreszenzmessverfahren erreicht werden [38].

In den oberflächenverstärkten Ramanspektren der Proteine (s. Abbildung 7.19) sind im Wesentlichen die Ramanbanden der Aminosäureseitenketten des Tyrosins, Phenylalanins und Tryptophans bei ca. 620, 645, 760, 830, 850, 878, 1003, 1010 und $1340 \mathrm{~cm}^{-1} \mathrm{zu}$ identifizieren, wobei eine exakte Zuordnung der Ramanbanden mittels der Angaben aus Kapitel 2 möglich ist. Desweiteren treten in den Ramanspektren breitbandige Intensitätsschwankungen auf, die mit sehr hoher Wahrscheinlichkeit von den bereits dargestellten ortsabhängigen und spektral breitbandigen Blindwertspektren des Klarite ${ }^{\circledR}$-Substrats herrühren.

Bei der Auftragung der integralen Intensitäten der stark ausgeprägten Ramanbanden der Proteinspektren gegen die Molekülanzahl (s. Abbildung 7.19 (rechts)) zeigt sich in allen Fällen ein nicht linearer Zusammenhang zwischen beiden Parametern, sondern ein Sättigungsverhalten der Ramanstreulichtintensität. Wie bereits mehrfach erwähnt, lassen sich die in Abbildung 7.19 (rechts) gezeigten Kurvenverläufe durch eine an die Langmuir-Isotherme angelehnte Funktion anpassen, die durch den Term

$$
I=I_{M a x} \frac{\bar{K} N_{M}}{1+\bar{K} N_{M}}
$$

mit der Konstanten $\bar{K}$ ausgedrückt wird. 

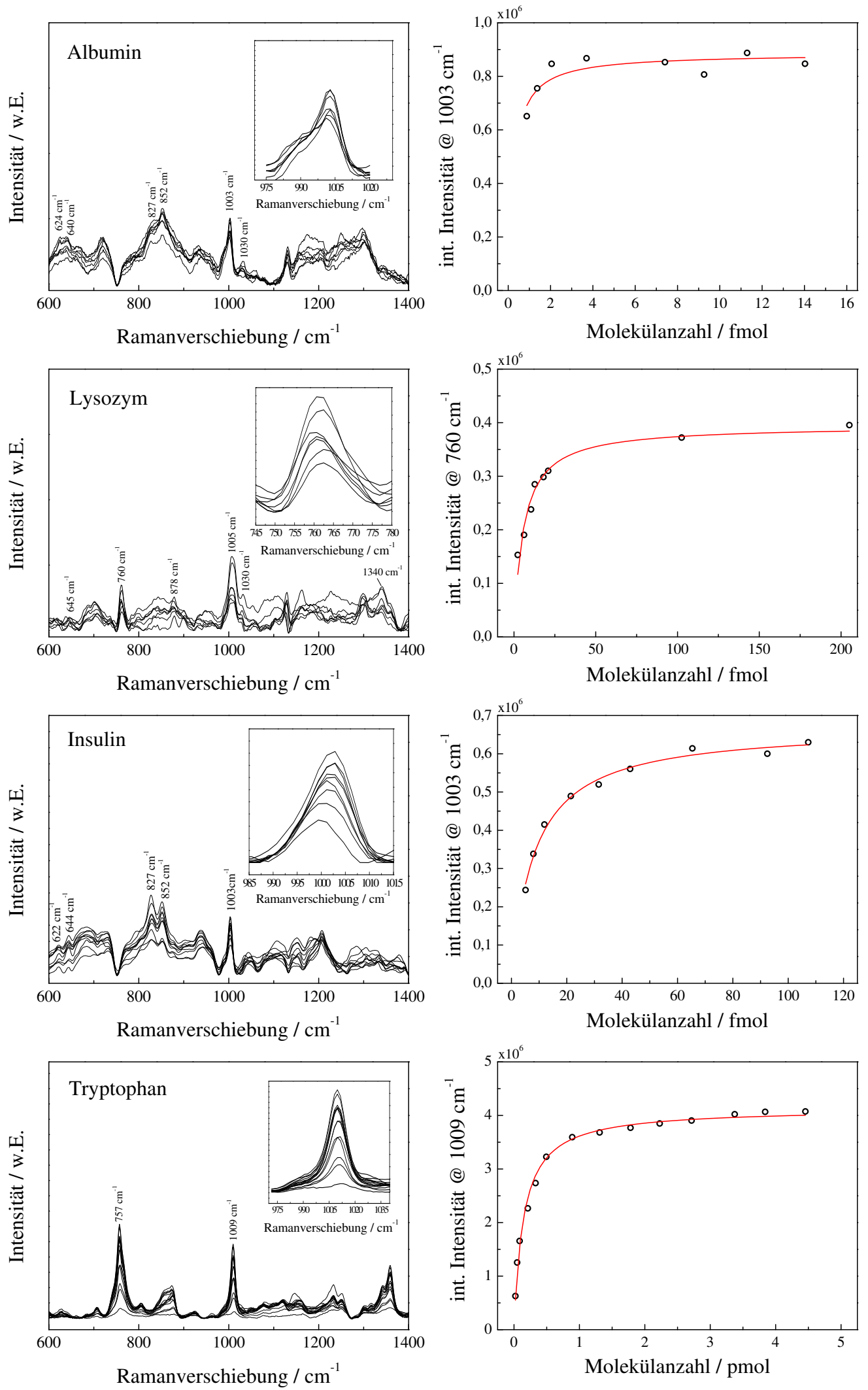

Abbildung 7.19: (Links) Oberflächenverstärkte Ramanspektren der untersuchten Proteine und der Aminosäure für verschiedene Molekülanzahlen. (Rechts) Kurvenverlauf der integralen Intensität ausgewählter Ramanbanden gegen die Molekülanzahl und Anpassung einer Funktion nach Gleichung 7.5 (rot). 
Diese Gleichung beruht ebenfalls auf der Annahme, dass die zum Signal beitragende Anzahl von Molekülen $N_{S}$ mit der Proteinkonzentration der aufgebrachten Tropfen korreliert, so dass sich nach dem Verdampfen des Lösungsmittels eine von der Molekülanzahl $N_{M}$ abhängige Oberflächenbelegung eingestellt hat. Die zum Signal beitragende Molekülanzahl $N_{S}$ entspricht dabei nicht zwangsläufig der gesamten Molekülanzahl im Tropfen $N_{M}$, denn beim Verdampfen des Lösungsmittels wandern die Moleküle in den Außenbereich des Tropfens und können sich im Bereich der Kontaktlinie mit der Substratoberfläche in mehreren Moleküllagen übereinander anordnen. Es trägt aber mit hoher Wahrscheinlichkeit, aufgrund der bereits vielfach erwähnten sehr kurzreichweitigen Feldverstärkungen, nur diejenige Moleküllage zum Signal bei, die unmittelbar auf der Oberfläche aufliegt. Wie bereits aus Abbildung 7.8 hervorgeht, nimmt die Ringbreite $B$ linear mit der Proteinkonzentration zu, so dass mit steigender Proteinkonzentration der von den Molekülen bedeckte Anteil der Klarite ${ }^{\circledR}$ _Oberfläche stetig mit der Ringbreite anwächst. Darüber hinaus können aber keinerlei Aussagen über die Molekülverteilung in der vom Ring eingeschlossenen Fläche gemacht werden. Dennoch deuten die abfallenden Ramanstreulichtintensitäten ab bestimmten Molekülanzahlen (s. Abbildung 7.19 (rechts)) darauf hin, dass keine vollständige Belegung in der vom Ring eingeschlossenen Fläche vorliegt.

Da Veränderungen der Proteinstrukturen beim Verdampfen des Lösungsmittels sehr wahrscheinlich sind und damit sowohl unterschiedliche Proteingrößen als auch Flächenbelegungen pro Molekül einhergehen, wird die molare Masse als charakteristische Kenngröße für die Oberflächenbelegung gewählt. Demnach sollte die Konstante $\bar{K}$ mit der molaren Masse des Moleküls monoton anwachsen, sofern die Größe der Moleküle ebenfalls mit der molaren Masse anwächst. Die Konstante $\bar{K}$ stellt für diesen Fall ein Maß für die Oberflächenbelegung in Abhängigkeit von der molaren Masse des Moleküls dar.

In Tabelle 7.1 sind die aus den Kurvenanpassungen nach Gleichung 7.7 der Konzentrationsreihen von Abbildung 7.19 (rechts) berechneten Konstanten $\bar{K}$ zusammengefasst.

\begin{tabular}{|c|c|c|}
\hline Molekül & molare Masse / kDa & $\bar{K} /(1 /$ fmol $)$ \\
\hline Tryptophan & 0,2 & $0,7 \cdot 10^{-5} \pm 0,4 \cdot 10^{-6}$ \\
\hline Insulin & 5,7 & $0,12 \pm 0,008$ \\
\hline Lysozym & 14,4 & $0,18 \pm 0,01$ \\
\hline Albumin & 66,3 & $4,04 \pm 1,01$ \\
\hline
\end{tabular}

Tabelle 7.1: Berechnete Konstanten $\bar{K}$.

Anhand der ermittelten Konstanten $\bar{K}$ kann gefolgert werden, dass eine Abhängigkeit von der molaren Masse der Moleküle zu der Konstanten $\bar{K}$ besteht, denn der Wert der 
Konstanten $\bar{K}$ wächst mit der Zunahme der molaren Masse der untersuchten Moleküle. Außerdem ist in Abbildung 7.19 (rechts) zu erkennen, dass sich die Sättigung der Ramanstreulichtintensitäten tendenziell mit zunehmender molarer Masse des Moleküls zu immer kleiner werdenden Molekülanzahlen verschiebt. Dies ist ein Indiz dafür, dass sich mit der Zunahme der Masse ebenfalls eine Zunahme der Oberflächenbelegung pro Molekül einstellt. Das kann nur auf die Größe des Moleküls zurückgeführt werden.

Im Fall von Albumin konnte im abfallenden Bereich der Ramanstreulichtintensitäten (s. Abbildung 7.19 (rechts)) für sehr geringe Molekülanzahl keine ausreichende Anzahl von Messdaten erfasst werden, da bei dieser Molekülanzahl keine Ringmuster visuell erkannt werden konnten. Deshalb ist die berechnete Konstante $\bar{K}$ für Albumin mit einem sehr hohen Fehler behaftet.

Damit werden deutlich die Grenzen dieses Messverfahrens zur quantitativen Konzentrationsbestimmung aufgezeigt. Bei Proteinen mit molaren Massen größer als die des Albumins (> $66000 \mathrm{kDa}$ ) ist die Oberflächenbelegung pro Molekül so groß, dass keine Ringmuster bei einer Proteinkonzentration bzw. Molekülanzahl, unterhalb derer sich eine vollständige Bedeckung der Oberfläche eingestellt hat, visuell zur Ramanstreulichtmessung herangezogen werden kann. Für solche Fälle können mit der vorgestellten Methode keine quantitativen Aussagen getroffen werden, da sich die Ramanstreulichtintensitäten für alle visuell erkennbaren Ringmuster mit derart geringen Molekülanzahlen in Sättigung befinden, also eine vollständige Oberflächenbelegung vorliegt.

Dennoch soll an dieser Stelle mit den Ergebnissen festgehalten werden, dass mit dieser experimentellen Herangehensweise erstmals Konzentrationsreihen von Proteinen mit Molekülanzahlen im Femtomol-Bereich gelungen sind. Darüber hinaus trägt aufgrund der Ringmusterbildung mit hoher Wahrscheinlichkeit nur ein sehr viel geringerer Anteil der gesamten Molekülanzahl im Tropfen zum Signal bei, so dass die angegebene Molekülanzahl zu einer geringeren Molekülanzahl korrigiert werden müsste.

\subsubsection{Abschätzung des Verstärkungsfaktors}

Wie bereits geschildert, trägt mit sehr hoher Wahrscheinlichkeit ein sehr viel geringerer Anteil von der gesamten Molekülanzahl im Ringmuster zum Signal bei. Exakte Aussagen bezüglich der zum Signal beitragenden Molekülanzahl sind aber nicht möglich, so dass lediglich eine Abschätzung des Verstärkungsfaktors vorgenommen werden kann. Dazu wurden exemplarisch nichtoberflächenverstärkte Ramanstreulichtmessungen an Ringmustern von Albumin und Lysozym auf einer unstrukturierten Goldoberfläche durchgeführt und auf die Integrationszeit und Laserleistung, wie sie bereits für die quantitativen oberflächenverstärkten Ramanstreulichtmessungen verwendet worden sind, normiert. Abbildung 7.20 stellt die beiden gemessenen Konzentrationsreihen gegenüber. 
Darin wird noch einmal deutlich, dass sich die oberflächenverstärkten Ramanstreulichtintensitäten im Gegensatz zu den nicht oberflächenverstärkten nicht linear mit der Konzentration verhalten, sondern in Sättigung übergehen.
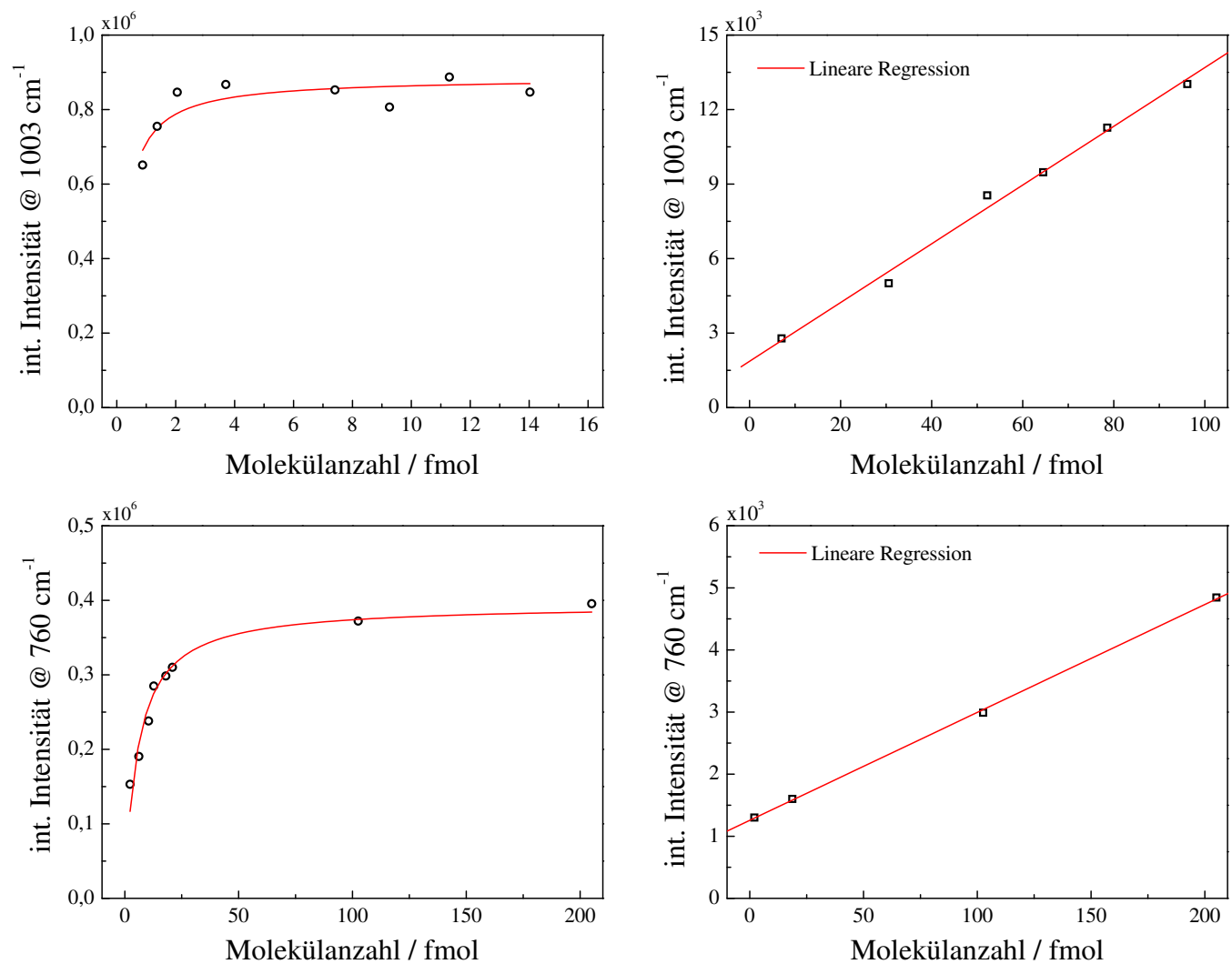

Abbildung 7.20: (Links oben) Integrale Intensitäten für eine Albumin-Konzentrationsreihe auf dem strukturierten Bereich des Klarite ${ }^{\circledR}{ }_{-}$Substrats. Die rote Linie entspricht der Kurvenanpassung nach Gleichung 7.7. (Rechts oben) Auftragung der integralen Intensitäten für eine Albumin-Konzentrationsreihe auf dem unstrukturierten Bereich des Klarite ${ }^{\circledR}$-Substrats. Die rote Linie entspricht der Kurvenanpassung mit einer linearen Regression. (Links unten) Integrale Intensitäten für eine Lysozym-Konzentrationsreihe auf dem strukturierten Bereich des Klarite ${ }^{\circledR}$-Substrats. Die rote Linie entspricht der Kurvenanpassung nach Gleichung 7.7. (Rechts unten) Auftragung der integralen Intensitäten für eine Lysozym-Konzentrationsreihe auf dem unstrukturierten Bereich des Klarite ${ }^{\circledR}$-Substrats. Die rote Linie entspricht der Kurvenanpassung mit einer linearen Regression.

Der Verstärkungsfaktor kann nach Gleichung 7.8 abgeschätzt werden, wobei $I_{O}$ und $I_{N O}$ die auf Laserleistung und Integrationszeit normierten oberflächenverstärkten und nicht oberflächenverstärkten Ramanstreulichtintensitäten für die Molekülanzahl $N_{M}$ bezeichnet. Für Albumin berechnet sich mit $N_{M} \approx 8 \mathrm{fmol}$ beispielsweise ein Verstärkungsfaktor von 260, wohingegen sich für Lysozym mit $N_{M} \approx 100 \mathrm{fmol}$ ein Verstär- 
kungsfaktor von 120 berechnet. Die berechneten Verstärkungsfaktoren liegen deutlich unterhalb des in Kapitel 4 am Beispiel von Thiophenol berechneten, und zwar um drei Größenordnungen.

$$
\Omega\left(N_{M}\right)=\frac{I_{O}}{I_{N O}}
$$

Ein Grund für die wesentlich kleineren Verstärkungsfaktoren ist die zur Berechnung des Verstärkungsfaktors herangezogene Molekülanzahl der Proteine. Diese liegt, wie bereits vielfach beschrieben, mit sehr hoher Wahrscheinlichkeit weit oberhalb der tatsächlichen zum Signal beitragenden Molekülanzahl. Unter der Annahme, dass sich über $90 \%$ der Proteinmoleküle im Ring befinden, ergäbe sich ein um ca. eine Größenordnung höherer Verstärkungsfaktor und läge damit näher an dem mit Thiophenol berechneten von $2,5 \cdot 10^{5}$. Darüber hinaus weisen die berechneten Verstärkungsfaktoren darauf hin, dass eine bereits in Kapitel 4 geschilderte vermutete Abhängigkeit der Verstärkungsfaktoren von der Größe der Moleküle existiert. Demnach sollten große Moleküle, wie Proteine, deutlich geringere Verstärkungsfaktoren aufweisen als kleinere Moleküle, wie das Thiophenol, was durch die Ergebnisse untermauert wird.

\subsection{Identifizierung ausgewählter Proteine auf dem Klarite ${ }^{\circledR}$-Substrat}

Nachdem die Quantifizierungsmöglichkeiten und -grenzen von Proteinen am Beispiel von Albumin, Insulin und Lysozym auf dem Klarite ${ }^{\circledR}$-Substrat im vorherigen Abschnitt aufgezeigt wurden, soll hier eine Methode zur Identifizierung dieser Moleküle vorgestellt werden. Im Vordergrund steht die in Abschnitt 7.2 gezeigte Querempfindlichkeit zwischen den oberflächenverstärkten Proteinramanspektren und dem Blindwertspektrum des Klarite ${ }^{\circledR}$-Substrates, die eine Identifikation erheblich erschwert. Aus diesem Grund wurde in der vorliegenden Arbeit ein in der Chemometrie häufig eingesetzter Auswertealgorithmus herangezogen, die so genannte Hauptkomponentenanalyse. Sie wurde zum ersten Mal von dem Mathematiker Karl Pearson im Jahr 1901 formuliert und veröffentlicht [86] und hält seither neben den Naturwissenschaften auch Einzug in Wirtschaftsund Sozialwissenschaften. Die Hauptkomponentenanalyse wird in der Mathematik unter die Rubrik der Eigenwertprobleme eingeordnet. Einen ausführlichen Überblick über den mathematischen Hintergrund der Hauptkomponentenanalyse und ihre Anwendung geben die Werke von Kessler [43], Henrion [36] und Danzer [15], wobei im Folgenden die grundlegenden mathematischen Vorgehensweisen beschrieben werden. 


\subsubsection{Theoretische Grundlagen der Hauptkomponentenanalyse}

Die Hauptkomponentenanalyse ist ein multivariates Verfahren, das versucht, die ursprünglichen Variablen einer Datenmatrix durch eine kleinere Anzahl von Variablen auszudrücken, und dies möglichst ohne Informationsverluste. Somit vollzieht sie eine Datenreduktion. Darüber hinaus bietet sie die Möglichkeit, Muster in mehrdimensionalen Messdaten zu identifizieren, indem die Daten so transformiert werden, dass sich ihre Ähnlichkeiten und Unterschiede hervorheben.

Dazu wird eine orthogonale Rotationstransformation der ursprünglichen Variablen in unkorrelierte Variablen vorgenommen, die als Hauptkomponenten (englisch: ,principal component"-PC) bezeichnet werden (s. Abbildung 7.21). Diese Hauptkomponenten sind Linearkombinationen der ursprünglichen Variablen. Dabei wird die erste Hauptkomponente so konstruiert, dass sie den größten Teil der Varianz der Daten beschreibt. Jede weitere Hauptkomponente ist dann entsprechend so konstruiert, dass sie in absteigender Reihenfolge den noch verbleibenden Varianzanteil in den Daten beschreibt.

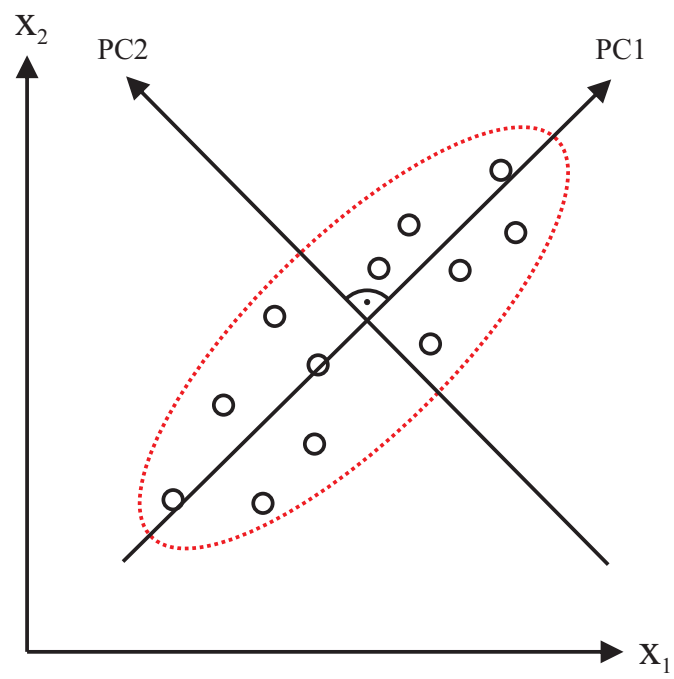

Abbildung 7.21: Veranschaulichung zweier Hauptkomponenten PC1 und PC2 einer zweidimensionalen elliptisch angeordneten Punktwolke mit den Koordinaten bzw. Variablen $\mathrm{x}_{1}$ und $\mathrm{x}_{2}$.

Hauptkomponenten, die nur noch sehr geringe Varianzanteile der Daten beinhalten, können dann vernachlässigt werden, so dass die effektive Dimension der Daten mit nur sehr geringem Informationsverlust durch die Darstellung in den Hauptkomponenten reduziert wird. Die der Hauptkomponentenanalyse zugrundeliegende Datenmatrix setzt sich dabei in der Regel zeilenweise aus den Objekten bzw. Fällen und spaltenweise aus den Variablen, den Merkmalen, zusammen.

In der vorliegenden Arbeit entsprechen die gemessenen Ramanstreulichtintensitäten 
den Elementen $m$ der Zeilenvektoren und die der Ramanstreulichtintensitäten zugehörigen Kanäle ${ }^{1}$ (Variablen) den Spaltenvektoren $n$. Die Datenmatrix sieht dann folgendermaßen aus:

$$
X=\left(\begin{array}{cccc}
x_{11} & x_{12} & \cdots & x_{1 m} \\
x_{21} & x_{22} & \cdots & x_{2 m} \\
\vdots & \vdots & \ddots & \vdots \\
x_{n 1} & x_{n 2} & \cdots & x_{n m}
\end{array}\right) .
$$

Die Grundlage der Hauptkomponentenanalyse sind Linearkombinationen, die durch eine gewichtete Summe der ursprünglichen Variablen gebildet und in der Matrixschreibweise als

$$
X^{\prime}=X \cdot w
$$

dargestellt werden. $w$ beschreibt dabei die Gewichtskoeffizientenmatrix und $X^{\prime}$ die Hauptkomponentenmatrix. In der Hauptkomponentenanalyse entspricht die Suche nach den $m$ Hauptkomponenten der Suche nach $m$ unkorrelierten Linearkombinationen der Variablen mit maximaler Varianz.

Die Varianz der Datenmatrix wird in der so genannten Kovarianzmatrix $S$ zusammengefasst (s. Gleichung 7.11), in der die Eigenvektoren die Hauptkomponenten bilden und der Betrag der korrespondierenden Eigenwerte ein direktes Maß für den Varianzanteil einer Hauptkomponente an der Gesamtvarianz der Datenmatrix angibt.

$$
S=\operatorname{Kov}(X)=\left(\begin{array}{cccc}
\operatorname{Var}\left(x_{1}\right) & \operatorname{Kov}\left(x_{1}, x_{2}\right) & \cdots & \operatorname{Kov}\left(x_{1}, x_{m}\right) \\
\operatorname{Kov}\left(x_{2}, x_{1}\right) & \operatorname{Var}\left(x_{2}\right) & \cdots & \operatorname{Kov}\left(x_{2}, x_{m}\right) \\
\vdots & \vdots & \ddots & \vdots \\
\operatorname{Kov}\left(x_{n}, x_{1}\right) & \operatorname{Kov}\left(x_{n}, x_{2}\right) & \cdots & \operatorname{Var}\left(x_{n}\right)
\end{array}\right)
$$

Die Varianz-Kovarianzmatrix geht durch die Multiplikation der ursprünglichen Datenmatrix $X$ mit der transponierten Datenmatrix $X^{T}$ hervor

$$
S=\operatorname{Kov}(X)=X X^{T}
$$

sofern der Mittelwert jeder Variablen - entspricht dem Mittelwert einer Spalte in der Datenmatrix - vor der Multiplikation subtrahiert wurde. Es wird dann von der so genannten zentrierten Datenmatrix gesprochen. Die Transformation der ursprünglichen Datenmatrix $X$ in das Koordinatensystem der Hauptkomponenten erfolgt dann über Gleichung 7.10, wobei $w$ der Eigenvektormatrix entspricht.

An dieser Stelle erfolgt die eigentliche Datenreduktion, indem die Eigenvektoren bzw. Hauptkomponenten, die nur einen sehr geringen Anteil an der Gesamtvarianz besitzen,

\footnotetext{
${ }^{1}$ entspricht der Anzahl von 1024 Halbleiterelementen im Ausleseregister des CCD-Sensors
} 
in der Eigenvektormatrix Null gesetzt werden. Damit lässt sich die rotationstransformierte Datenmatrix $X^{\prime}$ durch eine geringere Anzahl von Variablen ausdrücken, die die Hauptkomponenten über eine Linearkombination bilden.

In der vorliegenden Arbeit wird mit Hilfe der Hauptkomponentenanalyse allerdings keine Datenreduzierung durchgeführt, sondern eine weitere charakteristische Eigenschaft dieses Auswertealgorithmus ausgenutzt. Wie bereits beschrieben, ist die Hauptkomponentenanalyse in der Lage, Muster in mehrdimensionalen Messdaten zu identifizieren und diese Daten so zu transformieren, dass ihre Ähnlichkeiten und Unterschiede hervorgehoben werden. Auskunft darüber gibt die Auftragung der einzelnen Hauptkomponenten der Objekte in einer zwei- bis dreidimensionalen Darstellung. Diese Darstellung kann dann zum Aufdecken von Gruppierungen in den Objekten, in diesem Fall die Proteinramanspektren, verwendet werden.

Damit kann letztendlich gezeigt werden, ob die vom Blindwertspektrum des Klarite ${ }^{\circledR}$ Substrates dominierten Proteinramanspektren überhaupt ausreichende Unterscheidungsmerkmale aufweisen.

Falls in der Datenmatrix Muster oder systematische Beziehungen gefunden werden können und ein der Hauptkomponentenanalyse zugrundeliegendes mathematisches Modell aufgestellt ist, das so genannte Kalibriermodell, können anschließend die modellierten Eigenschaften neuer, „unbekannter“ Proben vorhergesagt bzw. interpoliert werden. Dabei handelt es sich um den so genannten Validierdatensatz. Mit diesem Validierdatensatz ist eine Beurteilung möglich, ob das Modell auch auf zukünftige Messungen übertragen und verallgemeinert werden kann. Eine derartige Datenanalyse wurde in der vorliegenden Arbeit mit Hilfe der in der Software Matlab (MathWorks) implementierten PLS-Toolbox4.1 der Firma Eigenvector Research umgesetzt.

\subsubsection{Experimentelle Vorgehensweise}

Für die Untersuchung der Identifikationsmöglichkeiten von Proteinen auf dem Klarite ${ }^{\circledR}$ _ Substrat mit Hilfe der Hauptkomponentenanalyse wurden zunächst ein Kalibrier- und Validierdatensatz angefertigt. Für den Kalibrierdatensatz wurden jeweils 15 Ringmuster der Proteine Albumin, Insulin und Lysozym mit einem Volumen von 0,3 nl pro Tropfen mit Molekülanzahlen von 4,5 fmol für Albumin, 52 fmol für Insulin und 20 fmol für Lysozym erzeugt. Die verwendeten Molekülanzahlen richteten sich dabei nach den bereits für die Konzentrationsmessungen in Abschnitt 7.4.2 eingesetzten Molekülanzahlen. Um einen möglichen Einfluss des ortsabhängigen Blindwertspektrums des Klarite ${ }^{\circledR}$ Substrates (s. Abschnitt 7.3) auf die der Identifikation zugrundeliegenden Proteinramanspektren mit in das Kalibriermodell einfließen zu lassen, wurden die Ringmuster 
mit einer regelmäßigen Anordnung in äquidistanten Abständen über die gesamte auf einem Klarite ${ }^{\circledR}$-Substrat zur Verfügung stehenden nanostrukturierten Oberfläche von 4 x 4 mm gemäß Abbildung 7.22 (a) erzeugt. Analog zu dieser Vorgehensweise wurden ebenfalls jeweils 6 Ringmuster pro Protein mit denselben Proteinkonzentrationen auf einem anderen Klarite ${ }^{\circledR}$-Substrat zur Validierung erzeugt (s. Abbildung 7.22 (b)). Anschließend wurden die Ringmuster mit einer Integrationszeit von $300 \mathrm{~s}$ und einer Laserleistung von $50 \mathrm{~mW}$, wie sie bereits bei der in Abschnitt 7.4.2 beschriebenen Konzentrationsmessung verwendet worden sind, ramanspektroskopisch vermessen.

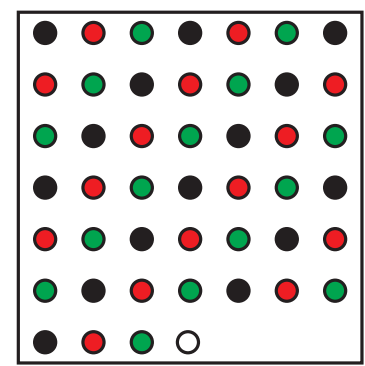

(a)

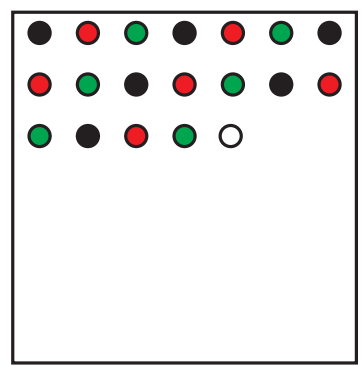

(b)

Abbildung 7.22: Ringmusterverteilung für den Kalibrierdatensatz (a) und für den Validierdatensatz (b).

Bevor eine Hauptkomponentenanalyse an den oberflächenverstärkten Ramanspektren durchgeführt werden kann, ist zunächst eine explorative Erkundung der Daten mittels graphischer Darstellungen notwendig, um einen ersten Eindruck darüber zu gewinnen, ob die aufgenommenen Spektren sichtbare Unterscheidungsmerkmale aufweisen. Dazu sind in Abbildung 7.23 die gemessenen Proteinramanspektren für das Kalibriermodell dargestellt und der Übersicht halber auf die Ramanbande bei $998 \mathrm{~cm}^{-1}$ normiert, die proteinunspezifisch ist und eindeutig dem Blindwertspektrum des Klarite ${ }^{\circledR}$ Substrates zugeordnet werden kann (s. Abbildung 7.23 (d)). Hier sollen nur die zur Kalibration herangezogenen Ramanspektren vorgestellt werden, da die Validierspektren nahezu identisch zu den Kalibrierspektren sind. Das Blindwertspektrum wurde sowohl für den Kalibrier- als auch den Validierdatensatz auf den jeweiligen Substraten bei gleichen Versuchsbedingungen gemessen. Aus Abbildung 7.23 (a) - (c) geht hervor, dass sich die Proteinramanspektren untereinander kaum unterscheiden, was auf das bereits vielfach beschriebene stark ausgeprägte Blindwertspektrum des Klarite ${ }^{\circledR}$ Substrates zurückzuführen ist, das die Proteinramanspektren überlagert. Insbesondere die Gegenüberstellung der Mittelwertspektren der Proteine mit dem Blindwertspektrum macht die hohe Ähnlichkeit deutlich, wobei nur sehr wenige Unterscheidungsmerkmale zwischen den Proteinramanspektren bei 757, 827 und $852 \mathrm{~cm}^{-1}$ visuell zu erkennen sind. 


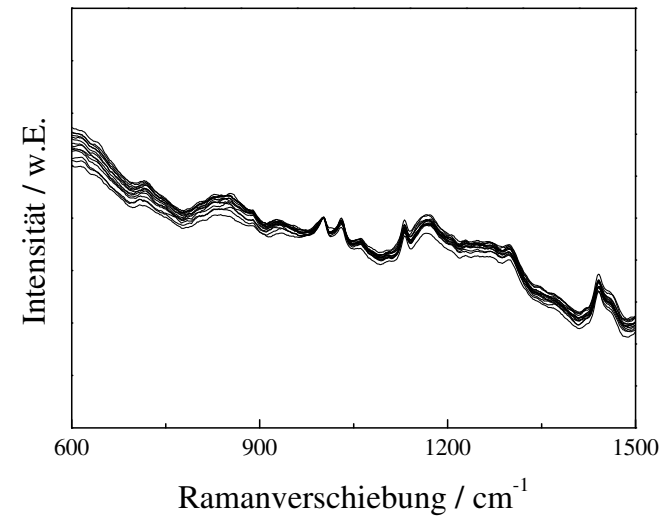

(a)

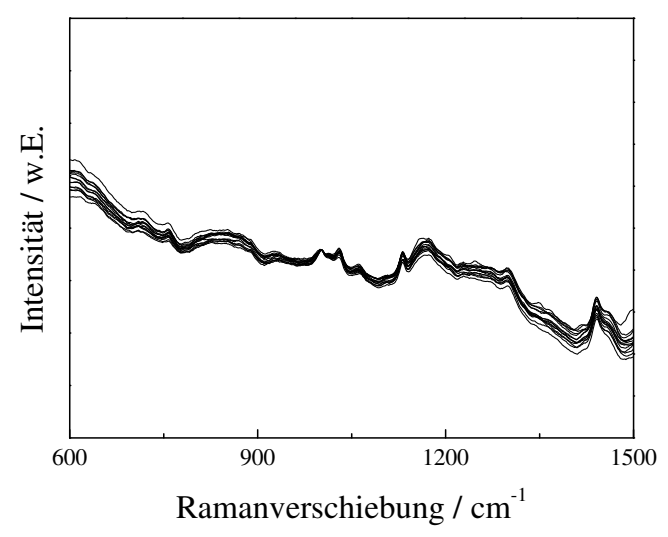

(c)

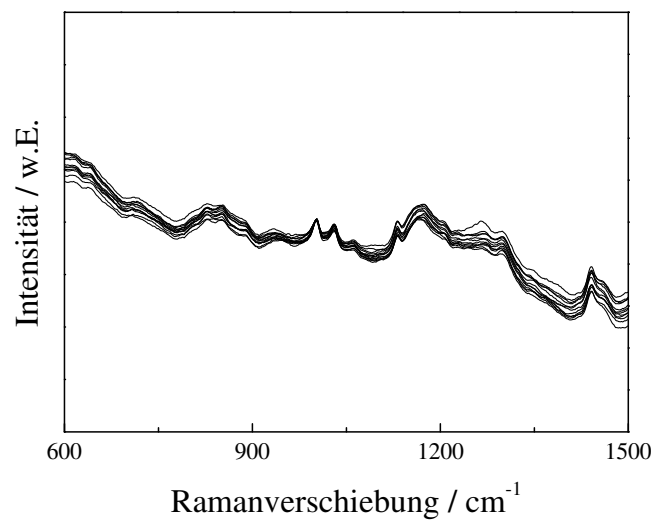

(b)

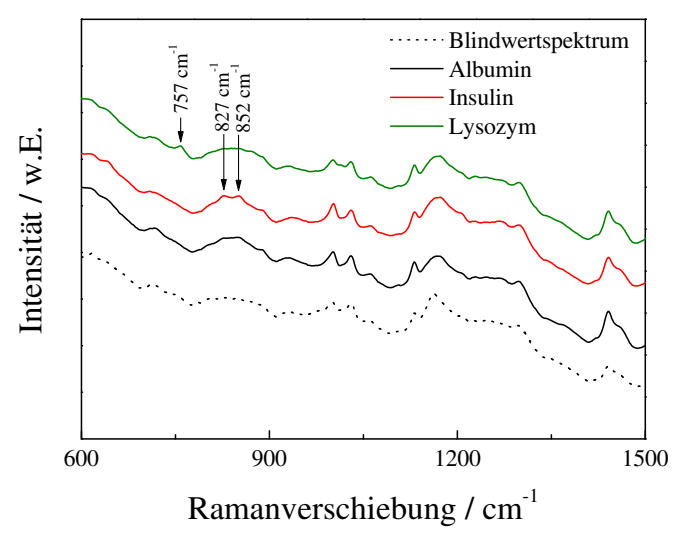

(d)

Abbildung 7.23: Auf die Ramanbande bei $998 \mathrm{~cm}^{-1}$ normierte oberflächenverstärkte Ramanrohspektren der Proteine (a) Albumin, (b) Insulin und (c) Lysozym für den Wellenzahlbereich von $600-1500 \mathrm{~cm}^{-1}$. In (d) sind die Mittelwertspektren der Proteine dem Blindwertspektrum des Klarite ${ }^{\circledR}$-Substrates gegenübergestellt.

\subsubsection{Ergebnisse der Hauptkomponentenanalyse}

Basierend auf den in Abbildung 7.23 dargestellten Proteinramanspektren, wurden drei unterschiedliche Strategien bei der Datenaufbereitung für die Hauptkomponentenanalyse verfolgt, die hier nun vorgestellt werden.

\section{Ohne Datenvorbehandlung}

Zum Einen wurde die Hauptkomponentenanalyse an den Rohspektren durchgeführt. Dazu wurden die Spektren gemäß Abschnitt 7.5.1 zunächst in einer Datenmatrix zusammengefasst und mit der in der Software Matlab bereitgestellten PLS Toolbox ausgewer- 
tet. In Abbildung 7.25 (a) ist der prozentuale Anteil der ermittelten Hauptkomponenten an der Gesamtvarianz der Datenmatrix dargestellt. Die Hauptkomponenten sind dabei nach ihrem prozentualen Anteil an der Gesamtvarianz der Datenmatrix geordnet. Darin ist zu erkennen, dass bereits die erste Hauptkomponente (PC1) über 99,8\% der Gesamtvarianz aufklärt und alle weiteren Hauptkomponenten nur noch die verbleibenden Promille. In Abbildung 7.25 (b) ist die Gewichtung der einzelnen Variablen, aus denen sich die erste Hauptkomponente über eine Linearkombination zusammensetzt, aufgetragen und dem Blindwertspektrum gegenübergestellt. Darin wird deutlich, dass die erste Hauptkomponente im Wesentlichen dem Kurvenverlauf des Blindwertspektrums entspricht und somit eine spektral-konstante Intensitätschwankung der Spektren darstellt.

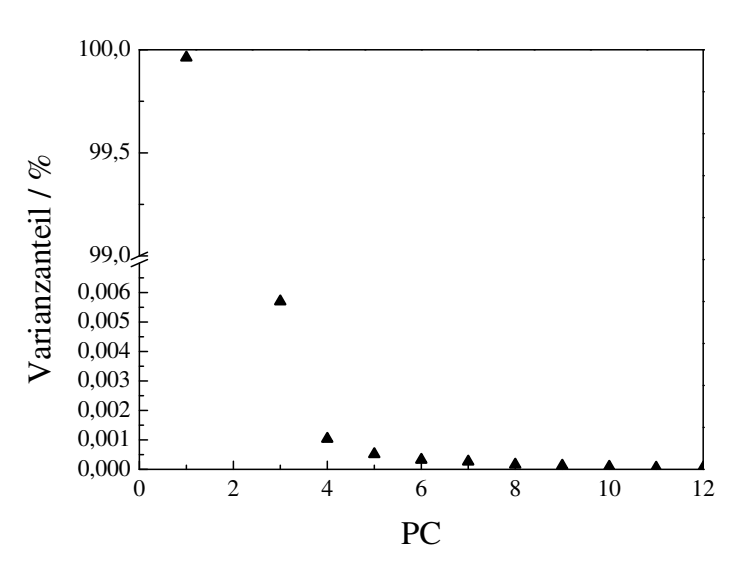

(a)

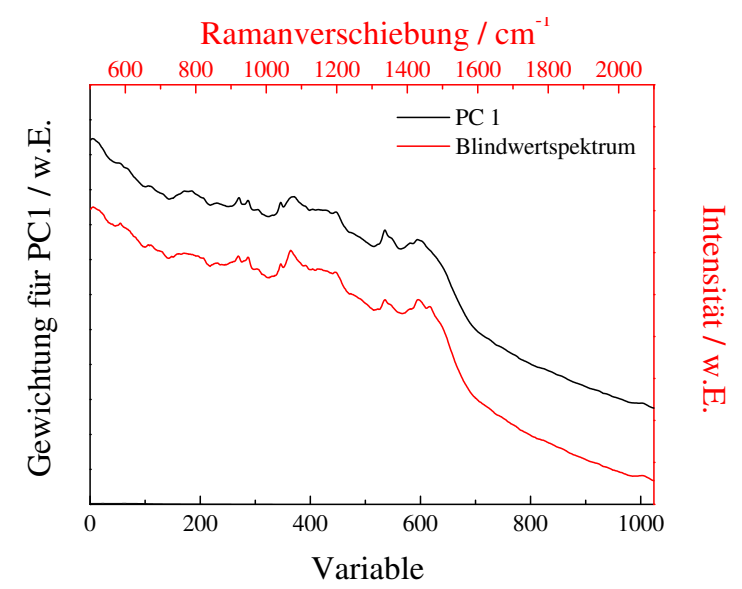

(b)

Abbildung 7.24: (a) Auftragung des prozentualen Anteils der Gesamtvarianz gegen die Hauptkomponenten (PC). (b) Vergleich der Gewichtung aller Variablen, aus denen sich die erste Hauptkomponente zusammensetzt, mit dem Blindwertspektrum.

Für gewöhnlich werden in der Hauptkomponentenanalyse die zweite und dritte Hauptkomponente (PC2 und PC3) gegeneinander aufgetragen, was einer zweidimensionalen Projektion des Hauptkomponentenraumes entspricht, die die größte Gruppentrennung (Clustertrennung) mit dem höchsten Signifikanzniveau aufweist [83]. Abbildung 7.25 stellt diese Auftragung für die hier vorliegende Datenmatrix dar. Jeder Datenpunkt kann einem Spektrum zugeordnet werden, wobei die Farben die Zugehörigkeit des Datenpunktes zu den jeweiligen Proteinen widerspiegeln. Daraus geht hervor, dass nur eine sehr schwache Gruppierung ohne signifikante Trennung zu erkennen ist und damit keine aussagekräftige Identifizierung stattfinden kann. Dies ist auch nicht verwunderlich, da der prozentuale Varianzanteil von PC2 und PC3 verschwindend gering ist. 


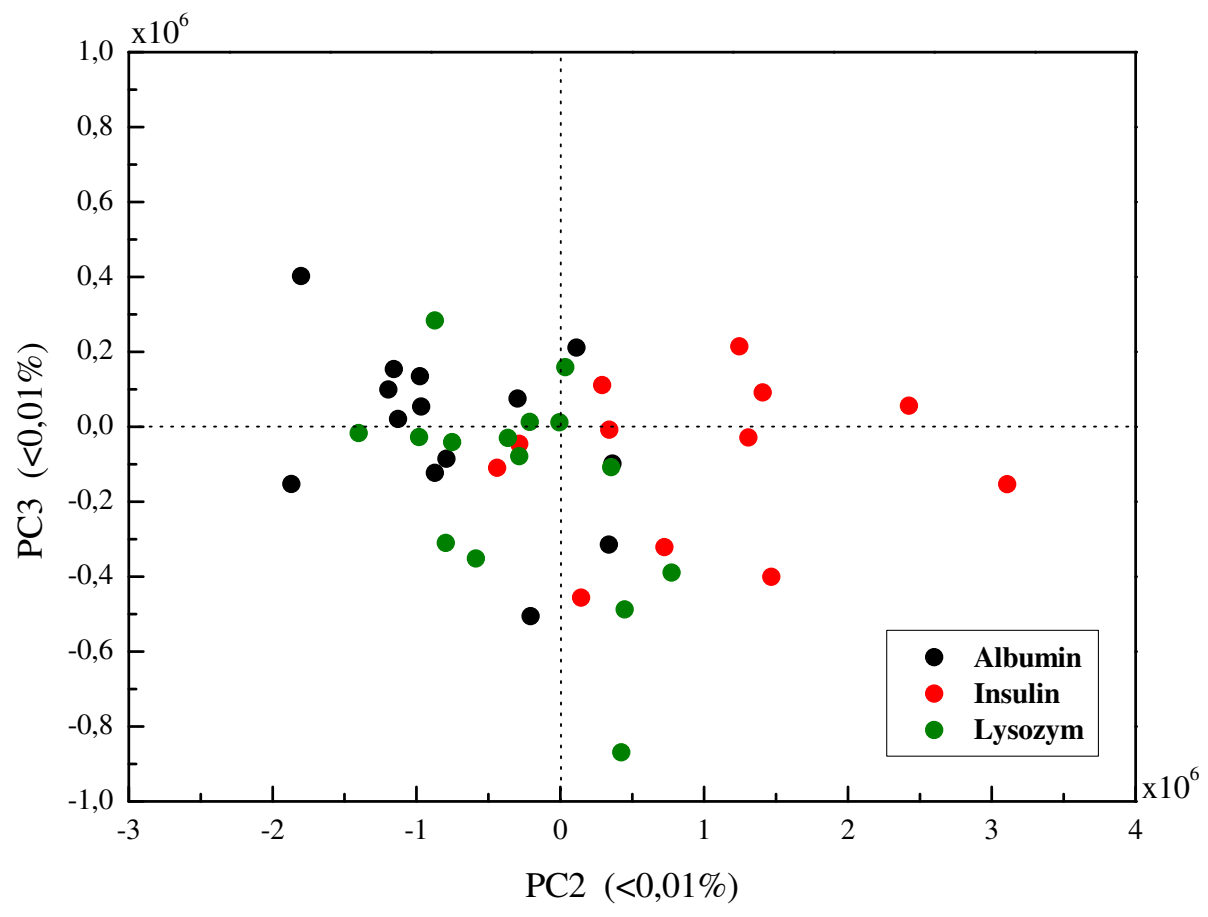

Abbildung 7.25: Auftragung der Hauptkomponente PC3 gegen PC2 ohne Vorbehandlung der Datenmatrix.

\section{Sukzessive Variablenreduktion}

Basierend auf den in den Mittelwertspektren der Proteine aus Abbildung 7.23 angedeuteten Unterscheidungsmerkmalen, wurde die bereits verwendete Datenmatrix solange sukzessiv in der Anzahl ihrer Spalten, beginnend bei der höchsten Spaltenzahl von 1024, reduziert - entspricht der sukzessiven Reduzierung der 1024 Variablen - und die aus der Hauptkomponentenanalyse resultierenden Hauptkomponenten PC2 und PC3 gegeneinander aufgetragen, bis das beste Ergebniss bezüglich Clusterung und signifikanter Trennung erreicht wurde. Dabei zeigt sich, dass die ersten 200 Variablen die besten Ergebnisse liefern. Wird der dazugehörige Spektralbereich mit demjenigen aus Abbildung 7.23 verglichen, für den rein optisch Unterscheidungsmerkmale zu erkennen sind, so stimmen beide gut überein. Sie liegen zwischen 600 und $900 \mathrm{~cm}^{-1}$. In Abbildung 7.26 ist die Auftragung der zweiten und dritten Hauptkomponente für die drastisch reduzierte Variablenanzahl von ursprünglich 1024 auf 200 dargestellt. Daraus geht hervor, dass die Reduktion der Variablen zu einer erheblichen Verbesserung der Clusterung und Trennung der proteinspezifischen Merkmale führt. Daraus kann gefolgert werden, dass zum Einen im Wesentlichen die Unterscheidungsmerkmale in dem der Variablen entsprechenden Wellenzahlbereich vorliegen, und zum Anderen die Variablen oberhalb 
der Variablen 200 einen signifikanten Störeinfluss auf die Hauptkomponentenanalyse aufweisen. Eine mögliche Erklärung für den Störeinfluss stellt das ortsabhängige Blindwertspektrum des Klarite ${ }^{\circledR}$-Substrates dar, das insbesondere Signalschwankungen oberhalb von $1100 \mathrm{~cm}^{-1}$ aufweist (s. Abschnitt 7.3), was den Variablen oberhalb der Variable 500 entspricht. Die Differenz der für die Hauptkomponentenanalyse optimalen Anzahl von 200 Variablen (Variable 1 bis 200) zu den Variablen oberhalb von 500, bei denen sich ortsabhängige Signalschwankungen in den Blindwertspektren zeigen, bleibt jedoch ungeklärt.

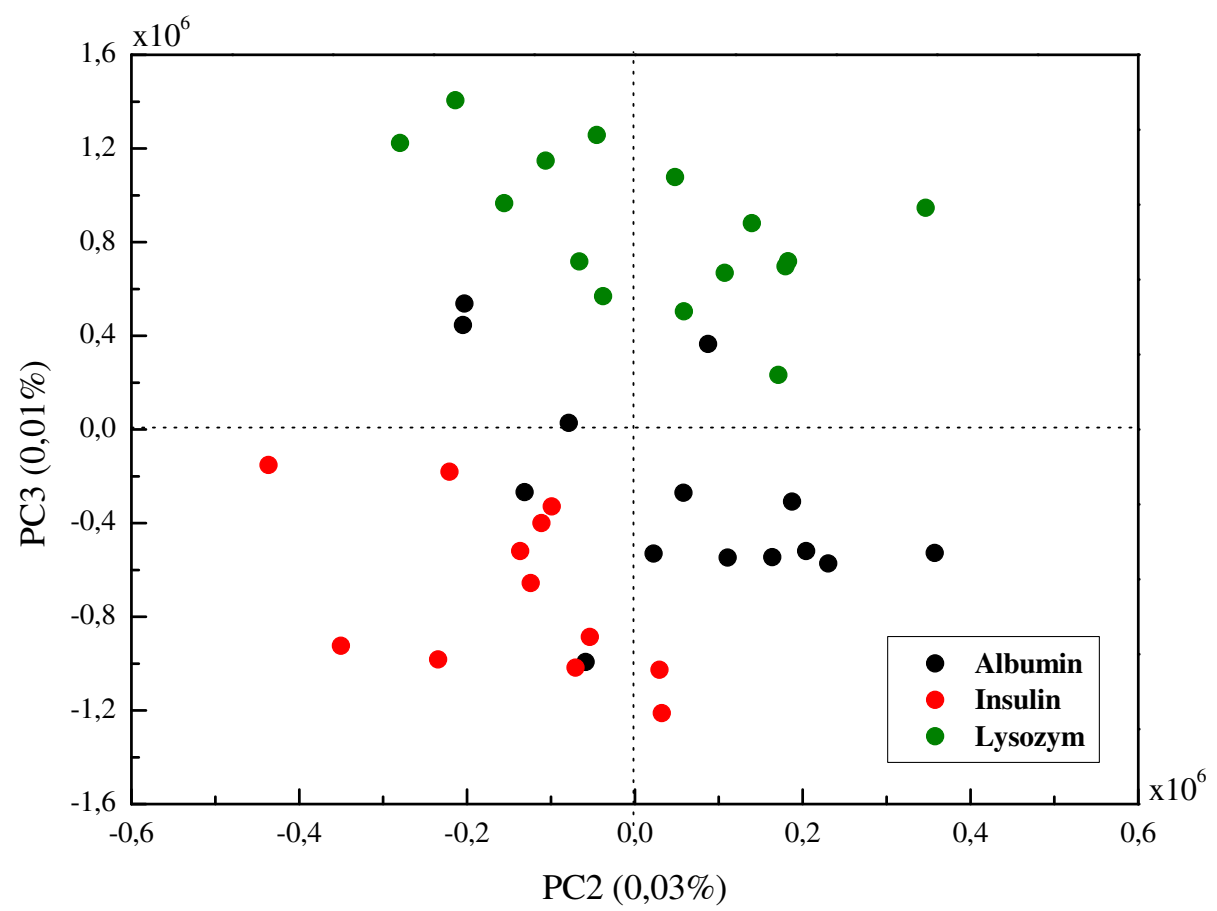

Abbildung 7.26: Auftragung der Hauptkomponente PC3 gegen PC2 unter Verwendung der Variablen 1 bis 200.

\section{Datenvorbehandlung der Datenmatrix nach Variablenreduktion}

Die besten Ergebnisse der Hauptkomponentenanalyse liefert die erste Ableitung der Variablen-reduzierten Protein-Ramanspektren mit Hilfe der Savitzky-Golay Spektrenglättung [98]. Bereits in der Auftragung des prozentualen Anteils der jeweiligen Hauptkomponenten an der Gesamtvarianz der Datenmatrix (s. Abbildung 7.27) nehmen die zweite und dritte Hauptkomponente einen deutlich höheren prozentualen Anteil ein als im Fall der Rohspektren (s. Abbildung 7.25). Dies ist ein Hinweis darauf, dass durch die Datenvorbehandlung mit der ersten Ableitung die Unterscheidungsmerkmale hervorgehoben werden. 


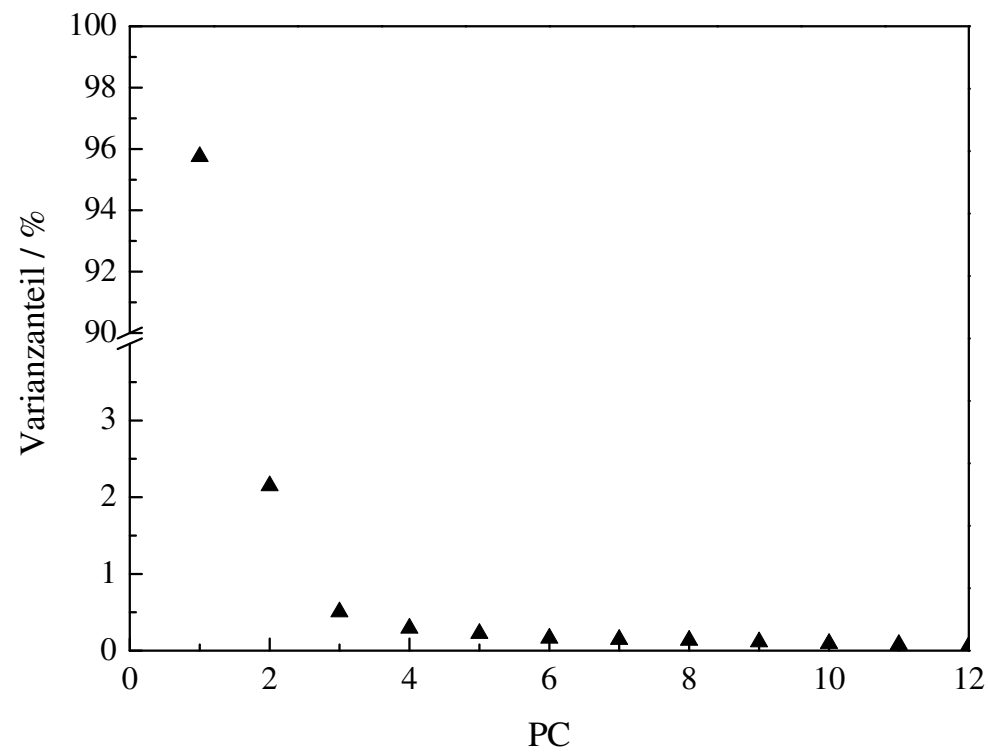

Abbildung 7.27: Auftragung des prozentualen Anteils der Gesamtvarianz gegen die Hauptkomponenten.

Die Hervorhebung der Unterscheidungsmerkmale wird besonders durch den Vergleich der nicht datenvorbehandelten mit den datenvorbehandelten Spektren in Abbildung 7.28 ersichtlich. Durch die erste Ableitung werden die Änderungen der Intensitätsverläufe der Spektren herausgearbeitet und jeglicher Untergrund in den Spektren eliminiert. Zur Verdeutlichung der Unterscheidungsmerkmale sind die Bereiche in den Kurvenverläufen der Ramanstreulichtintensitäten der ersten Ableitung in Abbildung 7.28 rot eingefärbt. Demnach liefert die Steigung der Spektren, die durch die erste Ableitung repräsentiert wird, eher einen proteinspezifischen „fingerprint" als die Ramanrohspektren.

In Abbildung 7.29 ist das Ergebnis der Hauptkomponentenanalyse unter Verwendung der ersten Ableitung der Spektren dargestellt. Die Auftragung der Hauptkomponente PC3 gegen die Hauptkomponente PC2 zeigt eine signifikante Clusterung der Proteinspezies, wobei jeder Cluster zusätzlich mit jeweils einer zweidimensionalen Gaussfunktion (Matlabskript s. Anhang) angepasst ist. Jede dargestellte Ellipse kann einer einfachen Standardabweichung $\sigma$ oder einer zweifachen Standardabweichung $2 \sigma$ für die Abweichung der Hauptkomponenten von dem jeweiligen Zentrum der Cluster zugeordnet werden. Diese Ringe repräsentieren die Reproduzierbarkeit der Datenpunkte und lassen eine quantitative Aussage bezüglich der Signifikanz der Abstände der proteinspezifischen Cluster zueinander zu. Im Allgemeinen dienen die Ringe der einfachen und zweifachen bzw. dreifachen Standardabweichung auch zur Bestimmung der diagnostischen Spezifität, die mit verschiedenen Substraten und/oder alternativen chemometrischen Auswertealgorithmen zur Clusteranalyse erreicht werden. 


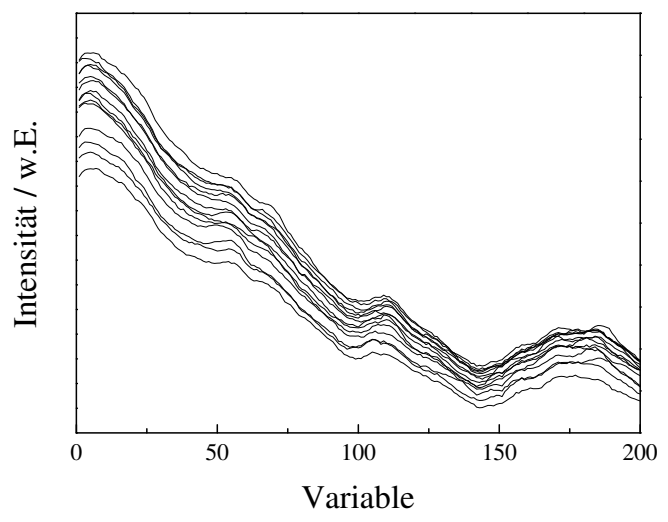

(a)

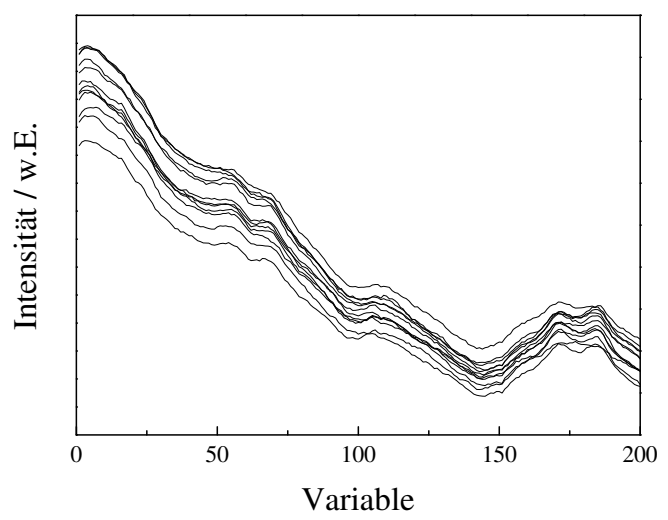

(c)

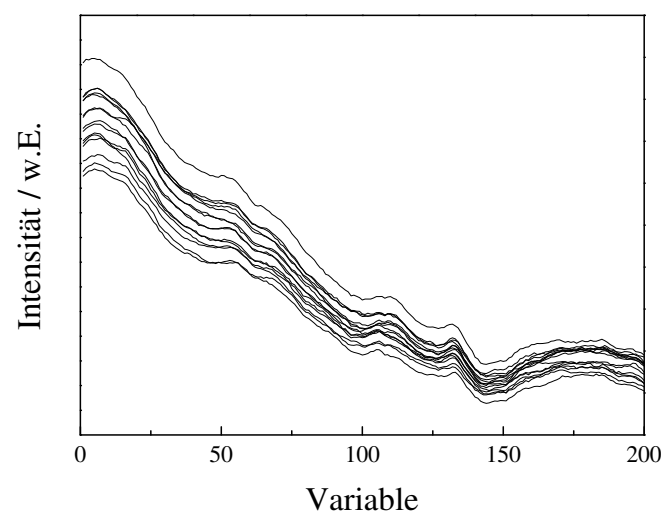

(e)

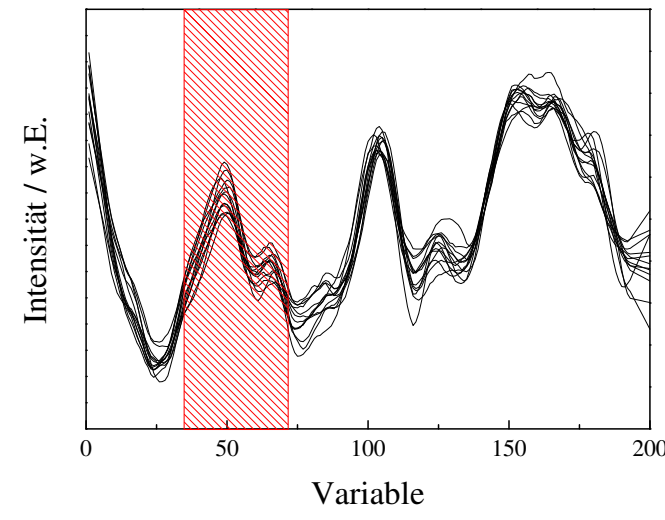

(b)

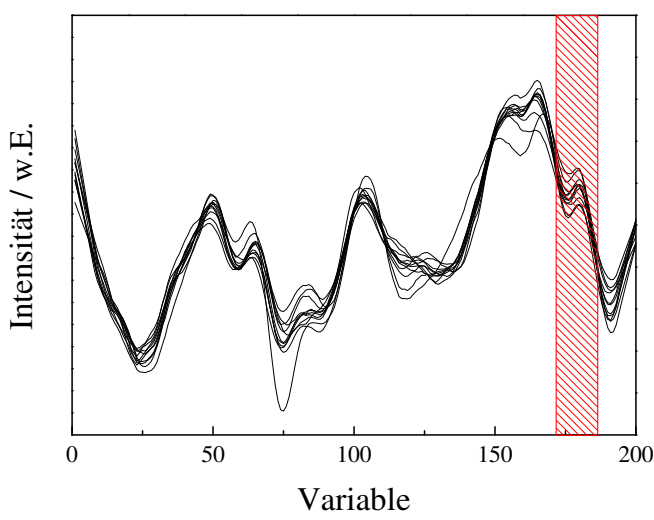

(d)

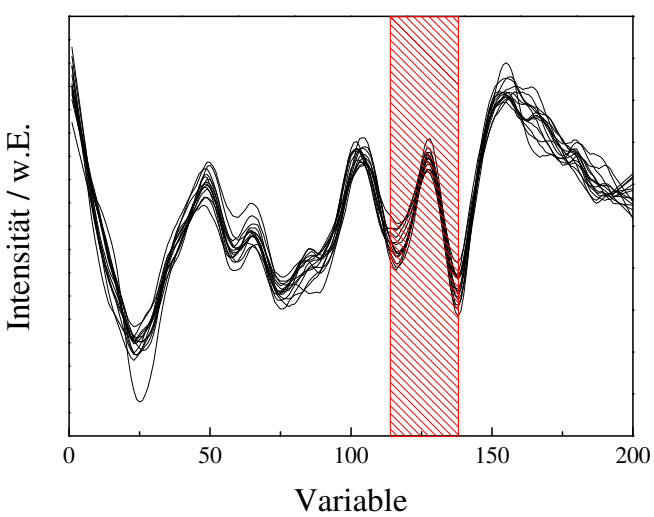

(f)

Abbildung 7.28: Auf die Ramanbande bei $998 \mathrm{~cm}^{-1}$ normierte oberflächenverstärkte Ramanspektren für die Variablen 1 bis 200 für (a) Albumin, (c) Insulin und (e) Lysozym. Erste Ableitung der oberflächenverstärkten Ramanstreulichtintensitäten für die Variablen 1 bis 200 für (b) Albumin, (d) Insulin und (f) Lysozym. Die Bereiche, in denen deutlich Unterscheidungsmerkmale zu erkennen sind, sind rot markiert. 
Desweiteren sind in Abbildung 7.29 zusätzlich die auf das erzeugte Modell angewendeten Validierdaten dargestellt. Sie werden eindeutig den entsprechenden Proteinspezies zugeordnet, doch sind die Zentren der Haupkomponentenverteilungen leicht verschoben. Mögliche Ursachen könnten zum Einen die unterschiedlichen Substrate und die damit verbundenen möglichen Variationen des Blindwertspektrums sein, auf denen die Kalibrier- und Validierdatensätze erzeugt wurden, und zum Anderen reicht die Anzahl der Kalibrierdaten unter Umständen nicht aus, jeden denkbaren physikalischen Einfluss zu berücksichtigen.

Dennoch zeigen die Ergebnisse der Hauptkomponentenanalyse, dass trotz der sehr hohen Querempfindlichkeit des Blindwertspektrums und der sehr geringen Konzentrationen im Femtomol-Bereich mit Hilfe einer entsprechenden Datenvorbehandlung eine signifikante Identifizierung möglich ist.

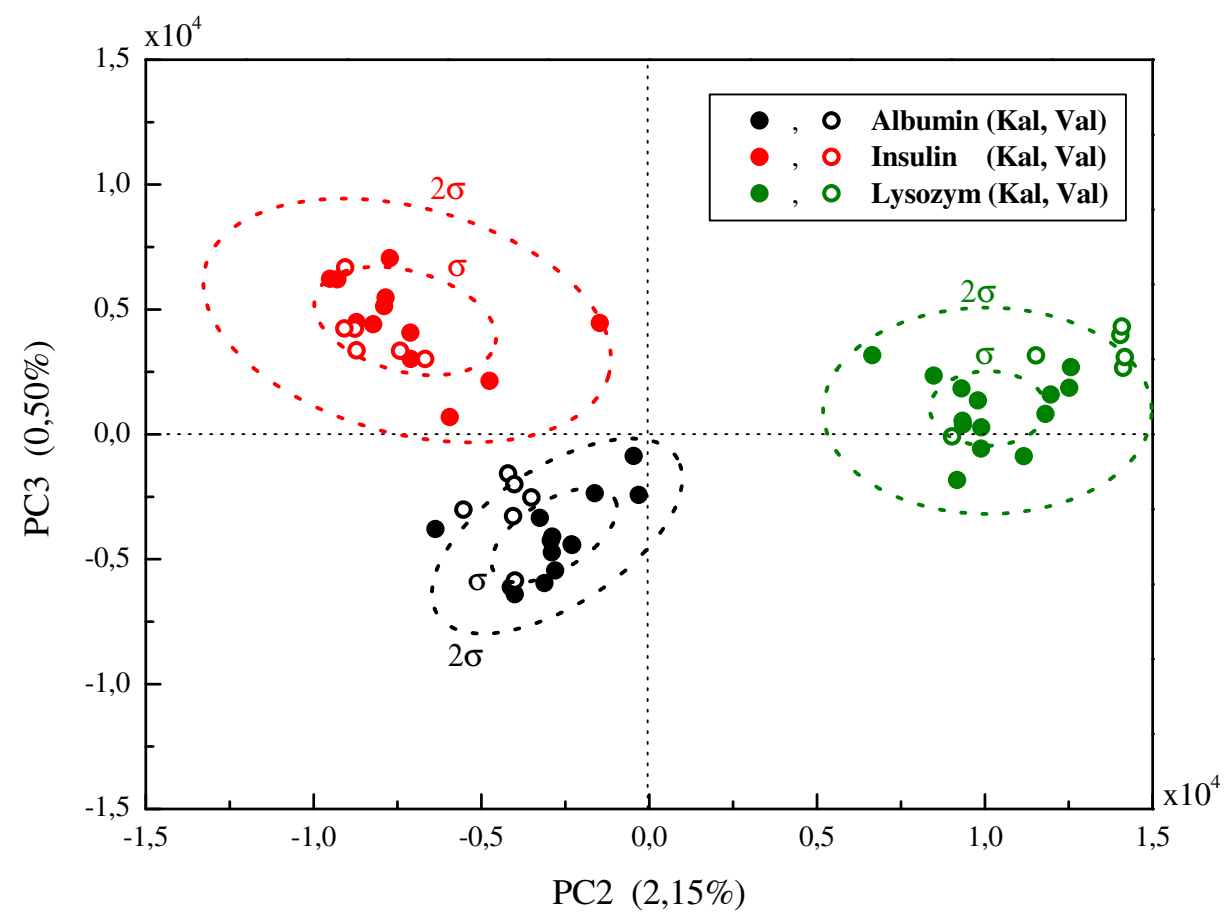

Abbildung 7.29: Auftragung der Hauptkomponente PC3 gegen PC2 unter Verwendung der Variablen 1 bis 200 der Datenmatrix. Es wurde zuvor die erste Ableitung der Spektren gebildet. Zusätzlich sind die auf das Modell angewandten Validierdaten eingezeichnet.

\subsection{Fazit}

Die vorgestellten Ergebnisse zeigen deutlich das Potential der oberflächenverstärkten Ramanspektroskopie zur Quantifizierung von Proteinen im Femtomol-Bereich auf, wobei die noch messbare Molekülanzahl durch die in Abschnitt 7.1 beschriebene Methode 
zur Probenauftragung auf das ramanstreulichtverstärkende Klarite ${ }^{\circledR}$-Substrat begrenzt wird.

Desweiteren deuten die Ramanstreulichtmessungen darauf hin, dass sich die Messmethode mit der speziellen Probenauftragung nur für molare Massen von bis zu ca. $60 \mathrm{kDa}$ eignet und sie damit insbesondere für schwerere bzw. größere Moleküle, wie beispielsweise Immuno-Globuline, die als Antikörper fungieren, unzugänglich ist.

Außerdem wurde eine hohe Querempfindlichkeit des zeit- und ortsabhängigen Blindwertspektrums des reinen Klarite ${ }^{\circledR}$-Substrates zu den oberflächenverstärkten Ramanspektren in den hier vorgestellten Konzentrationsbereichen festgestellt. Dieses Blindwertspektrum führt insbesondere in Wellenzahlbereichen oberhalb von $1100 \mathrm{~cm}^{-1}$ in den Ramanspektren zu starken Querempfindlichkeiten, die eine Quantifizierung deutlich erschweren. Damit ist der zur Quantifizierung geeignete Wellenzahlbereich stark eingeschränkt.

Am Beispiel ausgewählter proteinspezifischer Ramanbanden wird erstmals ein funktionaler Zusammenhang zwischen den gemessenen Ramanstreulichtintensitäten und der Molekülanzahl in dem zugrundeliegenden Ringmuster im Femtomol-Bereich in Analogie zur Langmuir-Isotherme hergestellt.

Darüber hinaus ergibt sich aus der rechnerischen Abschätzung der Verstärkungsfaktoren des Klarite ${ }^{\circledR}$-Substrates am Beispiel der Proteine Albumin und Lysozym ein von der Molekülgröße abhängiger Verstärkungseffekt, sofern die Ergebnisse bei der Berechnung des Verstärkungsfaktors am Thiophenol aus Kapitel 4 zum Vergleich herangezogen werden. Der an den Proteinen rechnerisch abgeschätzte Verstärkungsfaktor fällt dabei um 2-3 Größenordnungen kleiner aus im Vergleich zum Thiophenol.

Aus den Untersuchungen der Identifikationsmöglichkeiten von Proteinen auf dem Klarite ${ }^{\circledR}$-Substrat mit Hilfe der Hauptkomponentenanalyse kann geschlussfolgert werden, dass die signifikanten Unterscheidungsmerkmale in den Proteinramanspektren von dem Blindwertspektrum des Klarite ${ }^{\circledR}$-Substrates vollständig überlagert werden, so dass die Hauptkomponentenanalyse keine signifikanten Ergebnisse liefert. Erst durch die Datenvorbehandlung der Proteinramanspektren werden signifikante Unterscheidungsmerkmale in der Hauptkomponentenanalyse sichtbar, die - wie die Ergebnisse der Validierung zeigen - eine eindeutige Identifikation von Proteinspezies erlaubt.

Die Ergebnisse der Hauptkomponentenanalyse sind natürlich nicht stellvertretend für alle Proteinspezies, doch sind sie richtungsweisend, was die experimentelle Vorgehensweise und Datenvorbehandlung bei der Identifikation von Proteinspezies mittels der oberflächenverstärkten Ramanspektroskopie betrifft. 


\section{Kapitel 8}

\section{Zusammenfassung und Ausblick}

Im Rahmen der vorliegenden Arbeit wurde eine umfassende Untersuchung der Einsatzmöglichkeiten der Ramanspektroskopie zur Identifizierung und Quantifizierung von wässrigen Proteinlösungen mit Schwerpunkt auf der oberlächenverstärkten Ramanspektroskopie durchgeführt. Der Hintergrund dieser Untersuchungen bestand in der Beantwortung der Fragestellung, in wieweit die oberflächenverstärkte Ramanspektroskopie als direktes Messverfahren in der Proteinanalytik eingesetzt werden kann und ob die mit diesem Messverfahren erreichten Nachweisempfindlichkeiten mit den hohen Nachweisempfindlichkeiten des in der Proteinanalytik etablierten indirekten optischen Fluoreszenzmessverfahrens konkurrieren können. Fluoreszenzbasierte Messverfahren sind auf die Markierung der zu untersuchenden Proteine mit Fluorophoren angewiesen. Es finden jedoch mit zunehmender Anzahl der nachzuweisenden Proteine pro Protein-Array immer häufiger unspezifische Bindungen der fluoreszenzmarkierten Antigene bzw. Antikörper an das Protein-Array statt. Die unspezifischen Bindungsereignisse führen zwangsläufig zu einer falschen Interpretation bei der Auswertung der Protein-Arrays. Dementgegen ist die Ramanspektroskopie nicht auf die Markierung der Zielmoleküle angewiesen und erlaubt eine direkte Identifizierung und Quantifizierung der untersuchten Proteine anhand des molekülspezifischen Ramanspektrums.

Grundlage für die Durchführbarkeit der Untersuchungen in dieser Arbeit bildete die Entwicklung und Konstruktion eines hochsensitiven Ramanspektrometers, das speziell auf hohen Lichtdurchsatz und damit hohe Nachweisempfindlichkeit optimiert wurde. Am Beispiel wässriger Proteinlösungen von menschlichem Albumin und $\gamma$-Globulin, sowie in der Blutdiagnostik relevanter Moleküle, wie z.B. Glukose und Cholesterin, wurden Konzentrationsmessungen in einer Standardprobenanordnung (Quarzglasküvette) durchgeführt. Daraus ergaben sich Nachweisgrenzen, die weit unterhalb der physiologischen Konzentrationsbereiche eines gesunden Menschen angesiedelt sind und somit die hohe Nachweisempfindlichkeit des selbstentwickelten Ramanspektrometers widerspiegeln. 
Basierend auf diesen Ergebnissen wurden zwei unterschiedliche Flüssigkernhohlwellenleiter aus Teflon-AF 2400 zur Verstärkung des Ramanstreulichtes eingesetzt. Dazu wurden detaillierte Untersuchungen der Parameter Kapillarlänge und -durchmesser sowie der Kenngröße Reflexionskoeffizient durchgeführt, um optimale Ramanstreulichtausbeuten zu erzielen. Aufgrund der mit den Flüssigkernhohlwellenleitern realisierten Erhöhung der Wechselwirkungsstrecke zwischen dem Analyt und der Anregungsstrahlung gegenüber der Standardprobenanordnung konnte eine um den Faktor drei verbesserte Nachweisempfindlichkeit an Albumin- und $\gamma$-Globulinlösungen sowie eine fünfzig- bis sechzigfach höhere Ramanstreulichtausbeute erreicht werden. Unabdingbare Voraussetzung für die Umsetzung quantitativer Ramanstreulichtmessungen in den Teflon-AF Hohlwellenleitern bildete die Korrektur der von der Absorption der wässrigen Lösung abhängigen Ramanstreulichtintensität mittels eines Auswertealgorithmus zur Linearisierung des Zusammenhangs zwischen der gemessenen Streulichtintensität und der Konzentration. Dieser wurde erfolgreich an der Modellsubstanz Glaubersalz erprobt und auf die Konzentrationsmessungen an den wässrigen Proteinlösungen angewendet.

Neben der Erprobung des selbstentwickelten Ramanspektrometers an beispielhaften Proteinlösungen stand insbesondere die Entwicklung und der Einsatz nanostrukturierter Edelmetalloberflächen zur Verstärkung des Ramanstreulichtes im Vordergrund dieser Arbeit. Dazu wurden drei unterschiedliche Strategien bei der Herstellung geeigneter Substrate verfolgt und diese mit Hilfe selbstorganisierender Thiophenol-Monolagen sowohl hinsichtlich der mit ihnen erzielten Verstärkungsfaktoren und ihrer Signalreproduzierbarkeiten umfassend untersucht. Zu den Herstellungsverfahren zählten das Ätzen von Silizium-Wafern (die Substrate sind kommerziell unter dem Namen Klarite ${ }^{\circledR}$ erhältlich), die UV-Nanoimprint Lithographie sowie ein selbstentwickeltes Verfahren, bei dem dünne Goldschichten mit UV-Lasereinzelpulsen bestrahlt wurden. Mit den erzeugten Substraten konnten Verstärkungsfaktoren in der Größenordnung von $10^{5}$ bis $10^{6}$ erzielt werden und in einzelnen Fällen, abhängig von dem jeweiligen Substrat, räumliche Signalreproduzierbarkeiten von kleiner $5 \%$ Standardabweichung beobachtet werden. Insbesondere zeigten die mit den beiden erst genannten Herstellungsverfahren erzeugten regelmäßigen Strukturen erwartungsgemäß die höchste räumliche Signalreproduzierbarkeit, die im Einzelfall sogar bei nur 1\% Standardabweichung lag. Sie sind daher prinzipiell besonders gut für die quantitative Analyse von wässrigen Proteinlösungen geeignet. Bildgebende Messverfahren, wie die Rasterkraft- und Elektronenmikroskopie, lieferten darüber hinaus detaillierte Informationen über die Topographien der erzeugten Nanostrukturen. Die durch die UV-Laserbestrahlung erzeugten Substrate wiesen im Vergleich zu den aus den beiden anderen Herstellungsverfahren hervorgegangenen 
Substraten die höchsten Verstärkungsfaktoren auf. Daher fanden umfangreiche Untersuchungen des Einflusses der verwendeten Laserwellenlänge, der Goldschichtdicke und der Fluenz in Hinblick auf die mit den erzeugten Strukturen realisierten Verstärkungsfaktoren und Signalreproduzierbarkeiten statt. Die Ergebnisse dieser Untersuchungen zeigten auf, dass zum Einen sehr starke räumliche Signalschwankungen von teilweise über $50 \%$ Standardabweichung auftraten und zum Anderen eine Abhängigkeit der Signalverstärkung von der Goldschichtdicke und der eingesetzten Fluenz bestand. Es konnte jedoch kein funktioneller Zusammenhang zwischen diesen Parametern hergestellt werden. Lediglich im Fall der Goldschichten, die mit Lasereinzelpulsen der Wellenlänge von $308 \mathrm{~nm}$ bestrahlt wurden, konnte eine Proportionalität zwischen der erzeugten Strukturgröße und der Signalverstärkung festgestellt werden. Diese Strukturen wiesen darüber hinaus eine Signalreproduzierbarkeit mit einer Standardabweichung von $5 \%$ auf.

Desweiteren wurde in der vorliegenden Arbeit ein Verfahren zur Quantifizierung von Proteinen auf ramanstreulichtverstärkenden Oberflächen entwickelt und erfolgreich am kommerziell erhältlichen Klarite ${ }^{\circledR}$-Substrat erprobt. Bei den Proteinramanspektren zeigte sich ein dominanter Quereinfluss des Blindwertspektrums des reinen Klarite ${ }^{\circledR}$ Substrates, der im Detail zeit- und ortsabhängig untersucht wurde. Trotz dieses Einflusses konnten die gemessenen oberflächenverstärkten Ramanspektren zur quantitativen Analyse herangezogen werden. Erstmalig wurde eine Quantifizierung von Proteinmolekülanzahlen im Femtomol-Bereich mittels einer Analogie zur Langmuir-Isotherme nachgewiesen. Diese Ergebnisse machen das Potential der oberflächenverstärkten Ramanspektroskopie deutlich, da die nachgewiesenen Molekülanzahlen der ausgewählten Proteine im Bereich der Nachweisempfindlichkeit der in der Proteinanalytik eingesetzten Fluoreszenzmessverfahren liegt. Weiterhin konnte gezeigt werden, dass mit Hilfe der multivariaten Hauptkomponentenanalyse eine eindeutige Identifizierung von Proteinen mittels ihrer oberflächenverstärkten Ramanspektren trotz der vollständigen Überlagerung dieser Spektren durch das Blindwertspektrum des Klarite ${ }^{\circledR}$-Substrates mit entsprechender Datenvorbehandlung möglich war. Die vorliegende Arbeit zeigt auf, dass ein großer Schritt in Richtung des Transfers der oberflächenverstärkten Ramanspektroskopie als Messverfahren in die Proteinanalytik gemacht wurde.

Die Zukunft wird zeigen, ob die oberflächenverstärkte Ramanspektroskopie Einzug in die Proteinanalytik hält und inwieweit die grundlegende Entwicklung, Weiterentwicklung und Optimierung geeigneter Substrate fortgeführt wird. Dabei ist in hohem Maße der Einsatz moderner und effektiver Simulationsverfahren nötig. In Kombination mit neuartigen Herstellungsverfahren können damit Substrate mit hervorragenden Eigenschaften erzeugt werden. Damit werden neue Wege für die oberflächenverstärkte 
Ramanspektroskopie als optisches und nichtinvasives Messverfahren in viele weitere Bereiche der Forschung in Wissenschaft und Industrie eröffnet. 


\section{Anhang}

\section{Matlab-Skripte}

\section{Automatische Basislinienkorrektur}

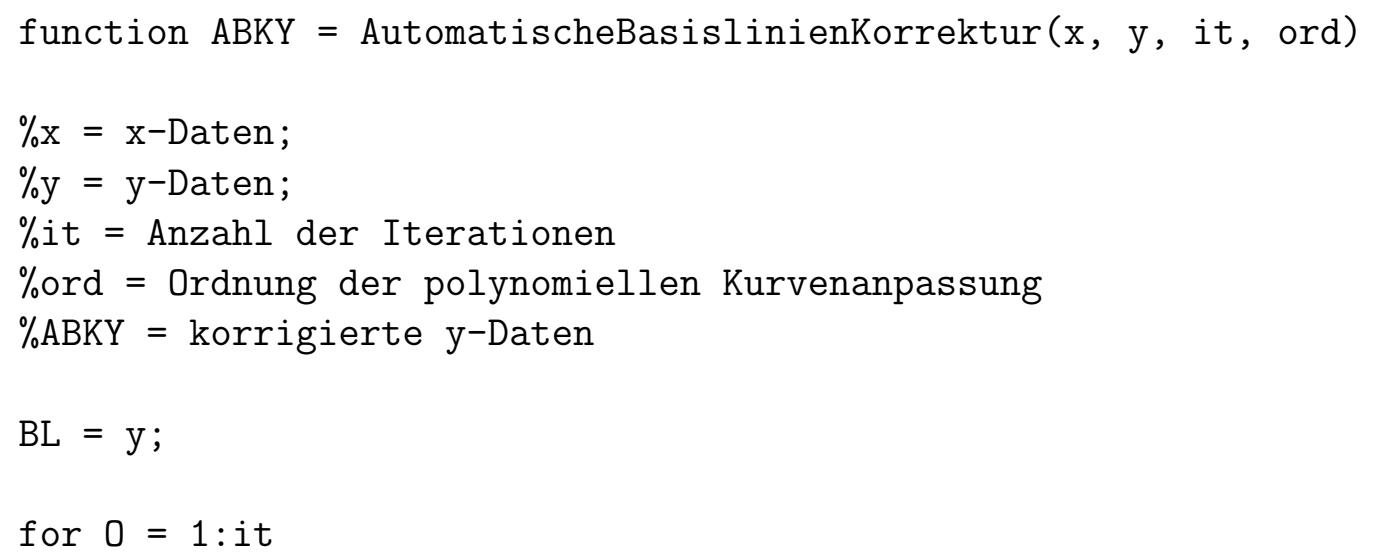

\%Ermittelung der Koeffizienten „Koeff“ des Polynoms „P(x)“ mit der Ordnung „ord“. Weitere Informationen zu der Funktion polyfit und polyval sind der Matlab-Hilfe zu entnehmen.

$$
\begin{aligned}
& \text { Koeff }=\operatorname{polyfit}(\mathrm{x}, \mathrm{BL}, \text { ord }) \\
& \mathrm{P}=\operatorname{polyval}(\text { Koeff, } \mathrm{x})
\end{aligned}
$$

\%Modifizierung der polynomiellen Kurvenanpassung.

$$
\begin{aligned}
& \text { for } i=1: \operatorname{length}(x) \\
& \text { if }(P(i)<=y(i)) \\
& \quad B L(i)=P(i) ; \\
& \text { else } B L(i)=y(i) ; \\
& \text { end } \\
& \text { end }
\end{aligned}
$$

end

\%Subtraktion der Basislinie von y.

$\mathrm{ABKY}=\mathrm{y}-\mathrm{BL}$ 


\section{Zweidimensionale Gauss-Kurvenanpassung}

function 2Dgauss $=2 \operatorname{Dgauss}(\mathrm{x}, \mathrm{y})$;

$\%$ xmean, ymean = Mittelwert von $\mathrm{x}, \mathrm{y}$

$\%$ xvar, yvar = Varianz von $\mathrm{x}, \mathrm{y}$

$\%$ xsd, ysd = Standardabweichung von $\mathrm{x}, \mathrm{y}$

$\%$ rho $=$ Korrelationskoeffizient zwischen $\mathrm{x}$ und $\mathrm{y}$

xmean $=\operatorname{mean}(\mathrm{x})$;

ymean $=\operatorname{mean}(\mathrm{y})$;

$\mathrm{xvar}=\operatorname{var}(\mathrm{x})$;

yvar $=\operatorname{var}(\mathrm{y})$;

rho $=\operatorname{corr} 2(\mathrm{x}, \mathrm{y})$;

$\mathrm{xsd}=\operatorname{sqrt}(\mathrm{xvar})$;

ysd $=\operatorname{sqrt}($ yvar $)$;

\%Überprüfung des Korrelationskoeffizienten.

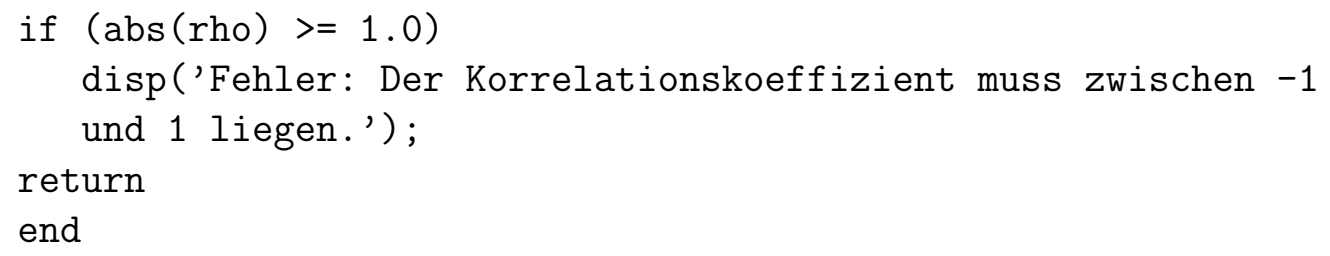

\%Berechnung der Kovarianz und Kovarianzmatrix.

covxy $=$ rho*xsd $* y s d ;$

$\mathrm{C}=[\mathrm{xvar}$ covxy; covxy yvar $]$;

\%Invertierung der Kovarianzmatrix.

$A=\operatorname{inv}(C) ; \%$ inverse Kovarianzmatrix

\%Berechnung der Stützstellen x1, y1 innerhalb der zweifachen Standardabweichung von x und y für die die Gauss-Kurvenanpassung vorgenommen werden soll.

$\operatorname{maxsd}=\max (\mathrm{xsd}, \mathrm{ysd})$

$\mathrm{x} 1=$ xmean $-2 * \operatorname{maxsd}: 250: \mathrm{xmean}+2 * \operatorname{maxsd} ;$

y1 $=$ ymean $-2 * \operatorname{maxsd}: 250:$ ymean $+2 * \operatorname{maxsd}$

\%Berechnung der 2D-Gauss-Kurvenanpassung.

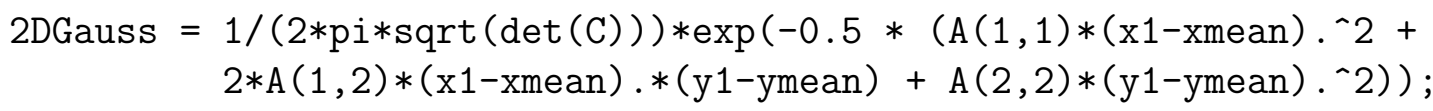




\section{Literaturverzeichnis}

[1] Adrian, F.J.: Charge transfer effects in surface-enhanced Raman scattering. In: Journal of Chemical Physics 77 (1982), S. 5302

[2] Alexander, T. A. ; Le, D.M.: Characterization of a commercialized SERSactive substrate and its application to the identification of intact Bacillus endospores. In: Applied Optics 46 (2007), S. 3878-3890

[3] Altkorn, R. ; Koev, I. ; Duyne, R. P. V. ; Litorja, M.: Low-loss liquidcore optical fiber for low-refractive-index liquids: fabrication, characterization, and application in Raman spectroscopy. In: Applied Optics 36 (1997), Nr. 34, S. 8992-8998

[4] Altkorn, R. ; Koev, I. ; Pelletier, M.J.: Raman performance characteristics of Teflon-AF 2400 liquid-core optical-fiber sample cells. In: Applied Spectroscopy 52 (1999), Nr. 10, S. 1169-1176

[5] Altkorn, R. ; Malinsky, M.D. ; Duyne, R.P. van ; Koev, I.: Intensity considerations in liquid core optical fiber Raman spectroscopy. In: Applied Spectroscopy 55 (2001), Nr. 4, S. 373-381

[6] Angel, S. M. ; Carrabbab, M. ; Cooneya, T.F.: The utilization of diode lasers for Raman spectroscopy. In: Spectrochimica Acta Part A: Molecular and Biomolecular Spectroscopy 51 (1995), S. 1779-1799

[7] Angenendt, P. ; Kreutzberger, J. ; Glökler, J. ; Hoheisel, J.D.: Generation of high density protein microarrays by cell-free in situ expression of unpurified PCR products. In: Molecular and Cellular Proteomics 5 (2006), S. $1658-1666$

[8] Aravind, P.K. ; Metiu, H.: Use of a perfectly conducting sphere to excite the plasmon of a flat surface. 1. Calculation of the local field with applications to surface-enhanced spectroscopy. In: Journal of Physical Chemistry 86 (1982), S. 5076-5084

[9] Ardenne, M. von ; Musiol, G. ; Reball, S.: Effekte der Physik und ihre Anwendungen. Harri Deutsch, 1997

[10] Aroca, R .. ; Battisti, D.: SERS of Langmuir Blodgett monolayers: coverage dependence. In: Langmuir 6 (1990), S. 250-254 
[11] Baum, T. ; Schiffrin, D.J.: Mechanistic aspects on anisotropic dissolution of materials. In: Journal of Chemical Society, Faraday Transactions 94 (1998), S. 691-694

[12] Brooker, M.H. ; Hancock, G. ; Rice, B.C. ; Shapter, J.: Raman frequency and intensity studies of liquid $\mathrm{H}_{2} 0, \mathrm{H}_{2}{ }^{18} 0$ and $\mathrm{D}_{2} 0$. In: Journal of Raman Spectroscopy 20 (1989), S. 683-694

[13] Cazares, L.H. ; Leung, S.M. ; Nasim, S. ; Adam, B.L. ; Yip, T.T. ; Schellhemmer, P.F. ; Gong, L. ; Vlahou, A.: Proteinchip surface-enhanced laser desorption/ionization (SELDI) mass spectrometer: a novel protein biochip technology for detection of prostate cancer biomarkers in complex protein mixtures. In: Prostate Cancer and Prostatic Disease 2 (1999), S. 264-276

[14] Chew, H. ; WAng, D.S. ; M. Kerker, M.: Effect of surface coverage in surfaceenhanced Raman scattering: Interaction of two dipoles. In: Physical Review B 28 (1983), S. 4169-4178

[15] Danzer, K. ; Hobert, H. ; Fischbacher, C. ; Jagemann, K.-U.: Chemometrik - Grundlagen und Anwendung. Springer, 2001

[16] Deegan, R.D. ; Bakajin, O. ; Dupont, T.F. ; Huber, G.H. ; Nagel, S.R. ; Witten, T.A.: Capillary flow as the cause of ring stains from dried liquid drops. In: Nature 389 (1997), S. 827-829

[17] Drachev, V.P. ; Thoreson, M.D. ; Nashine, V. ; Khaliullin, E.N. ; BenAmotz, D. ; Davisson, J. ; Shalaev, V.M.: Adaptive silver films for surfaceenhanced Raman spectroscopy of biomolecules. In: Journal of Raman Spectroscopy 36 (2005), S. 648-656

[18] Dupont-Gillain, C. ; Gurdak, E. ; Rouxhet, P.G. ; Somasundaran, P. (Hrsg.) ; Hubbard, A. (Hrsg.): Protein films adsorbed on solids: Use of AFM and XPS to characterize nanostructure. Taylor and Francis, 2007

[19] Ehrlich, G. ; DAnZer, K.: Nachweisvermögen von Analyseverfahren. Springer Verlag, 2006

[20] Filik, J. ; Stone, N.: Drop coating deposition Raman spectroscopy of protein mixtures. In: The Analyst 132 (2007), S. 544-550

[21] Fleischmann, M. ; Hendra, P.J. ; McQuillan, A.J.: Raman spectra of pyridine adsorbed at a silver electrode. In: Chemical Physics Letters 26 (1974), Nr. 2, S. 163-166

[22] Fliessbach, T.: Elektrodynamik. 1. Auflage. Elsevier, 2005

[23] Fuchs, A. ; Bender, M. ; Plachetka, U. ; Koch, L. ; Koo, N. ; Wahlbrink, T. ; Kurz, H.: Lithography potentials of UV-nanoimprint. In: Current Applied Physics 8 (2008), S. 669-674 
[24] Gersten, J. I. ; Nitzan, A.: Electromagnetic theory of enhanced Raman scattering by molecules adsorbed on rough surfaces. In: Journal of Chemical Physics 73 (1980), Nr. 7, S. 3023-3037

[25] GeSiM: Datenblatt Nanoplotter NP1.2, www.gesim.de/upload/PDFs/ Technische_Daten_Nano-Plotter_2009.pdf

[26] Giordano, B.C. ; Jin, L. ; Couch, A.J. ; Ferrance, J.P. ; Landers, J.P.: Microchip laser-induced fluorescence detection of protein at submicrogramm per milliliter levels mediated by dynamic labeling under pseudonative conditions. In: Analytical Chemistry 76 (2004), S. 4705-4714

[27] GmBH, AMO: AMONIL, http://www.amo.de/amonilflyer.0.html?\&L=1

[28] Gonzalez, M. ; Bagatolli, L.A. ; Echabe, I. ; Arrondo, J.L.R. ; ArGarana, C.E. ; Cantor, C.R. ; Fidelio, G.D.: Interaction of Biotin with Streptavidin. In: Journal of Biological Chemistry 272 (1997), S. 11288-11294

[29] Gottwald, W.: Statistik für Anwender. Wiley-VCH, 1999

[30] Graber, K.C. ; Freeman, R.G. ; Hommer, M.B. ; Natan, M.J.: Preparation and characterization of Au colloid monolayers. In: Analytical Chemistry of Materials 67 (1995), S. 735-743

[31] HAAB, B.B: Advances in protein microarray technology for protein expression and interaction profiling. In: Current Opinion in Drug Discovers and Development 4 (2001), S. 116-123

[32] Haken, Hermann ; Wolf, Hans C.: Molekülphysik und Quantenchemie. Springer Verlag, 2003

[33] Hall, E.A.H.: Biosensoren. Springer-Verlag, 2002

[34] Haynes, C.L. ; Duyne, R.P. van: Nanosphere lithography: a versatile nanofabrication tool for studies of size-dependent nanoparticle optics. In: Journal of Physical Chemistry 105 (2001), S. 599-611

[35] Haynes, C.L. ; Duyne, R.P. van: Plasmon-sampled surface-enhanced Raman excitation spectroscopy. In: Jornal of Physical Chemistry 107 (2003), S. 74267433

[36] Henrion, R. ; Henrion, G.: Multivariate Datenanalyse - Methodik und Anwendung in der Chemie und verwandten Gebieten. Springer, 1995

[37] Holtzhauer, M.: Methoden der Proteinanalytik. Springer-Verlag, 1996

[38] Hornauer, H. ; Klause, U. ; Müller, H.J.: IMPACT - Eine Protein-Array Technologie für die diagnostische Anwendung der Zukunft. In: Biospektrum Special: Proteomics in der molekularen Medizin (2004), S. 564-565 
[39] Kahl, M. ; Voges, E.: Analysis of plasmon resonance and surfce-enhanced Raman scattering on periodic silver structures. In: Physical Review B 61 (2000), S. $14078-14088$

[40] Kazuhito, A.: Electrochemical SPR sensing for nanospezific determination of protein concentration / Institute of Electronics, Information and Communication Engineers. 2005. - Forschungsbericht

[41] Kelly, K.L. ; Coronado, E. ; Zhao, L.L. ; Schatz, G.: The optical properties of metal nanoparticles: The influence of size, shape and dielectric environment. In: Journal of Physical Chemistry 107 (2003), S. 668-677

[42] Kerker, M. ; Simman, O. ; Wang, O.S.: Effect of aggregates on extinction and surface-enhanced Raman scattering spectra of colloidal silver. In: Journal of Physical Chemistry 88 (1984), Nr. 15, S. 3168-3170

[43] Kesslen, W.: Multivariate Datenanalyse. Wiley-VCH, 2007

[44] Khosrofian, J.M. ; Garetz, B.A.: Measurement of a Gaussian laser beam diameter through the direct inversion of knife-edge data. In: Applied Optics 22 (1983), S. 3406-3410

[45] Kneipp, K.: Raman spectroscopy of single molecules. In: Single Molecules 2 (2001), S. 291-292

[46] Kneipp, K. ; Kneipp, H. ; Itzkan, I. ; Dasari, R. R. ; Feld, M.S: Surfaceenhanced Raman scattering and biophysics. In: Journal of Physics 14 (2002), S. R597 - R624

[47] Kneipp, K. ; Wang, Y. ; Kneipp, H. ; Itzkan, I. ; Dasari, R.R. ; M.S. Feld, M.S: Population pumping of excited vibrational states by spontaneous surfaceenhanced Raman scattering. In: Physical Review Letters 76 (1996), S. 2444-2447

[48] Kneipp, K. ; Wang, Y. ; Kneipp, H. ; Perelman, L.T. ; R. Dasari, I. I. ; FELD, M.S.: Single molecule detection using surface-enhanced Raman scattering (SERS). In: Physical Review Letters 78 (1997), Nr. 9, S. 1667-1670

[49] Knoll, W.: Interfaces and thin films as seen by bound electromagnetic waves. In: Annual Review of Physical Chemistry 49 (1998), S. 569-638

[50] KNORR, I.: Nanostrukturierung metallischer Oberflächen und deren Anwendung für die oberflächenverstärkte Ramanspektroskopie, Universität Göttingen, Diplomarbeit, 2008

[51] Knorr, I. ; Christou, K .. ; Meinerts, J. ; Selle, A. ; Ihlemann, J. ; MaROWSKY, G.: Prediction and optimization of surface-enhanced Raman scattering geometries using COMSOL Multiphysics. In: European Comsol Conference Hannover, 2008 
[52] Koglin, E. ; Sequaris, J.M.: Surface-enhanced Raman scattering of biomolecules. In: Topics in Current Chemistry 134 (1986), S. 1-57

[53] Kou, L. ; Labrie, D. ; Chylek, P.: Refractive indices of water and ice in the 0,65 to 2,5 $\mu \mathrm{m}$ spectral range. In: Applied Optics Express 32 (1993), S. 3531-3540

[54] Kudelski, A.: Raman spectra of hydrogenated amorphous carbon deposited on electrochemically-roughened silver. In: Chemical Physics Letters 427 (2006), S. 206-209

[55] Kudelski, A. ; Pettinger, B.: SERS on carbon chain segments: monitoring locally surface chemistry:. In: Chemical Physics Letters 321 (2000), S. 356-362

[56] Kudelski, A. ; Pettinger, B.: Fluctuations of surface-enhanced Raman spectra of CO adsorbed on gold substrates. In: Chemical Physics Letters 383 (2004), S. $76-79$

[57] Kundu, S.: Morphology of thin silver films grown by DC sputtering on $\mathrm{Si}(001)$. In: Applied Physics 31 (1998), S. 73-77

[58] LAngmuiR, I.: The evaporation, condensation and reflection of molecules and the mechanism of adsorption. In: Physical Review 8 (1916), S. 149-176

[59] LEe, I. ; HAN, S. W. ; KIM, K.: Simultaneous preparation of SERS-active metal colloids and plates by laser ablation. In: Journal of Raman Spectroscopy 32 (2001), S. 947-952

[60] Lee, P. C. ; Meisel, D.: Adsorption and surface-enhanced Raman of dyes on silver and gold sols. In: Journal of Physical Chemistry 86 (1982), S. 3391-3395

[61] Lieber, C.A. ; A.Mahadevan-Jansen: Automated method for subtraction of fluorescence from biological Raman spectra. In: Applied Spectroscopy 57 (2003), Nr. 11, S. 1363-1367

[62] Lombardi, J.R. ; Birke, R.L. ; Lu, T. ; Xu, J.: Charge-transfer theory of surface-enhanced Raman spectroscopy: Herzberg-Teller contributions. In: Jornal of Chemical Physics 84 (1986), S. 4174-4181

[63] Long, D. A.: The Raman effect - A unified treatment of the theory of Raman scattering by molecules. 1. Auflage. Wiley and Sons, 2002

[64] Loo, B.H. ; Ibrahim, A. ; Emerson, M.T.: Analysis of surface coverage of benzotriazole and 6-tolytriazole mixtures on copper electrodes from surface-enhanced Raman spectra. In: Chemical Physics Letters 287 (1998), S. 449-454

[65] L.O.T.-GmBH: Datenblätter CCD-Kameras (Andor), http://www.lot-oriel. $\mathrm{com} /$ site/pages_de_en/products/ccd_etc/ccd.php 
[66] Lu, W. ; Feldman, L.C. ; SOng, Y. ; Dhar, S. ; Collins, W.E. ; Mitchel, W.C. ; Williams, J.R.: Graphitic features on $\mathrm{SiC}$ surface following oxidation and etching using surface-enhanced Raman spectroscopy. In: Applied Physics Letters 85 (2004), S. 3495

[67] Maruyama, Y. ; Ishikawa, M. ; Futamata, M.: Thermal activation of blinking in SERS signal. In: Journal of Physical Chemistry B 108 (2003), S. 673-678

[68] McCall, S.L. ; Platzmann, P.M.: Raman scattering from chemisorbed molecules at surfaces. In: Physical Review B 22 (1980), S. 1660-1662

[69] McFarland, A.D. ; Young, M.A. ; Dieringer, J.A. ; Duyne, R.P. van: Wavelength-scanned surface-enhanced Raman excitation spectroscopy. In: Journal of Physical Chemistry 109 (2005), S. 11279-11285

[70] Miura, T. ; Takeuchi, H. ; Herada, I.: Tryptophan Raman bands sensitive to hydrogen bonding and side-chain information. In: Journal of Raman spectroscopy 20 (1989), S. 667-671

[71] Moskovits, M.: Surface-enhanced Raman spectroscopy - a brief retrospective. In: Journal of Raman Spectroscopy 36 (2005), S. 485-496

[72] Moskovits, M. ; Dilella, D.P. ; Chang, R.K. (Hrsg.) ; Furtak, T.E. (Hrsg.): Surface-enhanced Raman scattering,. Plenum Press, 1982

[73] Murphy, T. ; Schmidt, H. ; Kronfeldt, H.D.: Use of sol-gel technique in the development of surface-enhanced Raman scattering (SERS) substrates suitable for in situ detection of chemical in sea-water. In: Applied Physics B 69 (1999), S. $147-150$

[74] Netti, M.C. ; Zoorob, M.E. ; Charlton, M.D.B. ; Ayliffe, P. ; MahnKopf, S. ; Stopford, P. ; Todd, K. ; Lincoln, J.R. ; Perney, N.M.B. ; Baumberg, J.J.: Probing molecules by surface-enhanced Raman spectroscopy. In: Biomedical Vibrational Spectroscopy III: Advances in Research and Industry SPIE Proceedings 6093 (2006), S. 95

[75] Nowicki, B.: Multiparameter representation of surface roughness. In: Wear 102 (1985), S. 161-176

[76] Oberg, K.A. ; ; Fink, A.L.: A new attanuated total reflectance Fourier transform infrared spectroscopy method for the study of protein in solution. In: Analytical Biochemistry 256 (1998), S. 92-106

[77] Oellerich, M.: Hinweise für Labor-Untersuchungen - Referenzintervalle für Erwachsene. In: Abt. Klinische Chemie - Klinikum der Universität Göttingen (2007)

[78] Ohtsu, M. ; Teramachi, Y.: Analyses of mode partition and mode hopping in semiconductor lasers. In: Quantum Electronics 25 (1989), S. 31-38 
[79] Ortiz, C. ; Zhang, D. ; Xie, Y. ; Davisson, V.J. ; Ben-Amotz, D.: Identification of insulin variants using Raman spectroscopy. In: Analytical Biochemistry 332 (2004), S. 245-252

[80] Ortiz, C. ; Zhang, D. ; Xie, Y. ; Ribbe, A.E. ; Ben-Amotz, D.: Validation of the drop coating deposition Raman method for protein analysis. In: Analytical Biochemistry 353 (2006), S. 157-166

[81] Отто, A.: Surface-enhanced Raman scattering (SERS), what do we know? In: Applied Surface Science 6 (1980), S. 309-355

[82] Отто, A.: What is observed in single molecule SERS, and why? In: Journal of Raman Spectroscopy 33 (2002), S. 593-598

[83] Patel, I.S. ; Premasiri, W.R. ; Moir, D.T. ; Ziegler, L.D.: Barcoding bacterial cells: a SERS-based methodology for pathogen identification. In: Journal of Raman Spectroscopy 39 (2008), S. 1660-1672

[84] PD-LD: Volume Bragg Gratings - A new platform technology for WDM applications, http://www.pdld.com/pdf/VBG_PAPER.pdf

[85] PDB: An information portal to biological macromolecular structures, http: //www.rcsb.org/pdb/home/home.do

[86] Pearson, K.: On lines and planes of closest fit to systems of points in space. In: Philosophical Magazine 2 (1901), S. 559-572

[87] Pelletier, M.J.: Effects of temperature on Cyclohexane Raman bands. In: Applied Spectroscopy 53 (1999), S. 1087-1096

[88] Perney, N.M.B. ; Baumberg, J.J. ; Zoorob, M.E. ; Charlton, M.D.B. ; Mahnkopf, S. ; NetTi, C.M.: Tuning localized plasmons in nanostructured substrates for surface-enhanced Raman scattering. In: Optics Express 14 (2006), Nr. 2, S. $847-857$

[89] PoegeL, K.: Kurzlehrbuch der Biologie. Thieme Verlag, 2005

[90] QI, D. ; Berger, A. J.: Quantitative concentration measuremnets of creatinine dissolved in water and urine using Raman spectroscopy and a liquid core optical fiber. In: Journal of Biomedical Optics 10 (2005), Nr. 3

[91] RAetheR, H.: Surface plasmons on smooth and rough surfaces and on gratings. Bd. 111. Springer Verlag, 1988

[92] Raman, C.V. ; Krishnan, K.S.: A new type of secondary radiation. In: Nature 121 (1928), S. 501

[93] Ray, K.G. ; MCCReery, R.L.: Simplified calibration of instrument response function for Raman spectroscopy based on luminescent intensity standards. In: Applied Spectroscopy 51 (1997), S. 108-116 
[94] Rohr, T.E. ; Cotton, T. ; Fan, N. ; Tarcha, P.J.: Immunoassay employing surface-enhanced Raman spectroscopy. In: Analytical Biochemistry 182 (1989), S. $388-398$

[95] Ross, B.M. ; LEE, L.P.: Comparison of near- and far-field measures for plasmon resonance of metallic nanoparticles. In: Optics Letters 34 (2009), S. 896-898

[96] Rothenhäuser, B. ; Rabe, J. ; Korpiun, P. ; Knoll, W.: On the decay of plasmon surface polaritons at smooth and rough Ag-air interfaces: A reflectance and photoacoustic study. In: Surface Science 137 (1984), S. 373-383

[97] Sandroff, C.J. ; Herschbach, D.R.: Surface-enhanced Raman study of organic sulfides adsorbed on silver: facile cleavage of sulfur-sulfur and carbon-sulfur bonds. In: Journal of Physical Chemistry 86 (1982), S. 3277-3279

[98] Savitzky, A. ; Golay, M.J.E.: Smoothing and differentiation of data by simplified least squares procedures. In: Analytical Chemistry 36 (1964), S. 1627

[99] Schittkowski, T.: Aufbau und Test eines konfokalen Raman-Mikroskops, Universität von Bayreuth, Diplomarbeit, 1999

[100] Seelenbinder, J.A. ; Brown, C.W. ; D.W.Urish: Novel substrate for surfaceenhanced infrared absorption. In: Applied Spectroscopy 54 (2000), S. 366-370

[101] Shikida, M. ; Sato, K. ; Tokoro, K. ; Uchikawa, D.: Comparison of anisotropic etching properties between $\mathrm{KOH}$ and TMAH solutions. In: Twelth IEEE International Conference on Micro and Electro Mechanical Systems, MEMS 4 (1999), S. 312-320

[102] Smekal, A.: Zur Quantentheorie der Dispersion. In: Naturwissenschaften 11 (1923), S. 873-875

[103] Sockalingum, G.D. ; Beljebbar, A. ; Morjani, H. ; Angiboust, J.F. ; Manifait, M.: Characterization of island films as surface-enhanced Raman spectroscopy substrates for detecting low antitumor drug concentrations at single cell level. In: Biospectroscopy 4 (1998), S. 71-80

[104] Socrates, G.: Infrared and Raman characteristic group frequencies. 3. Auflage. Wiley, 2005

[105] Sutherland, W.S. ; Winefordner, J.D.: Colloid filtration: a novel substrate preparation method for surface-enhanced Raman spectroscopy. In: Journal of Colloid and Interface Science 148 (1992), S. 129-141

[106] Szeghalmi, A. ; Kaminskyj, S. ; Rösch, P. ; Popp, J. ; Gough, K.M.: Time fluctuations and imaging in the SERS spectra of fungal hypha grown nanostructured substrates. In: Journal of Physical Chemistry B 111 (2007), S. 12916-12924

[107] Templin, M.F. ; Stoll, D. ; Schrenk, M.: Protein microarray technology. In: Trends in Biotechnology 20 (2002), S. 160-166 
[108] Thomas, G.J.: New structural insights from Raman spectroscopy of proteins and their assemblies. In: Biochemistry 67 (2002), S. 214-225

[109] Walrafen, G.E. ; Stone, J.: Intensification of spontaneous Raman spectra by use of liquid core optical fibers. In: Applied Spectroscopy 26 (1972), S. 585-589

[110] Wan, L.-J. ; Terashima, M. ; Noda, H. ; Osawa, M.: Molecular orientation and ordered structrure of benzenethiol adsorbed on gold. In: Journal of Physical Chemistry B 104 (2000), S. 3563-3569

[111] Weitz, D.A. ; Garoff, S. ; Gramila, T.J.: Excitation spectra of surfaceenhanced Raman scattering on silver-island films. In: Optical Letters 7 (1982), S. $168-170$

[112] Welfle, H.: Optische Spektroskopie. Springer-Verlag, 1996

[113] Wilson, T.: Confocal Microscopy. Academic Press, 1990

[114] Wu, D. ; Liu, X. ; Dai, S. ; Xu, X. ; Ren, B. ; Lin, S. ; Tian, Z.: Chemical enhancement effects in SERS spectra: A quantum chemical study of pyridine interacting with copper, silver gold and platinum metals. In: Physical Chemistry C 112 (2008), S. 4195-4204

[115] Xu, H. ; Aizpuua, J. ; KäLl, M. ; Apell, P.: Electromagnetic contributions to single-molecule sensitivity in surface-enhanced Raman scattering. In: Physical Review E 62 (2000), Nr. 3, S. 4318-4324

[116] Xu, H. ; KäLL, M.: Polarization-dependent surface-enhanced Raman spectroscopy of isolated silver nanoaggregates. In: Chemical Physics and Physical Chemistry 4 (2003), S. 1001-1005

[117] Zhang, D. ; Xie, Y. ; Mrozek, M.F. ; Ortiz, C. ; Davisson, V.J. ; BenAmotz, D.: Raman detection of proteomic analytes. In: Analytical Chemistry 75 (2003), S. 5703-5709 


\section{Danksagung}

An dieser Stelle möchte ich allen Personen danken, die zum Gelingen dieser Arbeit beigetragen haben. Allen voran danke ich dem Referenten meiner Arbeit Herrn Prof. Dr. Gerd Marowsky für die Möglichkeit, diese Arbeit am Laser-Laboratorium Göttingen e.V. anzufertigen. Ebenso gilt mein Dank Herrn Prof. Dr. Werner Lauterborn für die Übernahme des Korreferats.

Mein besonderer Dank gilt dem Leiter der Arbeitsgruppe "Photonische Sensorik“ Herrn Dr. Volker Beushausen für die spannende Aufgabenstellung, die Bereitstellung des Arbeitsplatzes und für meine Betreuung. Auch für die unzähligen Diskussionen und Anregungen bei der Umsetzung dieser Arbeit sei ihm herzlichst gedankt.

Den Kollegen Dipl. Phys. Wilhelm Hüttner, Dipl. Ing. Alexander Göhmann und Dr. Christoph Lenth bin ich für ihre tatkräftige Unterstützung im Labor und für die unzähligen fachlichen Diskussionen sowie für die immer fröhlichen Kaffeepausen zu Dank verpflichtet. Auf diesem Wege möchte ich mich auch ganz herzlich bei allen Mitarbeitern der Abteilung „Photonische Sensorik“ bedanken, die mir ein angenehmes Arbeitsklima ermöglichten.

Vielen Dank auch an Frau Dipl. Phys. Inga Knorr und Herrn Dr. Jürgen Ihlemann für die Bereitstellung von Substraten und die Durchführung von Simulationsrechnungen.

Im Rahmen dieser Arbeit ergaben sich einige Zusammenarbeiten, die wesentlich zum Gelingen dieser Arbeit beigetragen haben. Insbesondere seien an dieser Stelle Herrn Dr. Ing. Steffen Howitz und Herrn Dr. Frank-Ulrich Gast von der Firma GeSim genannt, die freundlicherweise eine Pipettiereinheit zur Verfügung stellten sowie Herrn Dipl. Ing. Ulrich Plachetka von der Firma AMO, Gesellschaft für Angewandte Mikround Optoelektronik mbH, für die Anfertigung diverser Substrate.

Schließlich möchte ich mich bei meinen Eltern bedanken, die mir mit ihrem Verständnis und ihrer Unterstützung immer zur Seite standen.

Der größte Dank gilt meiner Lebensgefährtin Johanna König, die mir in allen erdenklichen Phasen dieser Arbeit stets mit Verständnis und Liebe begegnet ist. 


\section{Lebenslauf}

\section{Persönliche Daten}

Name $\quad$ Konstantin Christou

Geburtstag 14. Juni 1978

Geburtsort Hamburg, Deutschland

Staatsangehörigkeit deutsch

Familienstand ledig

\section{Bildungsweg}

$02 / 2005$ - heute

Angestellt am Laser-Laboratorium Göttingen e.V. im Rahmen einer Doktorandenstelle

11/2004 Diplomprüfung im Fach Physik an der Georg-August-Universität Göttingen

10/2003-09/2004 Diplomarbeit zum Thema „Messung der Geschwindigkeitsfluktuationen eines turbulenten Unterschall-Freistrahls mit Hilfe der Mehrebenen-Stereo-Particle Image Velocimetry als Grundlage für Schallabstrahlungsberechnungen“ am DLR e.V. in Göttingen, betreut durch Prof. Dr. D. Ronneberger (Drittes Physikalisches Institut)

10/2001 Diplomvorprüfungen in Physik

10/1999 Beginn des Physikstudiums an der Georg-August-Universität Göttingen

11/1998-08/1999 Grundwehrdienstleistender im 7. Fernmelderegiment in Frankenberg an der Eder (Hessen)

06/1998 Erlangung der Allgemeinen Hochschulreife am Hainberg-Gymnasium in Göttingen 